\title{
FEASIBILITY OF MHD SUBMARINE PROPULSION
}

\section{Phase II - MHD Propulsion: Testing in a Two Tesla Facility}

\author{
ANL $-92 / 35$ \\ Editors \\ DE93 004662 \\ Ezzat D. Doss \\ Engineering Physics Division \\ Argonne National Laboratory \\ and \\ W. Christopher Sikes \\ Advanced Propulsion Technology \\ Newport News Shipbuilding and Dry Dock Company
}

\section{DISCLAIMER}

This report was prepared as an account of work sponsored by an agency of the United States Government. Neither the United States Government nor any agency thereof, nor any of their employees, makes any warranty, express or implied, or assumes any legal liability or responsibility for the accuracy, completeness, or usefulness of any information, apparatus, product, or process disclosed, or represents that its use would not infringe privately owned rights. Refer. ence herein to any specific commercial product, process, or service by trade name, trademark, manufacturer, or otherwise does not necessarily constitute or imply its endorsement, recommendation, or favoring by the United States Government or any agency thereof. The views and opinions of authors expressed herein do not necessarily state or reflect those of the United States Government or any agency thereof.

\section{Joint Research Program}

Argonne National Laboratory Newport News Shipbuilding and Dry Dock Company

September 1992 
Phase II - MHD Propulsion: Testing in a Two Tesla Facility

Edited By:

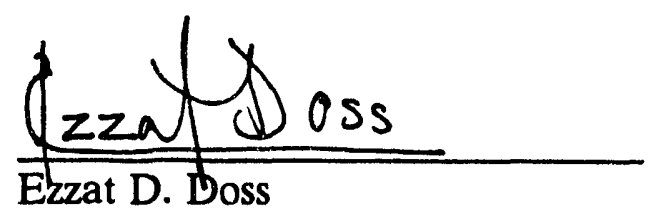

Reviewed By:

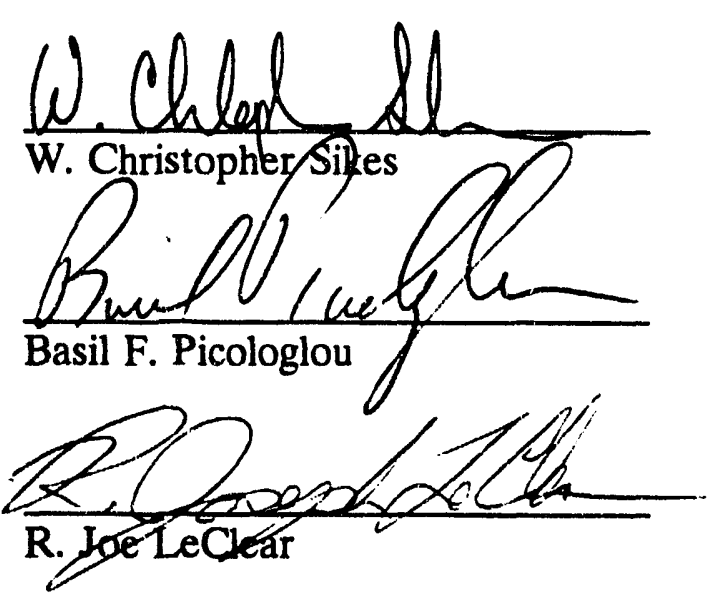

Approved By:

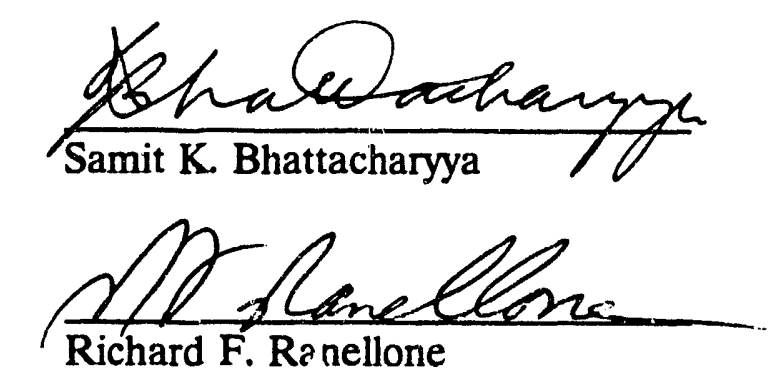

\section{Joint Research Program}

Argonne National Laboratory

Newport News Shipbuilding and Dry Dock Company 


\title{
FEASIBILITY OF MHD SUBMARINE PROPULSION
}

\section{Phase II - MHD Propulsion: Testing in a Two Tesla Facility}

\author{
Editors \\ Ezzat D. Doss \\ W. Christopher Sikes \\ Program Managers \\ Ezzat D. Doss (ANL) \\ Richard F. Ranellone (NNS)
}

Experimental Task

Basil F. Picologlou (ANL), Leader

Dave B. Black, Howard K Geyer, and Patrick M. Dombrowski (ANL)

W. Christopher Sikes, R. Joe LeClear, and Ralph M. Robinson (NNS)

J. Kent Koester (MHD Instruments)

September 1992

Joint Research Program

Argonne National Laboratory

Engineering Physics Division

9700 South Cass Avenue

Argonne, Illinois 60439

and

Newport News Shipbuilding and Dry Dock Company

Advanced Propulsion Technology

4101 Washington Avenue

Newport News, Virginia 23607 


\section{Table of Contents}

Page No.

Abstract $\ldots \ldots \ldots \ldots \ldots \ldots \ldots \ldots \ldots \ldots \ldots \ldots \ldots \ldots \ldots \ldots \ldots \ldots$

1.0 Executive Summary $\ldots \ldots \ldots \ldots \ldots \ldots \ldots \ldots \ldots \ldots \ldots$

2.0 Introduction $\ldots \ldots \ldots \ldots \ldots \ldots \ldots \ldots \ldots \ldots \ldots \ldots \ldots \ldots$

3.0 Program Background and Outline $\ldots \ldots \ldots \ldots \ldots \ldots \ldots \ldots \ldots \ldots$

3.1 Phase I - MHD Thruster Performance: Computer Model ...... 14 Development and Parametric Analysis

3.2 Phase II - MHD Thruster Performance: Experimental . . . . . . 14 Validation of Developed Models

3.2.1 Task 1 - Facility Design ................. 15

3.2.2 Task 2 - Facility Construction $\ldots \ldots \ldots \ldots \ldots \ldots \ldots \ldots$

3.2.3 Task 3 - Facility Operation ............... 16

3.2.4 Task 4 - Data Reduction and Analysis ........... 17

3.3 Technical Considerations and Developmental Needs . . . . . . 17

4.0 Computer Models for MHD Propulsion Systems . . . . . . . . . 19

4.1 Liquid Model ........................ 20

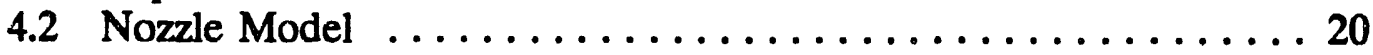

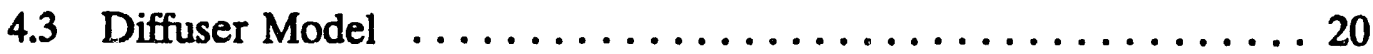

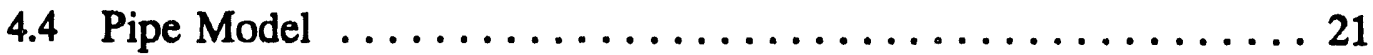

4.5 Loss Model ............................ 21

4.6 MHD0 Model ........................... 21

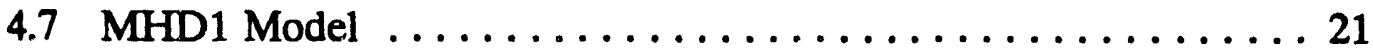

4.8 Drag Model ........................... 24

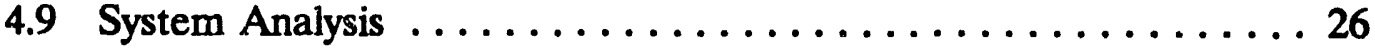

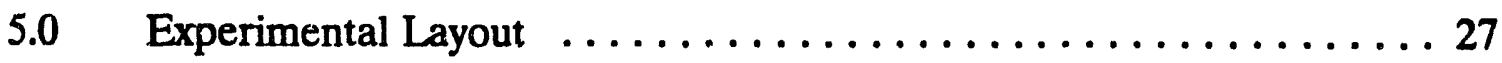

5.1 Working Fluid $\ldots \ldots \ldots \ldots \ldots \ldots \ldots \ldots \ldots \ldots \ldots \ldots \ldots \ldots \ldots$

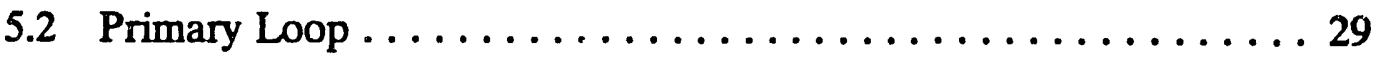

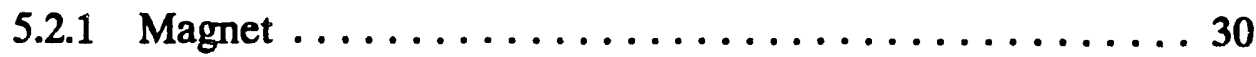

5.2 .2 Test Section $\ldots \ldots \ldots \ldots \ldots \ldots \ldots \ldots \ldots \ldots \ldots \ldots$ 


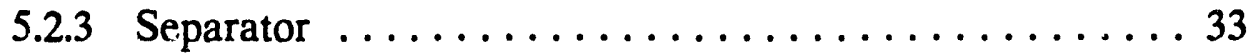

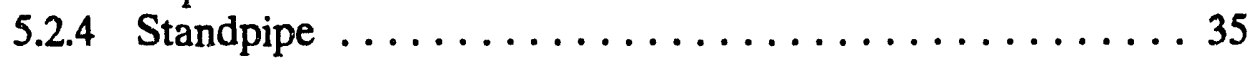

5.2 .5 Loop Pump .......................... 35

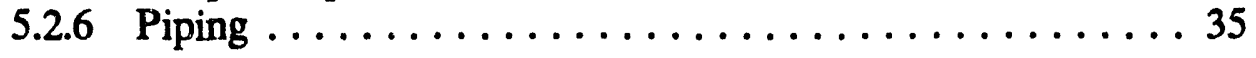

5.3 Secondary Loop $\ldots \ldots \ldots \ldots \ldots \ldots \ldots \ldots \ldots \ldots \ldots \ldots \ldots \ldots$

5.3.1 Circulation Pump . . . . . . . . . . . . . . . 39

5.3.2 Primary Storage Tank . . . . . . . . . . . . . . 39

5.3.3 Secondary Storage Tank $\ldots \ldots \ldots \ldots \ldots \ldots \ldots \ldots$

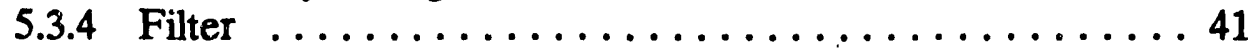

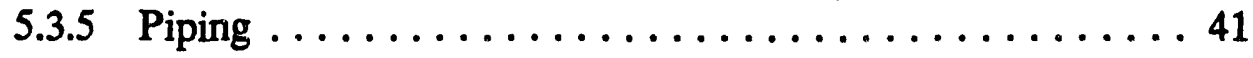

5.4 Additional Systems $\ldots \ldots \ldots \ldots \ldots \ldots \ldots \ldots \ldots \ldots \ldots 41$

5.4 .1 Nitrogen $\ldots \ldots \ldots \ldots \ldots \ldots \ldots \ldots \ldots \ldots \ldots \ldots 42$

5.4 .2 Oxygen Monitor $\ldots \ldots \ldots \ldots \ldots \ldots \ldots \ldots \ldots 44$

5.4 .3 Vent $\ldots \ldots \ldots \ldots \ldots \ldots \ldots \ldots \ldots \ldots \ldots 44$

5.4 .4 Electrode Power Supply $\ldots \ldots \ldots \ldots \ldots \ldots \ldots \ldots 46$

5.4 .5 Standpipe Drain $\ldots \ldots \ldots \ldots \ldots \ldots \ldots \ldots \ldots \ldots \ldots$

5.4 .6 Loop Pump Drain . . . . . . . . . . . . . . 50

5.4.7 Circulation Pump Flush Face Seal ............ 50

5.4 .8 Loop Fill $\ldots \ldots \ldots \ldots \ldots \ldots \ldots \ldots \ldots \ldots \ldots$

5.5 Instrumentation $\ldots \ldots \ldots \ldots \ldots \ldots \ldots \ldots \ldots \ldots \ldots \ldots$

5.5.1 Data Acquisition System ................ 51

5.5.2 Pressure Measurement $\ldots \ldots \ldots \ldots \ldots \ldots \ldots \ldots . \ldots \ldots 2$

5.5.2.1 Test Section Pressure Measurement . . . . . 52

5.5.2.2 Loop Pressure Measurement .......... 52

5.5.3 Potential Measurement $\ldots \ldots \ldots \ldots \ldots \ldots \ldots \ldots . \ldots 5$

5.5 .4 Current Measurement ................... 55

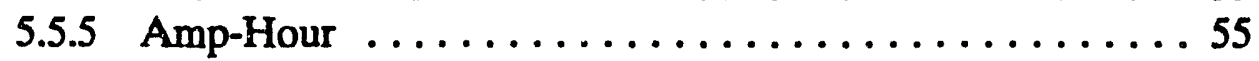

5.5 .6 Conductivity $\ldots \ldots \ldots \ldots \ldots \ldots \ldots \ldots \ldots \ldots \ldots$

5.5 .7 Flow Rate $\ldots \ldots \ldots \ldots \ldots \ldots \ldots \ldots \ldots \ldots \ldots . \ldots \ldots$

5.5 .8 Temperature $\ldots \ldots \ldots \ldots \ldots \ldots \ldots \ldots \ldots \ldots \ldots . \ldots \ldots$

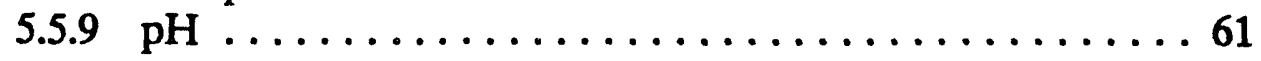


5.6 Bubble Diagnostics $\ldots \ldots \ldots \ldots \ldots \ldots \ldots \ldots \ldots \ldots \ldots \ldots$

5.6.1 Measurement Techniques ................664 64

5.6.2 Bubble Diagnostics Equipment ..............6 64

5.6 .3 Instrument Calibration . . . . . . . . . . . . 66

5.6 .4 Image Processing $\ldots \ldots \ldots \ldots \ldots \ldots \ldots \ldots \ldots$

6.0 Pre-Test Analysis $\ldots \ldots \ldots \ldots \ldots \ldots \ldots \ldots \ldots \ldots \ldots \ldots \ldots \ldots$

6.1 Parametric Analysis $\ldots \ldots \ldots \ldots \ldots \ldots \ldots \ldots \ldots \ldots \ldots \ldots \ldots$

6.2 Loop Chemistry ....................... 74

6.2.1 Electrolysis Products . . . . . . . . . . . . . 75

6.2.1.1 Mass ...................... 75

6.2.1.2 Volume $\ldots \ldots \ldots \ldots \ldots \ldots \ldots \ldots \ldots \ldots, 76$

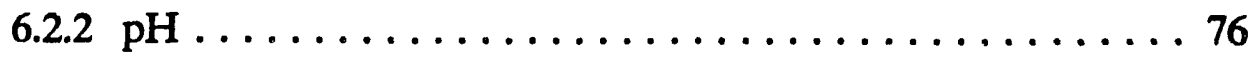

6.2 .3 Conductivity $\ldots \ldots \ldots \ldots \ldots \ldots \ldots \ldots \ldots \ldots \ldots$

6.3 Loop Energy Balance $\ldots \ldots \ldots \ldots \ldots \ldots \ldots \ldots \ldots \ldots$

7.0 Experimental Conditions $\ldots \ldots \ldots \ldots \ldots \ldots \ldots \ldots \ldots \ldots \ldots$

7.1 Test Matrix $\ldots \ldots \ldots \ldots \ldots \ldots \ldots \ldots \ldots \ldots \ldots \ldots \ldots$

7.2 Conditions for Bubble Tests . . . . . . . . . . . . . 84

8.0 Results and Discussion $\ldots \ldots \ldots \ldots \ldots \ldots \ldots \ldots \ldots \ldots \ldots$

8.1 Volt-Amp Characteristics . . . . . . . . . . . . . . 89

8.2 Current Density ........................... 93

8.3 Calculated and Measured Pressure Rise ............... 97

8.4 Thruster Efficiency and Losses $\ldots \ldots \ldots \ldots \ldots \ldots \ldots \ldots \ldots 10 \ldots \ldots$

8.5 Ideal Thrustei Efficiency ...................... 105

8.6 Bubbles ............................ 105

8.6.1 Qualitative Observations ................. 108

8.6.2 Bubble Size Results . . . . . . . . . . . . . . . . 109

8.7 Loop Chemistry $\ldots \ldots \ldots \ldots \ldots \ldots \ldots \ldots \ldots \ldots \ldots \ldots$

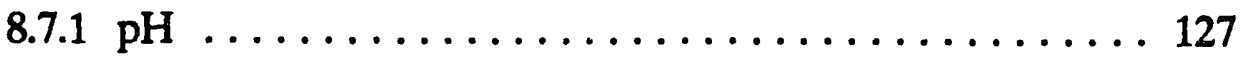




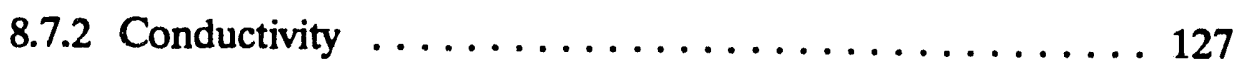

8.8 Working Fluid Temperature $\ldots \ldots \ldots \ldots \ldots \ldots \ldots \ldots \ldots \ldots$

8.9 Test Duration $\ldots \ldots \ldots \ldots \ldots \ldots \ldots \ldots \ldots \ldots \ldots \ldots \ldots \ldots$

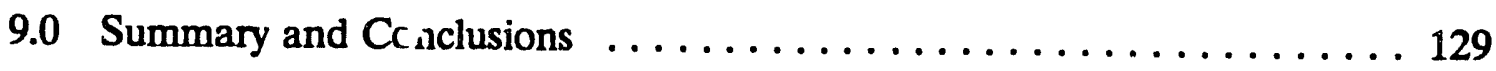

10.0 Recommendations $\ldots \ldots \ldots \ldots \ldots \ldots \ldots \ldots \ldots \ldots \ldots \ldots \ldots \ldots \ldots$

10.1 Definition of at-sea demonstration/design requirements . . . . . 134

10.2 Supporting R\&D/Technology Development ........... 134

10.3 Detail Design/Assembly/Test ................. 135

11.0 References $\ldots \ldots \ldots \ldots \ldots \ldots \ldots \ldots \ldots \ldots \ldots \ldots \ldots \ldots \ldots$

12.0 Acknowledgement $\ldots \ldots \ldots \ldots \ldots \ldots \ldots \ldots \ldots \ldots \ldots \ldots \ldots \ldots 14$

Appendices

Appendix A: Argonne MHD Test Loop - Main Loop Arrangement, . . . . A-1 Details \& List of Material

Appendix B: Argonne MHD Test Loop - Drain, Vent \& Storage Piping, . . B-1 Arrangement \& List of Material

Tables

Table 7.1: Test Matrix $\ldots \ldots \ldots \ldots \ldots \ldots \ldots \ldots \ldots \ldots \ldots \ldots$

Table 7.2: Conditions for Bubble Measurement Tests $\ldots \ldots \ldots \ldots$. . . 85

Table 7.3: Conditions for Instant Ocean Bubble Size Test ... . . . . 86

Table 8.4: Comparison of Measured and Calculated Conductivity . . . . . 89

Table 8.5: Electro-Chemical Potentials $\ldots \ldots \ldots \ldots \ldots \ldots \ldots \ldots$

Table 8.6: Conditions for Bubble Image Sequences $\ldots \ldots \ldots \ldots \ldots \ldots$ 


\section{Figures}

Figure 2.1: $\quad$ MHD Concept $\ldots \ldots \ldots \ldots \ldots \ldots \ldots \ldots \ldots \ldots \ldots$

Figure 5.1: Test Loop $\ldots \ldots \ldots \ldots \ldots \ldots \ldots \ldots \ldots \ldots \ldots \ldots \ldots$

Figure 5.2: $\quad$ B-Field Profile $\ldots \ldots \ldots \ldots \ldots \ldots \ldots \ldots \ldots \ldots \ldots \ldots \ldots$

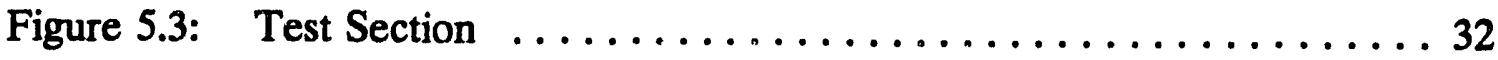

Figure 5.4: Bubble Separator $\ldots \ldots \ldots \ldots \ldots \ldots \ldots \ldots \ldots \ldots \ldots \ldots$

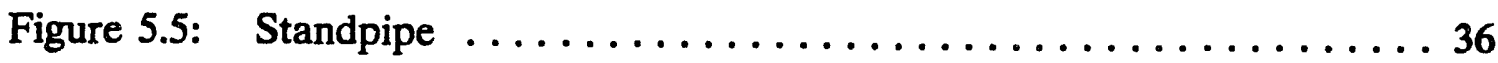

Figure 5.6: Secondary Loop $\ldots \ldots \ldots \ldots \ldots \ldots \ldots \ldots \ldots \ldots \ldots$

Figure 5.7: Nitrogen System $\ldots \ldots \ldots \ldots \ldots \ldots \ldots \ldots \ldots \ldots \ldots$

Figure 5.8: Vent System $\ldots \ldots \ldots \ldots \ldots \ldots \ldots \ldots \ldots \ldots \ldots \ldots$

Figure 5.9: Electrode Power Supply $\ldots \ldots \ldots \ldots \ldots \ldots \ldots \ldots \ldots \ldots$

Figure 5.10: Electrode Bus Layout $\ldots \ldots \ldots \ldots \ldots \ldots \ldots \ldots \ldots \ldots$

Figure 5.11: Standpipe Drain System $\ldots \ldots \ldots \ldots \ldots \ldots \ldots \ldots \ldots \ldots . \ldots 9$

Figure 5.12: Pressure Measurement System $\ldots \ldots \ldots \ldots \ldots \ldots \ldots \ldots \ldots$

Figure 5.13: Loop Pressure Measurement System ............. 54

Figure 5.14: Potential Measurement System $\ldots \ldots \ldots \ldots \ldots \ldots$

Figure 5.15: Current Measurement System $\ldots \ldots \ldots \ldots \ldots \ldots \ldots \ldots$

Figure 5.16: Conductivity Measurement System $\ldots \ldots \ldots \ldots \ldots \ldots$

Figure 5.17: Flow Rate Measurement System $\ldots \ldots \ldots \ldots \ldots \ldots \ldots$

Figure 5.18: $\mathrm{pH}$ Measurement System $\ldots \ldots \ldots \ldots \ldots \ldots \ldots \ldots \ldots \ldots$

Figure 5.19: Optics Train and Translation Hardware $\ldots \ldots \ldots \ldots \ldots$ 
Figure 5.20 Calibration Image $\ldots \ldots \ldots \ldots \ldots \ldots \ldots \ldots \ldots \ldots$

Figure 6.1: Mass of Electrolysis Products $\ldots \ldots \ldots \ldots \ldots \ldots \ldots \ldots 77$

Figure 6.2: Volume of Electrolysis Products $\ldots \ldots \ldots \ldots \ldots \ldots \ldots$

Figure 6.3: Change in $\mathrm{pH}$ as a Function of Amp-Hour $\ldots \ldots \ldots \ldots \ldots 80$

Figure 8.1: V-I Characteristics $\left(\sigma_{\text {measured }}=4.8 \mathrm{~S} / \mathrm{m}, \sigma_{\mathrm{V}-1 \text { slope }}=4.74 \mathrm{~S} / \mathrm{m}\right) \ldots .90$

Figure 8.2: V-I Characteristics $\left(\sigma_{\text {measured }}=22.5 \mathrm{~S} / \mathrm{m}, \sigma_{\mathrm{V} \text {-I slope }}=21.2 \mathrm{~S} / \mathrm{m}\right) \ldots 91$

Figure $8.3 \quad$ V-I Characteristics - Instant Ocean ............. 92 $\left(\sigma_{\text {measured }}=5.3 \mathrm{~S} / \mathrm{m}, \sigma_{\mathrm{V}-\mathrm{I} \text { slope }}=5.1 \mathrm{~S} / \mathrm{m}\right)$

Figure 8.4: Current Distribution Among Electrode Segments $\ldots \ldots \ldots . .94$ $(\sigma=4.5 \mathrm{~S} / \mathrm{m}, \mathrm{u}=4 \mathrm{~m} / \mathrm{s}, \mathrm{I}=105.5 \mathrm{~A}, \Delta \mathrm{V}=20.4 \mathrm{~V})$

Figure 8.5: Current Distribution Among Electrode Segments . . . . . . . 95 $(\sigma=22.5 \mathrm{~S} / \mathrm{m}, \mathrm{u}=4 \mathrm{~m} / \mathrm{s}, \mathrm{I}=98.2 \mathrm{~A}, \Delta \mathrm{V}=6 \mathrm{~V})$

Figure 8.6: Current Distribution Among Electrode Segments . . . . . . . 96 Instant Ocean $(\sigma=4 \mathrm{~S} / \mathrm{m}, \mathrm{u}=4 \mathrm{~m} / \mathrm{s}, \mathrm{I}=83.6 \mathrm{~A}, \Delta \mathrm{V}=15 \mathrm{~V})$

Figure 8.7: Comparison of Calculated and Measured Pressure Rise . . . . . 98 vs. Current Density $(\sigma=22.5 \mathrm{~S} / \mathrm{m})$

Figure 8.8: Comparison of Calculated and Measured Pressure Rise . . . . . 99 vs. Current Density $(\sigma=4.5 \mathrm{~S} / \mathrm{m})$

Figure 8.9: Comparison of Calculated and Measured Pressure Rise . . . . 100 vs. Current Density - Instant Ocean $(\sigma=5.5 \mathrm{~S} / \mathrm{m})$

Figure 8.10: Thruster Efficiency and Losses vs. Load Factor $\ldots \ldots \ldots \ldots 102$ $(\sigma=4.5, \mathrm{u}=2 \mathrm{~m} / \mathrm{s}$, B-vertical)

Figure 8.11: Thruster Efficiency and Losses vs. Load Factor $\ldots \ldots \ldots \ldots 103$ $(\sigma=22.5, u=2 \mathrm{~m} / \mathrm{s})$

Figure 8.12: Thruster Efficiency and Losses vs. Load Factor . . . . . . . . 104 Instant Ocean $(\sigma=5.5, \mathrm{u}=2 \mathrm{~m} / \mathrm{s})$ 
Figure 8.13: Ideal Efficiency vs. Load Factor $\ldots \ldots \ldots \ldots \ldots \ldots \ldots \ldots$

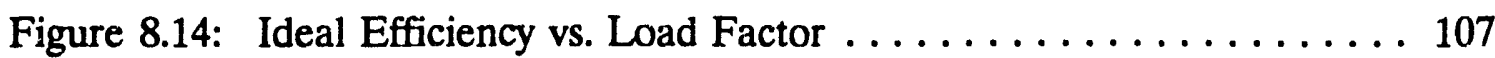
Instant Ocean

Figure 8.15: Bubble Photos S\#1 \& S\#2, N301 Sequence $\ldots \ldots \ldots \ldots \ldots 110$ Gentle Sharpen Filter

Figure 8.16: Bubble Photos S\#3 \& S\#4, N301 Sequence $\ldots \ldots \ldots \ldots \ldots . . \ldots 11$ Gentle Sharpen Filter

Figure 8.17: Bubble Photos S\#5 \& S\#6, N301 Sequence ........... 112 Gentle Sharpen Filter

Figure 8.18: Bubble Photos S\#7 \& S\#8, N301 Sequence $\ldots \ldots \ldots \ldots \ldots 113$ Gentle Sharpen Filter

Figure 8.19: Bubble Photos Sir9 \& S\#10, N301 Sequence . . . . . . . . 114 Gentle Sharpen Filter

Figure 8.20: Bubble Photos S\#1 \& S\#2, N301 Sequence $\ldots \ldots \ldots \ldots \ldots 115$ Vertical Filter

Figure 8.21: Bubble Photos S\#3 \& S\#4, N301 Sequence $\ldots \ldots \ldots \ldots \ldots 116$ Vertical Filter

Figure 8.22: Bubble Photos S\#5 \& S\#6, N301 Sequence ........... 117 Vertical Filter

Figure 8.23: Bubble Photos S\#7 \& S\#8, N301 Sequence $\ldots \ldots \ldots \ldots \ldots 118$ Vertical Filter

Figure 8.24: Bubble Photos S\#9 \& S\#10, N301 Sequence ........... 119 Vertical Filter

Figure 8.25: Bubble Photos S\#1 \& S\#2, N302 Sequence $\ldots \ldots \ldots \ldots \ldots 121$ Vertical Filter

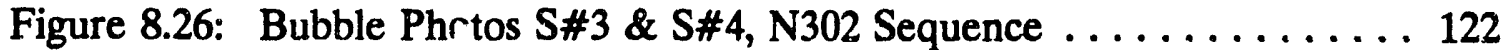
Vertical Fü^er 
Figure 8.27: Bubble Photos S\#5 \& S\#6, N302 Sequence ........... 123 Vertical Filter

Figure 8.28: Bubble Photos S\#7 \& Sł\&8, N302 Sequence $\ldots \ldots \ldots \ldots \ldots 124$ Vertical Filter

Figure 8.29: Bubble Phoios S\#9 \& S\#10, N302 Sequence $\ldots \ldots \ldots \ldots \ldots 125$ Vertical Filter 


\title{
FEASIBILITY OF MHD SUBMARINE PROPULSION \\ Phase II - MHD Propulsion: Testing in a Two Tesla Test Facility
}

\begin{abstract}
This report describes the work perfonmed during Phase I and Phase II of the collaborative research program established between Argonne National Laboratory (ANL) and Newport News Shipbuilding and Dry Dock Company (NNS). Phase I of the program focused on the development of computer models for Magnetohydrodynamic (MHD) propulsion. Phase II focused on the experimental validation of the thruster performance models and the identification, through testing, of any pisisomena which may impact the attractiveness of this propulsion system for shipboard applications.
\end{abstract}

The report discusses in detail the work performed in Phase II of the program. In Phase II, a two Tesla test facility was designed, built, and operated. The facility test loop, its components, and their design are presented. The test matrix and its rationale are discussed. Representative experimental results of the test program are presented, and are compared to computer model predictions. In general, the results of the tests and their comparison with the predictions indicate that the phenomena affecting the performance of MHD seawater thrusters are well understood and can be accurately predicted with the developed thruster computer models. 


\subsection{Executive Summary}

A multiphase/multiyear collaborative research program was established between Argonne National Laboratory (ANL) and Newport News Shipbuilding and Dry Dock Company (NNS) to demonstrate the feasibility of magnetohydrodynamic (MHD) seawater propulsion. This objective was met by developing computer models of thruster performance and conducting experiments to validate the adequacy of the developed models.

The need for high strength magnets (10-20 Tesla) and superconducting mat $c$ is to build these magnets is discussed. Also a historical and technical background of MHD seawater propulsion is presented.

Phase I of this research program focused on the development of a design-oriented lumped parameter computer code for MHD propulsion. The computer program is composed of individual models that predict the performance of an MHD propulsion system at different operating conditions. This work, funded by NNS, was completed during 1990.

Funding for Phase II, reported here, was equally shared by the DOE/Superconductivity Pilot Center at ANL and NNS through its Independent Research \& Development (IR\&D) Program. The focus of the second phase was the experimental validation of the thruster performance code ank identification through testing of any phenomena which may impact the attractiveness of this propulsion system for shipboard applications. To accomplish this in a cost effective manner, a test facility was designed and built at ANL utilizing an existing 2 Tesla conventional electromagnet. With the exception of the electrodes, the MHD test 
section (thruster) was fabricated from optically clear polycarbonate resin to enable visual observation of the electrolytically-generated gaseous bubbles.

Pre-test analysis was performed using the developed MHD propulsion code to establish the baseline performance of the test loop, define the test matrix, and determine instrumentation requirements. This facility was designed to provide prototypical flow velocities and electric current densities of a full size MHD seawater thruster that ensures prototypic bubble generation rates.

The facility instrumentation system included measurement of pressure distribution along the thruster, flow rate through the thruster, $\mathrm{pH}$ and electrical conductivity of the working fluid, electric current distribution over the electrodes and driving voltage, and measurement of the bubbles and their characteristics via high speed video camera.

Tests were performed, using an aqueous solution of sodium chloride and Instant Ocean $^{\mathrm{TM}}$, to investigate the effects of magnetic field orientation, flow velocity, current, voltage, and electrical conductivity on thruster performance and bubble generation.

Good agreement was found between the measured and predicted parameters. This has served to validate the thruster computer models deveioped at Argonne. Furthermore, the results indicate that the production of bubbles joes not have an impact on propulsion performance for electric current densities relevant to characteristics of full-size thrusters. Also, it was demonstrated that the thruster performance is independent of the orientation of the magnetic field relative to gravity. In general, the results of the tests and their comparison with predictions indicate that the phenomena affecting the performance of 
MHD seawater thrusters are well understood and can be accurately predicted with the developed thruster computer models. Good agreement between measured and predicted data served to validate the computer models developed during Phase I. 


\section{Introduction}

The idea of using MHD seawater propulsion for surface ships and submarines has been examined in the past by many investigators ${ }^{[1-6]}$ and was found to have sufficient merit to warrant further study. Both the original and more recent investigators ${ }^{[7]}$ have demonstrated that the attractiveness of this propulsion concept is dependent on the development of high magnetic flux density magnets.

Recent advances in superconductors have renewed interest in using this propulsion concept for ships and submarines. ${ }^{[8,9]}$ The potential benefits of this advanced propulsion system include: reduced noise (from the elimination of rotating machinery required to support conventional propulsion); potential for operating at higher speeds because an MHD thruster, unlike a propeller, is not cavitation-limited; and enhanced maneuverability through the use of vectored thrust. Moreover, the arrangement of components needed for $\mathrm{MHD}$ propulsion does not require a fixed longitudinal stack-up, thus allowing greater architectural flexibility for the shipbuilder. To explore these potential benefits, conceptual designs of surface ships and submarines are being pursued. ${ }^{[10]}$ Crucial to this process are validated design tools that can address the performance characteristics of MHD thrusters as a function of their geometry and operating parameters.

There may be, however, some noise related problems associated with MHD propulsion. Because sea water is an ionic conductor, electrolysis occurs at the electrodes and gases are evolved. The resulting formation of bubbles has been identified as a potential noise source. The behavior of these bubbles under the unique conditions of high flow velocity, high ambient pressures, large magnetic fields, and the separated electrodes characteristic of MHD 
propulsion devices have been the subject of recent investigations. ${ }^{[11-13]}$ Little, if any, data seems to exist on bubble characteristies under the conditions peculiar to MHD propulsion. Even the existence of bubbles at the cathode has been debated. Bubble size, density, distribution over the electrodes, and subsequent downstream behavior all require measurement in prototypic MHD propulsion experiments. ${ }^{[1]}$ Recent experiments have been performed to study bubble formation and bubble dynamics in MHD thrusters, ${ }^{[12,13]}$ and preliminary results are encouraging. However, conclusive prc if of these results would best be obtained from open sea testing of an MHD vehicle.

MHD seawater propulsion is dependent upon the conductivity of seawater to carry electric current and an applied magnetic field (Figure 2.1). Energy is supplied to the thruster by applying an external electric field. The resulting current (I) which interacts with the applied magnetic field (B) produces a Lorentz (IXB) force. Essentially the MHD thruster is an electromagnetic pump which accelerates the fluid (seawater) to provide thrust.

There are several MHD thruster configurations being considered for seawater propulsion. ${ }^{[10,14]}$ These configurations fall in two categories: internal, where MHD forces are produced in a duct; and external, where MHD forces are produced external to the hull. There are different thruster and magnet configurations possible in these categories (e.g. internal - annular shroud or pod mounted ducts with toroidal or dipole magnets). The internal thruster is being considered for naval applications by NNS.

For practical applications, increased propulsion efficiency should be attained. This is achieved by either increasing the fluid conductivity or by increasing the magnetic field strength. Seawater conductivity can be enhanced with a seeding procedure. However, this 


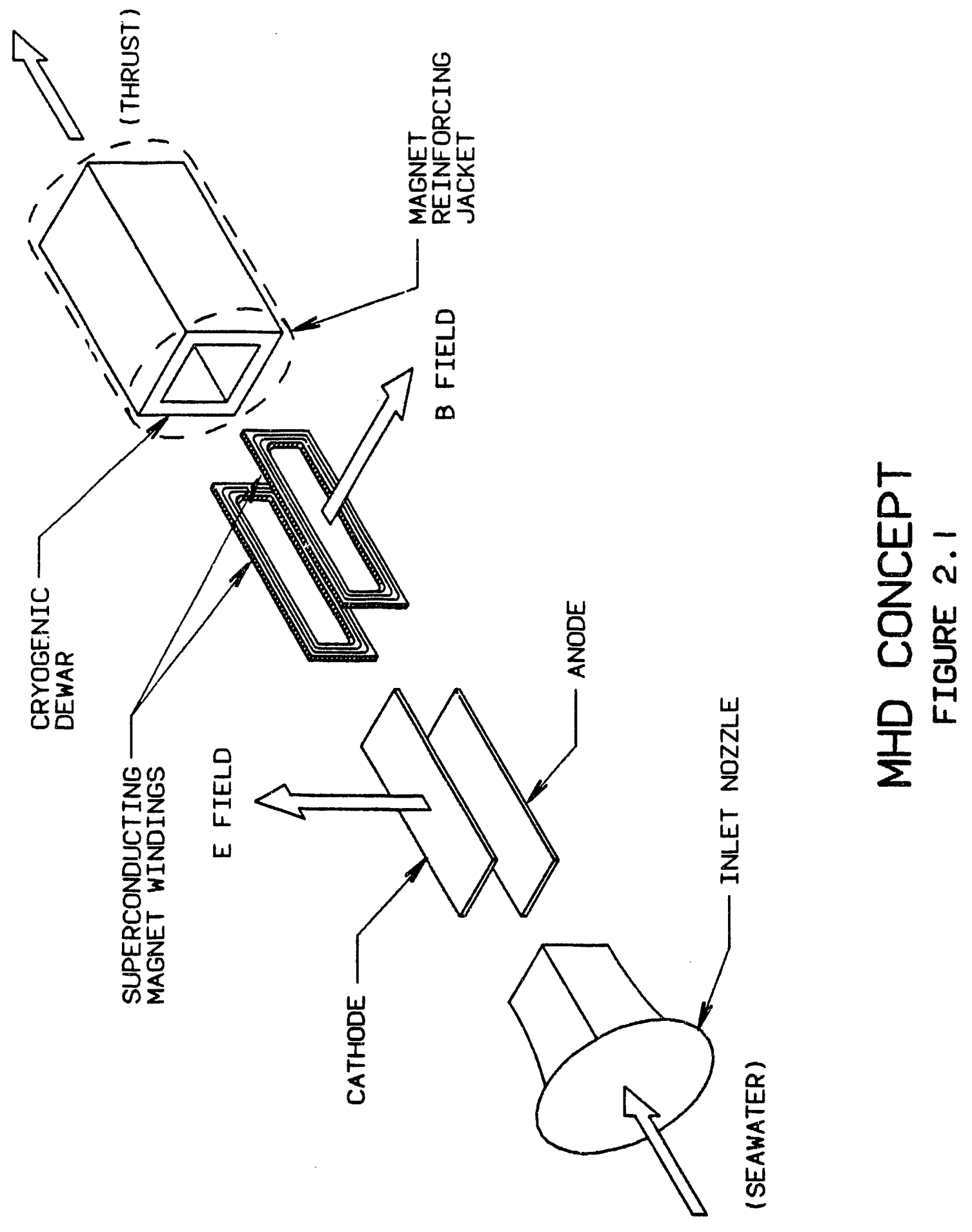


is not considered desirable because of the weight and volume penalties associated with storing a suitable conductivity enhancer, and/or the risk of leaving a detectable trail of highly conductive fluid. Thus, increasing magnetic field strength is the only method for improving propulsion efficiency.

The effects of magnetic field strength and other sperating parameters, such as cruising velocity and thruster geometry, have been studied by different researchers in the past using simple physical relationships. For exımple, Phillips ${ }^{[1]}$ performed a ícasibility study of MHD propulsion using different magnet configurations. He discovered that the propulsive efficiency of the system operating at 10 knots using a 0.6 Tesla magnet is only $8 \%$. His conclusion was that such low efficiency would make MHD seawater propulsion unattractive as an alternate propulsive concept.

To demonstrate the need for higher magnetic fields, Doragh ${ }^{[2]}$ performed an investigation which demonstrated that a propulsive efficiency of $60 \%$ could be achieved, at a speed of 10 knots with a magnetic field of 10 Tesla. These studies and simple back of the envelope calculations lead to the conclusion that a high flux density superconducting magnet must be used if practical MHD propulsion efficiency is to be achieved.

Stuart Way of Westinghouse ${ }^{[3,4]}$ successfully tested a $10 \mathrm{ft}$ long, $900 \mathrm{lb}$. submarine model to demonstrate proof-of-concept $\mathrm{MHD}$ propulsion. In addition, he performed a parametric study for submarines and found that propulsion efficiencies for a 7 Tesla magnetic field, and a $29 \mathrm{knot}$ cruising speed were as high as $80 \%$. Similar results regarding the enhancement of propulsion efficiency have been discussed by Hummert. ${ }^{[6]}$ 
Recent activities in the U.S. have included programs supported by the Navy (the Office of Naval Research - ONR, the Office of Naval Technology - ONT, and the Naval Undersea Warfare Center - NUWC), the Defense Advanced Research Projects Agency - DARPA, and Newport News Shipbuilding and Dry Dock Company. The objectives of these programs essentially fall into two categories:

- Development of accurate computer models which predict fluid flow and electric fields inside MHD thrusters to gain a thorough understanding of performance and loss mechanisms inside this propulsion system. ${ }^{[14-17]}$

- Conducting limited scope experiments and demonstrations that address critical issues, confirm theoretical predictions, and gain hands-on experience with the operation of MHD thrusters. ${ }^{[18-20]}$

Outside the U.S., Japan and Russia are very interested in MHD propulsion. In the early 1980's the Japanese Ship and Ocean Foundation launched a research and development program to acquire the technology necessary for MHD ship propulsion, and to construct an experimental ship to demonstrate this concept. ${ }^{[21]}$ The ship, Yamato I, was completed in the fall of 1991 and has completed sea trials..$^{[22-24]}$ This $\$ 40 \mathrm{M}$ ship has a displacement of 185 tons, length of $110 \mathrm{ft}$, design speed of 8 knots and is propelled by twin thrusters with 4 Tesla Low Temperature (Lo $T_{c}$ ) superconducting magnets. Because of the low magnetic field strength and the small size of the thrusters, the propulsion efficiency is low.

All studies of MHD propulsion lead to the conclusion that high magnetic flux density (10-20 Tesla) superconducting magnets must be used if practical MHD propulsion efficiency is to be achieved. In the past few years, the continued development of low temperature ( $\left(\mathrm{LO}_{\mathrm{c}}\right)$ superconducting materials has made the requirements of high magnetic fields and low weight for MHD propulsion seem attainable. Recent developments in high temperature 
superconducting materials have renewed interest internationally in reviving the concept of electromagnetic ship propulsion. ${ }^{[8,9]}$ Progress has been made in the development of high temperature $\left(\mathrm{Hi} \mathrm{T}_{c}\right)$ superconductors such as yttrium-barium-copper-oxide $\left(\mathrm{YBa}_{2} \mathrm{Cu}_{3} \mathrm{O}_{7}\right)$ and bismuth strontium calcium copper oxide $\left(\mathrm{Bi}_{2} \mathrm{Sr}_{2} \mathrm{Ca}_{3} \mathrm{Cu}_{2} \mathrm{O}_{8}\right)$. This new generation of ceramic superconductors can potentially achieve magnetic fields $\left(\mathrm{H}_{\mathrm{c}}>15\right.$ tesla) greater than their Lo $T_{c}$ counterparts. The critical temperature $\left(T_{c}\right)$ for the new generation of superconducting materials now extends to about $125 \mathrm{~K}$ which is well above the $77 \mathrm{~K}$ boiling point of liquid nitrogen. Cryogenic cooling with liquid nitrogen has several benefits:

- $\quad$ Liquid nitrogen can be manufactured on board (instead of being stored).

- Liquid nitrogen is much cheaper.

- Refrigeration equipment for liquid nitrogen is smaller, lighter and more efficient than those required for liquid helium.

- Commercial insulation can be used for liquid nitrogen refrigeration equipment and piping.

This will simplify the logistics of operation and maintenance and will lead to a reduction of space and weight. These advances in superconducting materials coupled with progress in high strength, low weight composite materials, which are required to contain the internal forces generated by the magnet, increase significantly the prospects for the development of full size seawater vehicles using MHD propulsion.

This report begins with a historical background of the two phase ANL/NNS joint research program. Phase I consisted of developing computer models and performing parametric studies to assess the feasibility of MHD ship propulsion. A brief description of the developed computer models is given. Phase II is the experimental validation of the developed models. A 2 Tesla conventional electromagnet, from an existing ANL facility, was 
used in a seawater MHD test loop. This test facility and related somponents are described in detail along with the instrumentation used to collect data on the loop and the MHD thruster. The test program and its rationale are discussed. Finally, representative experimental results are given and compared to pre-test computer model predictions. The report ends with a set of recommendations leading to an open-ocean test of an Unmanned Underwater Vehicle (UUV) propelled by an MHD thruster. 


\subsection{Program Background and Outline}

The work performed in this program was a joint research effort by the Engineering Physics Division of Argonne National Laboratory and the Advanced Propulsion Technology Group of Newport News Shipbuilding and Dry Dock Company. The overall objective of the program is to investigate the feasibility of $\mathrm{MHD}$ ship propulsion using superconducting magnets.

Newport News Shipbuilding has a long-standing interest in shipboard applications of superconductivity. ${ }^{[8]}$ Prior to becoming a member of ANL's Industrial Affiliates Program on Hi $T_{c}$ superconductivity, NNS approached ANL to explore a possible collaborative effort to study MHD seawater propulsion. ANL was selected as a teaming partner because of leadership in three areas:

1. Sizable research effort in superconducting materials.

2. Construction and operation of the world's largest superconducting magnets and channels for MHD applications.

3. Development of state-of-the-art, multi-dimensional, MHD computer codes.

The scope of work of this program was divided into two phases. ${ }^{[2]}$ A brief outline of work performed during both phases is provided in this section for completeness. A cursory review is given of other important issues for the successful application of the MHD concept for marine propulsion. Such issues include system design and integration of this concept for shipboard applications, and the development and design of superconducting materials for large magnets with strong magnetic fields. Also, some other technical considerations and developmental needs are included. 
Phase I was completely funded by Newport News. The Phase I work scope consisted of developing computer modzls and performing parametric studies to assess the feasibility of MHD ship propulsion. Also, existing ANL multi-dimensional MHD generator computer codes were modified for thruster applications and were used in this study. As part of Phase I, Argonne trained four NNS engineers in the use and application of the adapted codes for MHD ship and submarine propulsion. The st. of computer models that make up the thruster performance code and the environmeni in which they operate are described in Chapter 4.

Results of the parametric study performed during Phase I of the program confirmed the need for strong magnetic field strengths (10-20 Tesla) in order to achieve attractive propulsion efficiencies..$^{[7]}$ More recent results ${ }^{[1]}$ have further indicated that higher overall efficiencies of the propulsion system can be maintained over a wide range of cruising speeds $(2-20 \mathrm{~m} / \mathrm{s})$ for full-size submarines uperating at higher magnetic fields (15-20 Tesla).

\subsection{Phase II - MHD Thruster Peformance: Experimental Validation of Developed Models}

Besides the need for superconduc.ing magnets with strong magnetic fields, several key issues still remain to be addressed experimentally to assure feasibility of MHD seawater propulsion. These include the effect of operating parameters on performance of MHD thrusters such as flow velocity and electric load factor or applied voltage. Other issues that may affect MHD thruster performance are: electrode design and longevity; bubble generation; and the effect of magnetic field orientation, with respect to gravity, on the bubble size and their 
effect on the electrical performance of the thruster. These effects can be evaluated by performing small scale experiments. The need for these experiments has been recently emphasized at an ONR (Office of Naval Research) workshop on MHD propulsion. ${ }^{[26]}$ Results obtained from small scale experiments can be used to also verify the predictions of the computer models developed during Phase I of the project.

Based on the need for validation of the computer model, a proposal was written to the DOE/Superconductivity Pilot Center at ANL, for a joint research activity on the feasibility of MHD ship propulsion using superconducting magnets. The proposal was approved as the work for Phase II was funded equally by the Pilot Center and NNS's IR\&D program.

The work scope of Phase II of the MHD propulsion program included four tasks: Task 1 covered the design of a test facility using an existing 2 Tesla conventional electromagnet from the Argonne Liquid Metal MHD Experimental Facility (ALEX); Task 2 included the construction of the facility; Task 3 covered the operation of the facility; and Task 4 included data reduction and experimental analysis. This work was completed in 9 months. The following is a brief outline and the rationale of work performed for each task.

\subsubsection{Task 1 - Facility Design}

The 2 Ttrla test facility was designed to use an aqueous solution of $\mathrm{NaCl}$ and Instant $\mathrm{Ocean}^{\mathrm{TM}}$ as the primary working fluids. The facility is fully instrumented and capable of collecting detailed data on pressure, voltage, current, and velocity at any axial position within the bore of a 2.0 Tesla conventional electromagnet. This facility was designed using mostly off-the-shelf components to minimize cost. A pump was included in the flow loop to vary 
the fluid velocity between 2-8 m/s. An MHD thruster with segmented electrodes was designed using polycarbonate resin to facilitate observation of the electrolytically generated gaseous bubbles at the cathode. The magnet as well as the test section were designed to be rotated $90^{\circ}$ so the effect of magnetic field orientation, relative to gravity, on thruster performance could be determined. This change in orientation could affect the evolution of bubbles and thereby impact the performance of the thruster.

\subsubsection{Task 2 - Facility Construction}

In Task 2, the required materials were procured or borrowed from other experimental facilities at ANL. Items that could not be purchased, such as the test section and the pressure taps, were fabricated at NNS and ANL respectively. Facility construction took approximately 3 months.

\subsubsection{Task 3 - Facility Operation}

Following construction, experiments pertinent to operation of MHD propulsion on ships and submarines were conducted with both a horizontal and vertical magnetic field. Measurements were made of current, voltage, flow velocity, pressure, and magnetic field. Visual observation as well as high speed video recording were used to monitor the dynamics of bubbles formed during the experiment. Also, the effect of the fringing magnetic field on electrical end losses and performance of the thruster was investigated. 


\subsubsection{Task 4 - Data Reduction and Analysis}

Task 4 included both the pre- and post-test analysis for the experiment. The Phase I computer code was used for the pretest analysis and to assist in defining the operating parameters for the experiments. The results of the simulation tests were compared to experimental results to verify the predictions of the developed computer models. Data gathered by the instruments was recorded and entered in a computer spread sheet for tabulation and analysis.

\subsection{Technical Considerations and Developmental Needs}

Besides the basic understanding of the MHD thruster performance, there still remain several technical and design issues that should be addressed to assess the feasibility of this concept for naval applications. Some of these issues include the system design and integration of the MHD propulsion system, and the design of superconducting magnets with strong magnetic fields.

Work on integrated designs of propulsion systems using MHD thrusters is being pursued by NNS. ${ }^{[10]}$ The use of an MHD propulsion system allows greater flexibility in the equipment arrangement than a conventional mechanical drive system. The propeller and associated hardware are eliminated. The fixed longitudinal stack up required for the propulsion turbine, reduction gear, shaft, and propeller is no longer be necessary, allowing engine room spaces to be utilized more efficiently. Instead, the MHD thruster, DC power supply, and a superconducting magnet with its cryogenic support equipment, will be installed. 
One challenge facing the shipbuilder is the large number of small hull penetrations required to support an MHD thruster. This situation is in contrast to a conventional ship where a large dynamic penetration is required for propulsion shafting. The use of three dimensional modeling will ensure the success of the MHD ship design process.

Other issues that require technical development include the following: superconducting magnet design and material for large magnets with high magnetic field strengths, magnet structure integrity, magnet excitation and protection, cryogenic and structure design of the refrigeration system, size, weight, and cost of the superconducting magnets and cryogenic system, MHD duct geometrical configuration, electrode materials and configuration, electrode erosion, magnetic, acoustic, and chemical signature control, seawater and electrical conductivity variation and systems integration of the MHD thruster into seawater vehicle design. Among those issues, the construction of practical and reliable high strength superconducting magnets of reasonable size, mass, and cost is considered the most challenging.

Work is being pursued and good progress has been achieved at Argonne and elsewhere on the development of superconducting material and high strength, low density composite materials. 


\subsection{Computer Models for MHD Propulsion Systems}

From its inception in October of 1988, the NNS Magnetohydrodynamic Propulsion Development Program required a dynamic tool to analyze surface ship and submarine propulsiun concepts. Accordingly, an agreement was reached between Newport News Shipbuilding and Argonne National Laboratory to provide such a tool. Argonne was contracted to develop MHD thruster models and train four engineers in its use.

In June 1990 four NNS engineers visited Argonne National Laboratory for training in the use of the ANL/NNS MHD computer program. The two day session covered theory and practical applications of this code. Additionally, instruction was provided for modifying the source code to suit NNS' specific application.

The computer program ${ }^{[27]}$ is written in the $\mathrm{C}++$ programming language and is compiled for use on a personal computer. The first part of the program is a collection of models which describe fluid flow, thruster geometry, electromagnetic field interactions, and ship drag. The second part is the interactive environment in which these models operate.

Eight individual models ${ }^{[2]}$ comprise the first part of the code, they are: liquid model (liq), nozzle model (lnoz), diffuser model (ldif), pipe model (lpip), loss model (loss), mhd0 model (mhd0d), mhd1 model (mhd1d), and the drag model (drag). 


\subsection{Liquid Model (liq)}

The liquid model initiates the fluid flow conditions at the inlet of the MHD thruster with user specified values of velocity, pressure, density, viscosity, and electrical conductivity. The values of density, viscosity, and electrical conductivity are treated as constants while the other remaining values are updated by the code as required.

\subsection{Nozzle Model (lnoz)}

The nozzle model simulates incompressible flow through a nozzle by using a simple head loss. Total pressure drop through the nozzle is calculated by multiplying a user specified lumped loss coefficient by the dynamic head at the nozzle exit.

\subsection{Diffuser Model (ldif)}

The diffuser model describes fluid flow through a diffuser by multiplying the dynamic head at the inlet by the sum of frictional and local loss coefficients. Both loss coefficients are determined from empirical relationships based on fully developed turbulent flow. Frictional losses are determined as a function of wall roughness, Reynolds number, divergence angle and area ratio. Similarly, local losses are calculated as a function of divergence angle and area ratio. 


\subsection{Pipe Model (lpip)}

The pipe model calculates frictional head losses in a constant cross-sectional area pipe. These losses are determined from a turbulent head loss relationship where the friction factor is computed from an empirical equation as a function of roughness, hydraulic diameter, and Reynolds number.

\subsection{Lass Model (loss)}

The loss model simulates a loss in total pressure due to elbows, valves, or any other source of pressure drop. This is done by multiplying the inlet dynamic head by a user defined loss factor.

\subsection{MHTO Model (mhdOd)}

This portion of the code models a simple, one-dimensional MHD thruster. It uses a continuous electrode with a constant magnetic field and thruster geometry. The MHDO model includes ohmic and frictional losses as well as electrical end loss correction factors for pressure and current $\left(\mathbf{k}_{\mathrm{p}} \& \mathbf{k}_{\mathrm{i}}\right)$.

\subsection{MHD1 Model (mhd1d)}

The MHD1 model, like MHD0, is a one-dimensional thruster model. MHD1, however, couples a one-dimensional hydrodynamic model to a two-dimensional electrical model that calculates the electric field potential and current everywhere within the channel. While this 
model does not show effects of cross stream flow variations, it sufficiently accounts for the effects of wall friction, fringing electric and current density fields, and electrode surface potential losses on the thruster electrical efficiency.

The equations used in the hydrodynamic model are the usual one-dimensional equations for conservation of mass:

$$
m-\rho A u
$$

and conservation of momentum.

$$
\rho u \frac{d u}{d x}=-\frac{d p}{d x}+J \times B-\frac{f \rho u^{2}}{2 d}
$$

In equations $4.1 \& 4.2 \mathrm{~m}$, is mass flow rate, $\mathrm{u}$ is the average velocity, $\mathrm{A}$ is the cross sectional area, $\rho$ is the fluid density, $\mathrm{J}$ is the electric current density, B is the magnetic flux density, and $\mathrm{d}$ is the thruster hydraulic diameter. The coordinate system is taken with $\mathrm{x}$ along the flow direction and $y$ normal to the electrodes. The friction factor, $f$, is obtained from an empirical relationship representing the standard Moody diagram, as a function of Reynolds number and the average size of the surface roughness. The first order differential equations are solved using a $4^{\text {th }}$ order Runge-Kutta method.

The two-dimensional electrical model solves Maxweil's equation for the electrical field potential in conjunction with Ohm's law. The resulting modified Laplace equation for the electrical potential is given by:

$$
\frac{\partial^{2} \Phi}{\partial x^{2}}+\frac{\partial^{2} \Phi}{\partial y^{2}}=0
$$


where $\Phi$ is the electric field potential. This equation, written in a finite difference form, is solved using a successive overrelaxation procedure. The solution gives the values for $\mathbf{k}_{\mathrm{p}} \&$ $\mathbf{k}_{\mathrm{i}}$ (end loss correction factors). This two-dimensional electrical model is used to predict the fringing current fields near the electrode ends and to determine the electrical end losses in that region. ${ }^{[15]}$

The following boundary conditions are used in the 2-dimensional electrical model. On the electrodes, $\Phi$ is specified as a constant equal to $+V / 2$ on the anode and $-V / 2$ on the cathode, where $\mathrm{V}$ is the total applied potential difference. On the rest of the electrode walls, the normal current density is taken to be zero; from Ohm's law this boundary condition requires that:

$$
\frac{\partial \Phi}{\partial y}=u B \text { at } y= \pm \frac{d}{2}
$$

To include most of the fringing fields, cross stream boundaries were assumed sufficiently far upstream and downstream of the electrodes. Thus, the normal current density at these boundaries was taken to be zero.

$$
\frac{\partial \Phi}{\partial x}-0
$$

The electrical field potential everywhere within the channel is solved given the flow velocity, magnetic field, and applied potential. The computed potential field is then used to determine the centerline transverse electric field $E_{y}$ which in turn is used to determine $\mathrm{J}_{\mathrm{y}}$ along the centerline from Ohm's law, which for an MHD thruster can be written: 


$$
J_{y}=\sigma\left(E_{y}-u B\right)
$$

Note that $J_{y}$ is the transverse current field. The axial current field does not enter into this simple one-dimensional hydrodynamic model.

Additionally, MHD1 allows the user to enter a variable thruster height, width, and magnetic field as a function of thruster length.

\subsection{Drag Model (drag)}

In this model, developed at NNS, the submarine geometry is entered by specifying length, diameter and geometric exponents that describe the forward and after part of the ship. ${ }^{[28]}$ Default values for other constants such as propeller efficiency, free flood factor, and reserve buoyancy are assumed by the program if they are not specified.

This algorithm calculates the wetted surface area and volume of the submarine by assuming an elliptical forward end and a parabolic aft end. The submerged and surfaced displacements are then calculated.

Planform and surface areas, effective aspect ratio, lift and drag coefficients for all appendages are next calculated. ${ }^{[29]}$ Total hull drag coefficient $\left(\mathrm{Cd}_{\text {hull }}\right)$ is determined from the sum of the friction drag coefficient $\left(\mathrm{Cd}_{\mathrm{f}}\right)$, the user-specified pressure drag coefficient $\left(\mathrm{Cd}_{\mathrm{pr}}\right)$, and the hull friction drag correction factor $\left(\delta_{\mathrm{cf}}\right)$.

$$
c d_{h u 11}-c d_{f}+c d_{p z}+8 c t
$$


The drag is calculated for the hull and all appendages and then totaled;

$$
D=\frac{C d \rho A V^{2}}{2 g}
$$

where $C d$ is drag coefficient, $\rho$ is fluid density, $A$ is wetted surface area, $V$ is ship velocity, and $g$ is acceleration due to gravity.

The propulsive coefficient is determined as the product of the propeller efficiency, relative rotative efficiency, and the hull efficiency. ${ }^{[30]}$

$$
P C-\eta_{\text {prop }} \eta_{\text {rot }} \eta_{\text {bul1 }}
$$

The shaft horsepower (SHP) for each appendage and the hull is calculated and totaled ${ }^{[29]}$ once the effective horsepower (EHP) is determined.

$$
S H P=\frac{E H P}{P C}
$$

Where,

$$
E H P-D V
$$

Additionally, this program calculates structural and machinery weights as well as the machinery volume. 


\subsection{System Analysis}

The second part of the ANL MHD program is the interactive environment called GPS (Generalized Post Script). This PostScript-like language is used to interact with the developed models. In addition, GPS has a built in library of mathematical functions and logical operators used for independent analysis or in conjunction with the models. ${ }^{[27]}$

Essentially, GPS allows the user to treat each model separately. This means the models can be combined in any order, any number of times, to more accurately represent a large number of system configurations. GPS also allows the user to pass information from one model to another. For example, if the velocity of a fluid was changed in one model, the new velocity can be passed to the next model. Additionally, this environment allows the user to impose constraints or logical operations on the system being examined. In our case, the code considers steady state conditions where the thrust from the thruster equals the drag on the submarine.

Another advantage of GPS is that the models, logical and mathematical operators, and constraints can all be typed into a standard ASCII data file and piped into GPS for analysis. This allows the user to easily duplicate similar data input files and complete a study by executing a batch command from the DOS prompt. Similarly, the output of this program can be piped to a file (ASCII format), displayed on the monitor, or echoed to the printer. 


\subsection{Experimental Layout}

The test facility used for model validation is organized into five sections:

- Primary loop

- Secondary loop

- $\quad$ Additional Systems

- Instrumentation

- Bubble Diagnostics

The primary loop (Figure 5.1) consists of a 2 Tesla conventional electromagnet, a test section, gas separator, a loop pump, polyvinylchloride (PVC) piping, and related fittings. Additional systems support both loop operation and data acquisition.

\subsection{Working Fluid}

Two solutions were examined as candidate working fluids for this experiment:

- $\quad$ Aqueous solution of sodium chloride ( $\mathrm{NaCl}$ ).

- Instant Ocean ${ }^{\mathrm{TM}}$.

Aqueous solution of sodium chloride $(\mathrm{NaCl})$ was selected as the primary working medium in lieu of Instant Ocean $^{\mathrm{TM}}$ because the $\mathrm{NaCl}$ solution does not contain additional dissolved salts whose precipitates (e.g. calcium hydroxide $-\mathrm{Ca}[\mathrm{OH}]_{2}$ and magnesium hydroxide $\mathrm{Mg}[\mathrm{OH}]_{2}$ ) might foul the loop during operation. Increased $\mathrm{NaCl}$ concentrations beyond values characteristic of seawater are used to enhance electrical conductivity and thus achieve 


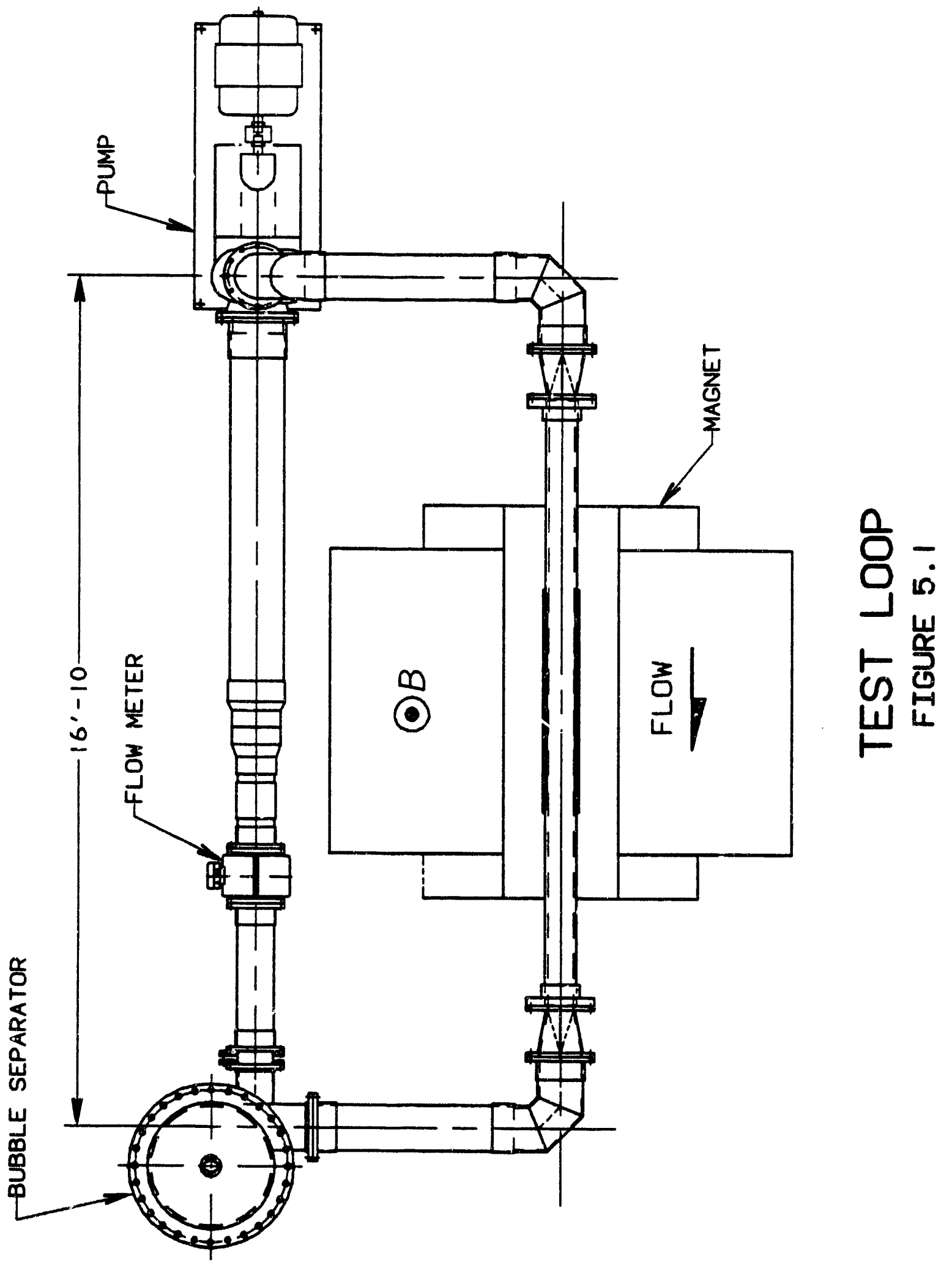


test operating conditions closer to prototypic than would have been possible with conductivities representative of seawater alone.

Instant Ocean ${ }^{\mathrm{TM}}$ was used at the end of the test program to verify the thruster performance for more than one working fluid and compare bubble evolution/behavior with the two working fluids.

All loop components were selected to be compatible with both primary and secondary working fluids and the products of electrolysis such as: hydrogen gas $\left(\mathrm{H}_{2}\right)$, sodium hypochlorite ( $\mathrm{NaClO})$, and hypochlorous acid ( $\mathrm{HClO}) .{ }^{[31]}$

\subsection{Primary Loop}

The purpose of the primary loop is to circulate the working fluid in support of data acquisition in the test section. The primary loop also provides for s moval of dissolved gasses in the working fluid. Components of the primary loop include:

- Magnet

- Test Section

- Separator

- Standpipe

- Loop Pump

- $\quad$ Piping

The loop is designed to function in two modes of operation: the pump assist mode, and the unassisted mode. In the pump assist mode, the pump overcomes the losses in the flow loop 
and induces a (variable) velocity into the test section. This allows the current to be varied independently of the velocity in the test section. In the unassisted mode the loop pump is removed from the test setup requiring the test section to develop sufficient thrust to balance the frictional losses in the loop. This mode was to be employed for demonstration purposes only.

\subsubsection{Magnet}

An existing 2 Tesla, iron core, conventional electromagnet with a uniform magnetic field volume of $8^{\prime \prime} \times 30^{\prime \prime} \times 50^{\prime \prime}$ is used in the test setup. This 67 ton, water-cooled electromagnet was selected because the magnetic field can be oriented either horizontally or vertically to observe the effect of gravity on bubble evolution and $\mathrm{MHD}$ thruster performance. The magnetic field as a function of length is plotted in Figure 5.2.

\subsubsection{Test Section}

Sheets of optically-clear polycarbonate resin were solvent welded with methylene chloride $\left(\mathrm{CH}_{2} \mathrm{Cl}_{2}\right)$, strengthened with brass screws, and sealed with a silicone rubber adhesive to form the $6^{\prime \prime} \times 6^{\prime \prime} \times 12^{\prime}$ test section (Figure 5.3). This material was selected to enable visual observation/measurement of the electrolytically-generated hydrogen bubbles at the cathode. Seven pressure taps were installed along the 50" active length of the test section (that portion of the test section where the electrodes are located) to measure the internal pressure distribution. Each electrode was segmented into five parts $\left(4^{\prime \prime}, 6^{\prime \prime}, 30^{\prime \prime}, 6^{\prime \prime}, 4^{\prime \prime}\right)$ enabling specific measurement of both applied current and voltage to better ascertain the impact of fringing current on thruster performance. The anode segments are a mixed-oxide coating 


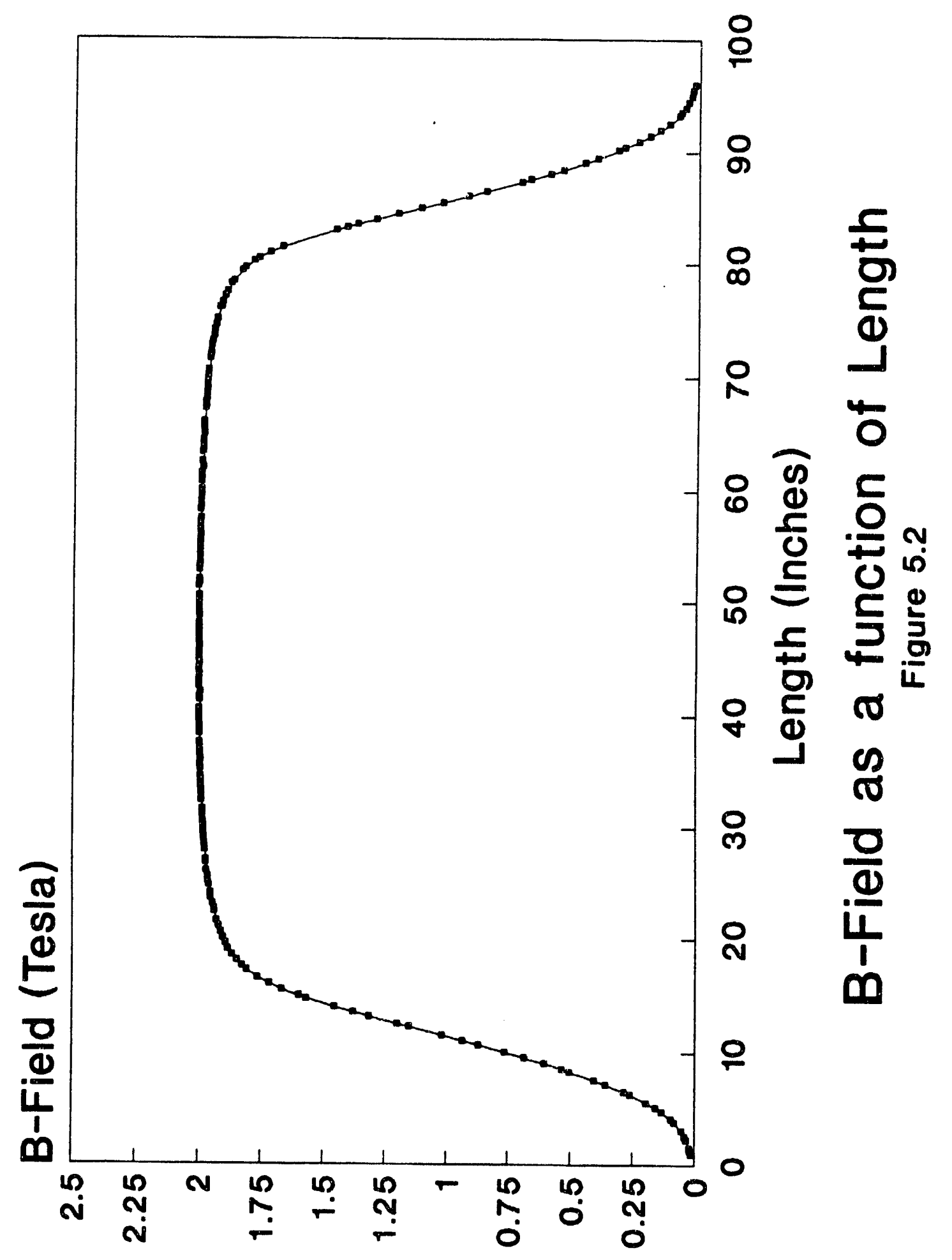




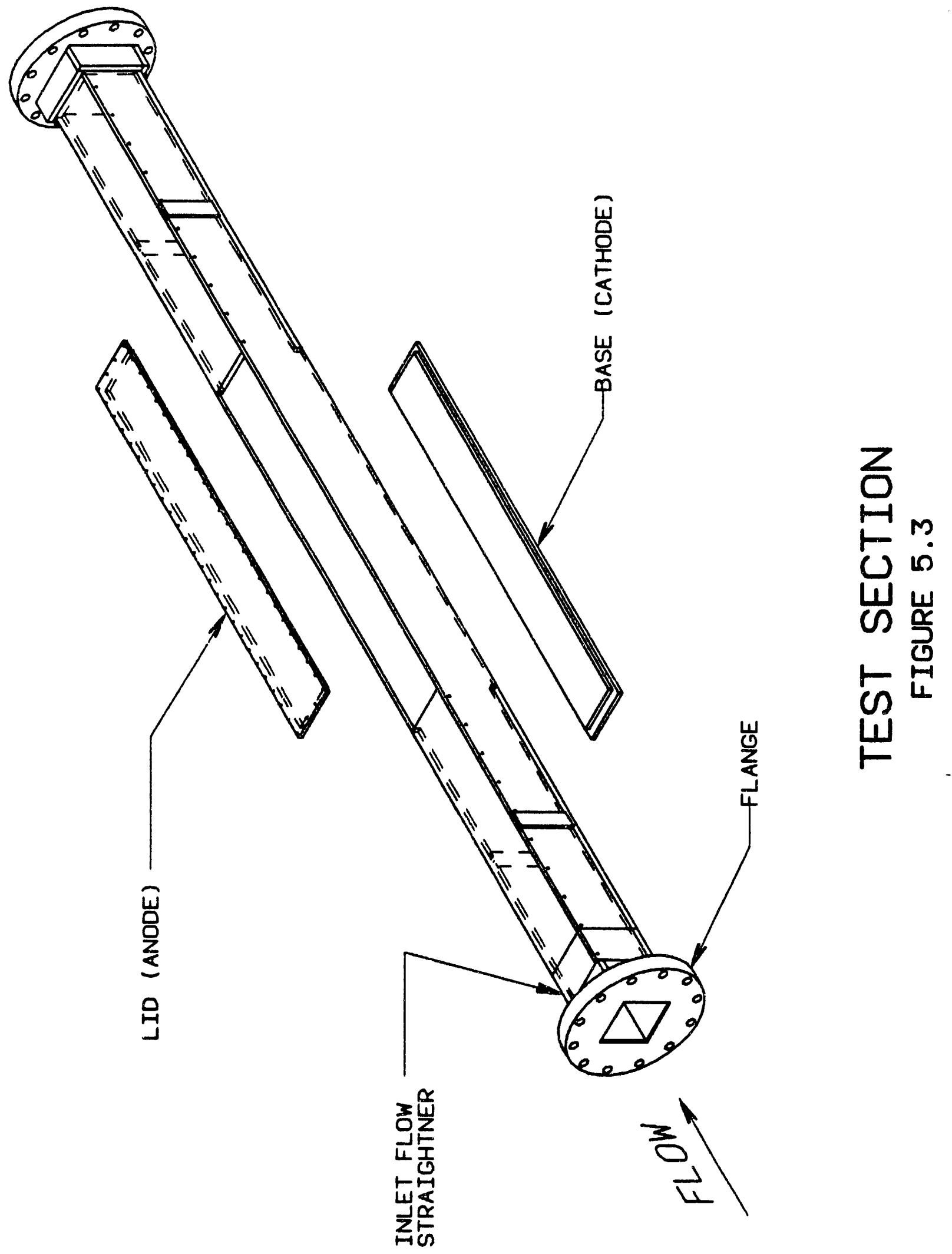




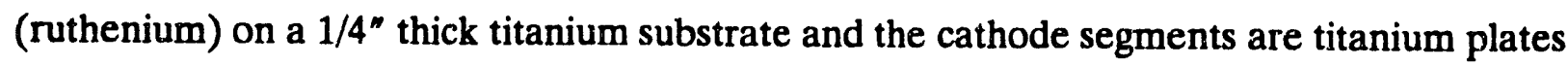
of the same thickness. A removable lid was installed to allow for electrode maintenance. The non-active portion of the test section was included in the design, along with an inlet flow straightener, to provide a well developed velocity profile for the active section of the thruster.

\subsubsection{Separator}

A bubble separator was included in the loop to assist in the separation of hydrogen bubbles from the working fluid. The separator tank design is based on a cyclone principle commonly used to separate solids and liquids from gas streams. In this application, the centrifugal field moves the hydrogen bubbles to the center where they rise, enter the standpipe gas space, are diluted by nitrogen gas below the flanmability limit, and are exhausted to the atmosphere. The tank is $30^{\prime \prime}$ in diameter and 741/2" tall (Figure 5.4). Inlet and outlet connections were installed off-axis to generate the centrifugal field required for separation. A flanged lid was provided to facilitate coating the interior of the tank with a synthetic rubber corrosion preventative. Elliptical heads were installed to facilitate gas removal and loop drainage. Other features of this tank include:

- A 3" connection at the top center of the separator required for the installation of the separator standpipe.

- A 2" loop drainage/fill connection at the bottom center of the tank.

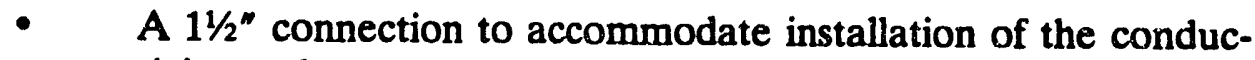
tivity probe. 


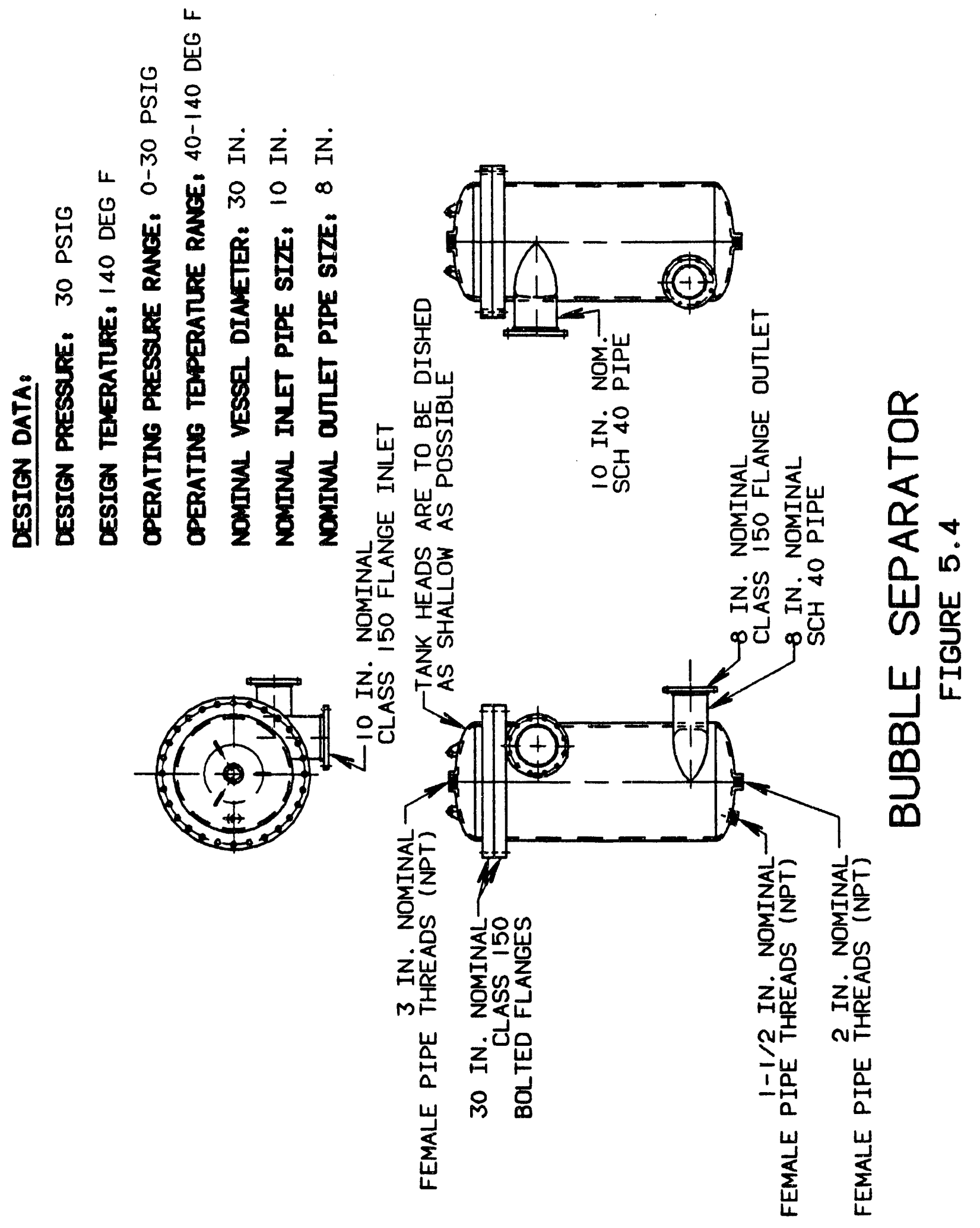




\subsubsection{Standpipe}

A 33" long, 4" diameter, 3/8" wall thickness, clear acrylic pipe is installed at the top of the separator to enable loop operators to monitor the working fluid level in the loop, facilitate the injection of nitrogen into the system, and provide an expansion volume (Figure 5.5). Loop pressurization, hydrogen dilution, and venting is accomplished through the following standpipe penetrations:

- A $3 / 8^{\prime \prime}$ nitrogen connection.

- A 1" vent connection located in the top of the standpipe.

- A $1 / 4^{\prime \prime}$ drain connection to lower the fluid level in the standpipe.

- A $1 / 4^{\star}$ connection for a level indicator tube to monitor fluid level during loop fill.

\subsubsection{Loop Pump}

The loop pump is a $30 \mathrm{kw}$ (40 hp), horizontal end-suction, $12^{\prime \prime} \times 10^{\prime \prime}$ centrifugal pump (Carver Pump ETAL 250-33 364T) whose motor is driven by a variable frequency speed controller (Emerson Industrial Pump Controller). This controller enables testing at fluid velocities in the range of $2-8 \mathrm{~m} / \mathrm{s}$ independently of current applied to the thruster electrodes.

\subsubsection{Piping}

Schedule 40 polyvinylchloride (PVC) piping was used in the primary loop. Pipe sizes were established by the pump discharge (10"), the flowmeter ( $\left.8^{\prime \prime}\right)$, and the pump suction (12"). An $8^{\prime \prime}$ to $12^{\prime \prime}$ concentric enlarger was installed downstream of the flowmeter to effect the 


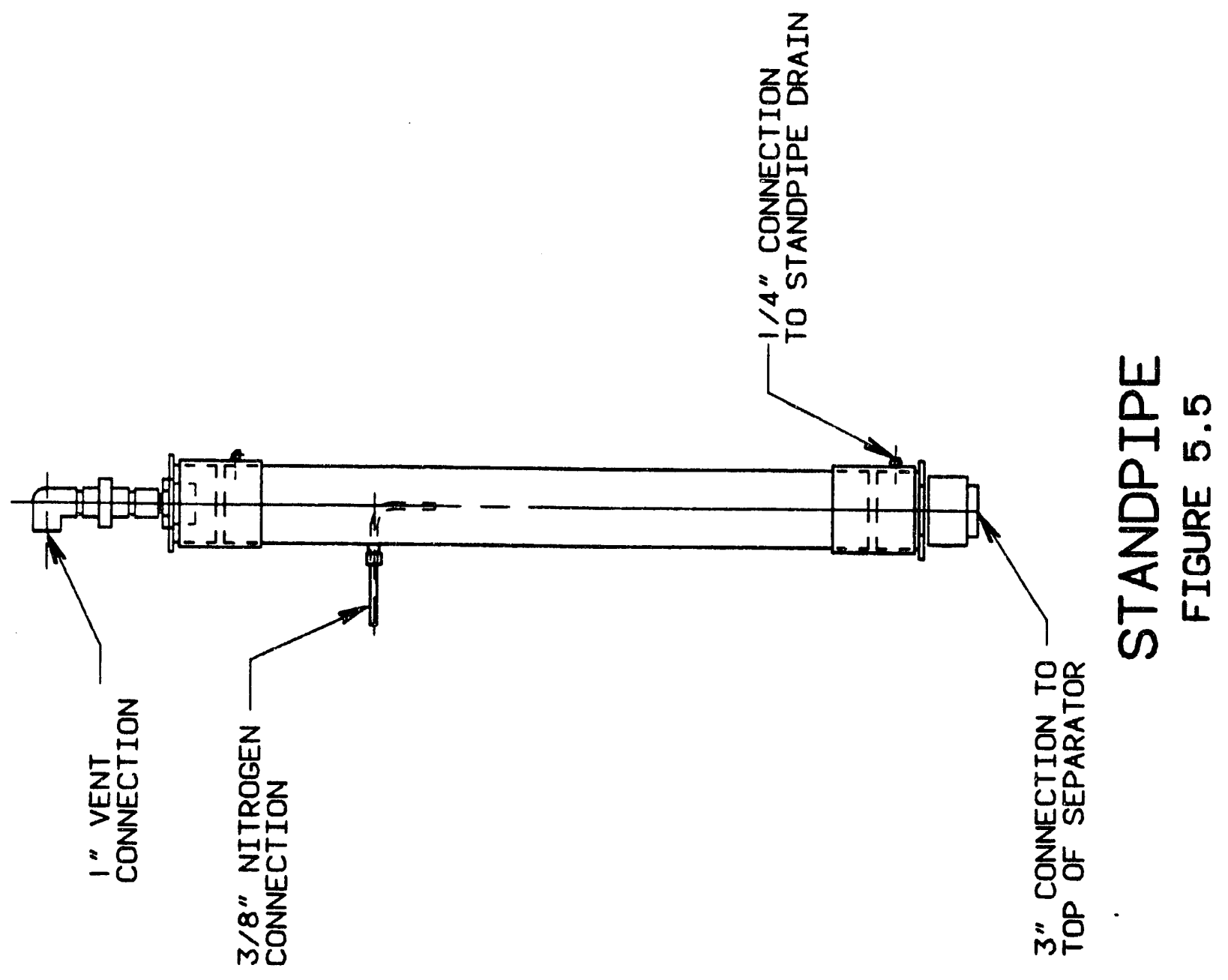


transition to the required size for the pump suction. Additionally, 10" round to 6 " square fiberglass reinforced piping transitions were installed to reduce flow losses into/out of the test section. An $8^{\prime \prime}$ flexible connection was installed between the two fixed points in the system, the loop pump and the separator tank, to accommodate changes in pipe length due to variations in temperature, reduce vibration in the loop from the pump, and accommodate any misalignment of loop components. Finally, $150 \mathrm{lb}$ slip on flanges were used, where necessary, to connect loop components.

\subsection{Secondary Loop}

The purpose of the secondary loop (Figure 5.6) is to:

- Fill/drain the loop from/to the primary storage tank.

- Mix the working fluid so that it possesses uniform properties.

- Transfer the used fluid to storage.

- Transfer the stored fluid to a waste disposal vehicle.

- Filter the working fluid during both loop fill and mixing operations.

The components that make up the secondary loop are:

- Circulation Pump

- Primary Storage Tank

- $\quad$ Secondary Storage Tank

- Filter

- $\quad$ Piping 


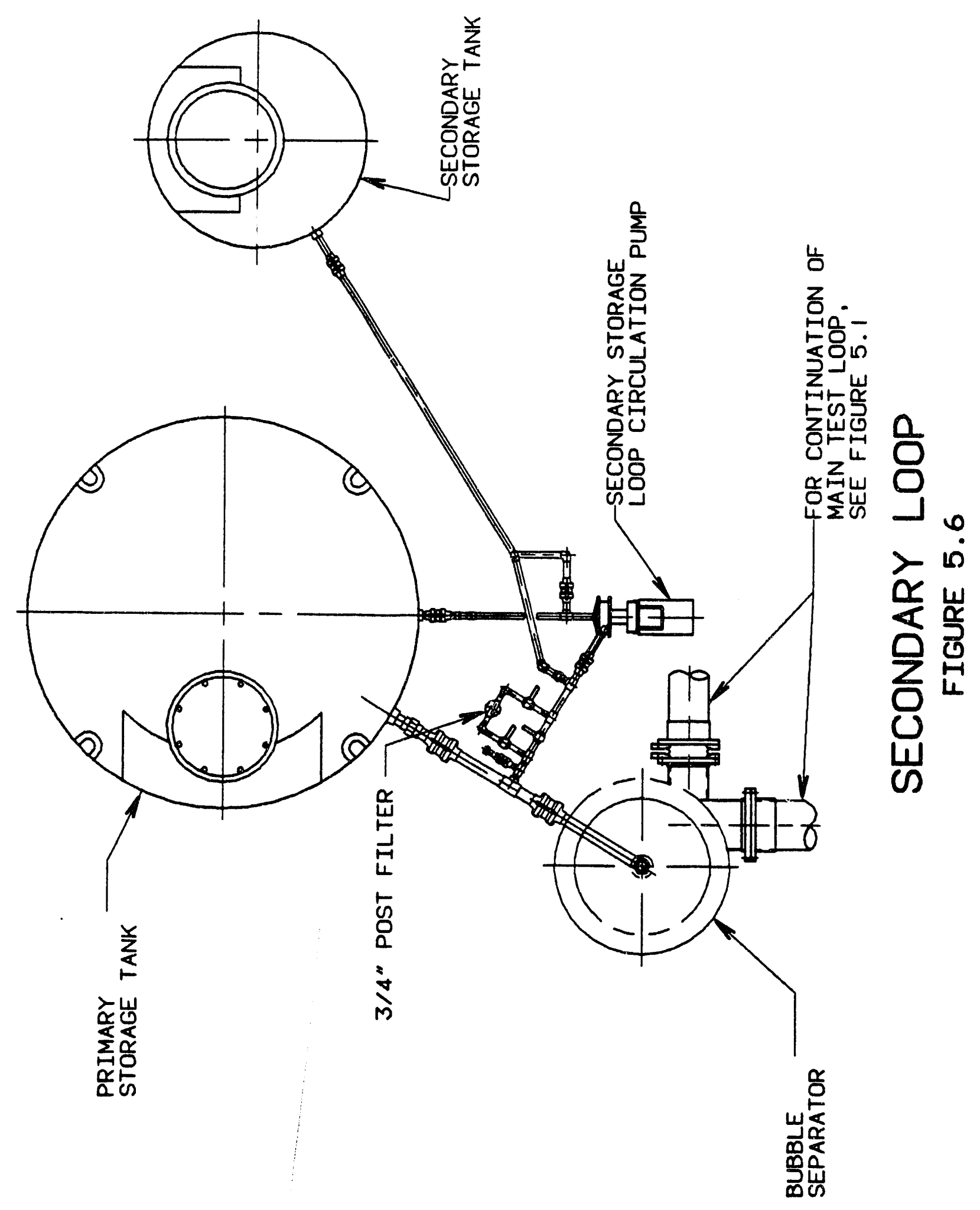




\subsubsection{Circulation Pump}

The circulation pump (Vanton CCGH-PY200) is used as a mixing/transfer pump. This $1 \frac{1}{2}$ hp, close-coupled centrifugal pump has a maximum flow rate of $25 \mathrm{gpm}$ at 15 feet total developed head. Additionally, this pump has a polypropylene water jacket and a 3/8" freshwater flush connection to rinse the seal face.

\subsubsection{Primary Storage Tank}

The primary storage tank is an 1100 gallon, $7^{\prime}-2^{\prime \prime}$ diameter, $4^{\prime}-6^{\prime \prime}$ tall vertical tank fabricated in one piece of high density cross-linked polyethylene. The purpose of this tank is to contain the entire contents ( 375 gallons) of the loop and enable the loop to drain by gravity in the event of an emergency. Additionally, a 1/2" thick, 19" diameter PVC bolted manway with a $3 / 8^{\prime \prime}$ foarn gasket is provided for tank maintenance. Other features of this tank include:

- A 3/8" nitrogen connection which allows dilution of the gasses, which may evolve out of solution when the loop is emptied and the working fluid depressurized, below their flammability limit.

- A 1" vent connection to allow displaced gasses to be vented to the building exterior.

- A $1 / 4^{\prime \prime}$ connection for the standpipe drain system.

- A 3/4" connection with a valve (DV2) and funnel which permits purged fluid from the test section pressure measurement system to be returned to the primary storage tank without the removal of the tank lid.

- A 0-3 psi pressure gauge (G4).

- $\quad$ A $0-15^{\prime \prime} \mathrm{H}_{2} \mathrm{O}$ vacuum gauge (G5). 
- 2" bulkhead penetration for loop drainage/fill connection.

- $\quad 1^{\text {" }}$ bulkhead penetration for pump inlet.

- $3 / 4^{\prime \prime}$ bulkhead penetration for installation of the $\mathrm{pH}$ probe.

The geometrical constraint for the selection of this tank was that the total volume of working fluid has to be stored in $24^{\prime \prime}$ of vertical height (the distance between the bottom of the separator and the floor).

\subsubsection{Secondary Storage Tank}

The secondary tank is a 550 gallon, $4^{\prime}-0^{\prime \prime}$ diameter, $6^{\prime}-8^{\prime \prime}$ tall verticil storage tank which serves as an interim storage site of expended fluid between rest runs. This tank is fabricated from the same material and furnished with a similar manway as the primary storage tank. Principal features of this tank include:

- A $1^{\text {"n }}$ vent connection.

- A 0-3 psi pressure gauge (G6).

- A 1" bulkhead penetration for tank drain/fill.

There are no constraints on the selection of this tank except that it contain the volume of the working fluid in the loop. 


\subsubsection{Filter}

A 3/4", single cartridge, 5 micron, post filter (Housing - CWC fluids model S1101 and Filter - model R100) was installed parallel to the pump discharge to allow the loop operator a choice of using the filter for the loop fill and the working fluid mixing operations.

\subsubsection{Piping}

Piping material for the secondary loop was the same as the primary loop. Pipe sizes were established by equipment connections, specifically $1^{\text {" }}$ for the circulation pump, and $2^{\text {" for }}$ the separator drainage. Two 2" ball valves (V1 \& V2), five 1" ball valves (V3, V5, V6, V7 \& V8), and three $3 / 4^{\prime \prime}$ ball valves (V4, V9 \& V10) were installed in the circulation loop to enable operation in different modes of operation (e.g. fill, drainage, mixing, transfer, and filter). Also, a ball check valve (CV4) was installed in the pump discharge to prevent back flow through the circulation pump.

\subsection{Additional Systems}

Eight systems are required to support both loop operation and data acquisition, they are:

- Nitrogen

- Oxygen Monitor

- Vent

- Electrode Power Supply

- Standpipe drain

- Loop Pump Drain 
- Circulation Pump Flush Face Seal

- Loop Fill

\subsubsection{Nitrogen}

Nitrogen gas is supplied (Figure 5.7) from an existing manifold/regulator to the following points:

- Separator standpipe - to reduce the concentration of the separated hydrogen gas below its flammability limit and to maintain the working pressure of the tank/loop.

- $\quad$ Primary \& secondary storage tanks - to provide an inert atmosphere for working fluid storage.

Nitrogen is delivered to the experiment via a $3 / 8^{\prime \prime}$ supply line which branches to serve the separator standpipe and both storage tanks. Flow rate is controlled in both branches with dedicated needle valves (NV1 \& NV2) and is monitored using rotameters (FM1 \& FM2). Tank selection is made with ball valves (V11 \& V12) installed downstream of the rotameter (FM2). Backflow is prevented in the standpipe and both tanks with check valves (CV1, CV2 \& CV3) set at $1 / 3$ psi. oop pressure is safeguarded with a $1 / 4^{\prime \prime}$ adjustable relief valve (PRV1) set to crack at $10 \mathrm{psi}$. Pressure gauges are installed on both the primary \& secondary storage tanks (G4 \& G6) and on the separator standpipe rotameter (G3 0-15 psi) to monitor component pressure and nitrogen supply pressure respectively.

Nitrogen was selected as the pressurizing/diluting agent because it is a cost effective nonreactive gas. 


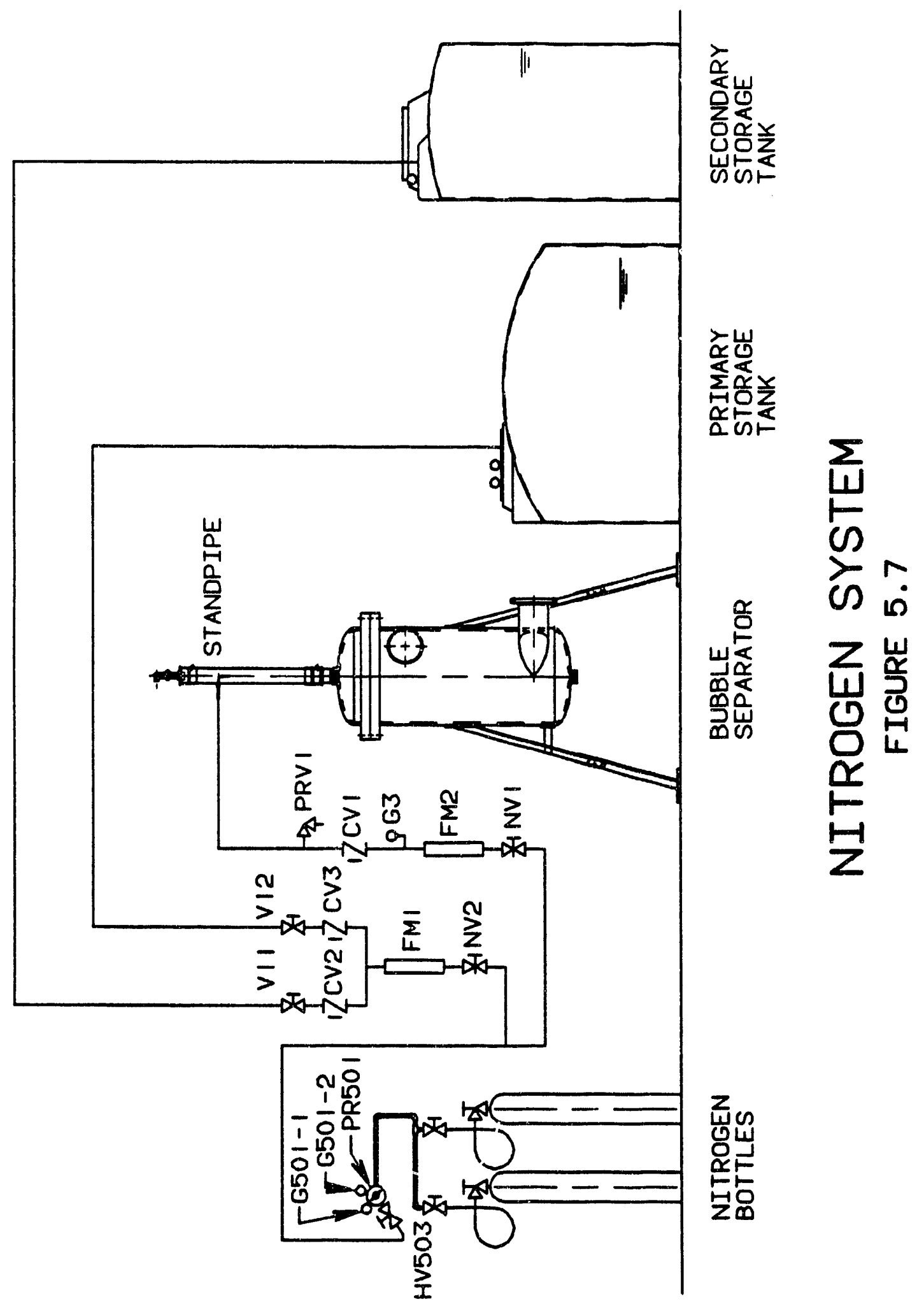




\subsubsection{Oxygen Monitor}

A portable oxygen monitor (Edmont-Wilson Model 60-400) is used to monitor the concentration of $\mathrm{O}_{2}$ in the primary storage tank. This system is calibrated prior to each test series and enables the loop operator to determine if conditions inside the primary storage tank support detonation of gases which may evolve out of solution when the loop is drained and the working fluid depressurized. The storage tank is purged with nitrogen during the loop fill operation. Testing begins once the monitor indicates that a stable, inert environment exists (i.e. that oxygen concentration is less than $4 \%$ by volume).

The portable monitor is recharged with a nickel-cadmium battery charger (Edmont-Wilson Model 60-401) at the end of each test run or daily, whichever occurred first.

\section{$\underline{5.4 .3 \text { Vent }}$}

The vent system (Figure 5.8) conveys unwanted gases outside the building and is connected to the following points:

- $\quad$ Separator standpipe.

- $\quad$ Primary \& secondary storage tanks.

Loop pressure is controlled both by the supply of nitrogen (as described in section 5.4.1) and the throttling of the resultant flow from the separator standpipe vent with a 1" bronze globe valve (VV1). Loop pressure is monitored with gauges placed in the standpipe vent (G1 0-5 psi \& G2 0-30 psi) and a pressure transducer (PT105). Backflow into both of storage tanks is prevented by ball check valves (CV5 \& CV6). Additionally, gas flow from the primary 


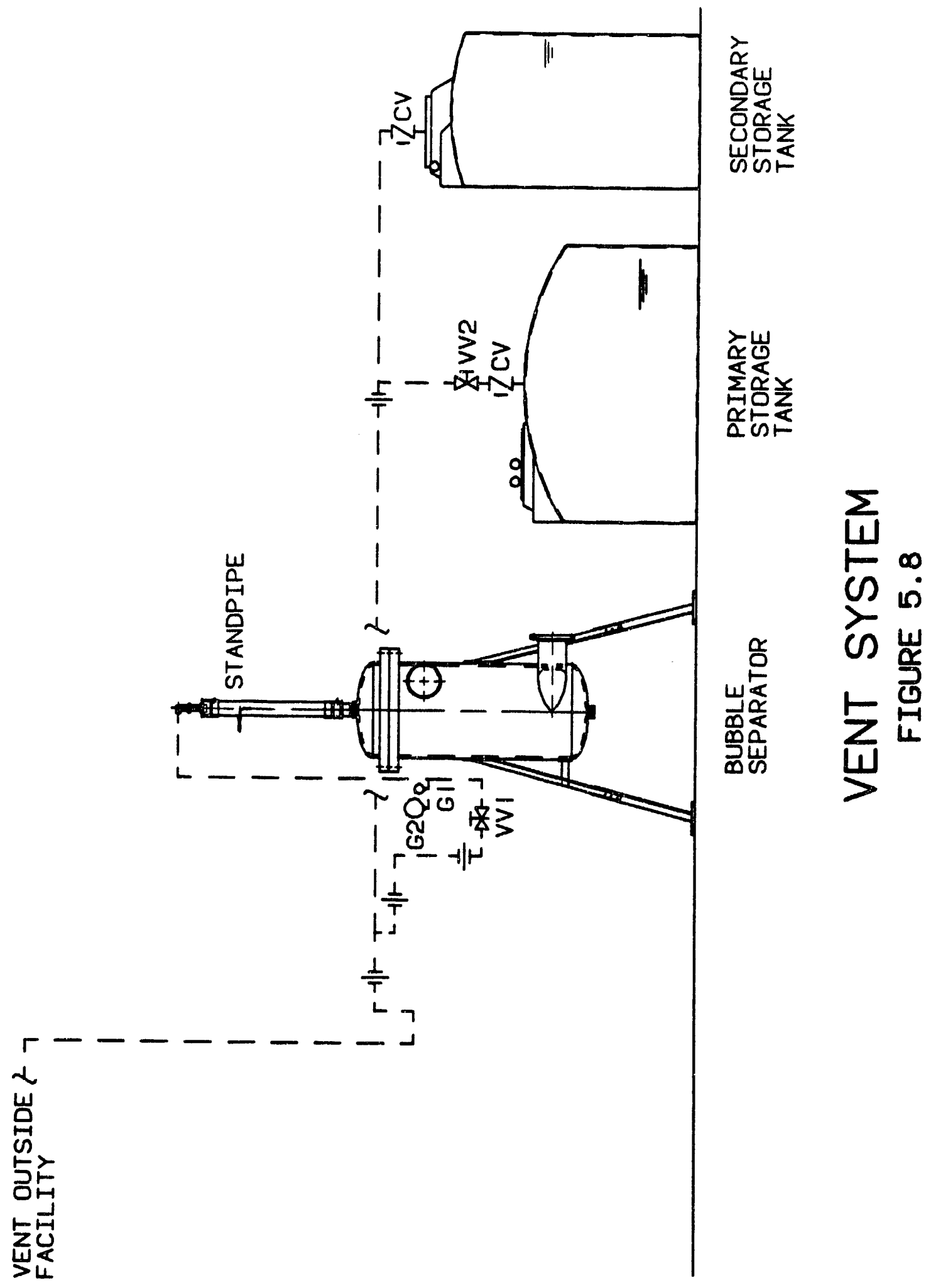


storage tank can be stopped by closing a PVC ball valve (VV2) in order to maintain an inert atmosphere in the tank.

\subsubsection{Electrode Power Supply}

Power is supplied to the electrodes from a water cooled, 1200 amp power supply (ACME Rectifier). Connections are made on power supply flags at the back of the cabinet. A $50 \mathrm{mV}$ shunt is installed in each cable which serves individual anode/cathode segments (Figure 5.9). The gauge and length of the power cables were selected so that the voltage drop in all of the leads is the same. To insure uniform distribution of current to the electrodes, the cables are attached to $3 / 4$ " wide copper busses (Figure 5.10) which are bolted to the electrode studs on the test section. Finally, the cables are strapped to the test section using insulated hose clamps to prevent the $\mathrm{JxB}$ forces from pulling them away from the test section when the magnet is energized.

\subsubsection{Standpipe Drain}

The standpipe drain (Figure 5.11) enables the loop operator to drain displaced working fluid which may rise in the standpipe, due to gas generation in the loop and/or expansion of the working fluid from a rise in temperature, back to the primary storage tank. This system consists of a $1 / 4$ " connection at the base of the standpipe with a 1/4" tube attached to a plug valve installed in the primary storage tank lid. 


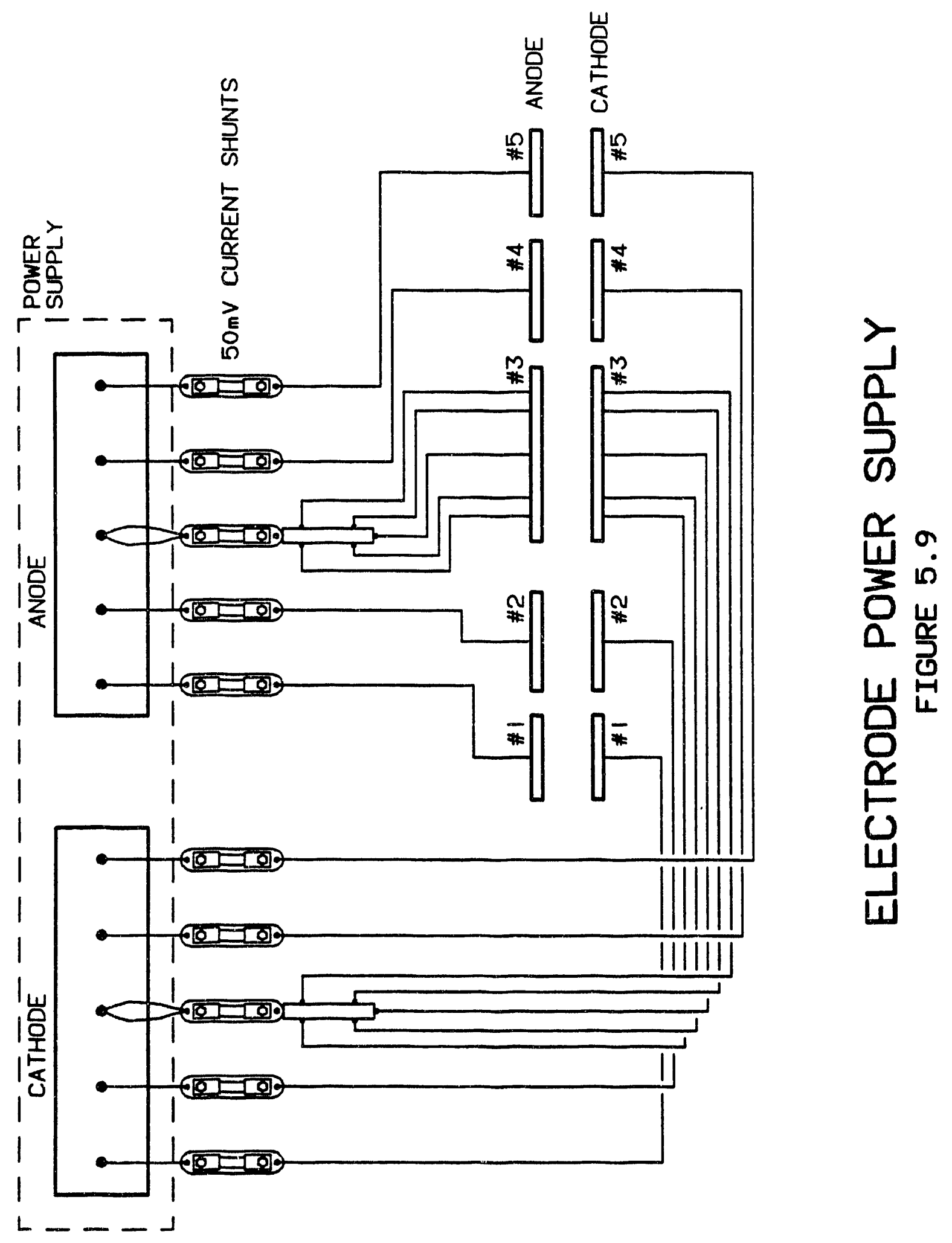




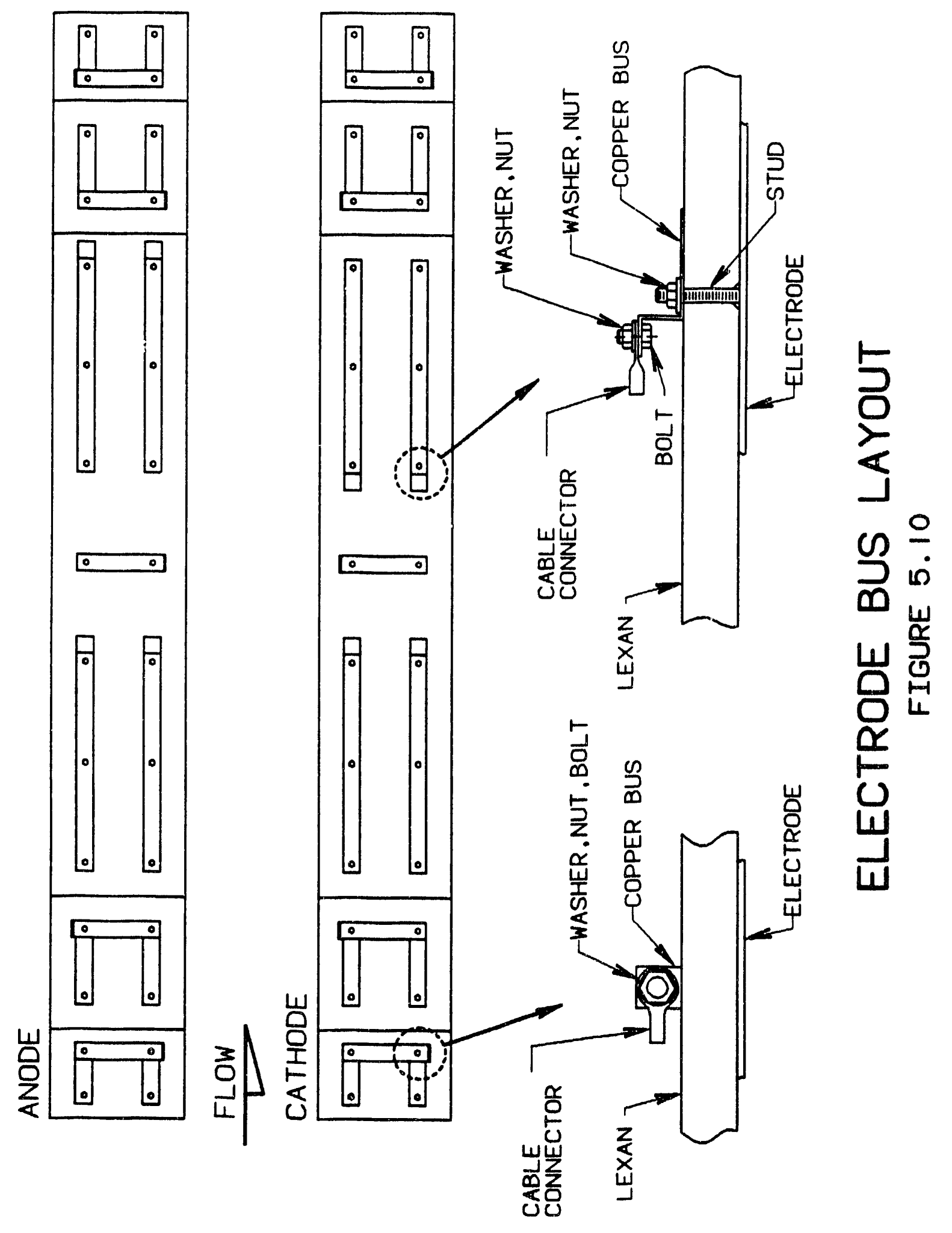




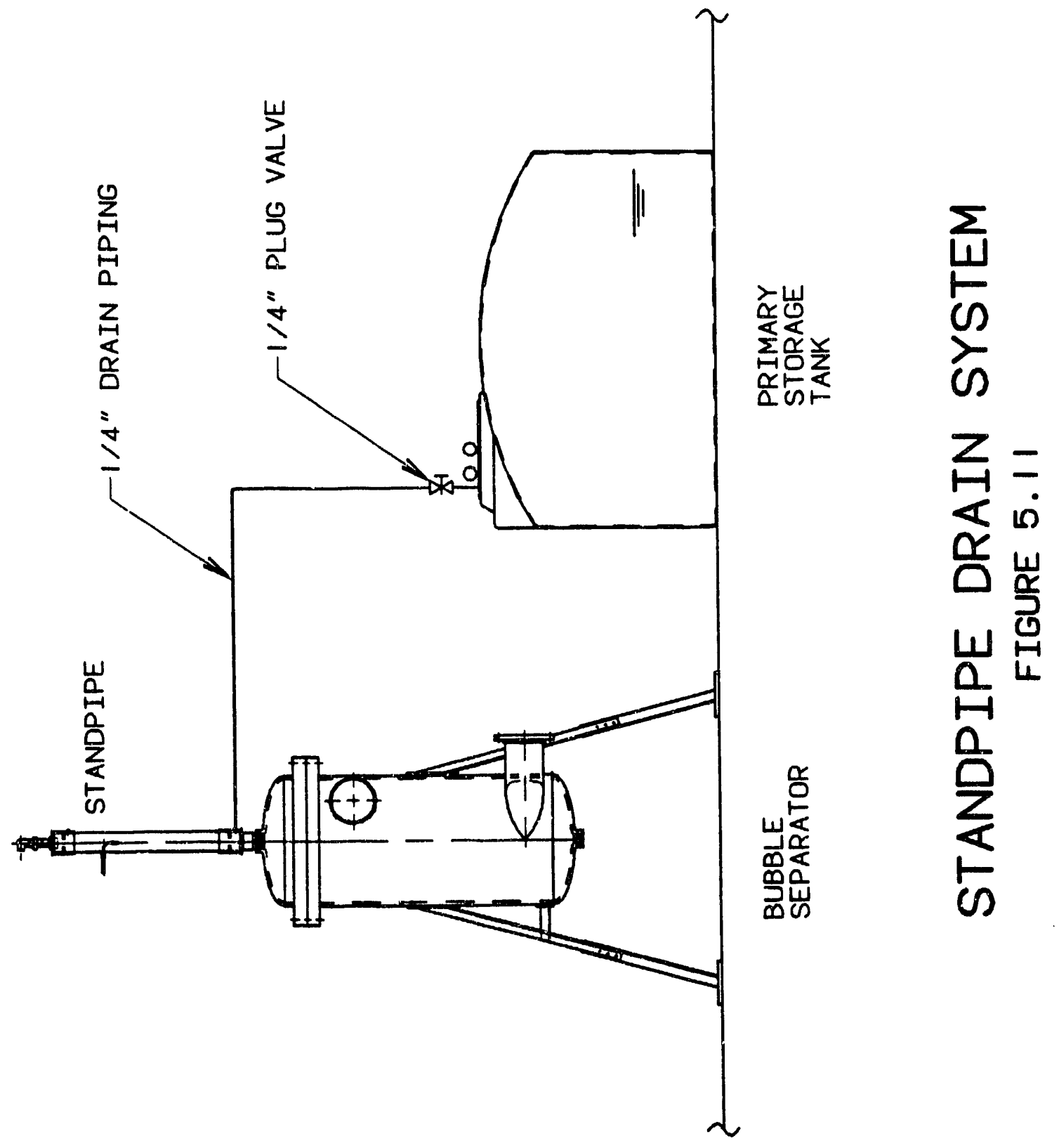




\subsubsection{Loop Pump Drain}

This system enables the working fluid trapped in the pump case and the $12^{\prime \prime}$ run between the flowmeter and the pump, to be drained back to the primary storage tank. A 3/8" bronze ball valve was installed at the base of the pump case with a clear $1 / 2^{\prime \prime}$ hose that connects to the secondary loop at the $3 / 4^{\prime \prime}$ inlet/outlet connection (V4).

\subsubsection{Circulation Pump Flush Face Seal}

Freshwater required to flush the seal face of the circulation pump is supplied via $3 / 8^{\text {" tubing }}$ from an existing $3 / 4^{\prime \prime}$ spigot. The waste fluid (return) is similarly transferred to an existing drain.

\subsubsection{Loop Fill}

Water for loop fill system originates at an existing $3 / 4^{\prime \prime}$ spigot then travels through a water demineralizer (Culligan) and finally connects to the circulation system at the $3 / 4^{\prime \prime}$ inlet/outlet connection (V4).

\subsection{Instrumentation}

Two types of instrumentation were used in the test program. The first type includes the instrumentation that supplies the data necessary to satisfy the primary objective of the test program, i.e. the determination of thruster performance. The second type includes all 
instrumentation necessary to monitor loop performance and carry out the various operations during preparation for loop start-up, testing, and post-test loop shutdown.

\subsubsection{Data Acquisition System}

The Data Acquisition System (DAS) utilized in the NNS/ANL 2 Tesla Test Facility consists of hardware and software that perform the following functions:

- $\quad$ Data Sampling

- Data Reduction

- Display

- Data Storage

The analog output signals processed by the DAS are supplied by the instrumentation, outlined in sections 5.5.2-5.5.9, through Barrier Terminal Strips (BTS). The heart of the DAS is a Real Time Peripherals (RTP) G-2 LAN Compatible analog and digital I/O system. The clata input is performed by an RTP Universal Controller and associated analog/digital conversion and analog input cards. The $\mathrm{I} / \mathrm{O}$ is controlled and coordinated by the G-2 processor and the data is passed to the VAXStation 3100 for further reduction and processing. ${ }^{[32]}$

The software package used for data acquisition is called SCAN-G2. This software consists of a constantly changing collection of over 200 Fortran subroutines that perform specialized tasks during experimental runs. There are two main programs that calibrate the RTP analog input cards and scan the instruments during an experimental run. ${ }^{[32]}$ 


\subsubsection{Pressure Measurement}

\subsubsection{Test Section Pressure Measurement}

Two differential pressure transducers (Rosemount Analytical model 1151DP) connected in parallel are attached to seven pressure taps located along the $50^{*}$ active portion of the test section (Figure 5.12). These transducers, which have different sensitivity ranges (DPT1 0-1 psi \& DPT2 0-10 psi), measure the differential pressure that develops in the test section. The transducers and associated plumbing, which isolates the pressure taps under investigation, are located in instrumentation and control cabinet 2 (ICC2). Output from these transducers is displayed both on the transducer, in percent of maximum pressure, and at the DAS. Required power for these transducers is provided from a dedicated 15 volt DC supply (Computer Products Model PM502) mounted in ICC4.

\subsubsection{Loop Pressure Measurement}

Six transducers (Omega 140 Series, 0-15 psig) are installed in the loop (Figure 5.13) to measure system pressure at the following locations:

- PT101 \& PT102 pump outlet and inlet respectively.

- PT103 test section downstream of the flow straightener.

- PT104 \& PT106 separator outlet and inlet.

- PT105 separator standpipe vent.

Individual output from the transducers is displayed (Omega DP2000-P5 Digital Transducer Indicator) at ICC1. Display selection is made with a six-position switch (Omega). Output 


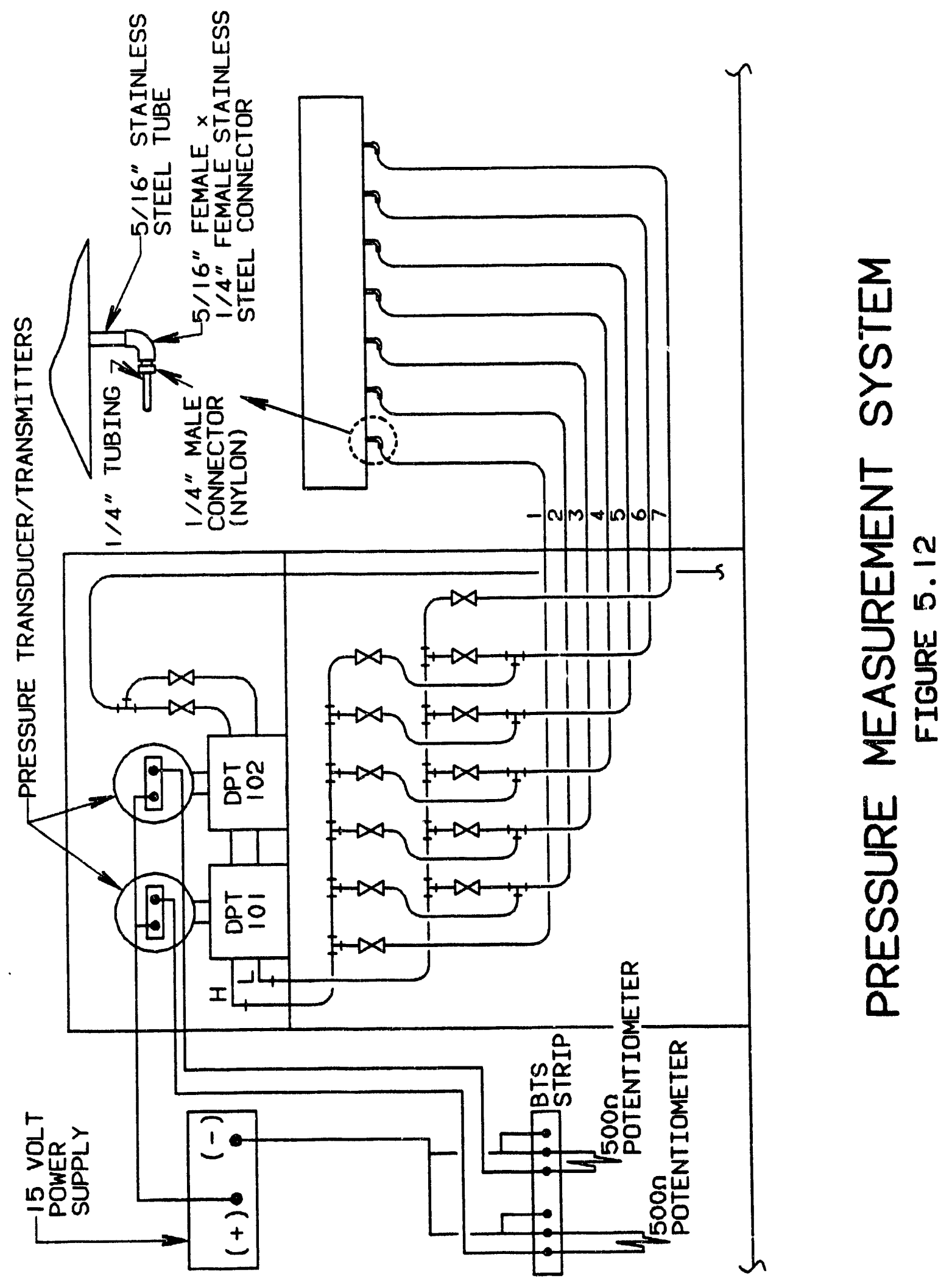




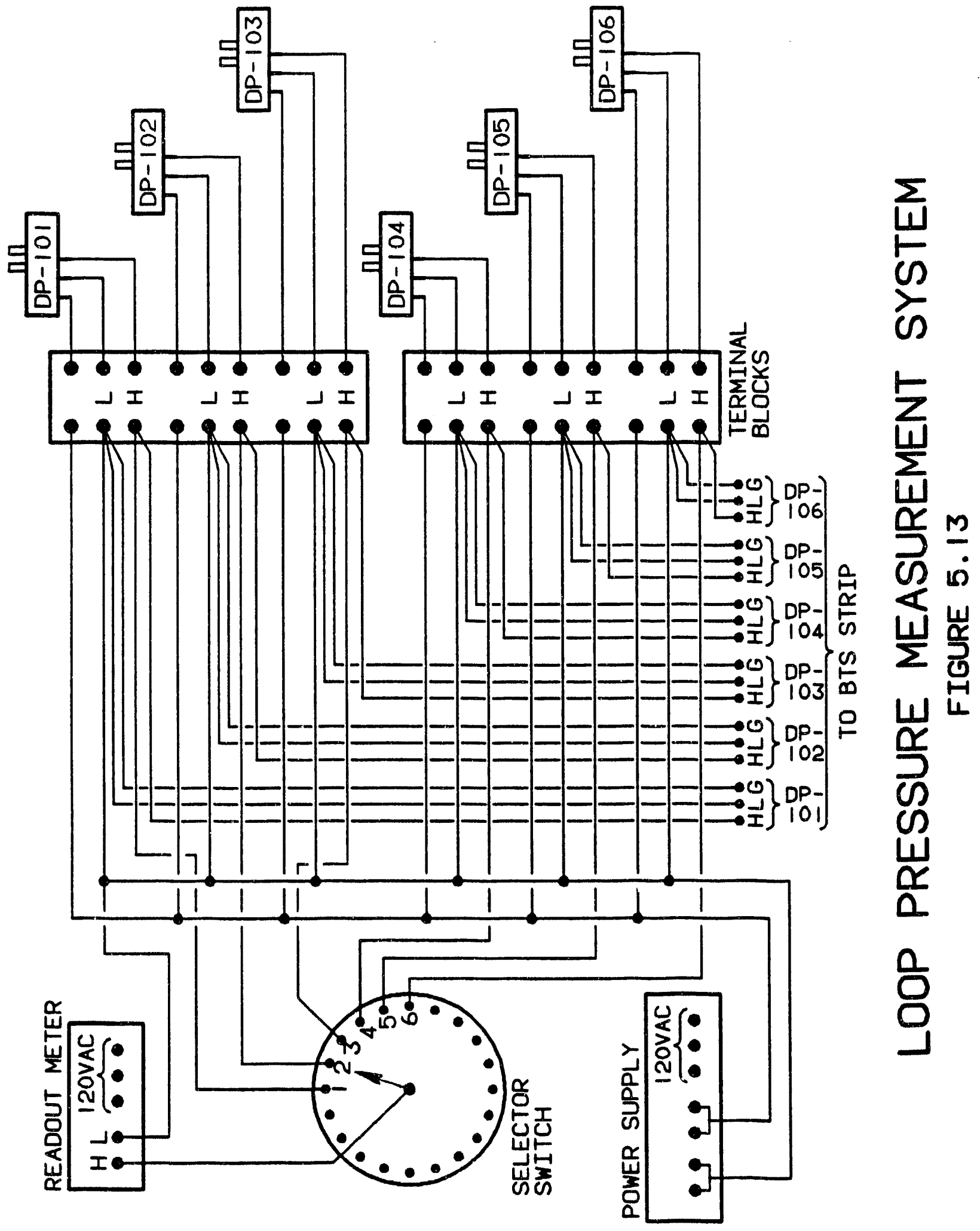


from the transducers is connected to DAS via BTS strips. Power required for both the transducers and the display is provided from a dedicated 8 volt DC supply (Omega Model PST-4130).

\subsubsection{Potential Measurement}

Potential across all five electrode pairs as well as total potential is measured with a voltmeter (Solartron 7061 Systems Voltmeter). Output leads are connected to each pair of electrodes as well as the electrode power supply for total voltage (Figure 5.14). Output is transmitted from the voltmeter to the Micro 488 controller then to the ADI Modem and finally to the VAXStation 3100 for analysis and storage.

\subsubsection{Current Measurement}

Electrode current is measured using $50 \mathrm{mV}$ DC Ammeter shunts (Empro Manufacturing Type HA) installed between the power supply flags and the cable runs to the individual electrodes. Shunts were sized to accommodate the maximum current for the individual electrodes (Figure 5.15). Shunt outputs are connected directly to the BTS strips of the DAS.

\subsubsection{Amp-Hour}

An ampere time totalizer (Kraft Dynatronix Model ATC 1000T) with bisilt-in display (Omron H7EC) measures the number of coulombs per run. Current leads (input) for this meter connect to an internal power supply shunt. The output is not connected to the DAS. Power for this meter is supplied from a 120 Volt AC outlet strip mounted in ICC2. 


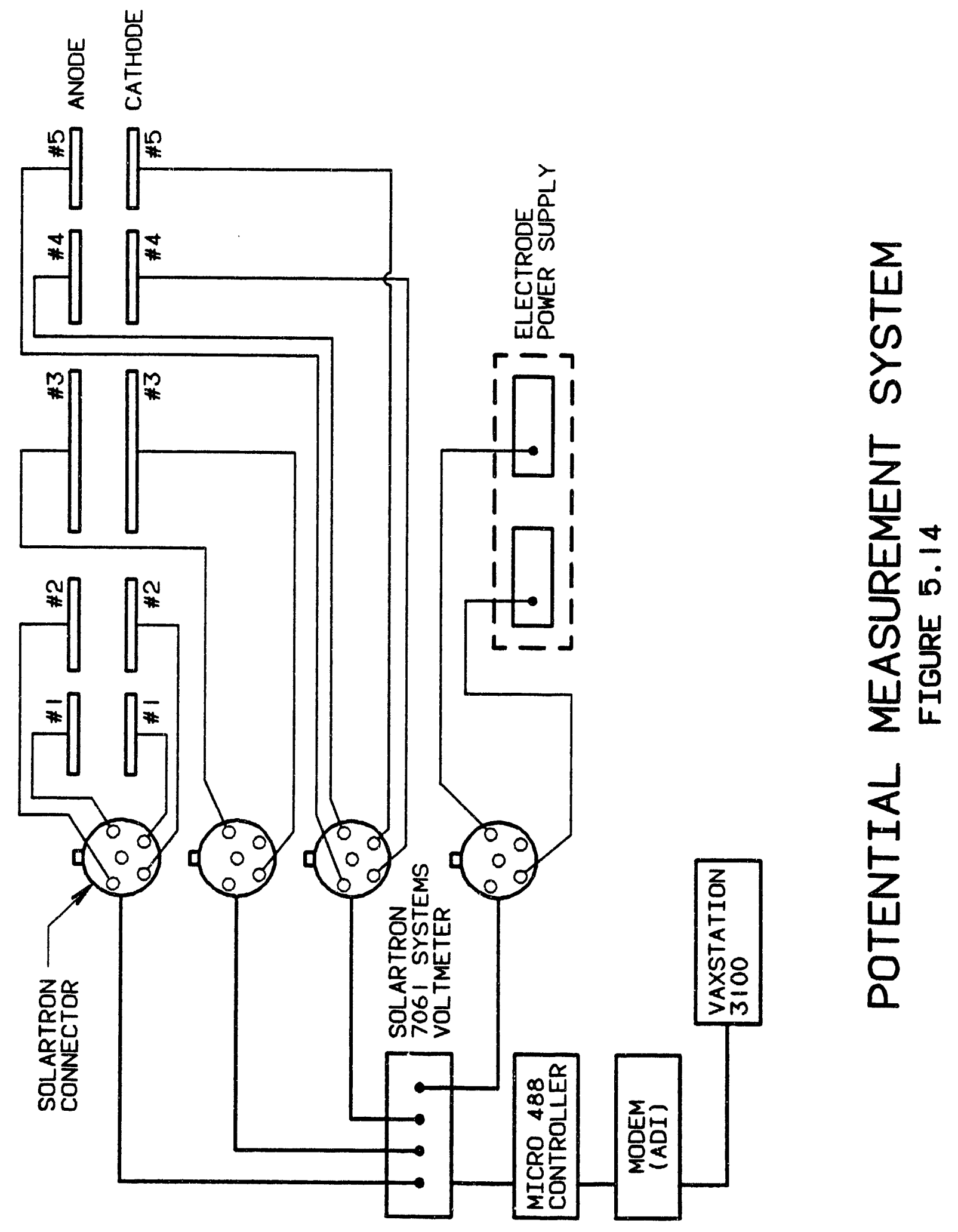




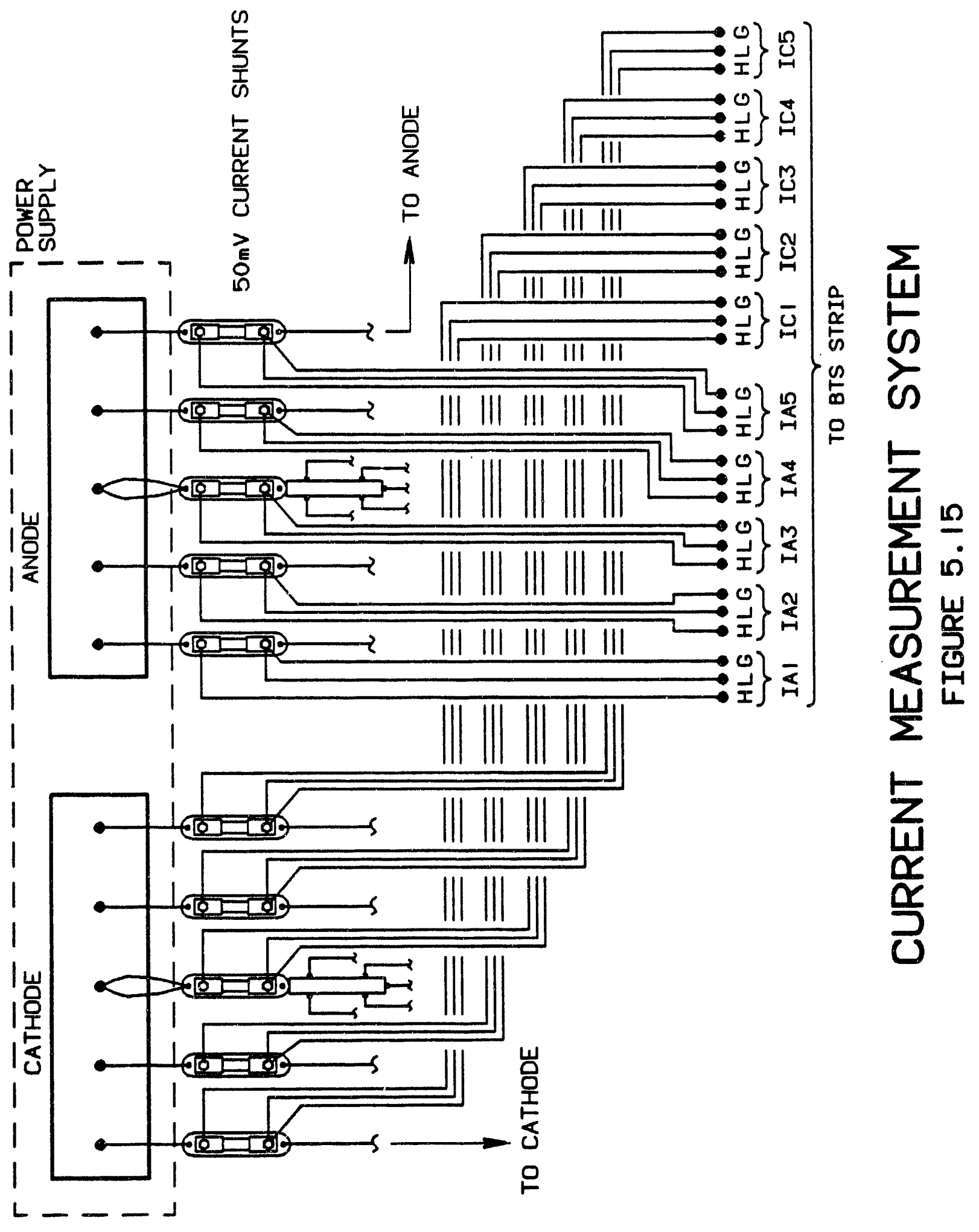




\subsubsection{Conductivity}

A submersion/insertion toroidal conductivity sensor (Rosemount Analytical Model 228) is installed in the base of the separator tank. This probe is connected to a microprocessor analyzer (Rosemount Analytical Model 1054A T) mounted in ICC3 which displays both the working fluid conductivity and the temperature (Figure 5.16). Output from this instrument connects to the DAS via a BTS strip. Power for the microprocessor analyzer is from a 120 Volt AC outlet strip in ICC3.

\subsubsection{Flow Rate}

An 8" electromagnetic flow meter (Endress \& Hauser.Viromag Series Model FTI1943) is installed downstream of the separator and is used to monitor flow (Figure 5.17). Output from this device connects both to a multipurpose display (Digitec B 401) at ICC 1 and to the DAS. Power for the flowmeter is provided from a 120 Volt AC outlet strip mounted in ICC3. Power for the display is from a similar outlet strip located in ICC4.

Flow rate is controlled using a potentiometer located in ICC 1 which regulates pump RPM with an existing $30 \mathrm{hp}$ motor controller (Emerson Industrial Pump Controller).

\subsubsection{Temperature}

A chromel-alumel thermocouple (Omega K-type) located downstream of the flow straightener in the test section is used to monitor temperature. Output from this device connects to a cold junction compensator (Omega type CJ) and then to the DAS BTS strip. 


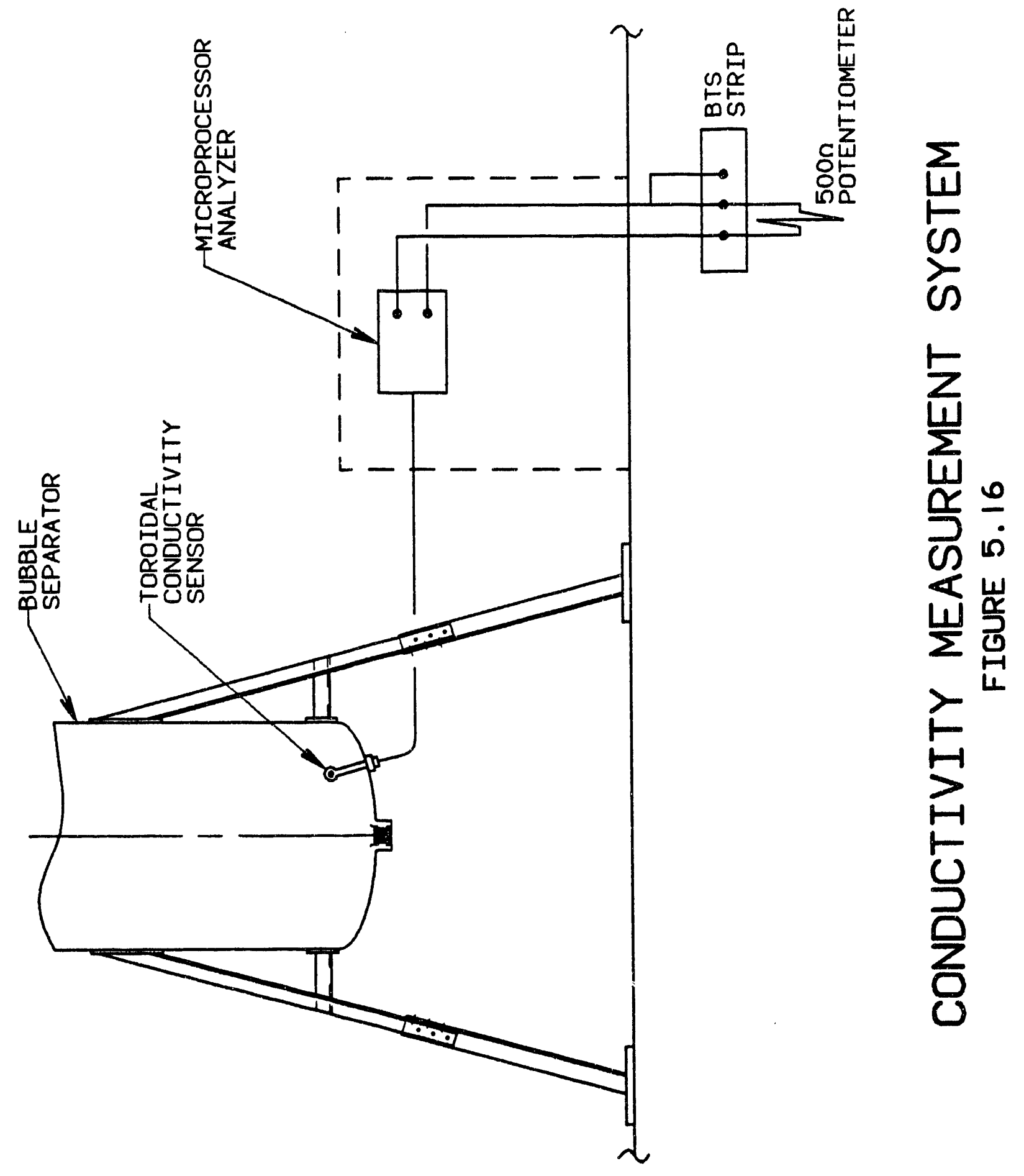









\section{$\underline{5.5 .9 p H}$}

The $\mathrm{pH}$ probe (Omega Model phtx-92) is installed in the primary storage tank with a bulkhead fitting. Output from this probe is connected to the display/transmitter (Omega model PHTX-92) at ICC 3 (Figure 5.18). Working fluid $\mathrm{pH}$ need not be constantly monitored by the Data Acquisition System and therefore is only recorded at the beginning and end of each test run.

\subsection{Bubble Diagnastics}

Options for bubble photography include the use of xenon flash tubes or pulsed laser in conjunction with cine (high speed mechanical) cameras or low speed video cameras. The double flash, shadow (backlit) photography technique is a standard diagnostic for measuring droplet behavior in spray combustion. Pulsed laser systems are fast (a few nanoseconds), but relatively expensive. Flash tube systems are less expensive, but with marginally fast pulse times. ${ }^{[11]}$

MHD Instruments of Palo Alto California has recently developed a high speed gated, intensified video camera (GIVCAM) by combining an intensifier tube with a solid state CCD video camera. With this equipment, the behavior of gas bubbles evolved from rod electrodes was directly observed in sea water as a function of current density. These first results were reported at the Second ONR Workshop on MHD Submarine Propulsion in November of 1989..$^{[33]}$ Bubble size decreased with current density and at a value of 2500 $\mathrm{A} / \mathrm{m}^{2}$, bubbles with diameters in the 50-100 micron range were measured. Even under the relatively low velocities of buoyancy, the small size of these bubbles required a gate time 
(electronic shutter time) of 1 millisecond and less. For the conditions of MHD propulsion experiments, the high velocities of several meters per second require fast gate times of a few microseconds or less to "freeze" the motions of these microscopic bubbles. ${ }^{[1]}$

Diagnostics on the evolution and distribution of gaseous bubbles downstream of the electrodes in the ANL/NNS MHD test loop was the goal of this assignment. The specific objective was the measurement of bubble size, bubble density, and bubbles velocity in the boundary layer and the mainstream flow. A secondary objective was the verification of the significant changes in bubble behavior induced by changing the type of "salt" water $(\mathrm{NaCl}$ versus Instant Ocean $\left.^{\mathrm{TM}}\right) !^{[11]}$

In situ bubble diagnostics in $\mathrm{MHD}$ propulsion test loops must meet three primary requirements imposed by the test environment: 1) magnification, 2) fast shutter speed, 3) discrimination. Since the anticipated bubble size is small, a magnification of 2 to 3 is required for adequate resolution. At these values of magnification, the field of view is limited to a few millimeters. For complete characterization of the bubble density distribution, this field of view must be traversed across the flow. Since the anticipated bubbles are small and moving at speeds of several meters per second, fast shutter speeds in the range of 0.3 to 3 microseconds are required. Since a large number of bubbles are distributed throughout the boundary layer and possibly into the core flow, techniques for discriminating bubbles under measurement from the "cloud" of bubbles is required. ${ }^{[1]}$ 


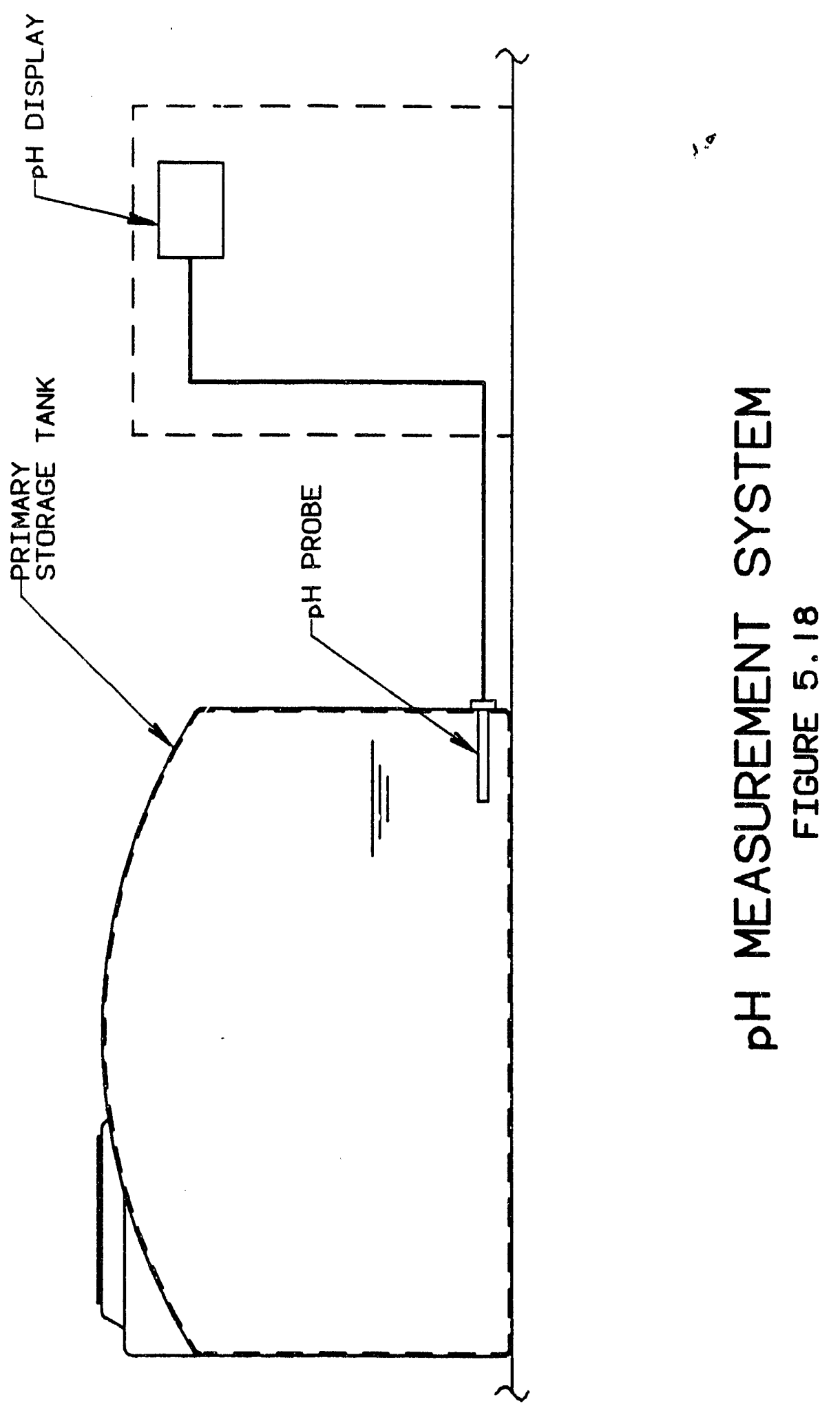




\subsubsection{Measurement Techniques}

Two techniques were developed and used for the direct imaging measurements of bubbles: shadow photography and streak photography. In the shadow technique, the bubbles are back illuminated by a collimated light source. The bubble shadows are "frozen" by a fast shutter speed. Discrimination within the "cloud" of bubbles is effected by the small depth-offield controlled by the f-number of the optics. Since light entering the edge of a bubble is refracted away, the edge appears as a circular shadow. Light passes unimpeded through the center of a bubble so that a bright spot should appear in the center of the circular shadow. The bubble diameter can be directly measured from the diameter of its shadow. The circularity of the shadow may be used as a criteria for separation of bubbles from debris in the flow. ${ }^{[1]}$

Streak patterns are best observed by illumination with a sheet of laser light from the side. By using a relatively long exposure times, streaks of light are photographed as the bubbles pass through the sheet of illumination. The camera optics must be focused at the same location as the laser sheet. The bubble speed is determined by measuring the streak length and knowing the exposure time. The velocity vector (in the plane of the field-of-view) is also determined by the direction of the streaks. ${ }^{[11]}$

\subsubsection{Bubble Diagnostics Equipment}

The bubble diagnostics system developed by MHD Instruments consists of five major system components:

- The gated, intensified video camera (GIVCAM) with microprocessor control. 
- Imaging optics train consisting of $300 \mathrm{~mm}$ telephoto lens with custom extension tube.

- $\quad$ Remotely operated translation mechanisms.

- Computer controlled with super-VHS video recorder and video monitor.

The optics train was designed to meet the above requirements for magnification and minimum separation distance between the flow field and the camera lens. A telephoto lens with a $300 \mathrm{~mm}$ focal length was chosen to meet these constraints. For control over the discrimination distance, an f/2.8 lens is used. A corresponding adjustable extension tube was fabricated to match this lens. In normal operation, this extension tube is set to a length of $635 \mathrm{~mm}$. Two types of illumination sources were developed. For shadow photography, an intense, uniform background is desired. This source was designated around a $300 \mathrm{~W}$ projection lamp with a custom collimating optics. For streak photography, a helium-neon laser with a nominal output of $9 \mathrm{~mW}$ is used. The laser beam is transformed into a sheet with a cylindrical lens. A rotating front surface mirror, placed after the cylindrical lens, steers the laser sheet throughout the boundary layer; beam steering is driven by a computercontrolled stepper motor. Since the ANLNNS test channel is constructed of optically clear polycarbonate resin, the bubble diagnostics equipment was readily mounted at the magnet exit for optical access to the flow field. ${ }^{[11]}$

The central component of the bubble diagnostics system is the GIVCAM intensified video camera. This camera is based on a microprocessor controlled microchannel plate (MCP) intensifier tube with supporting optics and high voltage power supplies. The intensifier tube image is focused via relay optics on a standard $\mathrm{CCD}$ video camera. The onboard microprocessor and timing circuits allow pulse times down to 100 nanoseconds which are synchronized with the $60 \mathrm{~Hz}$ video camera. The CCD imaging module is a complete monochrome solid-state TV camera. In stardard EIA interlaced mode, its resolution is 610 
horizontal by 488 vertical pixels. Recall that a TV frame consists of two interlaced fields of 244 lines acquired every $1 / 60$ of a second. Use of the TV standard allows the application of low cost video recorders and monitors. Super-VHS video recorders provide a good match to the resolution of the present GIVCAM which is built around a $18 \mathrm{~mm}$ intensifier tube. Furthermore, this pixel resolution results in a good match with reasonably priced framegrabber boards and the super VGA standard for PC computers. ${ }^{[1]}$

In order to scan throughout the boundary layer an into the core flow without changing magnification, the entire optics train was translated. The GIVCAM, extension tube, and telephoto lens were mounted to an optics beam which was in turn attached to two linear translation mechanisms. The optics beam is driven by a stepper motor via a lead screw. The stepper motor is mounted compactly between the optics beam and the mounting channel. The completed optics train and translation hardware are shown by Figure 5.19.[11]

The diagnostics hardware was controlled with a 386 PC computer equipped with hard disk, VGA monitor, and control cards. The stepper motors were connected to a special port on the stepper motor card while the GIVCAM was operated through a standard serial port. The video data was recorded on a JVC model HR-S6600U super-VHS video recorder. A composite monitor was added to view the camera output directly. ${ }^{[11]}$

\subsubsection{Instrument Calibration}

Both the bubble size and streak velocity require an accurate calibration of the length scale. Since the aspect ratio of the CCD detector element is $4 / 3$, the field-of-view area is also known. For quantitative measurements of bubble density, the effective depth-of-field for a 
bubble shadow must be determined. Note that the objects of interest, bubbles, are in a medium with a different index of refraction than the optics train. The theory for a simple lens completely surrounded by air with the object in water indicates that the magnification is not affected, but that the focus distance is changed. The bubble diagnostics optics was focused on a scale with and without water in the path; the effect of water on the length scale was negligible, as expected. ${ }^{[1]}$

The bubble diagnostics system was set up for the same parameters as used during the tests and calibrated by directly recording the image of a six inch scale. All of the processed images were reproduced with the proper $4 / 3$ aspect ratio and with a standard size format. The calibration image shown by Figure 5.20; here, each division is 1/100 inch. The calibrated size scale is then 1035 microns per inch. Note that the corners of the image in Figure 5.20 are slightly rounded. This is caused by the adjustment of the relay lens to use as much of the intensifier tube area as possible for the greatest resolution. Since this tube has an active diameter of $18 \mathrm{~mm}$, the magnification ratio is determined by scaling the distance between corners; the resulting magnification is 2.5 which verifies the design value. Similarly, by scaling the frame, the field-of-view size is determined as $6.31 \mathrm{~mm}$ by 4.73 $\mathrm{mm}^{[11]}$

The focus distance in water was directly measured by translating the camera from one side of the channel to the opposite wall. The correction factor for distance in water was determined as $73 \%$ of the distance moved by the camera. ${ }^{[1]}$ 


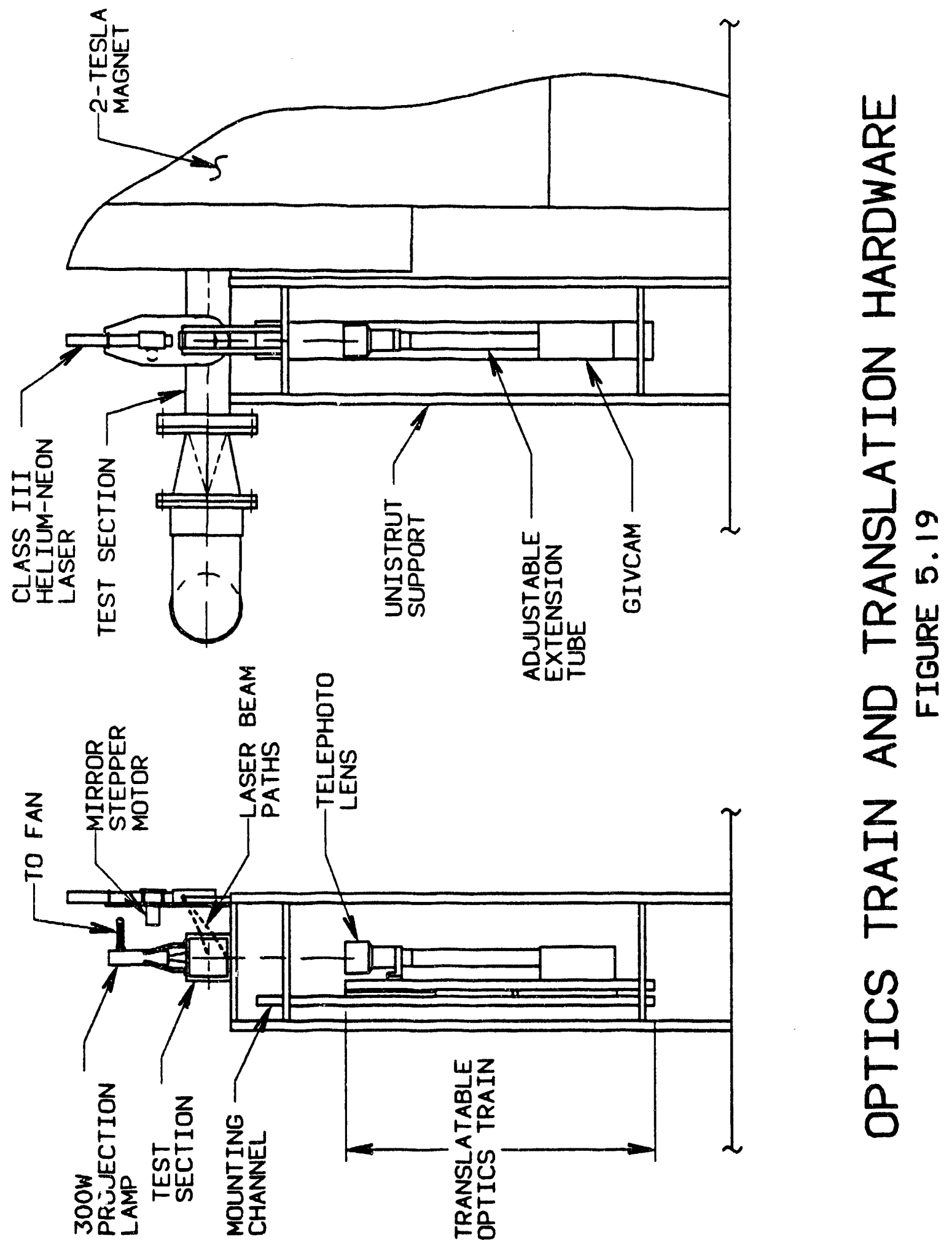




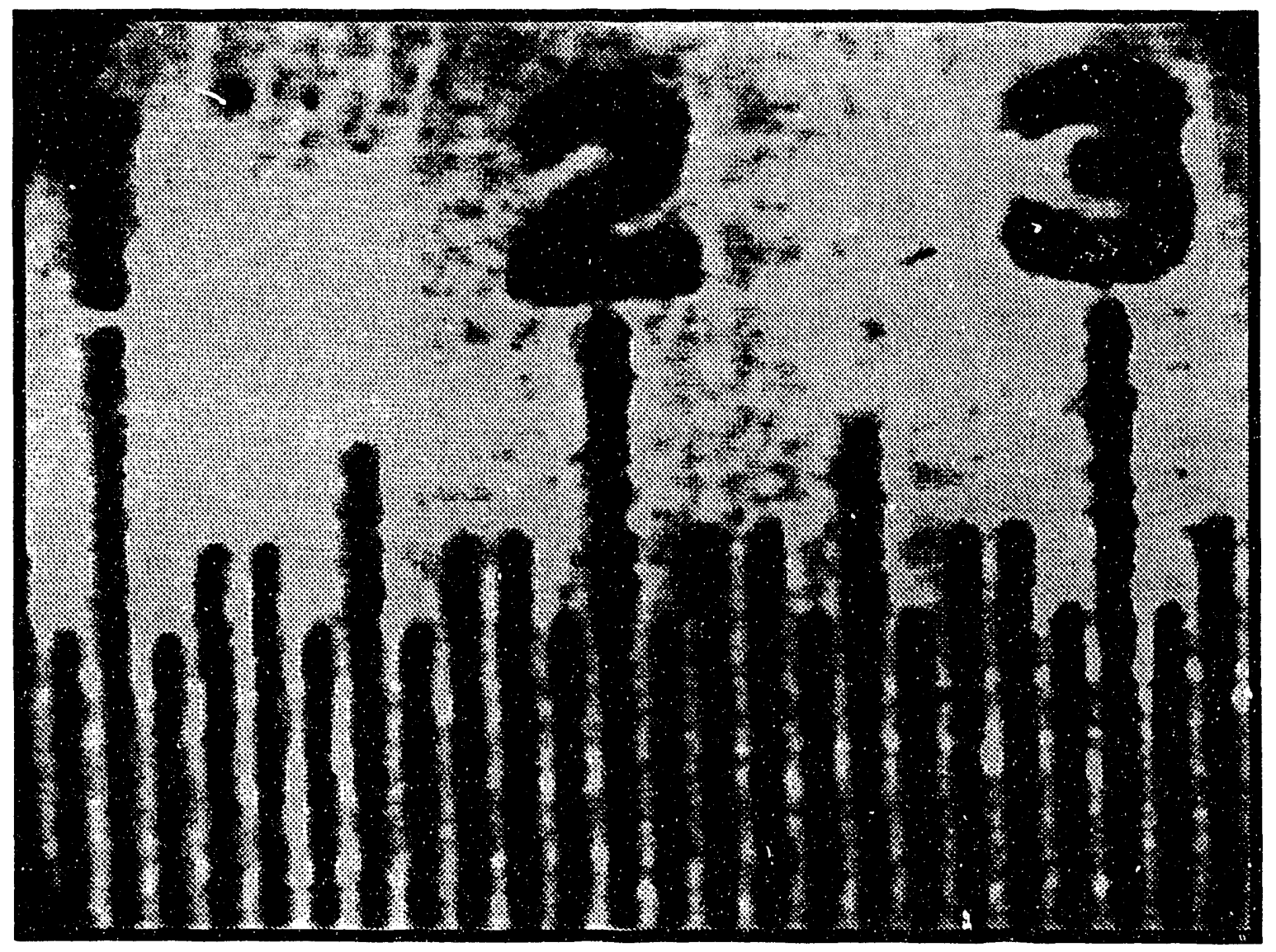

\section{Calibration Image}

Figure 5.20 
The effective depth-of-field for bubble shadows is more difficult to accurately measure. The traditional formula for depth-of-field may be used as a guide:

$$
\Delta s= \pm b(f / \#) \frac{1}{m}\left(1+\frac{1}{m}\right)
$$

where $\mathrm{m}$ is magnification and $\mathrm{b}$ is the blur size at the film or detector plane. Since the object will be defocused by moving toward it or away from it, the total depth-of-field is $2 \Delta s$. Good experimental results were obtaines at $\mathrm{f} / 4$ and with the magnification value of 2.5 , the depth-of-field for this system is about 4.5 times the blur size. For an intensifier tube, the blur length is around 30 microns so that a depth-of-field of 135 microns is indicated. However, bubble shadows are still clearly visible over this distance. The effective distance for imaging bubble shadows (called depth-of-shadow here) was determined empirically by a bench top experiment. The resulting measurement for depth-of-shadow was about \pm 1.5 $\mathrm{mm}$ with a spread of $\pm 25 \%$. The present calibration procedure allows the quantitative estimation of bubble density by using the measured values of field-of-view area and depth-ofshadow to provide a value for measurement volume. This volume is $6.31 \times 4.73 \times 3 \mathrm{~mm}^{3}$ which equals $90 \mathrm{~mm}^{3} .^{[11]}$

\subsubsection{Image Processing}

The image data stored on analog video tape was digitized with an HRT-512 frame grabber board installed on a 486 PC computer with 8 MB of RAM. The HRT-512 frame grabber digitizes with a resolution of $512 \times 512$ pixels with 8 bit accuracy. This pixel resolution

provides a good match to the CCD camera pixel format. The 8 bit accuracy implies a gray scale of 256 shades with a value of 0 for black and a value of 255 for white. This gray scale 
results in near photographic quality and is a good match with the super VGA video standard for PC computers. This frame grabber is controlled by a custom computer program, BUBBLE2, developed by MHD Instruments. The latest version of this program can operate in a batch mode in which sequences of images are digitized and stored in memory up to the limit of RAM installed. For the present study, 10 images were grabbed in sequence every $500 \mathrm{~ms}$. The image sequence may then be stored as a file, enhanced, and/or reproduced as a halftone picture on a laserjet printer. This program is written and compiled in turbo-C. ${ }^{[11]}$

Recall that a standard TV video frame consists of two intcrlaced fields taken at intervals of $1 / 60$ second. To avoid a double exposure at the fast shutter speeds used the GIVCAM was triggered only once $1 / 30$ second (per frame). The resulting digitized image has an unexposed field so that every other line is black. The first image enhancement routine inspects each frame to detect if a field is black; if so, the routine fills in the missing field by linear interpolation of the neighboring good lines. At this point, the image sequence was archived for subsequent processing. ${ }^{[1]]}$

An eight step procedure was developed for enhancing the quality of the digitized images. First, the image is gently smoothed with a nine point convolution kernel. Then a routine for computing the image statistics is called; this routine computes the histogram, and such key features as its peak value and the value of gray scale at the edge of the histogram peak. At this point, the contrast in increased to $\mathrm{C}(0$, peak value) where the zero value implies black is still black and all other pixels are stretched in value so that the peak vaiue is shifted to a value of 255. The "iris" effect, in which the center appears overexposed, is next corrected. To correct for the "iris" effect, the brightness of each pixel was increased by an error function which depends on both radius and angle. The radial function used is a displaced 
linear functional $\mathrm{C}\left(\mathrm{r}-\mathrm{r}_{\mathrm{o}}\right)$ while the angular function is made up of the first five terms of the Fourier series. In step 5 , the image is contrasted towards the black by $\mathrm{C}(\mathrm{min}, 255)$ where min depends on the dip and peak values. Step 6 smooths out the contrast operation. Then the image is contrasted towards the white by an algorithm which adjusts all images to about the same level of brightness (regardless of their original value). ${ }^{[1]}$

Finally, the images are sharpened by one of two convolution filters. The first filter is a gentle sharpening used in conjunction with a lower target brightness, so that detail of the background is preserved for comparison. The second option consists of a vertical filter in conjunction with a whiter contrast which tends to eliminate most of the background. The vertical filter "lifts" out the bubbles and imparts a three-dimensional character to their appearance. $^{[11]}$ 


\subsection{Pre-Test Analysis}

A pre test analysis was performed to support the design of the test loop and provide guidance in establishing a test matrix. This analysis was divided into three areas:

- A Parametric Analysis

- Loop Chemistry

- Loop Energy Balance

\subsection{Parametric Analysis}

The system code developed in Phase I was used to design loop components, define optimum operating conditions, assist in the selection of instrumentation for individual componerts, and predict overall characteristics of the test loop.

A parametric sweep was performed on the test loop using the following variables:

- Separator loss coefficient $\mathrm{x}=0-1.25$

- Working fluid conductivity $\sigma=4.5-22.5 \mathrm{~S} / \mathrm{m}$

- Test section fluid velocity $u=2-8 \mathrm{~m} / \mathrm{s}$

- $\quad$ Load Factor $K=1.1-30$

Output values include voltage, current, loop component velocity and pressure drop, and pressure loss/recovery in the test section. The actual magnetic flux distribution of the 2 Tesla magnet was used in the facility model. 


\title{
6.2 Loop Chemistry
}

Prior to testing the facility was chemically modeled. The scope of this study was to:

- Determine the MHD test loop chemistry.

- Calculate the amount of the products of electrolysis produced as a function of ampere-hour.

- Determine the change in $\mathrm{pH}$ as a function of ampere-hour.

- Determine the change in conductivity of the working fluid as a function of ampere-hour.

The electrolysis of an aqueous solution of $\mathrm{NaCl}$ results in the generation of chlorine gas $\left(\mathrm{CL}_{2}\right)$ at the anode and hydrogen gas $\left(\mathrm{H}_{2}\right)$ at the cathode, as follows:

Anode

$$
2 \mathrm{Cl}^{-} \rightarrow \mathrm{Cl}_{2}+2 e^{-}
$$

Cathode

$$
2 e^{-}+2 \mathrm{H}_{2} \mathrm{O} \rightarrow \mathrm{H}_{2}+2(\mathrm{OH})^{-}
$$

\begin{abstract}
A surplus of electrons at the cathode creates conditions for chemical reduction (gain of electrons) and the resulting deficit at the anode supports oxidation (loss of electrons). ${ }^{[31]}$
\end{abstract}

More complicated reactions can occur depending upon the level of current supplied. The chlorine generated at the anode will quickly be hydrolyzed and hydrogen gas generated by: $[31,34]$

$$
\mathrm{Cl}_{2}+\mathrm{H}_{2} \mathrm{O} \rightarrow \mathrm{HClO}+\mathrm{Cl}^{-}+\mathrm{H}^{+}
$$




$$
\begin{gathered}
\mathrm{HClO} \rightarrow \mathrm{H}^{+}+(\mathrm{ClO}) \\
(\mathrm{ClO})^{-}+\mathrm{Na}^{+}+\rightarrow \mathrm{Na}(\mathrm{ClO}) \\
\mathrm{H}^{+}+\mathrm{OH}^{-} \rightarrow \mathrm{H}_{2} \mathrm{O} \\
2 \mathrm{H}^{+}+2 \mathrm{Ce}-\mathrm{H}_{2}
\end{gathered}
$$

\subsubsection{Electrolysis Products}

\subsubsection{Mass}

The mass of the electrolysis products was calculated ${ }^{[35]}$ by first determining the number of moles produced, n, using Faraday's Law:

$$
n=\frac{Q}{F}
$$

where $\mathrm{Q}$ is the number of applied coulombs, and $\mathrm{F}$ is the faraday constant. The mass, $\mathrm{m}$, can then be calculated by equation 6.9 .

$$
m=n F W
$$

Where FW is the formula weight. 
Because equations $6.3 \& 6.4$ represent equilibrium relationships, there is no straightforward method for determining the amount of electrolysis products produced. Instead, the amount of hypochlorous acid $(\mathrm{HClO})$ produced is determined assuming that reaction $6.4 \mathrm{did}$ not occur. Similarly the amo'ant of Sodium Hypochlorite ( $\mathrm{NaClO}$ ) produced is calculated as if all the hypochlorous acid was cunverted to the hypochlorite ion ( $\left.\mathrm{ClO}^{-}\right)$, and in-turn all of the hypochlorite combined with the sodium $\left(\mathrm{Na}^{+}\right)$spectator ion as indicated in reaction 5.5 . These assumptions were made in the hopes of bracketing the mass of electrolysis product produced. Results are shown in Figure 6.1.

\subsubsection{Volume}

The volume for the gaseous products of electrolysis (chlorine and hydrogen gas) was calculated $^{[31]}$ using the Ideal Gas Law:

$$
V=\frac{m R T}{P}
$$

Where $\mathrm{V}$ is volume, $\mathrm{m}$ is mass (from section 6.2.1.1), $\mathrm{R}$ is the gas constant for either chlorine or hydrogen, $\mathrm{T}$ is fluid temperature, and $\mathrm{P}$ is system pressure. Results are indicated in Figure 6.2.

\section{$\underline{6.2 .2 p H}$}

The principal effect governing the $\Delta \mathrm{pH}$ of the system occurs at the cathode. ${ }^{[36]}$ The excess electrons will generate hydroxide ions as shown in equation 6.2. The change in $\mathrm{pH}$ as a function of ampere-hour was calculated ${ }^{[37]}$ by first determining the molarity of the hydroxide 


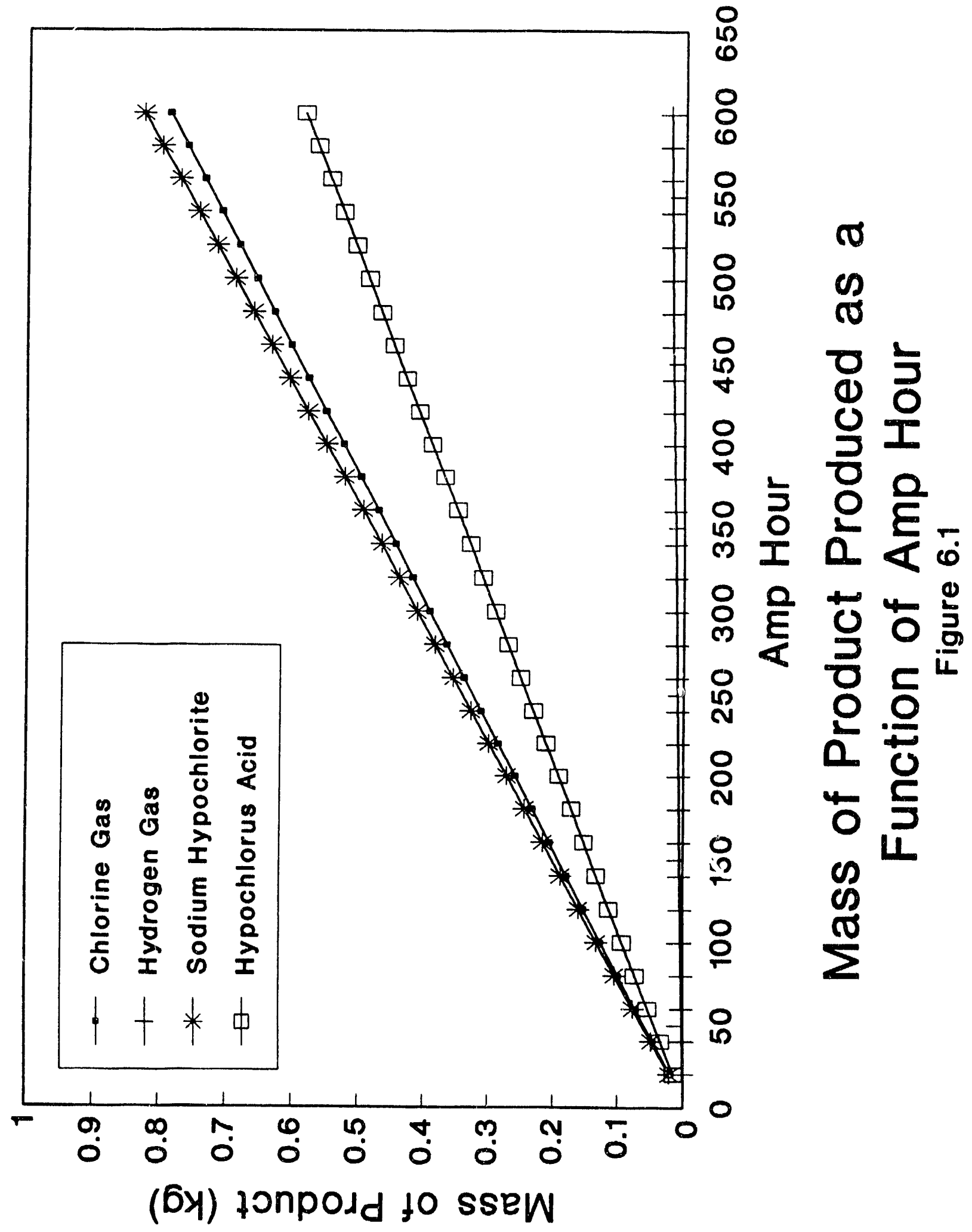




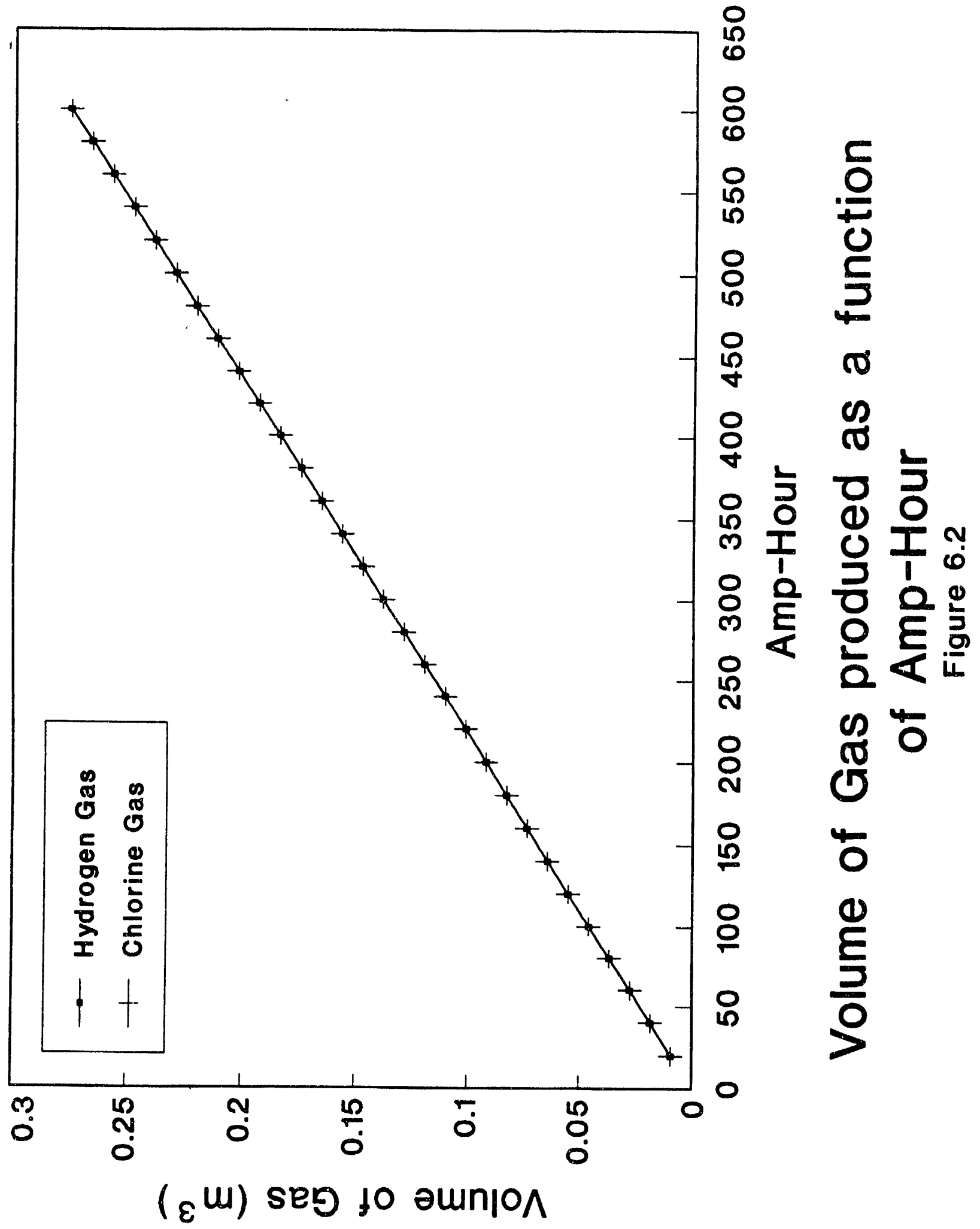


ions $\left(\mathrm{OH}^{*}\right)$ produced by equation 6.2. Then the molarity of hydronium, $\mathrm{H}_{3} \mathrm{O}$, is calculated by dividing the ionic product constant of water by the molarity of hydroxide. Finally the system $\mathrm{pH}$ is determined by:

$$
\mathrm{pH}=-\log \left[M_{H_{3} \mathrm{O}}\right]
$$

However:

- The $\mathrm{pH}$ of the system is dependent on whether or not the hydrogen and chlorine are vented from the system or allowed to recombine."[38]

Figure 6.3 displays the worst case change in system $\mathrm{pH}$, where none of the electrolyzed hydrogen gas was allowed to recombine and was vented from the system.

\subsubsection{Conductivity}

With regard to change in specific conductivity:

- The ionic equivalent exchange of chlorine ions for hydroxide ions is not expected to result in a net change in conductivity (assuming solution volume constant).":38]

This conclusion is supported by the DARPA funded 6 Tesla MHD test loop at ANL, ${ }^{[39]}$ where it was determined that the change in conductivity based on the chlorate conversion is $0.05 \%$. 


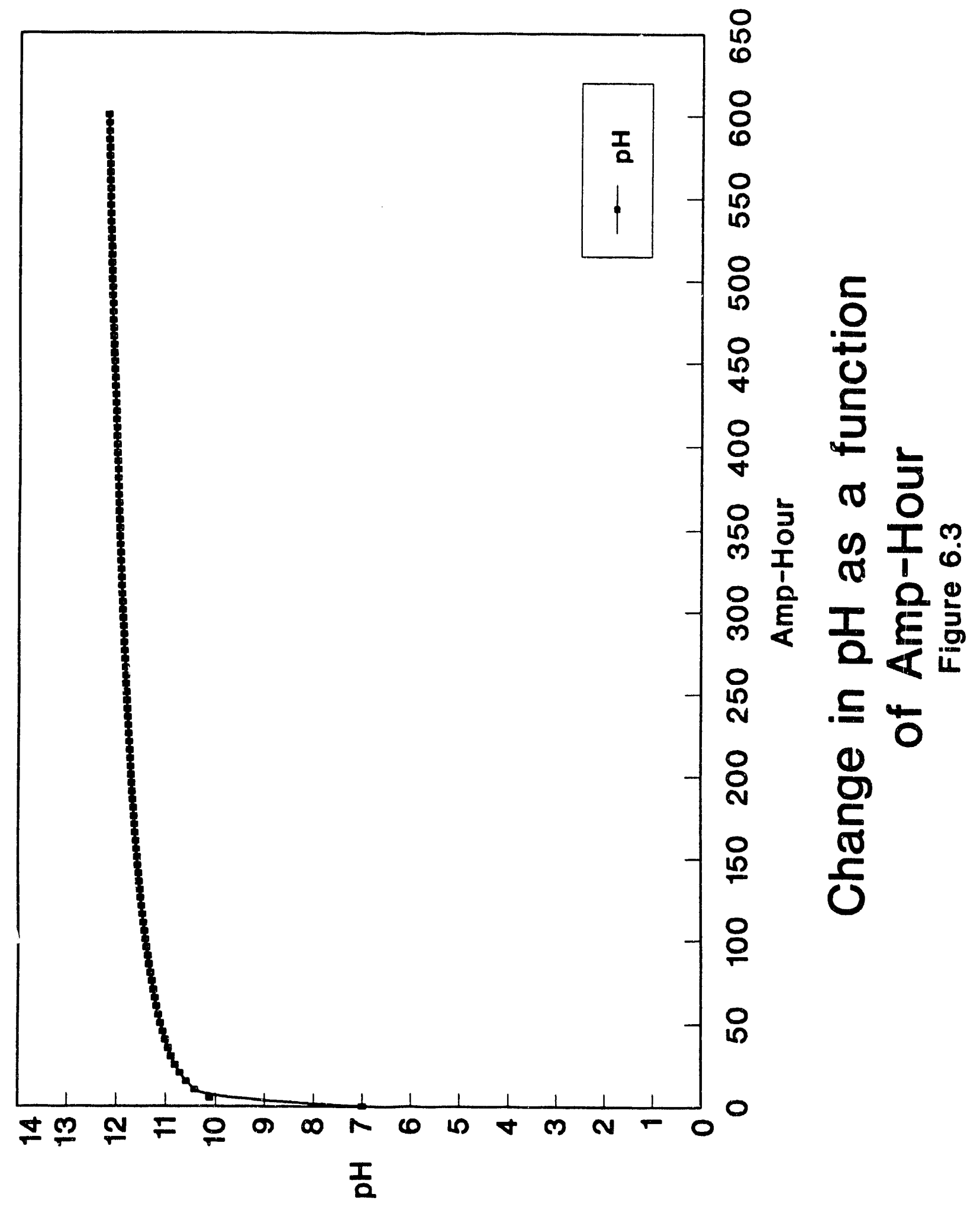




\subsection{Loop Energy Balance}

This analysis was performed to determine loop cooling requirements, if any. Assuming no heat transfer, no change in kinetic energy of the fluid, and no changes in elevation, the first law of thermodynamics for a steady-state steady-flow process reduces to:

$$
W_{c v}-m\left(h_{2}-h_{1}\right)
$$

A change in enthalpy, assuming a constant specific heat, can be represented by:

$$
h_{2}-h_{1}-C_{p}\left(T_{2}-T_{1}\right)
$$

By combining and rearranging these relationships, we can determine the change in temperature per unit time by:

$$
\frac{\Delta T}{\Delta t}-\frac{W_{C V}}{m C_{p}}
$$

With the work into the control volume, $\mathrm{W}_{\mathrm{CV}}$, taken to be:

$$
w_{c V}-w_{p u m p}+w_{t s}
$$

Where $\mathrm{W}_{\text {pump }}$ and $\mathrm{W}_{\mathrm{ts}}$ are work from the pump and work from the test section respectively, and are expressed as:

$$
W_{p u m p}-\Delta p Q \quad W_{t s}-V I
$$

Where $\Delta \mathrm{p}$ is the pressure rise in the pump, $\mathrm{Q}$ is the volumetric flow rate, $\mathrm{V}$ is the applied potential to the test section, and I is the applied current. 
Results from this analysis indicate that the predicted worst case working fluid temperature rise is $.57^{\circ} \mathrm{F} / \mathrm{min}$ or $34.2^{\circ} \mathrm{F} /$ hour $\left(.32^{\circ} \mathrm{C} / \mathrm{min}\right.$ or $19.16^{\circ} \mathrm{C} /$ hour $)$. This analysis indicates that by limiting the duration of a test run, a loop cooler would not be required. 


\subsection{Experimental Conditions}

\subsection{Teat Matrix}

The design of the test matrix was based on results from the pre-test analysis and is summarized in Table 7.1.

\begin{tabular}{|c|c|c|c|c|}
\hline \multicolumn{5}{|c|}{ Test Matrix } \\
\hline Warting Fluid & $\begin{array}{c}\text { Conductivity } \\
(\mathrm{S} / \mathrm{m})\end{array}$ & $\begin{array}{c}\text { Velocity } \\
(\mathrm{m} / \mathrm{s})\end{array}$ & $\begin{array}{c}\text { Current } \\
\text { Density } \\
\left(\mathrm{A} / \mathrm{m}^{2}\right)\end{array}$ & $\begin{array}{c}\text { Magnet } \\
\text { Orientation }\end{array}$ \\
\hline NaCl Solution & $\sigma=4.5$ & $\mathrm{u}=2-8$ & $\mathrm{~J}=100-800$ & Horizontal \\
\hline NaCI Solution & $\sigma=22.5$ & $\mathrm{u}=2-8$ & $\mathrm{~J}=100-800$ & Horizontal \\
\hline Nacl Solution & $\sigma=22.5$ & $\mathrm{u}=2-8$ & $\mathrm{~J}=80-800$ & Vertical \\
\hline Instant Ocean TM & $\sigma=5.5$ & $\mathrm{u}=2-8$ & $\mathrm{~J}=80-800$ & Vertical \\
\hline
\end{tabular}

Table 7.1: Test Matrix

The test program consisted of the following measurements in both primary and secondary working fluids:

1. Measurement of pressure distribution in the test section with zero magnetic field over a velocity range of $2-8 \mathrm{~m} / \mathrm{s}$ to determine the baseline frictional losses.

2. Measurement of pressure distribution in the test section at 2 Tesla with no current supplied to the thruster over a velocity range of $2-8 \mathrm{~m} / \mathrm{s}$ to determine the modification of the pressure distribution by the magnetic field alone. 
3. Measurement of the volt-ampere characteristics of the thruster at zero magnetic field to determine the total electrochemical potential, confirm the conductivity of the working fluid, and obtain preliminary evidence on the effect of bubbles on the electrical performance of the thruster.

4. Measurements of the thruster performance at a magnetic field of 2 Tesla over a velocity range of $2-8 \mathrm{~m} / \mathrm{s}$ and a current density range of $70-820 \mathrm{~A} / \mathrm{m}^{2}$.

\subsection{Conditions for Bubble Tests}

Four tests were conducted with the bubble diagnostics instrumentation during two separate testing periods. Sodium Chloride solution was used for the first testing period in April, 1992 while Instant Ocean $^{\mathrm{TM}}$ was used for the second test period. The dates of these tests and salient conditions are summarized in Table 7.2. Each test was recorded on ST-120 superVHS video tape cassettes in normal mode ( 2 hours duration). Over the test program, three cassettes (labeled N1 through N3) were used. The cassettes used for each test are listed in Table 7.2 along with the coordinating tape counter time. A logbook based on the tape time counter (accurate to one second) was maintained for key test conditions and diagnostic parameters. Many of these events, such as a change in camera gain or switching the thruster power supp 1 , are directly observable on the video monitor so that logbook consistency can be verified. ${ }^{[1]}$ 


\begin{tabular}{|c|c|c|c|c|}
\hline $\begin{array}{c}\text { Test } \\
\text { Date }\end{array}$ & $\begin{array}{c}\text { Video } \\
\text { Tapes }\end{array}$ & Test Fluid & $\begin{array}{c}\text { Type } \\
\text { Diagnostic }\end{array}$ & $\begin{array}{c}\text { Tape Time } \\
\text { (hr:min:3ec) }\end{array}$ \\
\hline $4 / 22 / 92$ & $\mathrm{~N} 1$ & $\mathrm{NaCl}$ & Shadow Size & $0: 00-18: 40$ \\
\hline $4 / 22 / 92$ & $\mathrm{~N} 1$ & $\mathrm{NaC}$ & Laser Streak & $18: 40-42: 00$ \\
\hline $4 / 23 / 92$ & $\mathrm{~N} 1$ & $\mathrm{NaC}$ & Shadow Size & $42: 00-1: 27: 00$ \\
\hline $4 / 24 / 92$ & $\mathrm{~N} 1$ & $\mathrm{NaC}$ & Shadow Size & $1: 27: 00-1: 45: 36$ \\
\hline $4 / 24 / 92$ & $\mathrm{~N} 2$ & $\mathrm{NaC}$ & Shadow Size & $0: 00-39: 30$ \\
\hline $4 / 24 / 92$ & $\mathrm{~N} 2$ & $\mathrm{NaC}$ & Laser Streak & $39: 30-1: 02: 00$ \\
\hline $4 / 26 / 92$ & $\mathrm{~N} 3$ & Instant Ocean & Shadow Size & $0: 00-1: 08: 21$ \\
\hline
\end{tabular}

Table 7.2: Conditions for Bubble Measurement Tests

The flexibility of the ANL/NNS loop design allowed convenient installation of the bubble diagnostics equipment; this equipment performed well for all of the tests. Both the shadow photography as well as the laser streak techniques were applied during the first testing period. During the first test, the laser streak data was used to verify the calibration factor for the loop flow meter. During the final test, bubble size measurements were emphasized in anticipation of the effert of Instant Ocean ${ }^{\mathrm{TM}}$. This test plan was optimized to obtain the best bubble size data by reducing the saturation of the test fluid with hydrogen gas. At each data point, the current was only applied for $\mathbf{3 0}$ seconds. This procedure provided a sample of 900 video pictures at each condition while also supplying a definitive marker for electrode produced bubbles (versus saturation bubbles). The detailed conditions for the Instant Ocean $^{\mathrm{TM}}$ test are listed in table 7.3. Nominal velocity values of 2 and of $8 \mathrm{~m} / \mathrm{sec}$ were used with nominal current valued of 50, 100, and 150 amps. At each flow condition, the boundary layer was scanned by translating the bubble diagnostics instrument. The relationship between camera position and boundary layer location is described in section 8.6. Critical GIVCAM parameters are also listed.[11] 


\begin{tabular}{|c|c|c|c|c|c|}
\hline \multicolumn{6}{|c|}{$\begin{array}{l}\text { Date 6/26/92 Clock Sync: tape start time } 00: 00: 09=3: 09: 00 \mathrm{pm} \text { clock time } \\
\text { Pressure }=5 \text { poig } / \text { Magnetic Field }=0 \text { Tesla } / \text { Conductivity }=4.7 \mathrm{~S} / \mathrm{m}\end{array}$} \\
\hline $\begin{array}{l}\text { Velocity } \\
(\mathrm{m} / \mathrm{s})\end{array}$ & $\begin{array}{l}\text { Tape Time } \\
\text { (hr:min:sec) }\end{array}$ & $\begin{array}{l}\text { Electrode } \\
\text { Current } \\
\text { (amps) }\end{array}$ & $\begin{array}{l}\text { Camera } \\
\text { Position } \\
\text { (inches) }\end{array}$ & $\begin{array}{l}\text { Camera Gain/ } \varepsilon / \# \\
\text { (volts/-) }\end{array}$ & 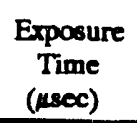 \\
\hline 2 & $2: 04$ & 50 & 0.2 & $640 / f / 4$ & 0.9 \\
\hline 2 & $3: 28$ & 50 & 0.4 & $640 / t / 4$ & 0.9 \\
\hline 2 & 5:26 & 50 & 1.0 & $640 / t / 4$ & 0.9 \\
\hline 2 & 6:58 & 50 & 3.0 & $640 / f / 4$ & 0.9 \\
\hline 2 & 8:58 & 50 & 0.0 & $640 / t / 4$ & 0.9 \\
\hline 2 & $10: 57$ & 50 & 0.1 & $640 / f / 4$ & 0.9 \\
\hline 2 & $12: 42$ & so & 0.1 & $670 / f / 4$ & 0.9 \\
\hline 8 & $15: 46$ & 50 & 0.1 & $670 / f / 4$ & 0.9 \\
\hline 8 & $17: 35$ & 50 & 0.0 & $670 / f / 4$ & 0.9 \\
\hline 8 & $19: 44$ & 50 & 0.2 & $670 / f / 4$ & 0.9 \\
\hline 8 & 21:16 & 50 & 0.4 & $670 / f / 4$ & 0.9 \\
\hline 8 & $22: 58$ & 50 & 0.1 & $670 / f / 4$ & 0.9 \\
\hline 8 & 25:42 & 150 & 0.1 & $700 / f / 4$ & 0.9 \\
\hline 8 & $26: 29$ & 150 & 0.1 & $700 / 1 / 4$ & 0.9 \\
\hline 8 & $29: 22$ & 150 & 0.1 & $660 / 0.8$ & 0.9 \\
\hline 8 & $31: 46$ & 100 & 0.1 & $700 / E / 4$ & 0.9 \\
\hline 8 & $33: 06$ & 100 & 0.2 & $700 / \varepsilon / 4$ & 0.9 \\
\hline 8 & $34: 11$ & 100 & 0.3 & $700 / t / 4$ & 0.9 \\
\hline 8 & $35: 21$ & 100 & 0.5 & $700 / \ddot{44}$ & 0.9 \\
\hline 8 & $36: 43$ & 100 & 1.0 & $700 / 54$ & 0.9 \\
\hline 2 & $39: 20$ & 100 & 0.1 & $700 / f / 4$ & 0.9 \\
\hline
\end{tabular}

\section{Tak' $1.3:$ Conditions for Instant Ocean ${ }^{\mathrm{TM}}$ Bubble Size Test}

After the test run at counter time 36:43, bubbles were observed remaining in the flow after electrode current was switched off. This condition became severe for the lower velocity case at time 39:20. At this point, the test was interrupted and an attempt was made to remove gas form the test fluid. Further runs were made at velocity values of 2,8 , and $4 \mathrm{~m} / \mathrm{sec}$ while 
the current ranged from 50 to 100 amps. Video data was recorded until a counter time of 1:08:21. However, the test data appears suspect after the saturation point was reached. Based on these observations, the allowable electric charge for saturation is about 14 amphours for this loop. ${ }^{[11]}$ 


\subsection{Results and Discussion}

\section{Volt-Ampere Chanacteristics}

The measured Volt-Ampere (V-I) characteristics for the center pair of thruster electrodes (30" in length) are shown in Figures 8.1, 8.2 \& 8.3 for different flow velocities, conductivities (4.8, $22.5 \mathrm{~S} / \mathrm{m}$ and $5.3 \mathrm{~S} / \mathrm{m}$ ), and for both working fluids. The linear nature of the V-I characteristics indicates that, for thruster-relevant current densities:

- The generation of hydrogen bubbles at the cathode has a negligible effect on the current transport across the working fluid.

- Single electrode potentials (SEP's) are essentially independent of the current density.

The fact that the V-I characteristics are independent of velocity provides further support to the first conclusion. The calculated fluid conductivity, $\sigma_{\mathrm{V}-\mathrm{I} \text { slope }}$, from the slope of the V-I characteristics, is in excellent agreement with the value measured, $\sigma_{\text {messured, }}$ by the conductivity probe and is summarized in Table 8.4.

\begin{tabular}{|c|c|c|}
\hline Working Fluid & $\begin{array}{c}\text { Measured Conductivity } \\
\sigma_{\text {measured }}(\mathrm{S} / \mathrm{m})\end{array}$ & $\begin{array}{c}\text { Calculated Conductivity } \\
\sigma_{\mathrm{V}-\mathrm{I} \text { slope }}(\mathrm{S} / \mathrm{m})\end{array}$ \\
\hline $\mathrm{NaCl}$ Solution & 4.8 & 4.7 \\
\hline $\mathrm{NaCl}$ Solution & 22.5 & 21.2 \\
\hline Instant Ocean $^{\mathrm{TM}}$ & 5.3 & 5.14 \\
\hline
\end{tabular}

Table 8.4: Comparison of Measured and Calculated Conductivity 


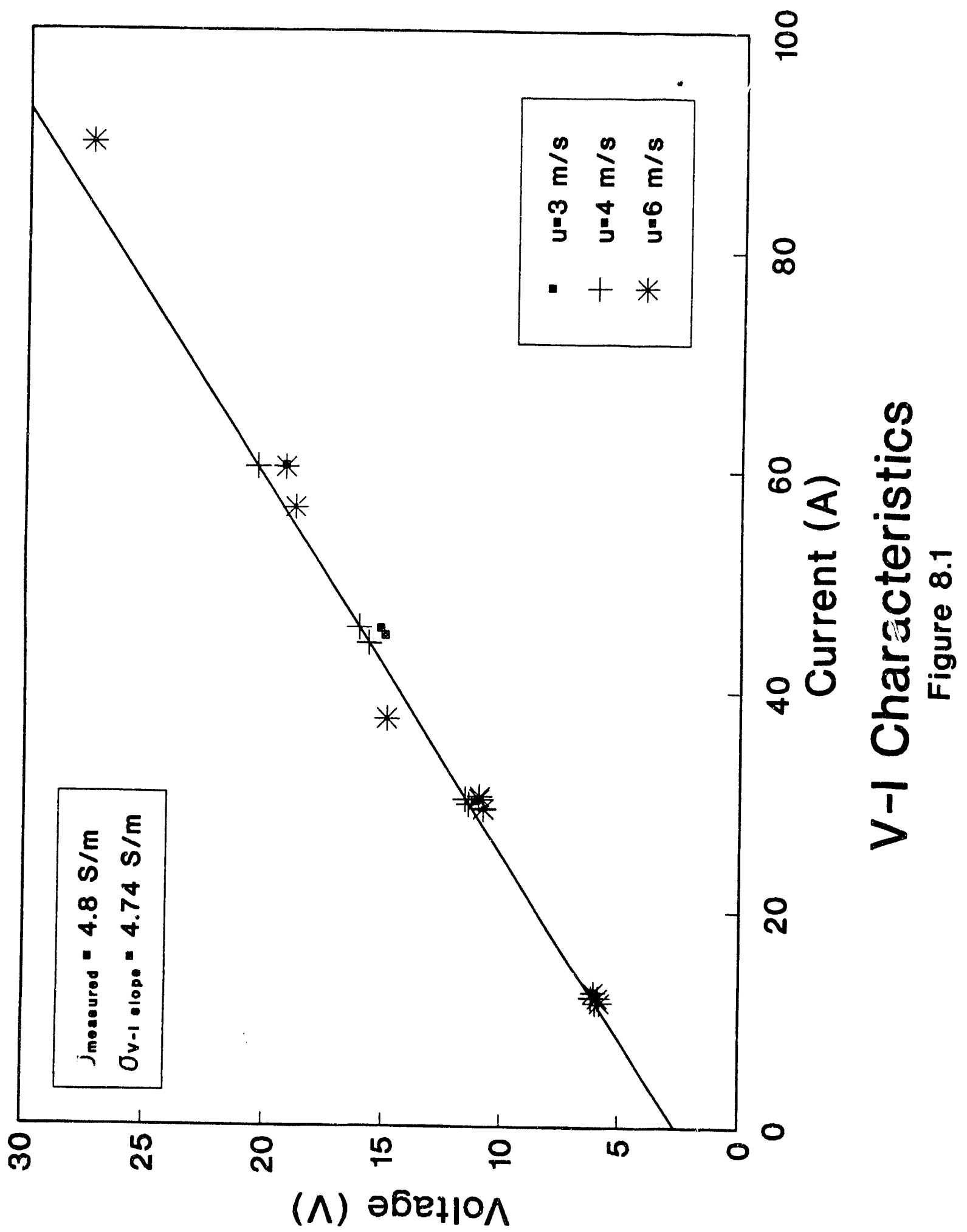




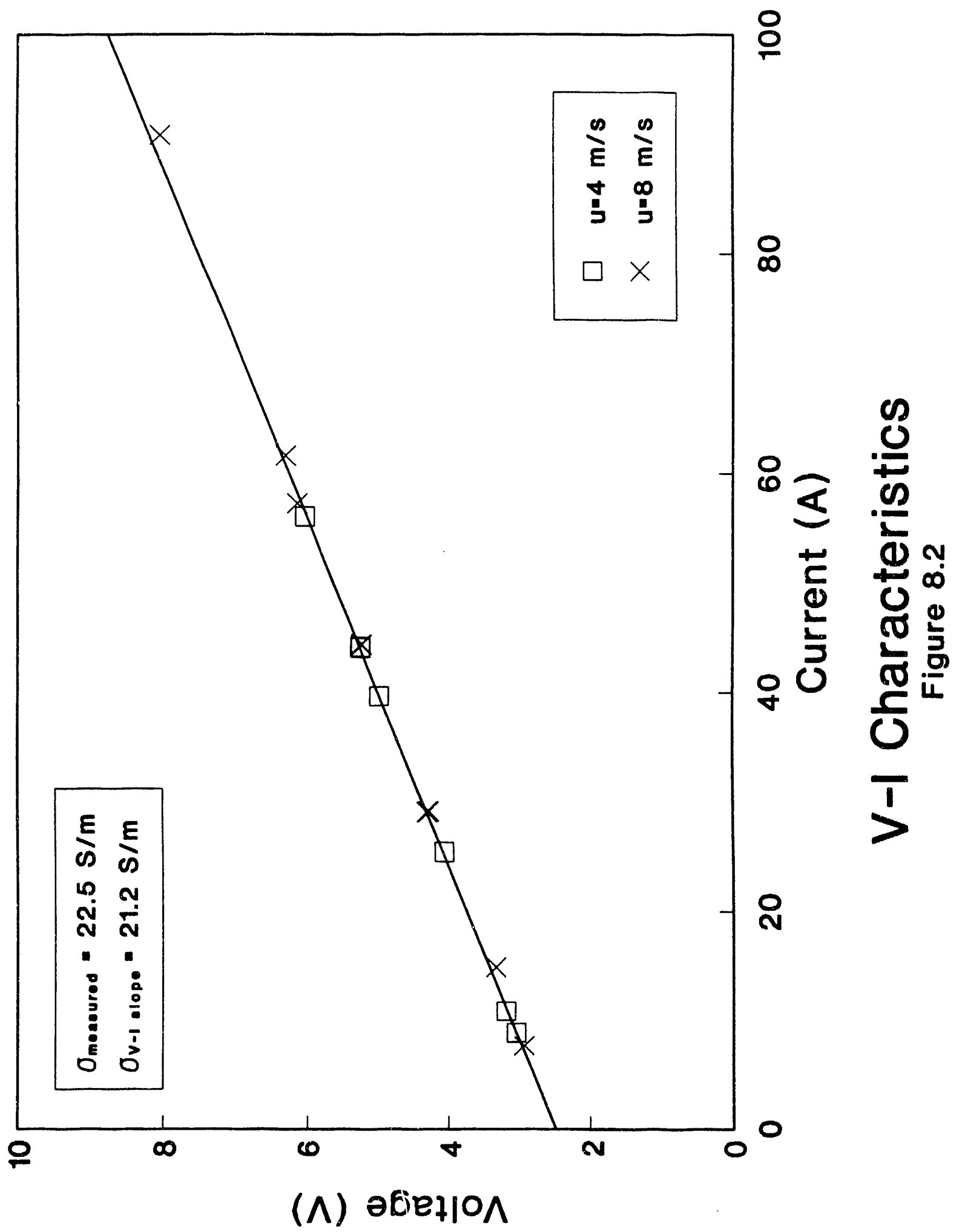




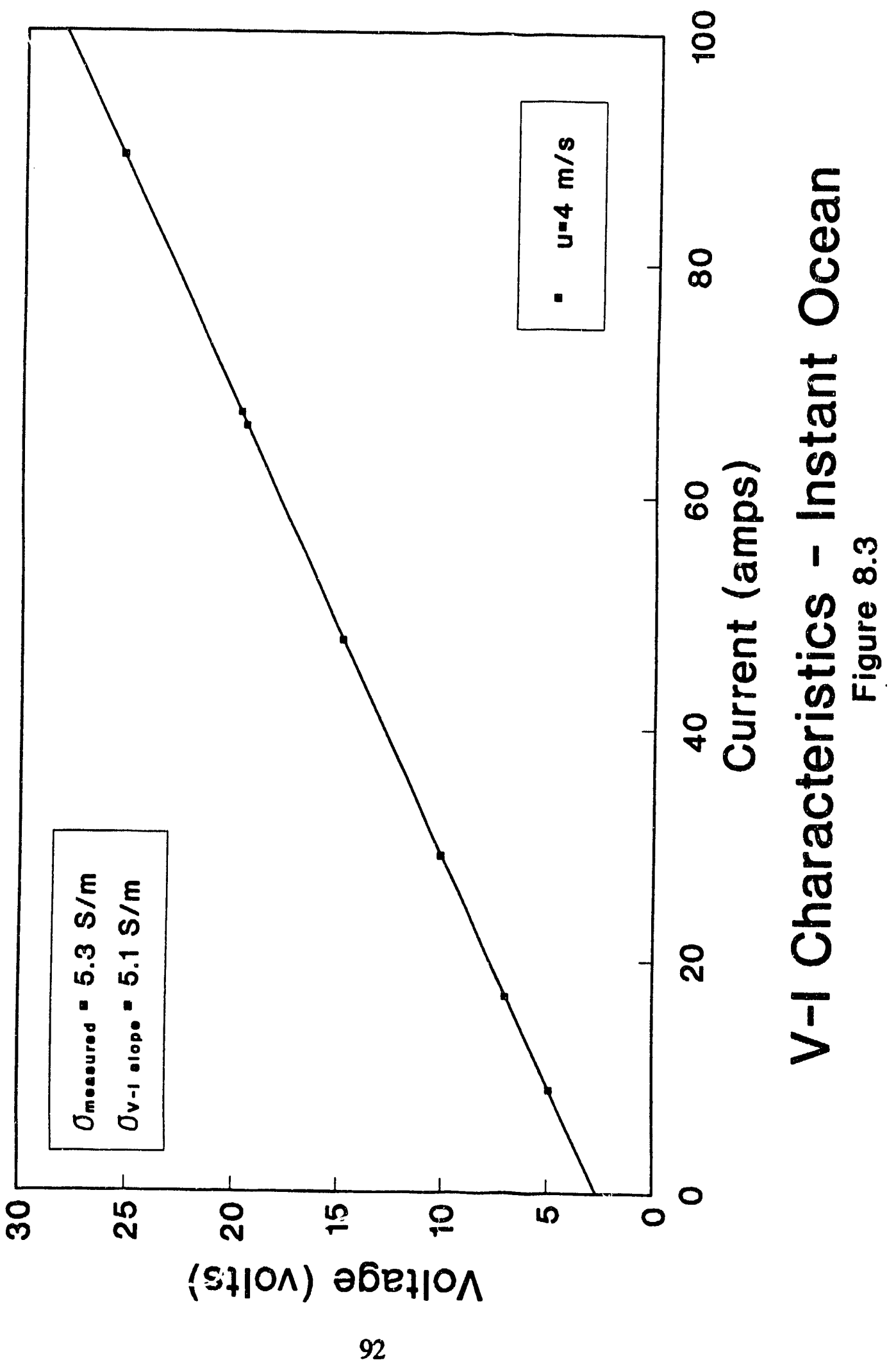


Finally, the sum of the SEP's at the anode and cathode ( $\left.\Delta V_{\text {chem }}\right)$, given by the $y$-intercept of the V-I characteristic, shown in Table 8.5, is in excellent agreement with the sum of the single electrode potentials provided by Eltech, the electrode manufacturer. Eltech quoted a measured SEP of 1.1 volts for the anode and an estimated value, based on literature, of $1.5 \mathrm{~V}$ for the cathode (these figures are expected to increase slightly with increased cirrent density and decreasing salt concentration).

\begin{tabular}{|c|c|c|}
\hline Working Fluid & $\begin{array}{c}\text { Measured Conductivity } \\
\sigma_{\text {measured }}(\mathrm{S} / \mathrm{m})\end{array}$ & $\begin{array}{c}\text { Electro-Chemical Potential } \\
\Delta \mathrm{V}_{\text {chem }} \text { (volts) }\end{array}$ \\
\hline $\mathrm{NaCl}$ Solution & 4.8 & 2.6 \\
\hline $\mathrm{NaCl}$ Solution & 22.5 & 2.5 \\
\hline Instant Ocean ${ }^{\mathrm{TM}}$ & 5.3 & 2.7 \\
\hline
\end{tabular}

Table 8.5: Electro-Chemical Potentials

In their totality, the V-I characteristic results demonstrate that for current densities of interest to MHD seawater propulsion, well established constant values of SEP's and fluid conductivity are the only electrical material properties that enter into the calculation of current transport and thruster performance.

\subsection{Current Density}

Since the electrodes are segmented, the measurement of individual currents permits the determination of fringing current effects at the electrode ends. Figures 8.4, 8.5 \& 8.6 show the measured and calculated average current densities over the five electrode segments for two electrical conductivities in the $\mathrm{NaCl}$ solution $(\sigma=4.5 \& 22.5 \mathrm{~S} / \mathrm{m})$ and for Instant 


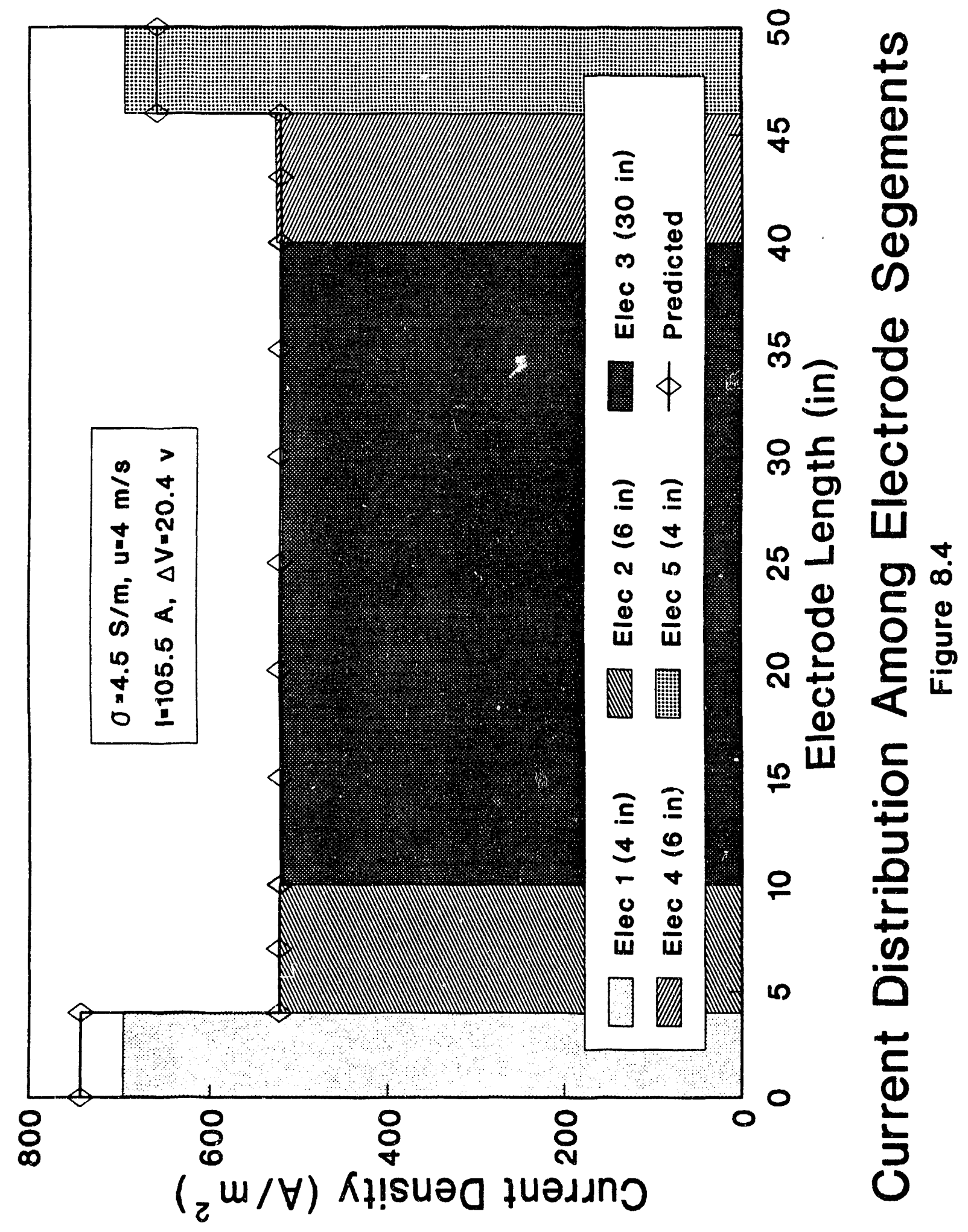




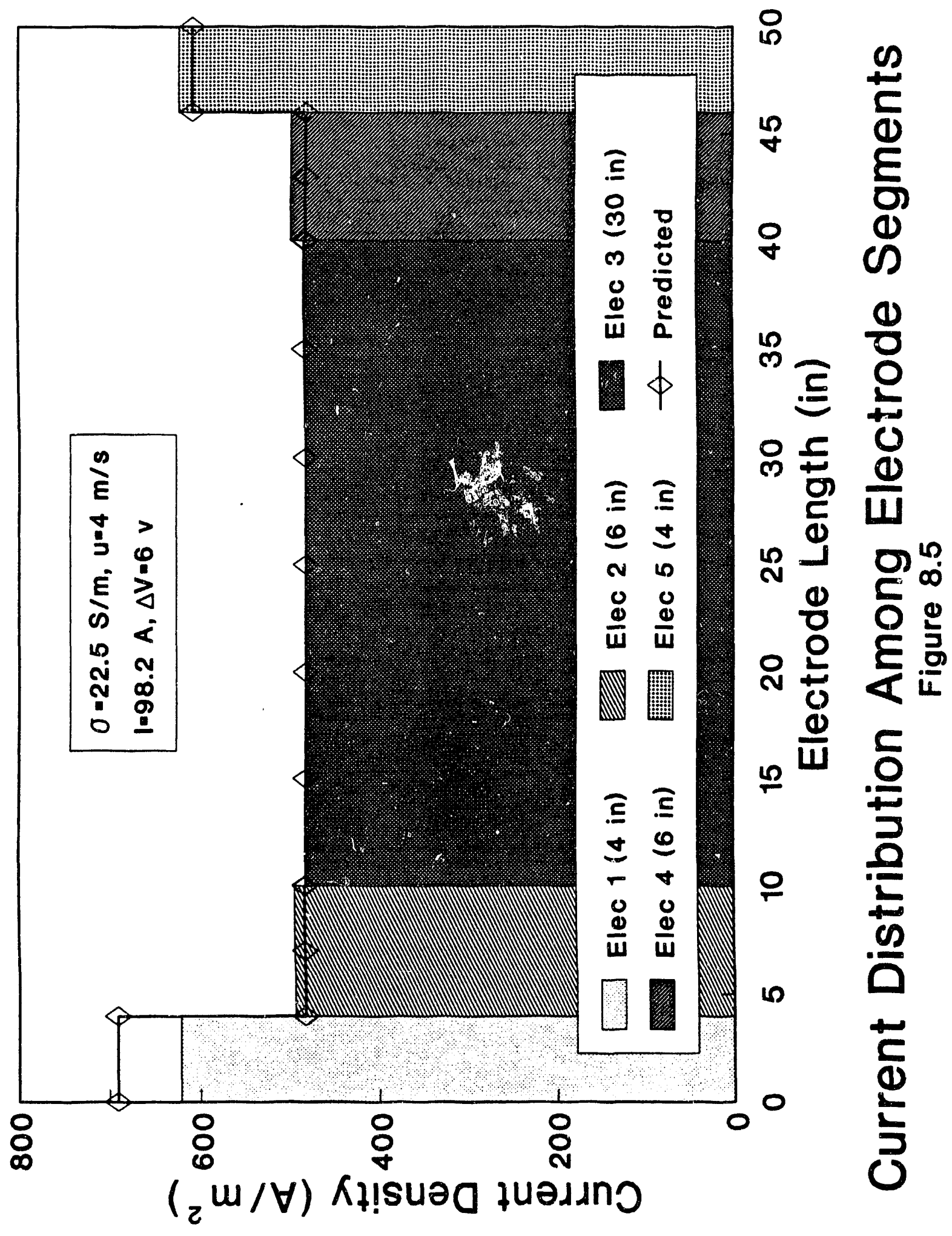







$\operatorname{Ocean}^{\mathrm{TM}}(\sigma=5.5 \mathrm{~S} / \mathrm{m})$. The figures indicate that the fringing current effects are confined to relatively small areas and, as such, they are expected to have a small effect on the performance of thrusters with moderately large electrode length to width ratios ( 8.3 in the present case). The effect of electrical end losses (due to fringing fields near the electrode ends) on MHD thruster performance has been investigated in detail. ${ }^{[15,17]}$ It has been found that, as the aspect ratio (electrode length/electrode width) and load factor increase, the electrical end losses decrease. The electrical end losses were shown to have a significant adverse effect on the thruster efficiency for load factors close to one. ${ }^{[15]}$

\subsection{Calculated and Measured Pressure Rise}

The measured pressure difference over the $30^{\prime \prime}$ center electrode was used to determine the degree to which the performance of the thruster follows theoretical predictions. Specifically, the measured pressure difference during thrust producing operation was reduced by the measured pressure difference at the same velocity and magnetic field, but at zero current. The resultant MHD pressure rise, normalized by the theoretical pressure rise as calculated on the basis of the measured current, is plotted as a function of the current density in Figure 8.7 for different flow velocities and magnetic field orientations for $\sigma=22.5 \mathrm{~S} / \mathrm{m}$. As shown on this figure, there is good agreement between measured and calculated pressure rise (thrust). Similar results were obtained for $\sigma=4.5 \mathrm{~S} / \mathrm{m}$ in an aqueous solution of sodium chloride and for $\sigma=5.5 \mathrm{~S} / \mathrm{m}$ in thstant Ocean $^{\mathrm{TM}}$, as shown in Figures 8.8 \& 8.9 respectively. 


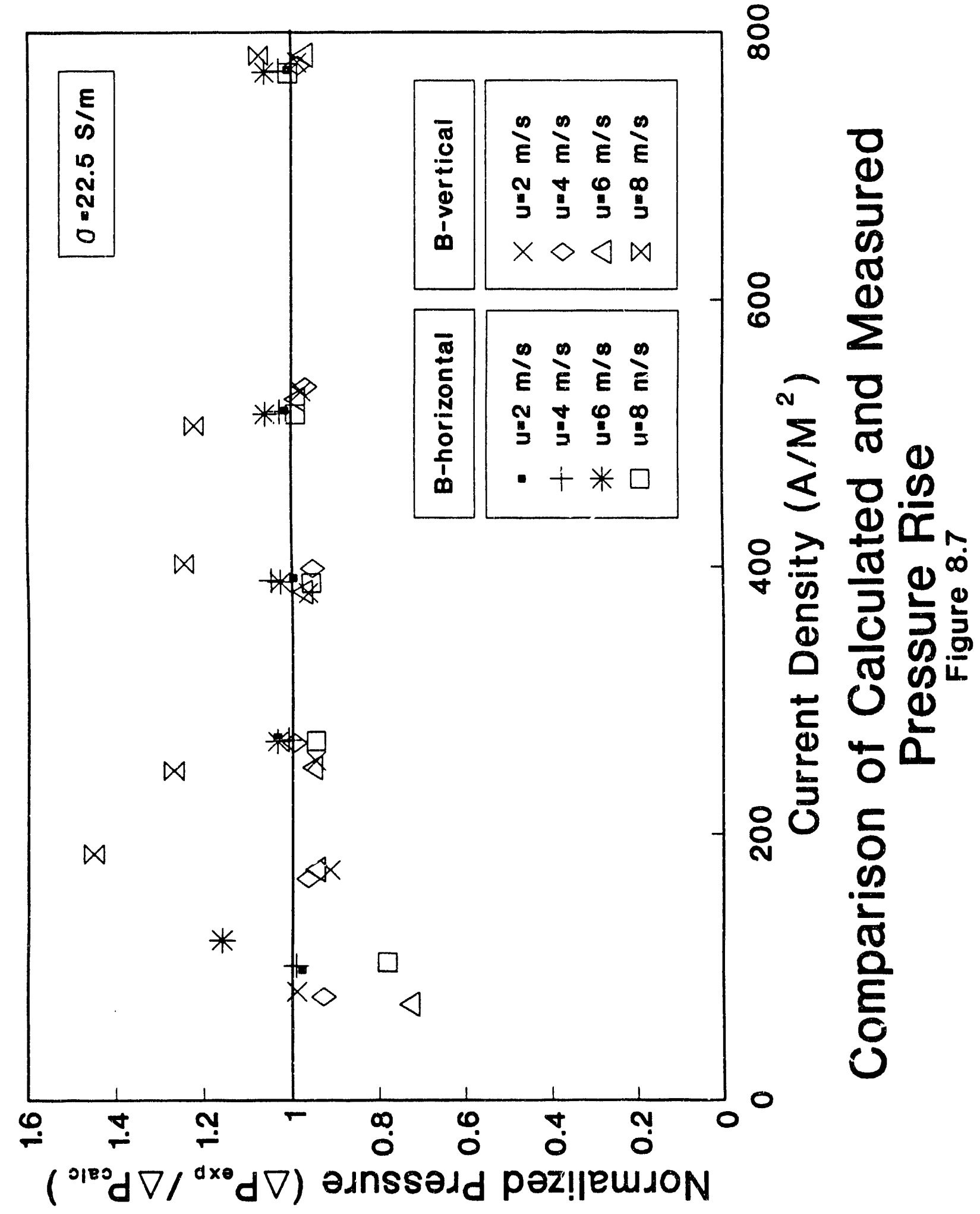




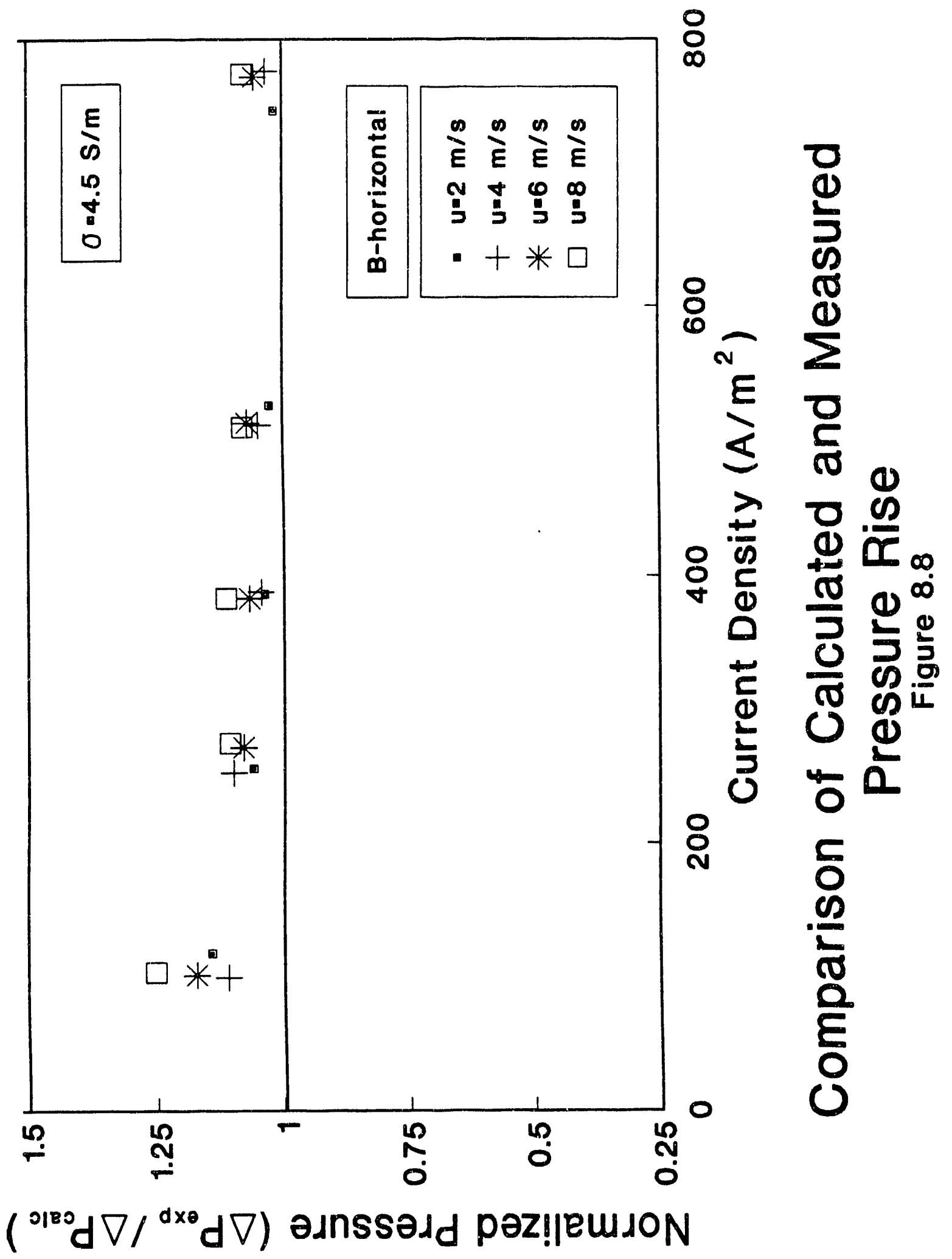




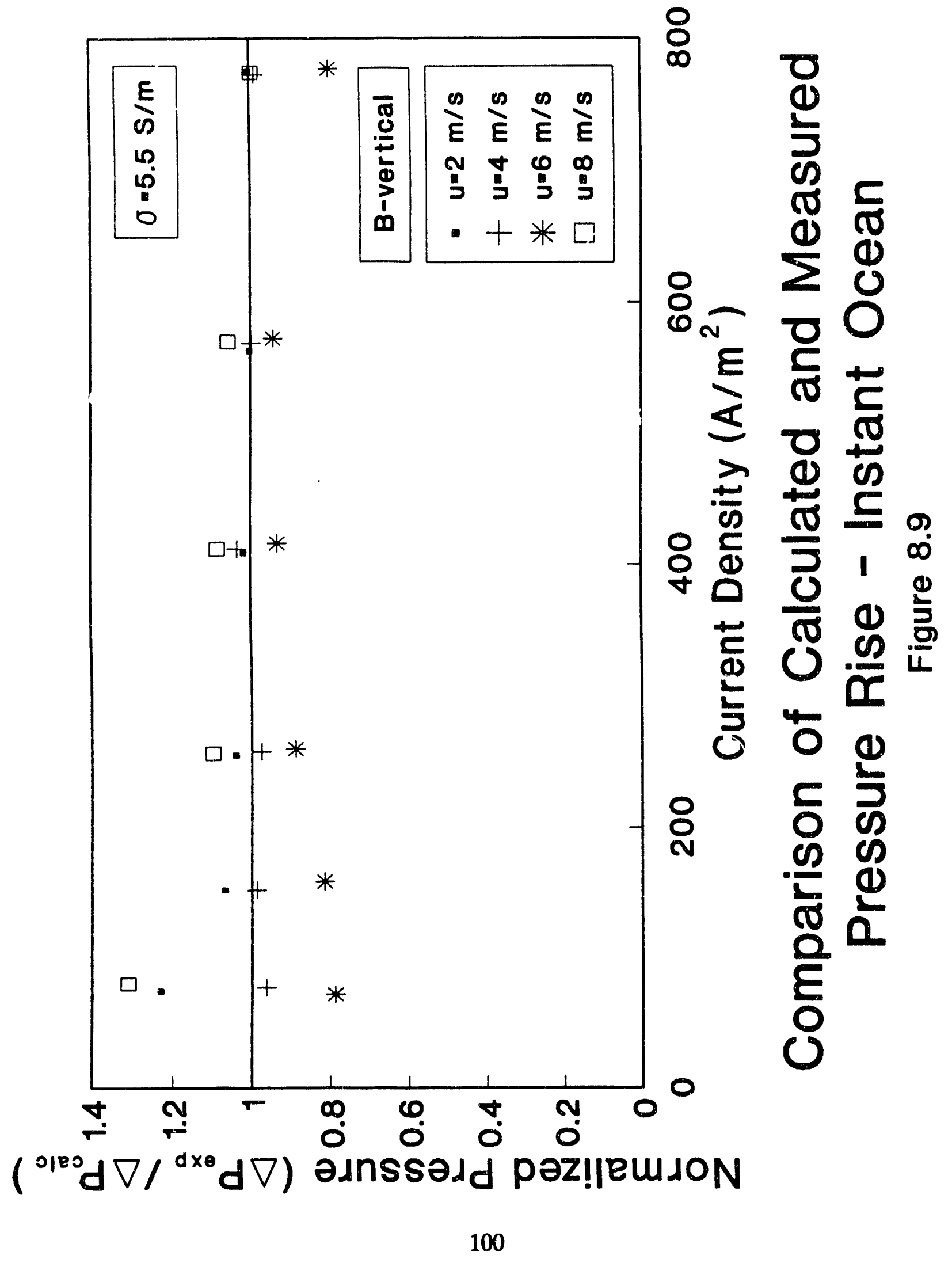




\section{Thruster Efficiency and Lasses}

Thruster efficiency, defined as the ratio of mechanical power generated by the thruster to electrical power supplied to the thruster, is given by:

$$
\eta=\frac{\Delta p Q}{\Delta V I}
$$

where $\Delta \mathrm{p}$ is the pressure rise along the thruster, $\mathrm{Q}$ is the volumetric flow rate, $\Delta \mathrm{V}$ is the potential difference across the electrodes, and I is the electric current.

In Figures 8.10, 8,11 \& 8.12, the measured total efficiency for an aqueous solution of sodium chloride $(\sigma=4.5 \mathrm{~S} / \mathrm{m}$ and $\sigma=22.5 \mathrm{~S} / \mathrm{m})$ and Instant $\operatorname{Ocean}^{\mathrm{TM}}(\sigma=5.5 \mathrm{~S} / \mathrm{m})$, at $\mathrm{u}=2 \mathrm{~m} / \mathrm{s}$ is plotted against the load factor $\mathrm{K}$,

$$
K=\frac{\Delta v / d}{u B}
$$

where $d$ is the electrode separation, $B$ is magnetic flux density, and $u$ is the fluid velocity. As shown, total efficiencies of approximately $4 \%$ and $8.4 \%$ for the sodium chloride solution and $4 \%$ for the Instant Ocean ${ }^{\mathrm{TM}}$ were achieved under these conditions. As expected, the results indicate that thruster efficiency increases as electrical conductivity increases. In addition, Figure 8.11 demonstrates that thruster performance is not affected by a change in orientation of the magnetic field. Figures $8.10,8.11 \& 8.12$ also show that the total efficiency is given by the ideal thruster efficiency (equal to $1 / \mathrm{K}$ ) reduced by frictional drag and SEP losses. Since both the losses and the ideal thruster efficiency are easily calculated, the performance of MHD thruster can be predicted with confidence. The calculation of the 


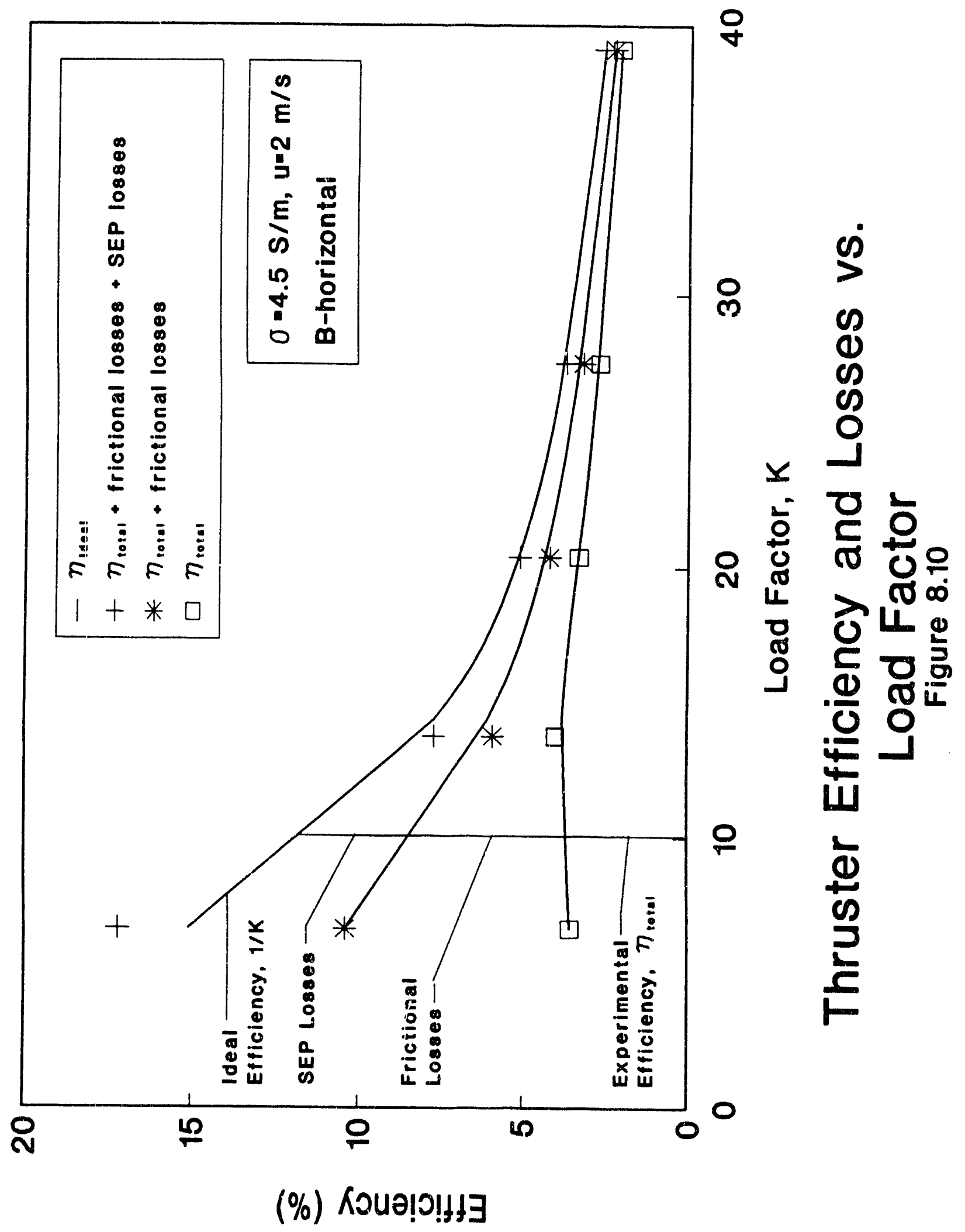




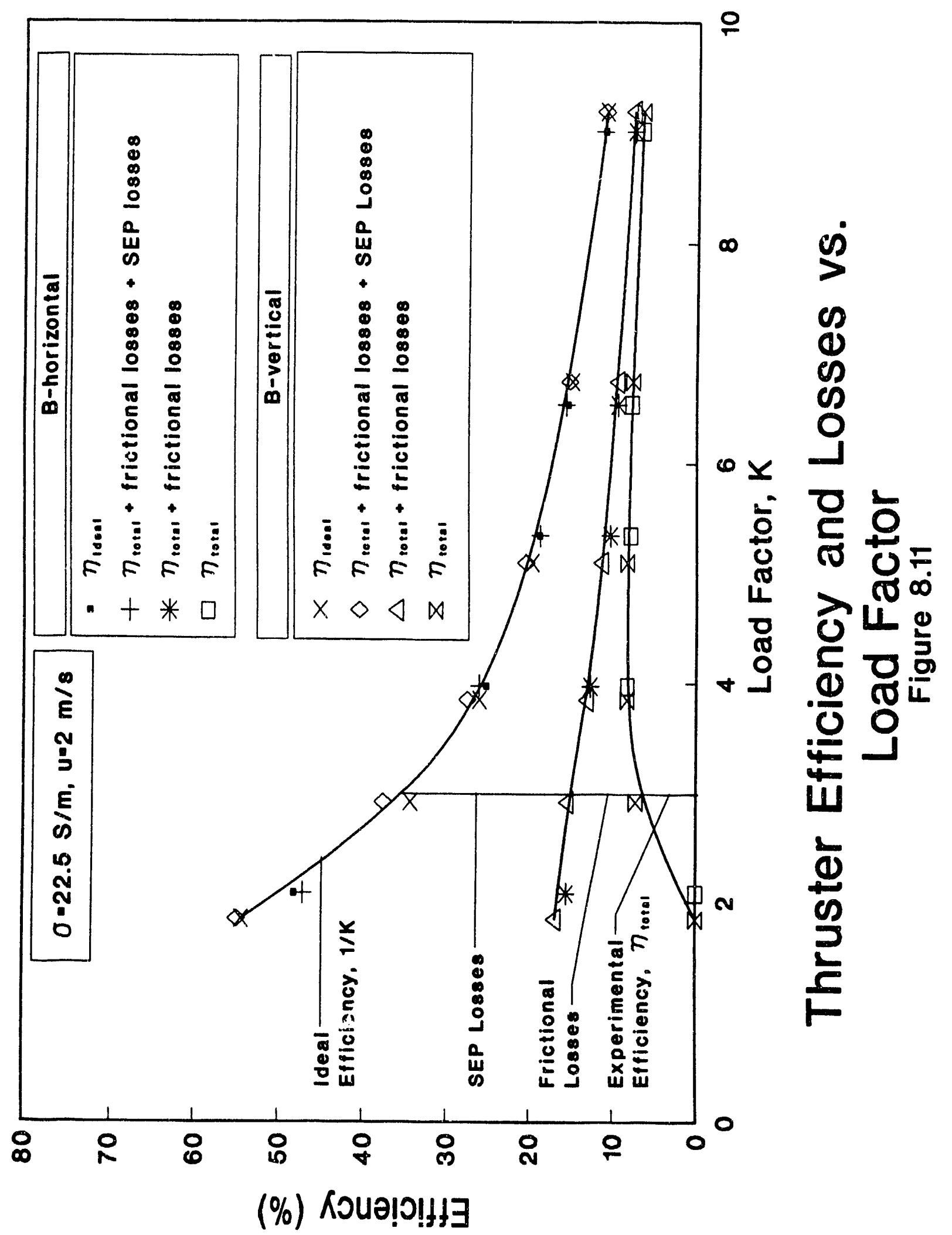




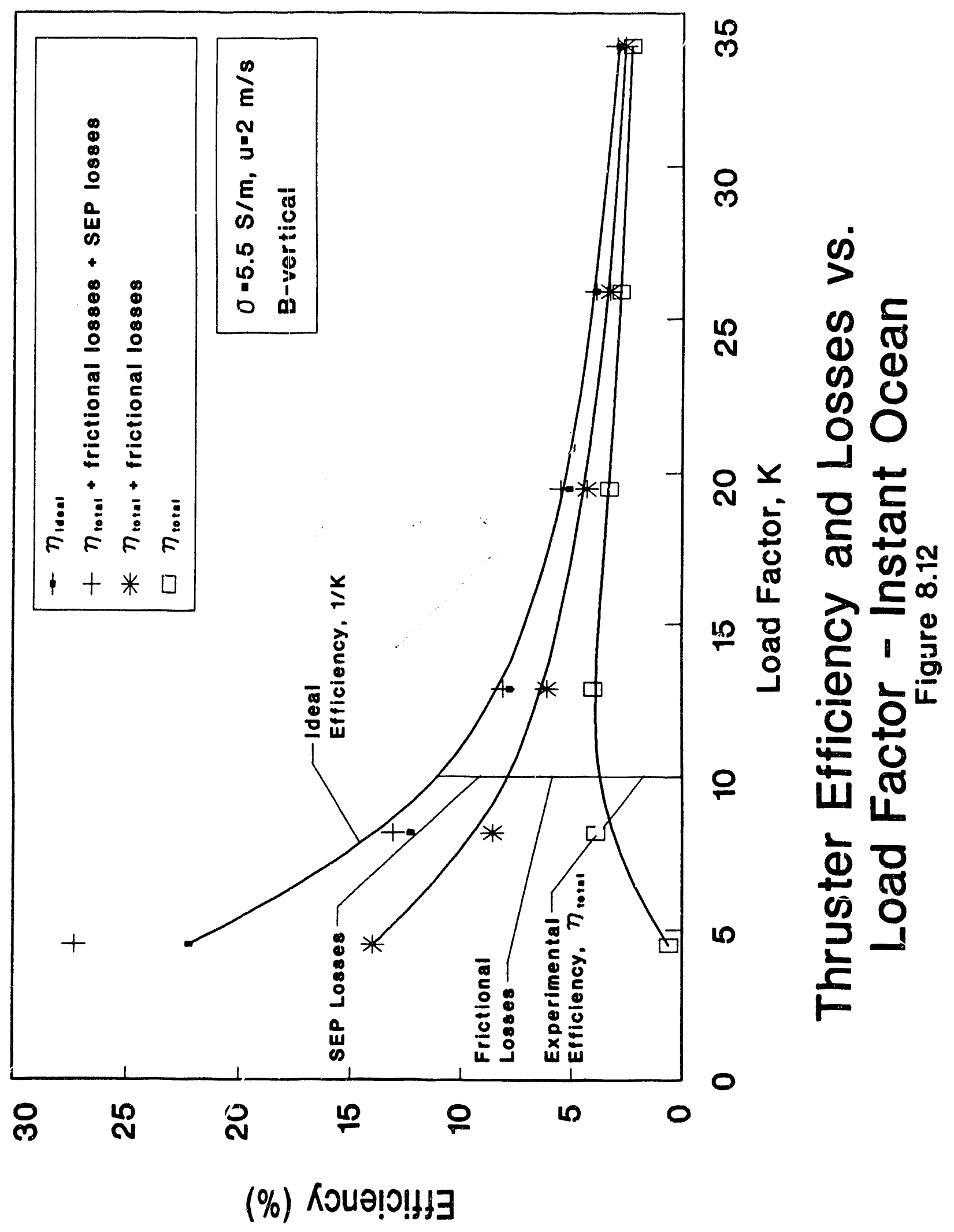


effect of end losses on efficiency is more complicated, but such losses are of little practical importance unless thrusters with magnetic flux densities in excess of 10 Tesla operating near load factors $\mathrm{K}=1$ are under consideration. ${ }^{[16]}$

\subsection{Ideal Thruster Efficiency}

The "ideal" thruster efficiency for both working fluids at different operating conditions, calculated from the measured total efficiencies and losses, is plotted against the load factor in Figures 8.13 \& 8.14. As shown in these figures, there is good agreement between the experimentally determined ideal efficiencies and the theoretical dependence of $1 / \mathrm{K}$.

As seen from the preceding figures, the theoretical predictions are in good agreement with the measured values. Deviations can be attributed to experimental errors, given the fact that differential pressure measurements are as small as a few tenths of a psi for some of the cases. The results presented here are confined to the central portion of the thruster, away from the fringing current areas. Measurements in the end regions are subject to large experimental error because the pressure differentials involved are small. Calculations indicate that losses associated with such end sffects are much smaller than frictional losses for the expected parametric range of actual seawater thrusters.

\subsection{Bubbles}

The detailed characteristics of bubbles must be determined by processing a statistical sampling of images recorded at various locations in the flow field. Since both the size of bubbles as well as their number density fluctuate in time, hundreds of samples are desired 


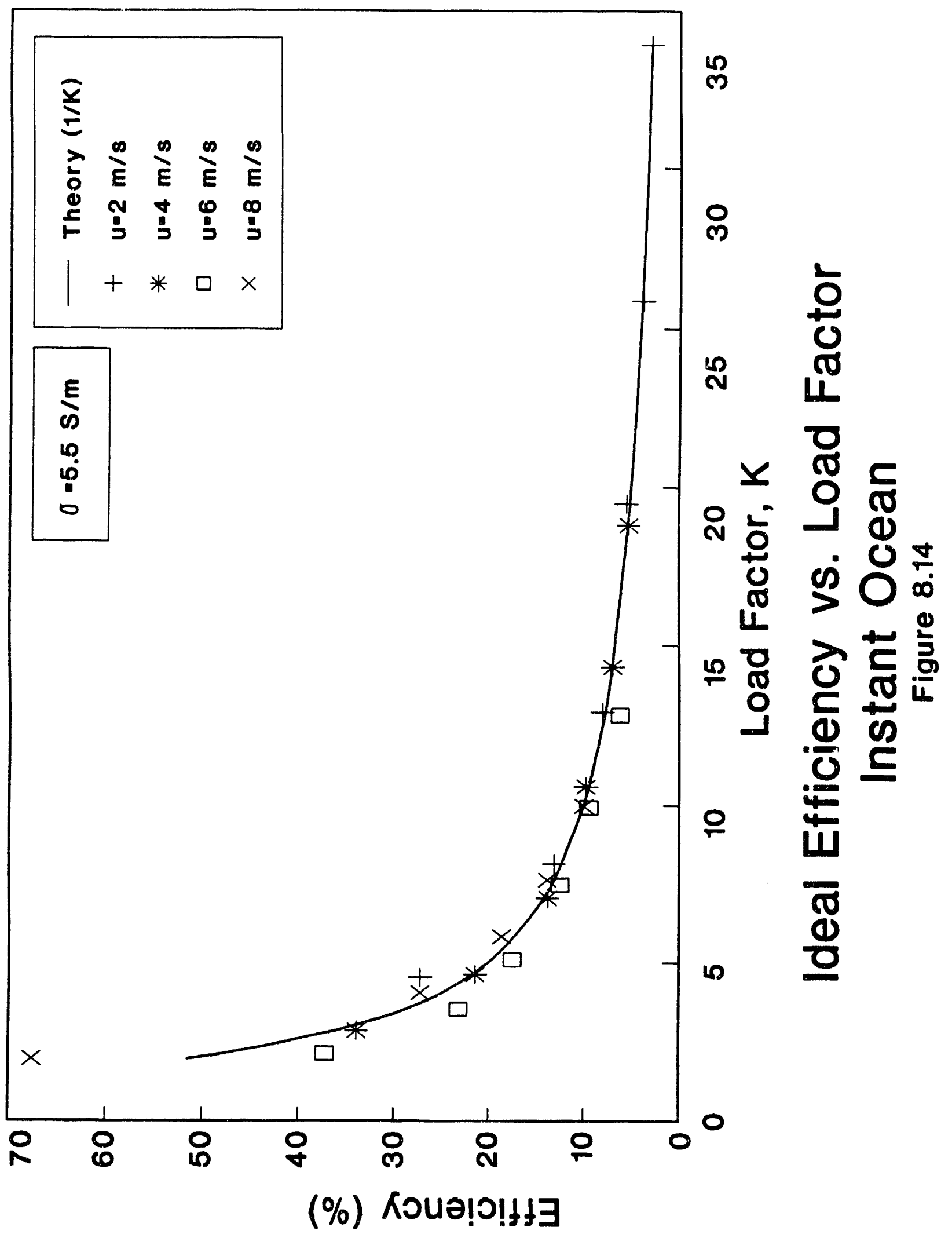


at each condition for accurate measurements. Calibration of the equipment for both length scale and measurement volume are required for quantitative measurements. In addition, image processing software is required for translating the thousands of video frames recorded into a format amenable to data reduction. ${ }^{[1]}$

\subsubsection{Qualitative Observations}

During the first three tests with $\mathrm{NaCl}$ solution, bubble shadows were not observed by direct imaging. Despite the use of fast shutter speeds (less than 1 microsecond), high electrode current (200 amperes), and measurement locations near the cathode wall, medium size (40 micron diameter) or larger bubbles v/ere not observed. However, visual observations revealed a "cloudy" appearance of the fluid near the cathode wall. This effect was rendered visible by the projection lamp and increased with electrode current. This optical activity was manifested as a strong scattering of the background illumination source with a large reduction in background intensity as measured by the video camera. The test fluid became increasingly cloudy with the number of ampere-hours discharged until finally it took a dense yellowish hue. ${ }^{[1]]}$

The results of the final test with Instant Ocean ${ }^{\mathrm{TM}}$ were dramatically different: many large bubbles with diameters in the 100 to 300 micron range were observed upon application of current even at $\mathbf{5 0}$ amperes. For this test, the current was applied for $\mathbf{3 0}$ second intervals and the bubble activity diminishes within seconds of switching off the current. A decrease in overall intensity is also noted for this "large" bubble case due to scattering of light from bubbles outside the measurement volume. The region of strongest bubble activity occurred within a few millimeters of the electrode wall; beyond this thin layer, the bubble number 
density rapidly decreases. The number of large bubbles per frame was observed to increase in rough proportion with electrode current. As expected, the bubble number density decreases as the flow velocity is increased. Before the test solution became saturated, only a few bubbles were observed in the core flow (with current on) or near the wall with the current off. Before saturation occurred during the fourth test with Instant Ocean $^{\mathrm{TM}}$, over 18,000 video frames of bubbles shadows were recorded at various conditions. ${ }^{[11]}$

\subsubsection{Bubble Size Results}

During data reduction, the image analysis process was semi-automated so that each entire sequence of images was processed for all eight steps in batch mode. The image sequence was then printed out two on a page. Each image print contains the file header at the top of the page and its sequence number overhead. In addition, the original value of average intensity is recorded along with the value for the final enhanced version (level $=$ original $->$

enhanced). Evidence of the many large bubbles produced during the Instant Ocean ${ }^{\mathrm{TM}}$ test is showr ty the enhanced images reproduced for the N301 sequence. This sequence of ten frames of video data is shown first for the gentle sharpen filter with background (Figures 8.15 - 8.19), then as a sequence ( $\# 1$ through $S \# 10$ ) for the vertical filter with more background removal (Figures 8.20 - 8.24). These ten images provided a statistical sample of the bubbles produced near the cathode wall $(0.19 \mathrm{~cm}$ from the wall in this case). Note that several tens of black circular shadows are visible on each frame. These black "dots" correspond to bubbles with diameters in the 40 to 260 micron range. The gray shadows represent bubbles that are on the edge of the effective focal volume for the imaging optics. The gray background is caused by the dense "cloud" of bubbles generated near the wall.[11] 

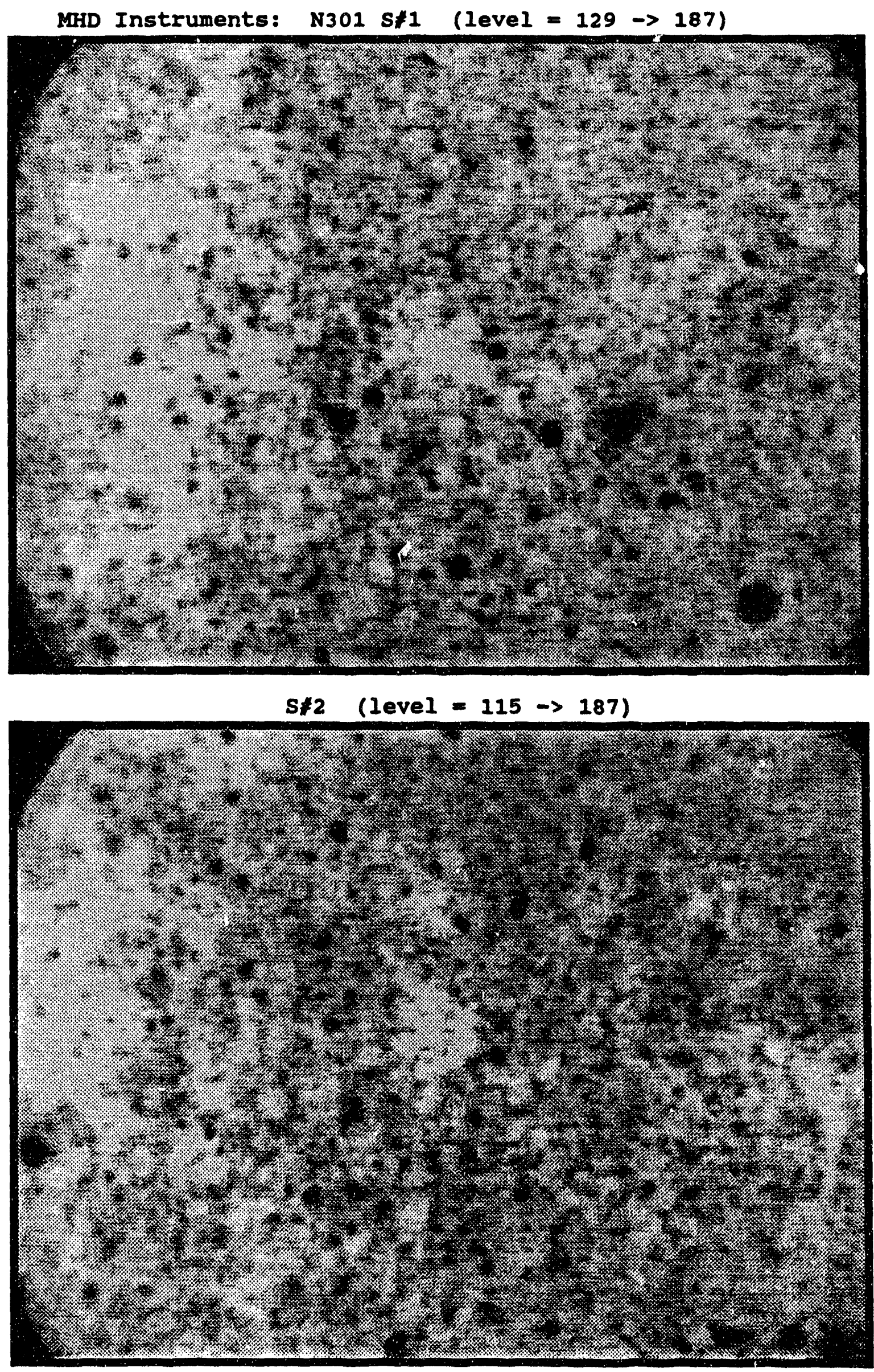

Bubble Photos S\#1 \& S\#2, N301 Sequence - Gentle Sharpen Filter Figure 8.15 

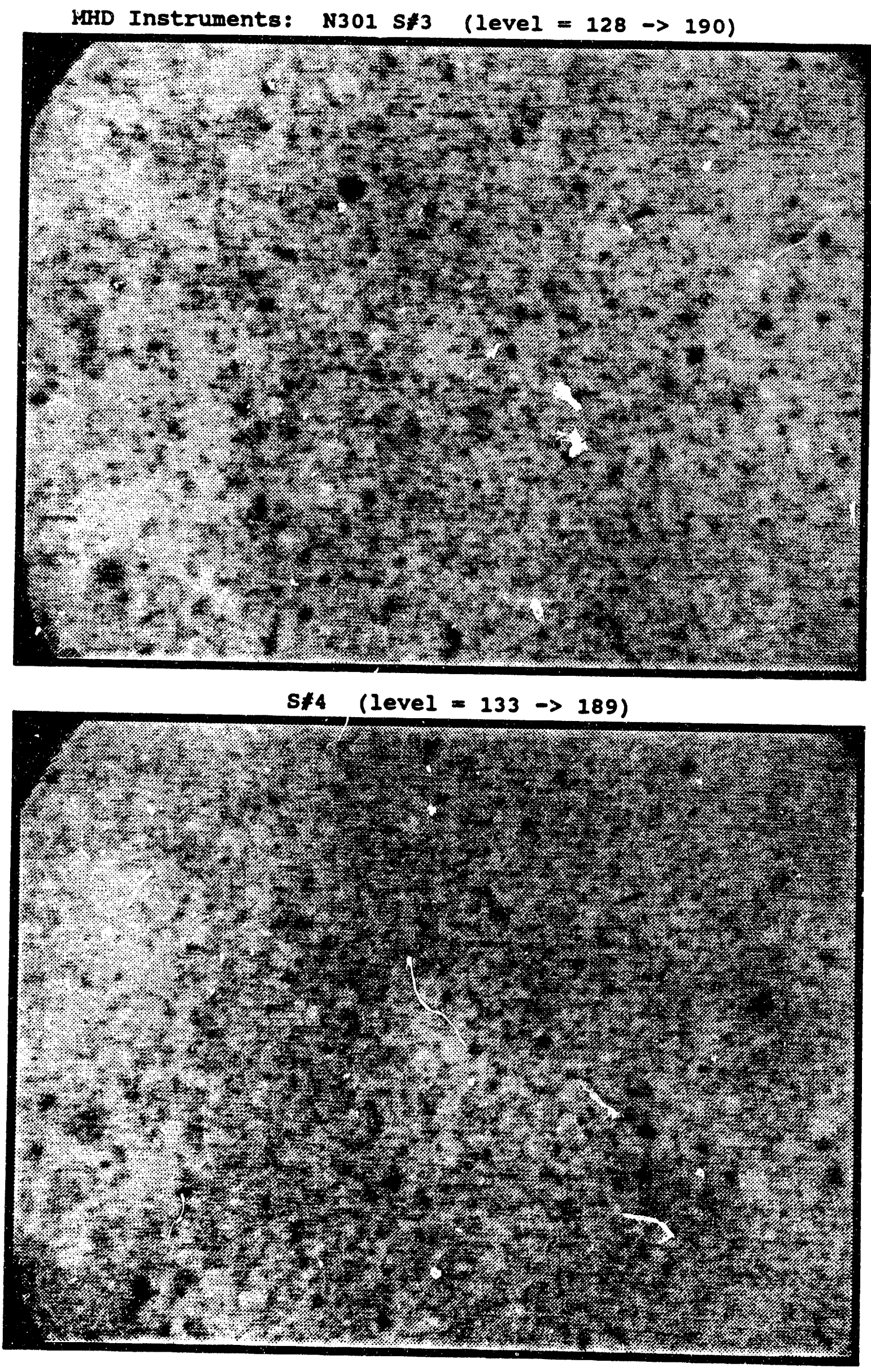

Bubble Photos S\#3 \& S\#4, N301 Sequence - Gentle Sharpen Filter Figure 8.16 

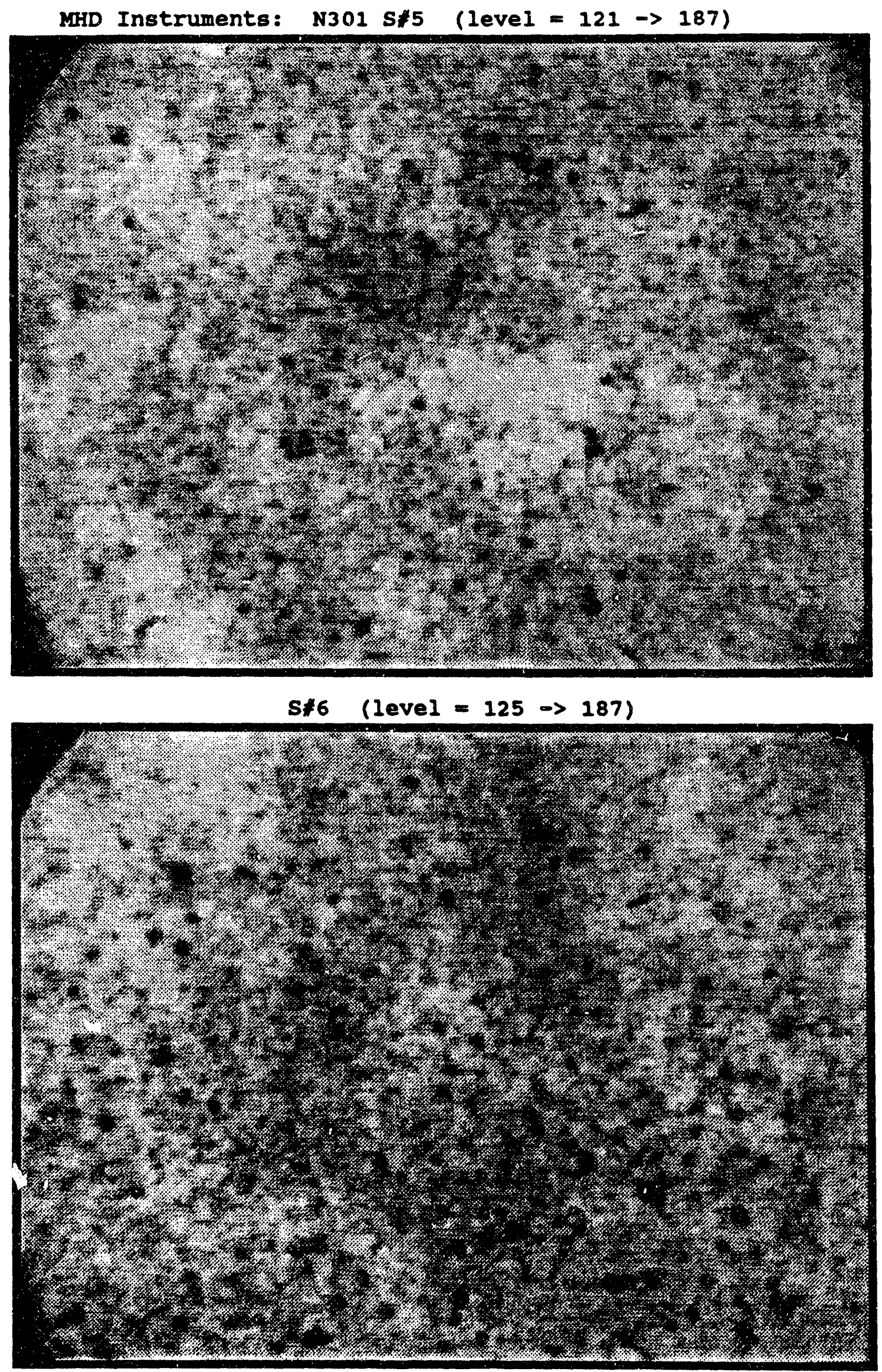

Bubble Photos S\#5 \& S\#6, N301 Sequence - Gentie Sinarpen Fiiter Figure 8.17 


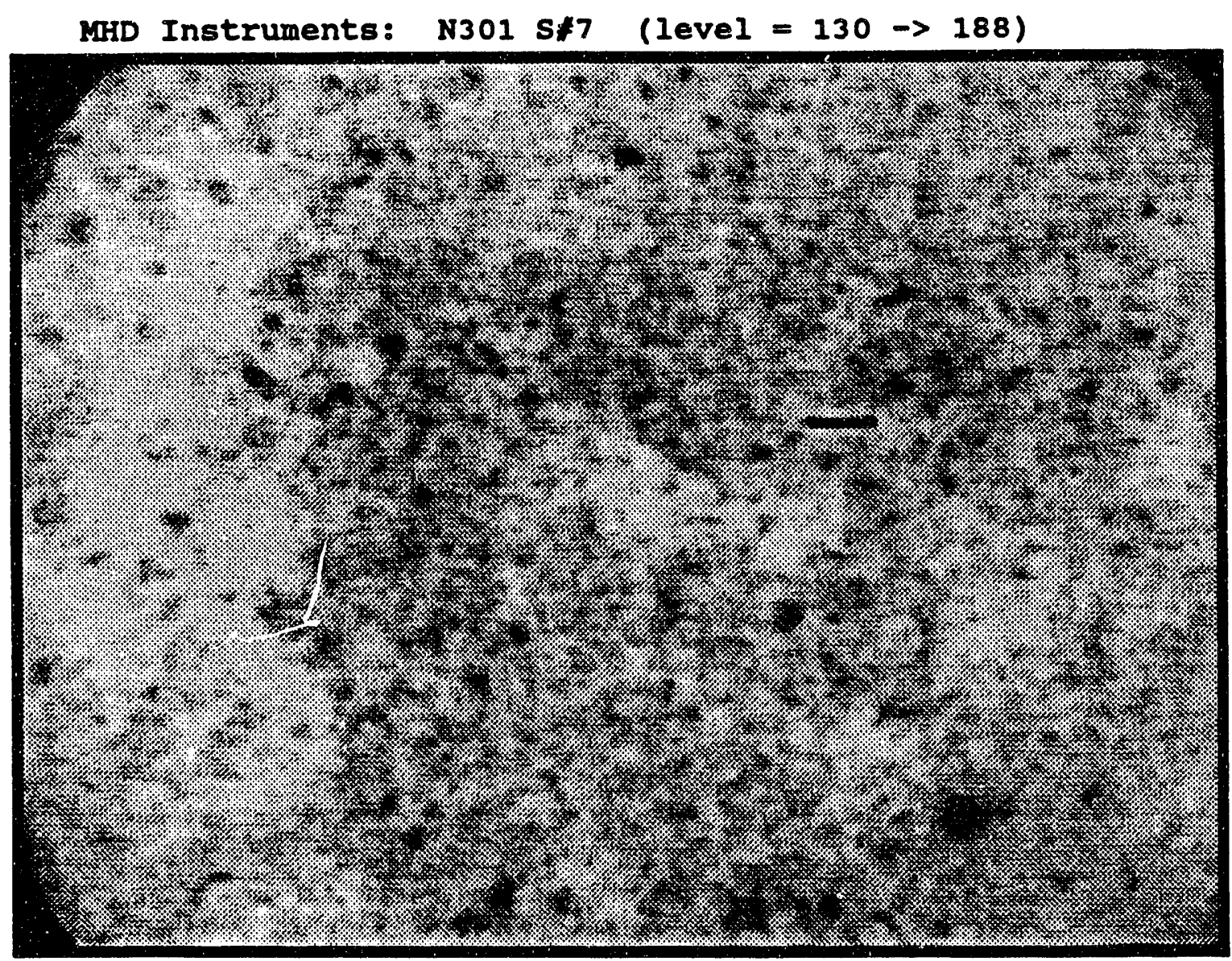

S:8 (level $=117 \rightarrow$ 194)

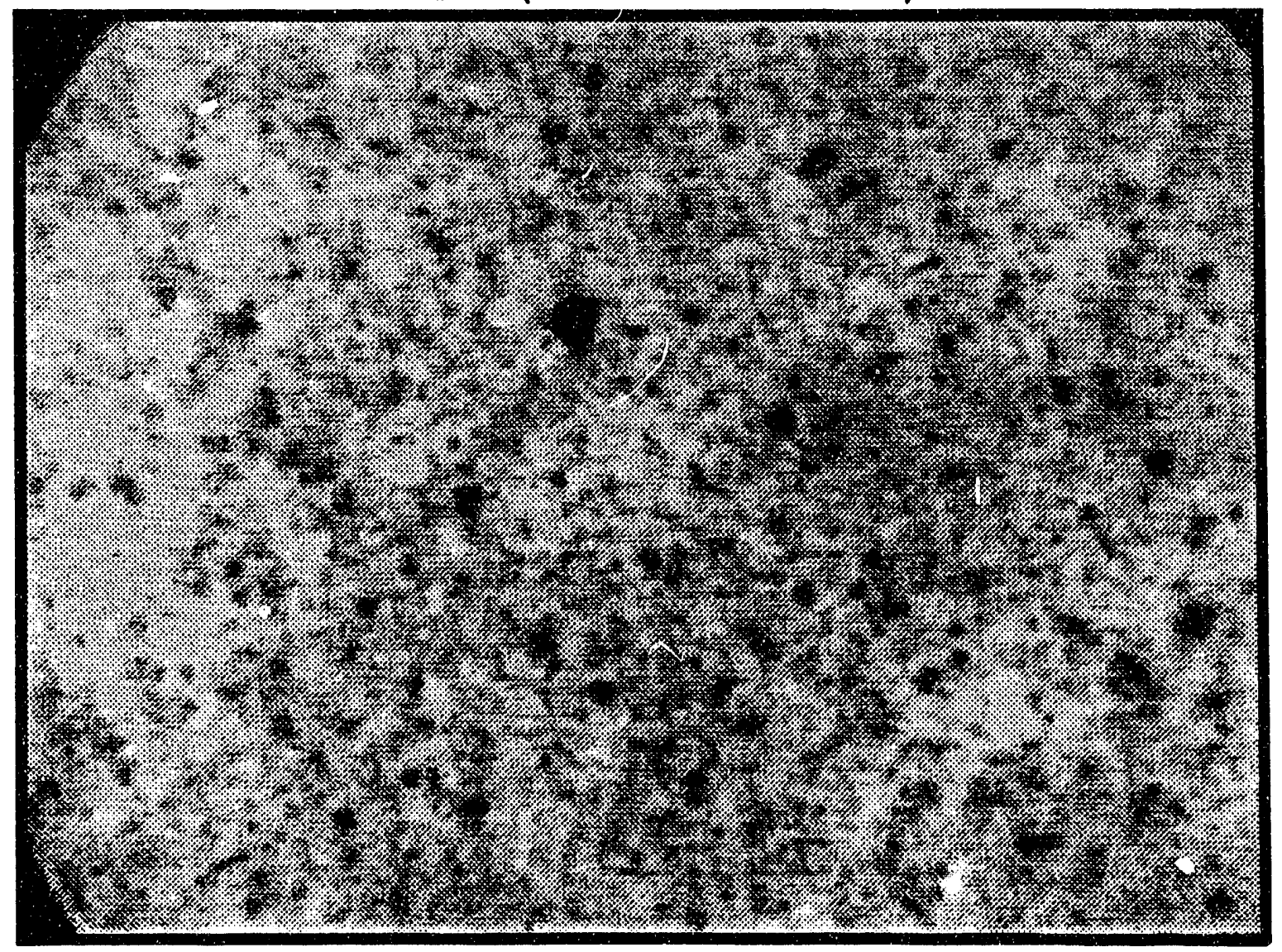

Bubble Photos S\#7 \& S\#8, N301 Sequence - Gentle Sharpen Filter Figure 8.18 

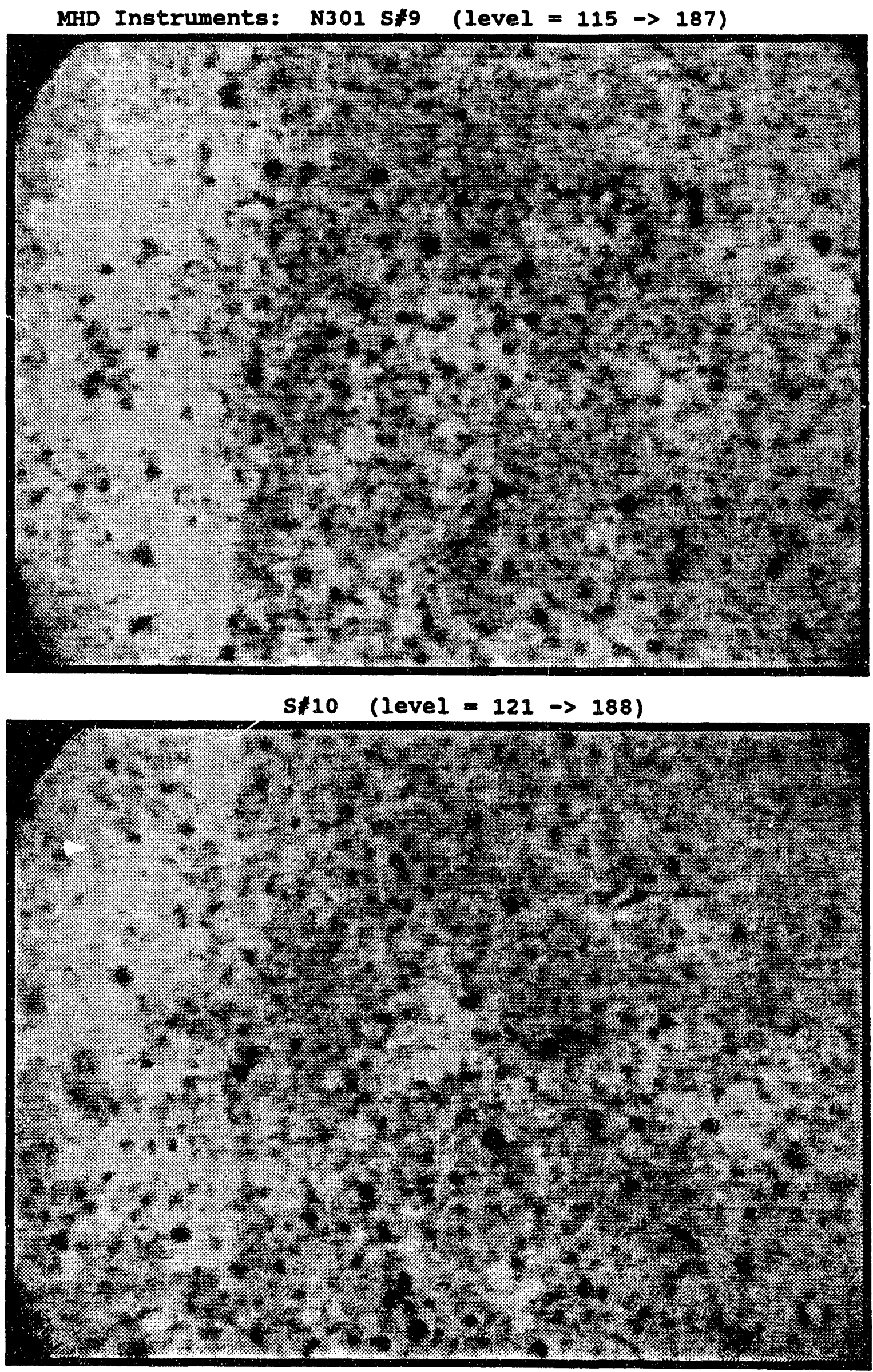

Bubble Photos S\#9 \& S\#10, N301 Sequence - Gentle Sharpen Filter Figure 8.19 

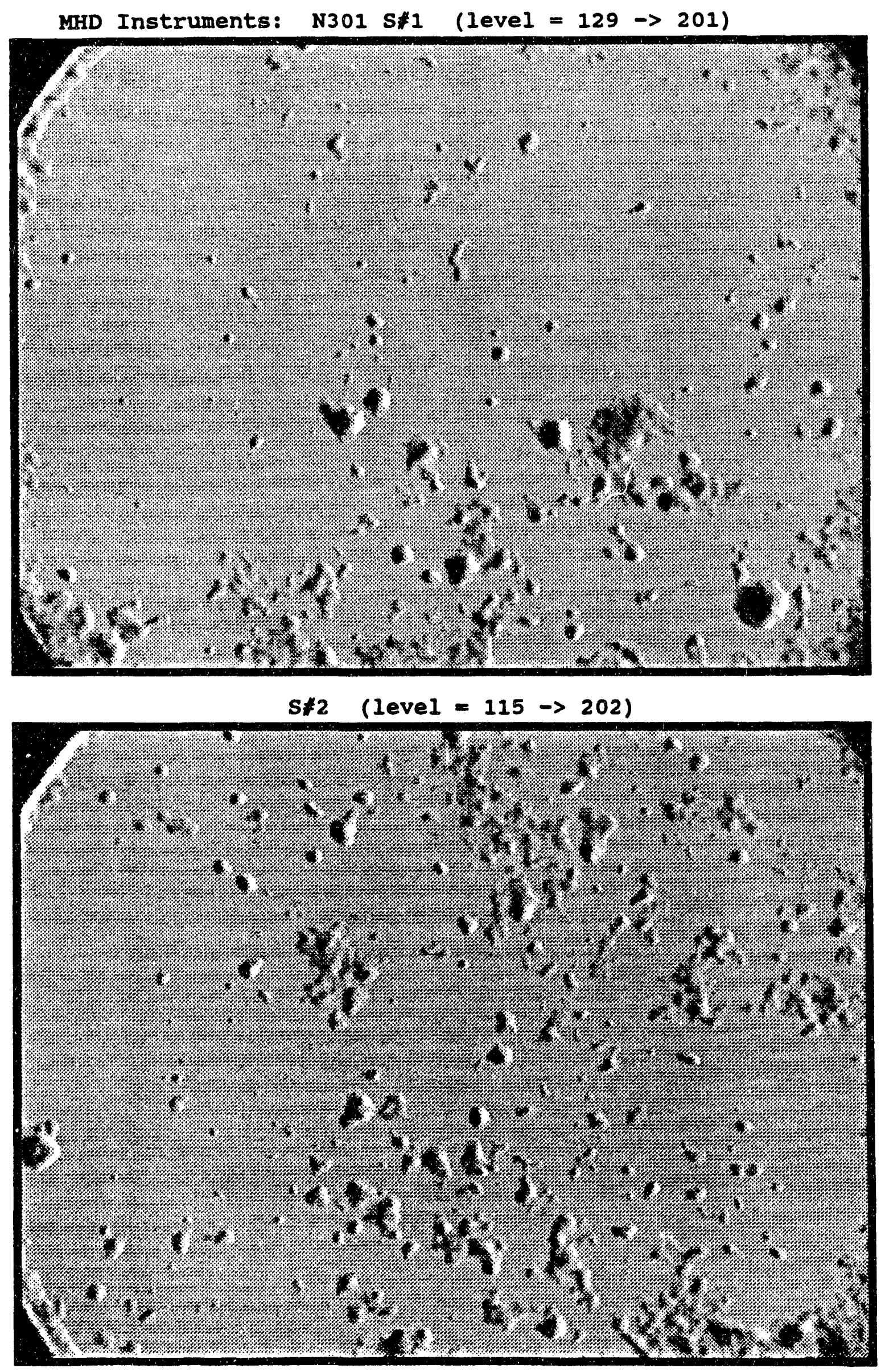

Bubble Photos S\#1 \& S\#2, N301 Sequence - Vertical Filter

Figure 8.20 

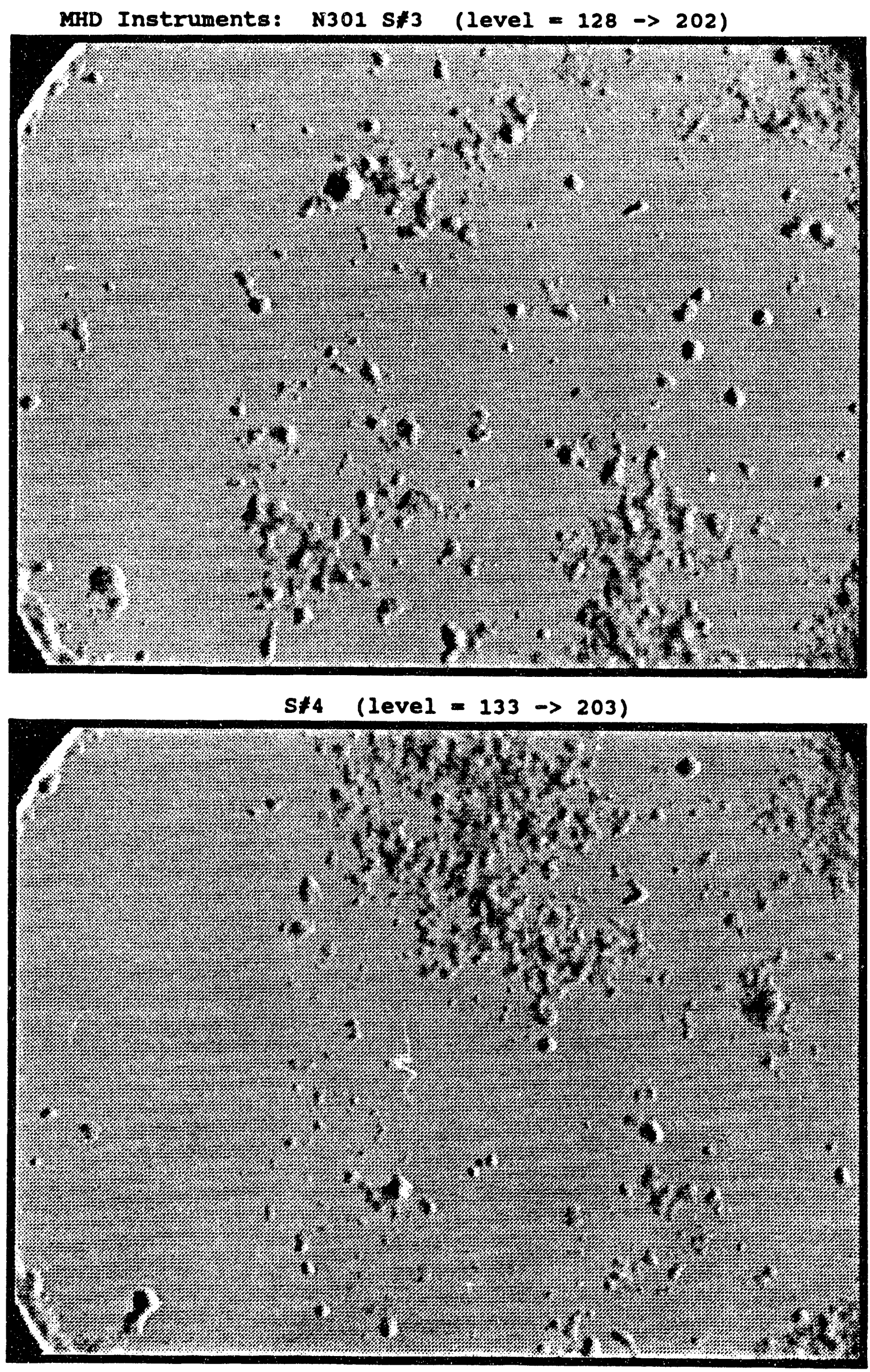

Bubble Photos S\#3 \& S\#4, N301 Sequence - Vertical Filter

Figure 8.21 

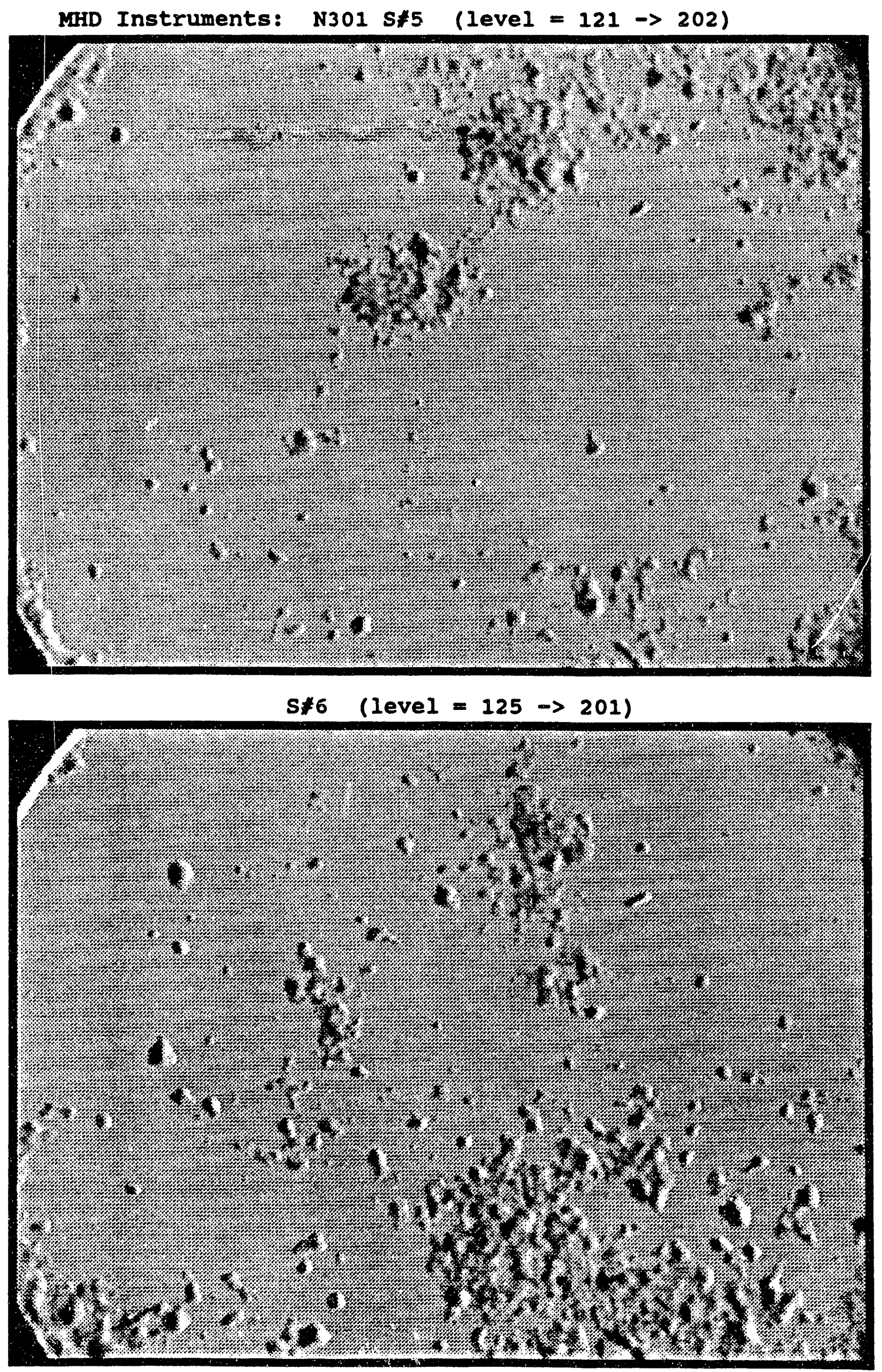

Bubble Photos S\#5 \& S\#6, N301 Sequence - Vertical Filter

Figure 8.22 



Bubble Photos S\#7 \& S\#8, N301 Sequence - Vertical Filter Figure 8.23 

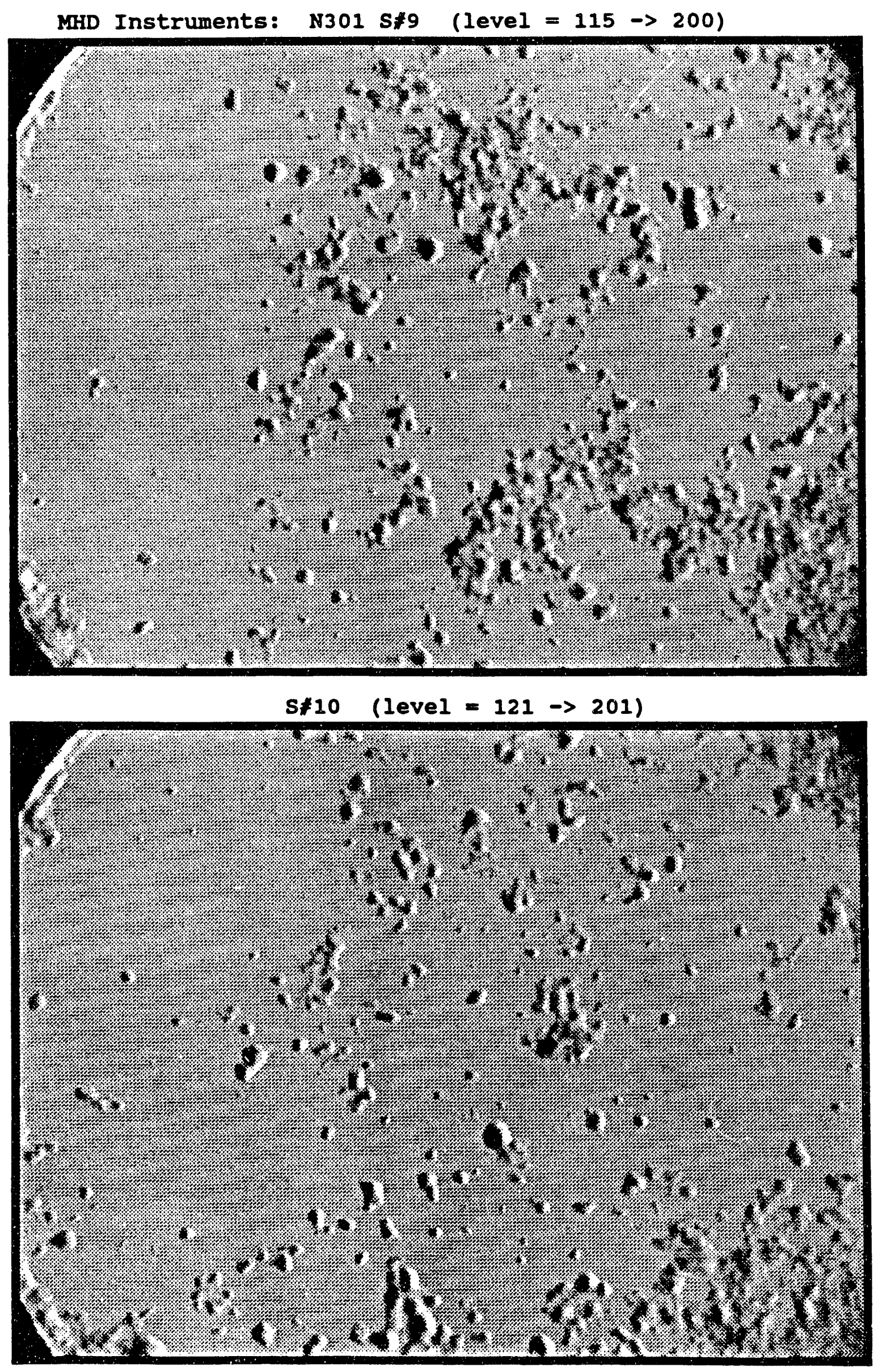

Bubble Photos S\#9 \& S\#10, N301 Sequence - Vertical Filter

Figure 8.24 
As a check on the origin of these bubbles (electrode generated versus recirculation), the video frame sequence N302 (Figures 8.25 - 8.29) was taken only 5 seconds after the electrode current was turned off. Note that the bubble activity is greatly reduced to less than 10 bubbles per frame. The conditions for these two sequences (with and without current) are summarized in Table 8.6. The tape time is indicated at the start of each sequence so that the test conditions may be determined by referral to Table 7.3. A further indicator of bubble density is given by the background intensity level; heavy bubble activity results in a reduction of the background illumination (ideally white). This indicator is also shown in Table 8.6 as a percentage (100\% corresponding to white). Note that without current, the average intensity level is $\mathbf{7 2}$ percent (before enhancement). With current, the background level dropped to only 48 percent. ${ }^{[1]]}$

\begin{tabular}{|c|c|c|c|c|c|}
\hline \multicolumn{6}{|c|}{$\begin{array}{l}\text { Date: 6/26/92 Clock Sync: tape start time 00:00:09=15:09:00 clock time } \\
\text { Instant Ocean }{ }^{\text {TM }}: \text { Pressure }=5 \text { psig / Magnetic Field }=0 \text { Tesla } / \text { Conductivity }=5.2 \mathrm{~S} / \mathrm{m}\end{array}$} \\
\hline $\begin{array}{c}\text { Image } \\
\text { Sequence } \\
\text { (file *) }\end{array}$ & $\begin{array}{l}\text { Tape Time } \\
\text { (hr:min:sec) }\end{array}$ & $\begin{array}{c}\text { Distance } \\
\text { From Wall } \\
\text { (cm) }\end{array}$ & $\begin{array}{c}\text { Electrode } \\
\text { Current } \\
\text { (amperes) }\end{array}$ & $\begin{array}{c}\text { Average } \\
\text { Intensity Level } \\
(\%)\end{array}$ & Comments \\
\hline N301 & $00: 12: 55$ & 0.19 & 54 & 48 & $\begin{array}{l}20 \text { to } 100 \text { bubbles per } \\
\text { frame; } 40-260 \text { microns }\end{array}$ \\
\hline $\mathrm{N} 302$ & $00: 13: 18$ & 0.19 & 0 & 72 & $\begin{array}{l}<10 \text { bubbles per } \\
\text { frame; } 60-130 \text { microns }\end{array}$ \\
\hline
\end{tabular}

\section{Table 8.6: Conditions for Bubble Image Sequences}

At this point in the data analysis, the black (in focus) bubble shadows are counted and classified according to size. These bubble diameters are then averaged to find their volume and diameter and normalized to an average number per frame. Since the focal volume is known, the bubble number density can be determined quantitatively. Finally this process is repeated for each location in the flow field until the bubble activity drops off to zero. ${ }^{[1]}$ 



Bubble Photos S\#1 \& S\#2, N302 Sequence - Vertical Filter

Figure 8.25 

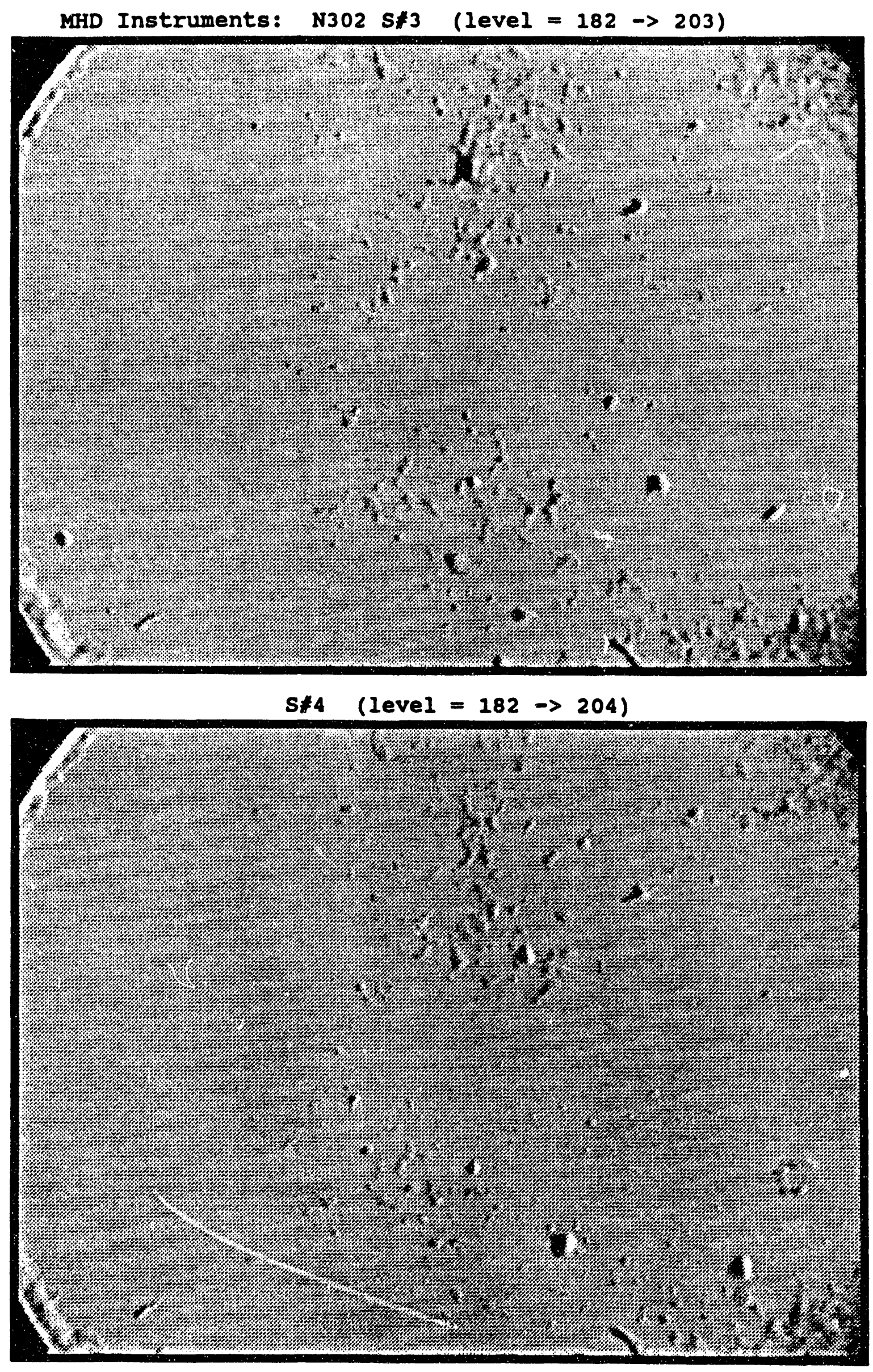

Bubble Photos S\#3 \& S\#4, N302 Sequence - Vertical Filter

Figure 8.26 


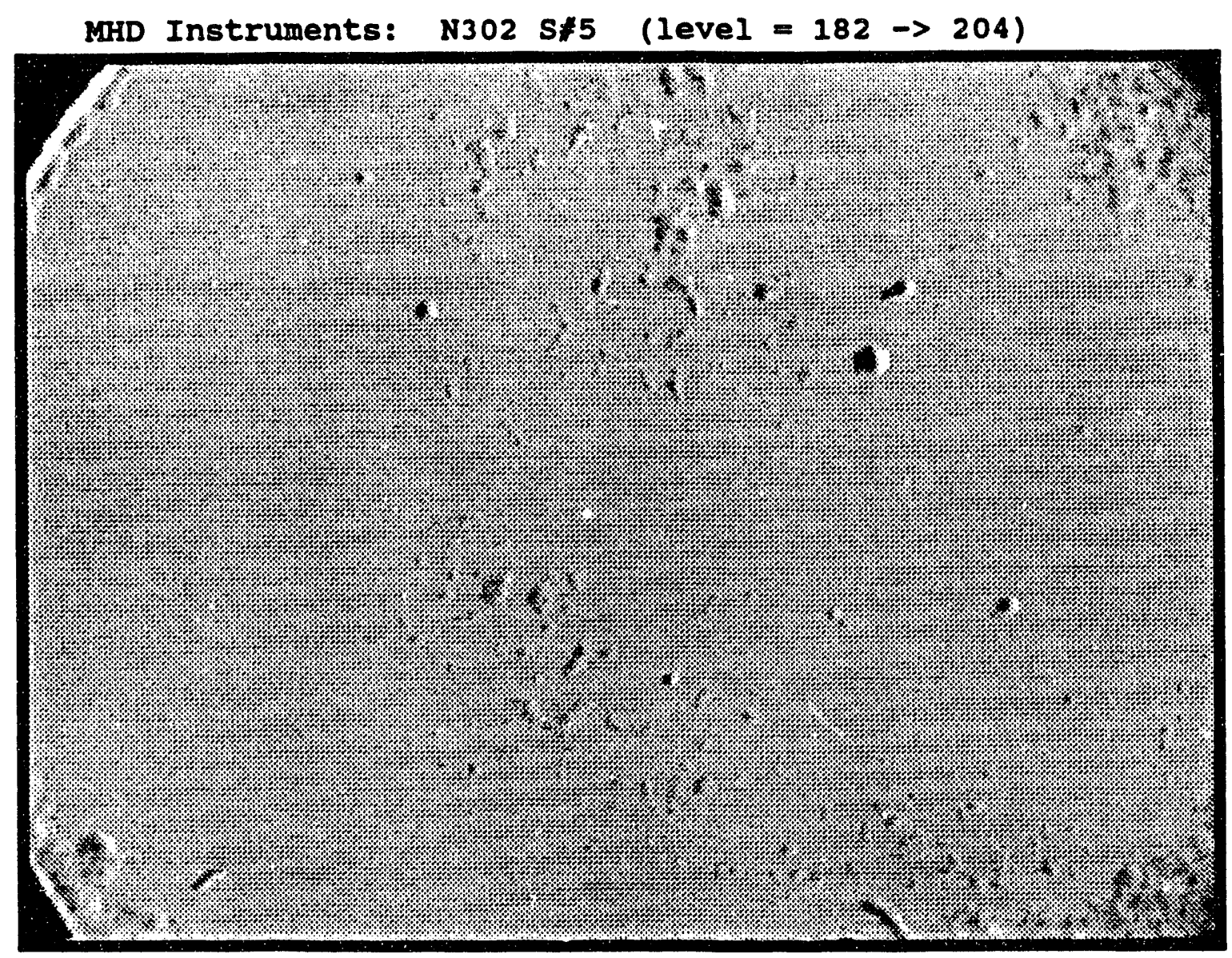

\section{S\$6 (level = $182 \rightarrow 204$ )}

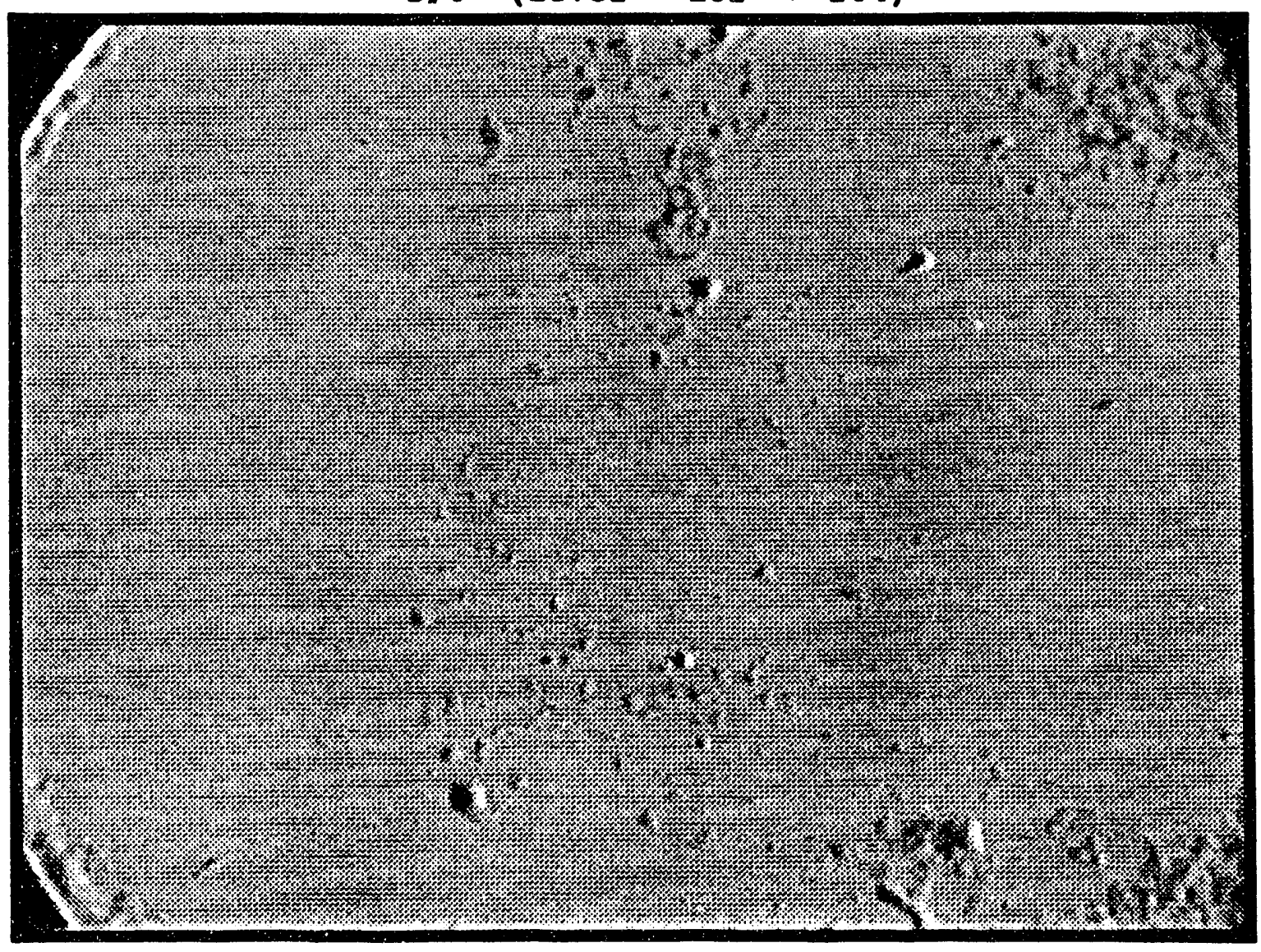

Bubble Photos S\#5 \& S\#6, N302 Sequence - Vertical Filter

Figure 8.27 

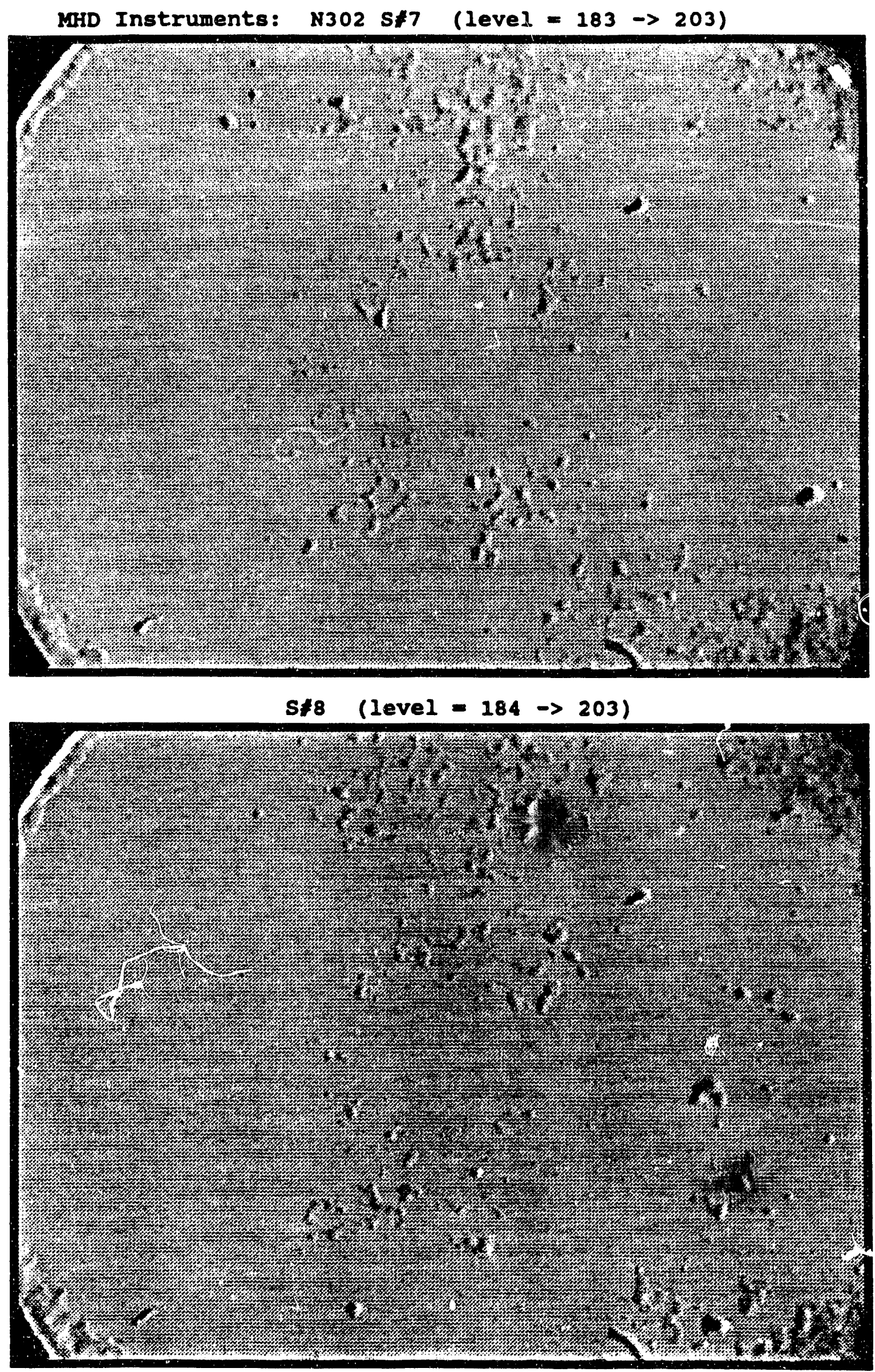

Bubble Photos S\#7 \& S\#8, N302 Sequence - Vertical Filter Figure 8.28 


\section{MHD Instruments: N302 S\$9 (level = 183 $\rightarrow$ 204)}
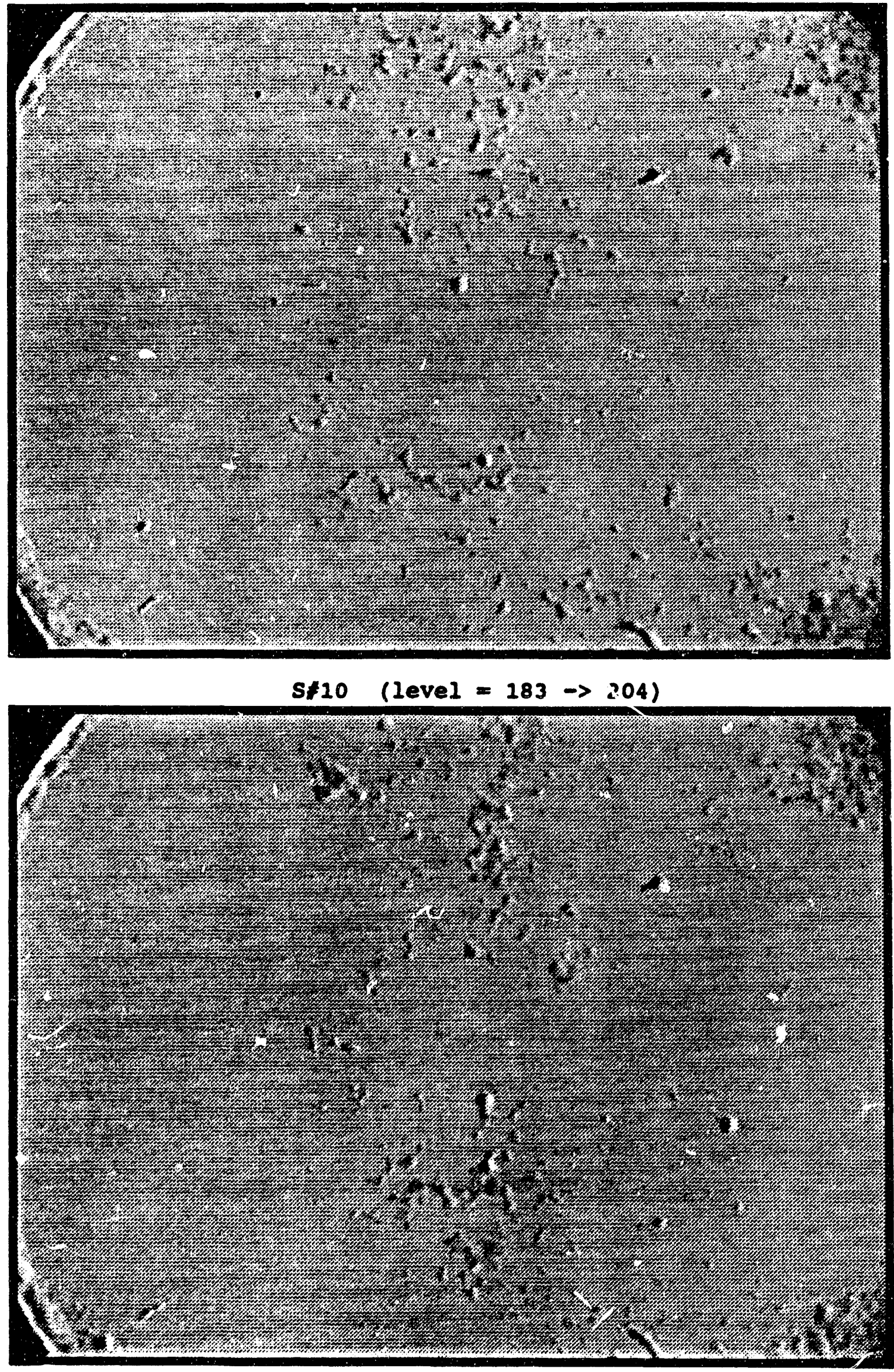

Bubble Photos S\#9 \& S\#10, N302 Senuence - Vertical Filter Figure 8.29 
Bubble sizes in static electrolysis experiments have indicated sizes in the 50 to 100 micron range for similar values of current density. ${ }^{[33,40]}$ The larger (by several factors) bubbles observed for Instant Ocean ${ }^{\mathrm{TM}}$ in the present tests were surprising since the dynamic forces were expected to reduce bubble size. The converse result of very small micro-bubbles for the $\mathrm{NaCl}$ solutions is more amenable to rationalization by shear stress effects and diffusion of hydrogen gas. While the two test solutions have about the same chlorine content (at equal conductivity), Instant $\mathrm{Ocean}^{\mathrm{TM}}$ (like sea water) contains significant concentrations of magnesium and calcium in addition to sodium. Presumably, these additional ions have modified the electro-chemistry in the boundary layer in a manner which dominates bubble size. At present, the influence of electrode surface parameters versus boundary layer effects on bubble size are not well understood.

Since the resonant frequency of bubble noise scales with the inverse of size, the large hubbles observed for the Instant Ocean ${ }^{\mathrm{TM}}$ test may play a significant role in the acoustic signature of MHD propulsion devices. Presumably, operation with sea we ser will be similar to Instant Ocean $^{\mathrm{TM}}$ since the inorganic chemical constituents are matched.

The behavior of bubbles generated under the unique operating conditions of ar. MHD propulsion test loop has been elucidated by direct measurements based on imaging diagnostics. Surprising results, with important consequences for the submarine application, have been observed over a range of electrode currents. ${ }^{[1]}$ 


\subsection{Loop Chemistry}

\subsection{1pH}

The system $\mathrm{pH}$ was measured before and after test runs and only varied slightly. Typically at the beginning of a test series the $\mathrm{pH}$ was $\mathbf{7 . 8}$ and at the end of the test it only reached 8.4. This small change is believed to be the result of the fact that the fluid velocity in the test section allowed most of the electrolyzed hydrogen bubbles to be driven into solution and recombine to neutralize the hydroxide.

\subsubsection{Conductivity}

The principal effect governing the change in conductivity of the working fluid was the change in temperature of the working fluid.

\subsection{Working Fluid Tempenature}

The rate at which the working fluid temperature rose was significantly less than modeled in section 6.3. During the course of the experiment the working fluid rose, on average, 8 ${ }^{\circ} \mathrm{C} /$ hour.

\subsection{Test Duration}

The phenomena which limited test duration was the amount of electrolytically generated hydrogen bubbles. At low fluid velocity and high current, a large volume of bubbles evolved 
off of the cathode, and saturated the working fluid. This effect occurred after about 14 ampere-hours of operation and was especially pronounced in our test facility because of the small fluid volume (375 Gallons). During these conditions, the loop was operated to saturation, and the current shut off. The working fluid was circulated until all of the evolved hydrogen was removed from the test setup with the bubble separator. 


\subsection{Summan and Conchusions}

The following are the major accomplishments and main conclusions achieved during phase II of the program.

1. A one-of-a-kind magnetohydrodynamic test facility had been designed, fabricated, tested, and operated to provide unique data on MHD seawater propulsion. The thruster, a rectangular duct with electrodes to pass the electrical current, was fabricated from optically clear polycarbonate resin, for visual observation and characterization of the generated bubbles.

2. A pre test analysis was performed to support the design of the loop and provide guidance in establishing a test matrix, using the MHD system code established in Phase I. This code was used to design loop components, define optimum operating conditions, assist in the selection of instrumentation for the individual components, and predict the overall characteristics of the loop.

3. The thruster was modeled with a one-dimensional hydrodynamic model coupled to a two-dimensional electrical model. The thruster model includes the major loss mechanisms that affect the performance of MHD thrusters. Among these losses are the joule dissipation losses, frictional losses, electrical end losses, and single electrode potential (SEP) losses. 
4. Tests were performed, with salt water and Instant $\operatorname{Ocean}^{\mathrm{TM}}$ (a fluid chemically similar to seawater), to investigate the effects of magnetic field orientation, flow velocity, current, voltage, electrical conductivity, and bubble generation on thruster performance.

5. Good agreement was found between the measured and predicted parameters. This has served to validate the developed NNS/ANL thruster computer models. Furthermore, the results indicate that the phenomena affecting the performance of marine MHD thrusters are well understood and can be adequately predicted with the developed computer models.

6. For current densities relevant to seawater thruster applications single electrode potentials (surface potential losses) are essentially independent of the current density.

7. MHD thruster performance is independent of magnetic field orientation relative to gravity.

8. The generation of hydrogen bubbles at the cathode has a negligible effect on current transport across the working fluid and does not appear to have an impact on performance for current densities relevant to full size thrusters.

9. A bubble diagnostics system for measuring bubble behavior directly by imaging techniques was successfully applied at the exit of the ANLNNS test channel. The effectiveness of using shadow photography for size measurements and of using streak photography for bubble velocity measurement were both demonstrated. 
10. Bubble formation at the cathode (and presumably related noise) is dependent on both current density and fluid velocity.

11. The bubble size results revealed an order of magnitude difference in diameter depending on the type of salt water used. Evidence for substantial gas evolution by the cathode was observed for both salt water and instant ocean. In the case of $\mathrm{NaCl}$ solutions, a dense "cloud" of micro-bubbles was inferred by their large reduction in background intensity. Since these bubbles were not imaged, but scattered light, their size must be in the 1 to 20 micron range. The use of Instant Ocean $^{\mathrm{TM}}$ test fluid resulted in the generation of much larger bubbles (up to nearly 300 microns in diameter). At the channel exit, these bubbles were localized within millimeters of the cathode wall. 
132 


\subsection{Recommendations}

The raeasurement of large bubbles for the test with Instant Ocean ${ }^{\mathrm{TM}}$ indicate that basic and specialized testing is required to predict bubble behavior for full-scale MHD thrusters. The mechanisms of bubble generation and of bubble development downstream need investigation. ${ }^{[11]}$

A series of small-scale tests are needed to confirm the impact of $\mathrm{NaCl}$ solutions versus Instant Ocean ${ }^{\mathrm{TM}}$ on bubble behavior. Tests with both of the above fluids plus samples of ocean water should be carried out. Careful attention to saturation limits must be observed for any test work (bench scale or flow loop). Any measurements of bubble behavior and bubble induced noise should be confirmed by tests in open sea-water with a prototypic test vehicle. ${ }^{[1]}$

Therefore, it is recommended that a follow-on program be considered. ${ }^{[41]}$ The objectives of this program are to evaluate hydroacoustic and other relevant performance characteristics of MHD seawater propulsion relative to conventional systems and to demonstrate scale-up of performance to larger vehicles.

To reduce cost and assure program success, it is proposed that an existing vehicle be modified to accommodate a seawater MHD thruster. Based on a survey of vehicles the DARPA/Charles Stark Draper Laboratory (Draper) Unmanned Undersea Vehicle (UUV) is considered a suitable test platform because:

- Support hardware/software for vehicle launch/recovery exists.

- Data acquisition, tracking, and related support systems required for at sea testing have been demonstrated. 
- A fully operational vehicle/mission package simulation facility, which can support redesign, exists.

- This vehicle currently has no mission.

- This vehicle permits testing in the submarine performance envelope.

Elements of an at-sea demonstration program would include:

\subsection{Definition of at-sea demonstration/design requirements}

- Performance Objectives - speed, duration, transient behavior, maneuverability and control (including thrust reversal) for surface and submerged conditions.

- Component/System Design Requirements - battery power supplemented with tethered power will be considered. Fully autonomous operation could be conducted for realism with low speed and low endurance, while the addition of tethered power as an addition or substitute for batteries could enable demonstration of higher speed and endurance. Vehicle maneuverability and control will also influence design requirements.

- UUV Modifications - addition of hull modules, propeller removal, rearrangement for battery and/or electronics section, and other modifications to accommodate MHD thruster and auxiliary systems will be specified.

- Hydroacoustic Performance - test plan for implementation at Navy test range (e.g. MONOB) will be prepared. Existing acoustic data base for the UUV will be used for comparative analysis.

- Cost/schedule estimates - estimates of cost and schedule for major program elements.

\subsection{Supporting R\&D/Technologv Development}

- Magnet - several configurations will be evaluated for propulsive performance, magnetic signature, producibility, ease of integration, and salability to full size submarines. 
- Electrodes - material selection and segmentation based on ANL/NNS test results and other available data.

- Cryogenic systems - selection based on ability to miniaturize for integration into the UUV, and potential to meet Navy requirements for shock, vibration, and noise level.

- Data base for drsign scale-up - data generated at various MHD test loops will be used as a casis for selection of thruster configuration and auxiliary equipment that can be scaled to full size submarines with a high confidence level. Additional data will be generated an these loops as required to validate the design.

\subsection{Detail Design/Assembly/Test}

- Detail design - perform detail design of UUV modifications, thruster and auxiliary systems.

- Simulation - using the existing UUV simulation facility, the effects of installing an MHD propulsion system on the vehicle will be simulated to validate the design.

- Component fabrication/procurement - preparation of qualified supplier list and identification of long-lead items for fabrication or purchase.

- Component/system verification testing - laboratory testing of components will be considered as an option, to reduce risk and/or cost of at-sea demonstration.

- Installation on UUV - install thruster, cryogenic systems, and auxiliary equipment on UUV in accordance with prepared procedures.

- Test in Navy underwater range - implement test plan including launch/recovery, hydroacoustic and other performance data acquisition, and data analysis.

- Producibility assessment - evaluate salability of construction/testing costs to full size submarines. 


\subsection{References}

1. Phillips, O.M., "The Prospects for Magnetohydrodynamic Ship Propulsion" J. Ship Research, Vol. 43, March 1962, pp 43-51.

2. Doragh, R.A., "Magnetohydrodynamic Ship Propulsion Using Superconducting Magnets", Proc. Naval Arch. and Marine Engineers Transaction, Vol. 71, 1963.

3. Way, S., and Devlin C., "Prospects for the Electromagnetic Submarine", Proceedings of the AIAA $3^{\text {rd }}$ Propulsion Joint Specialist Conference, July 17-21, 1967.

4. Way, S., "Electromagnetic Propulsion for Cargo Submarines", Journal of Hydraulics, Vol. 2, No. 2, April 1968, pp 49-57.

5. Saji, Y., Kitano, M., and Iwata, A., "Basic Study of Superconducting Electromagnetic Thrust Device for Propulsion in Seawater", Advances in Cryogenic Engineering (Timmerhaus, K.D. editor), Vol. 23, 1978, pp. 159-169.

6. Hummert, G.T., "An Evaluation of Direct Current Electromagnetic Propulsion In Seawater", Report ONR-CR168-007-1, Westinghouse Research Laboratories, Pittsburgh, Pennsylvania, July 1979.

7. Doss, E.D., and Geyer, H.K., "The Need for Superconducting Magnets for MHD Seawater Propulsion", Proceedings of the $25^{\text {th }}$ Intersociety Energy Conversion Engineering Conference (IECEC), August 1990, Vol. 5 pp. 540-545.

8. Dutton, J.L., and Forbes, D.A., "Shipboard Applications of Superconductivity", Newport News Shipbuilding Independent Research and Development Report, December 1991.

9. Wolsky, A.M., Giese, R.F., and Daniels, E., "The New Superconductors: Prospects for Applications", Scientific American, Vol. 260, No. 2, February 1989, pp. 61-69.

10. Ranellone, R.F., "Ship Integration and Construction Considerations", Proceedings of the International Symposium on Superconducting Magnetohydrodynamic Ship Propulsion, Kobe, Japan, pp. 261-268, October 1991.

11. Koester, J.K., "Diagnostics of Gas Bubbles Generated During the ANLNewport News Experiments on Marine MHD Thrusters", MHD Instruments Company, Palo Alto, Ca., July 12, 1992. 
12. Tempelmeyer, K.E., "Electrolysis Bubble Noise In Small Scale Tests of a Seawater MHD Thruster", David Taylor Research Center, Report No. DTRC-90/30, Bethesda, Maryland, September 1990.

13. Tempelmeyer, K.E., Norfolk, J., Nesbitt, S., and Gordon, J., "Noise In Small MHDType Seawater Thruster In Real and Simulated Ocean Waters", IEEE Meeting, Hawaii, October 1991.

14. Swallom, D.W., Sadovnik, I., Gibbs, J.S., Gurol, H., Nguyen, L.V., and Bergh, H.V., "Magnetohydrodynamic Propulsion Systems", Naval Engineers Journal, Vol. 103, No. 3, May 1991. pp 141-157.

15. Doss, E.D. and Geyer, H.K., "Effects of Friction and End Losses on MHD Thruster Efficiency", Proceedings of the $28^{\text {th }}$ Engineering Aspects of Magnetohydrodynamics, Chicago, Illinois, June 1990, pp.III 2.1-III 2.8.

16. Doss, E.D. and Roy, G.D., "Flow Characteristics Inside MHD Seawater Thrusters", Journal of Propulsion and Power, Vol. 7, No. 4, July-August 1991, pp 635-641.

17. Doss, E.D. and Geyer, H.K., "An Overview of MHD Seawater Thruster Performance and Loss Mechanisms", Proceedings of the $27^{\text {th }}$ Intersociety Energy Conversion Engineering Conference (IECEC), Vol. 3, pp. 299-304, San Diego, California, August 1992.

18. Petrick, M., Thomas, A., Genes, L, Libera, J., Nietert, R., Boullard, J., Pierson, E., Hill, D., Picologlou, B., Ohlsson, O., Kasprzyk, T., and Berry, G., "Magnetohydrodynamic Sea Water Propulsion", Proceedings of the International Symposium On Superconducting Magnetohydrodynamic Ship Propulsion, Kobe, Japan, October 1991.

19. Meng, J.C., Hrubes, J.D., Hendricks, P.J., Thivierge, D.P., and Henoch, C.W., "Experimental Studies of a Superconducting Electromagnetic Thruster For Seawater Propulsion", Proceedings of the International Symposium On Superconducting Magnetohydrodynamic Ship Propulsion, Kobe, Japan, October 1991.

20. Picologlou, B.P., Doss, E.D., Black, D.B. and Sikes, W.C., "Experimental Determination of Magnetohydrodynamic Seawater Thruster Performance in a Two Tesla Test Facility", Proceedings of the $27^{\text {th }}$ Intersociety Energy Conversion Engineering Conference (IECEC), Vol. 3, pp. 305-310, San Diego, California, August, 1992.

21. Motora, S., Inaichi, K., Nakato, M., and Takezawa, S., "An Outline of the R\&D Project On Superconducting MHD Ship Propulsion In Japan", Proceedings of the International Symposium On Superconducting Magnetohydrodynamic Ship Propulsion, Kobe, Japan, October 1991. 
22. Reid, T.R., "Japan Tests Propulsion System Reminiscent of 'Red October", Washington Post Article, June 17, 1992.

23. Reid, T.R., "The Historic Cruise of Prop-Less Yamato I", Washington Post Article, June 23, 1992.

24. Huang, T., "Japanese Ship Sails in Silence", Virginia Pilot Article, July 7, 1992.

25. Doss, E.D., and Herman, H., "Feasibility of MHD Ship Propulsion Using HT Superconducting Magnets", Proposal No. P89021 to Newport News Shipbuilding and Dry Dock Company, December 1988.

26. Proceedings of the Second ONR Workshop On Magnetohydrodynamic Submarine Propulsion, San Diego, California, November 16-17, 1989, Report No. NOSC TD 1869, Naval Ocean Systems Center, San Diego, California, July 1990.

27. Geyer, H.K, and Doss, E.D., "Computer Models' Description and Applications for MHD Seawater Ship Propulsion",Report for Newport News Shipbuilding, June 1990.

28. Jackson, H.A., "Submarine Parametrics", The Royal Institute of Naval Architects, International Symposium on Naval Submarines, Vol. I, No. 3, May 17-20, 1983, London England.

29. Lamma, E.E., "A Parametric Approach to Submarine Power Requirement Determination and Pressure Hull Design", Newport News Shipbuilding IR\&D Report, September 1984.

30. Brockett, T., "Lectures on Resistance and Propulsion of Submerged Vehicles", J.J. McMullen Associates, Inc., Presentation to Newport News Shipbuilding, June 1991, pp. D-9.

31. Tempelmeyer, Kenneth E., "Electrical Characteristics of a Seawater MHD Thruster", David Taylor Research Center Propulsion and Auxiliary Systems Department Research \& Development Report, DTRC-9r,017, p 2-4. (June 1990).

32. Burney,H.M. and Reed,C.B., "System Desion Description for the Data Acquisition System Used in ALEX", Argonne National Laboratory Document \# G0553-0061-SA, October 1986.

33. Koester, J.K, "Low Noise Electrode Systems for MHD Propulsion", Proceedings of the Second ONR Workshop on Magnetohydrodynamic Submarine Propulsion, Naval Ocean Systems Center, San Diego, Ca., November 1989. 
34. Doss, E.D., and Sikes, W.C., meeting with Nagy, Z., Materials Science Division and Chemical Technology Division, Argonne National Laboratory, September 18, 1991.

35. Gillespie, Ronald J., Humphreys, Ddvid A., Baird, N. Colin, Robinson, Edward A. "Chemistry", Allyn and Bacon Publishing Inc. p 590-596, 1986.

36. Sikes, W.C., phone communication with Nagy, Z., Materials Science Division and Chemical Technology Division, Argonne National Laboratory, October 1991.

37. Masterson, William L., Slowinski, Emil J., Stanitski, Conrad L., "Chemical Principals, 5th Edition Saunders Publishing. p 400-404, 1981.

38. Sikes, W.C., personal communication with J.K. Brandau, Laboratory Services, Department O-31, Newport News Shipbuilding, October 1991.

39. Beck, Theodore R., "Feasibility Study for Cleanup of MHD Test Loop Seawater, Electrochemical Technology Corporation, February 16, 1990.

40. Sides, P.J., "Phenomena and Effects of Electrolytic Gas Evolution", Modern Aspects of Electrochemistry, No. 18, edited by R.E. White, J.M. Bockris, and B.E. Conway, Plenum Press, New York, NY, pp. 303-354, 1986.

41. Porvell, M.L., "Newport News Shipbuilding/Argonne National Laboratory Proposed M.DD Demonstration Program", White Paper to DARPA, May 28, 1992. 


\subsection{Acknowledgement}

The editors would like to acknowledge the contributions to this work by: Argonne National Laboratory's Basil Picologlou, Howard Geyer, Dave Black and Pat Dombrowski; and Newport News Shipbuilding and Dry Dock Company's Rich Ranellone, Bill Joyce, Bob Wheeler, Joe LeClear, and Ralph Robinson; and MHD Instrument's Kent Koester.

This work has been supported by the U.S. Department of Energy, Office of Conservation and Renewable Energy as a part of a program to develop electric power technology, under Contract W-31-109-Eng-38 through Argonne National Laboratory's Pilot Center for Superconductivity and Newport News Shipbuilding and Dry Dock Company. The multidimensional computer models used in the analysis were developed through the support of the Office of Naval Research (ONR), under Contract No. N00014-89-F-0064. 
Appendix A: Argonne MHD Test Loop - Main Loop Arrangement, Details \& List of Material

A-1 


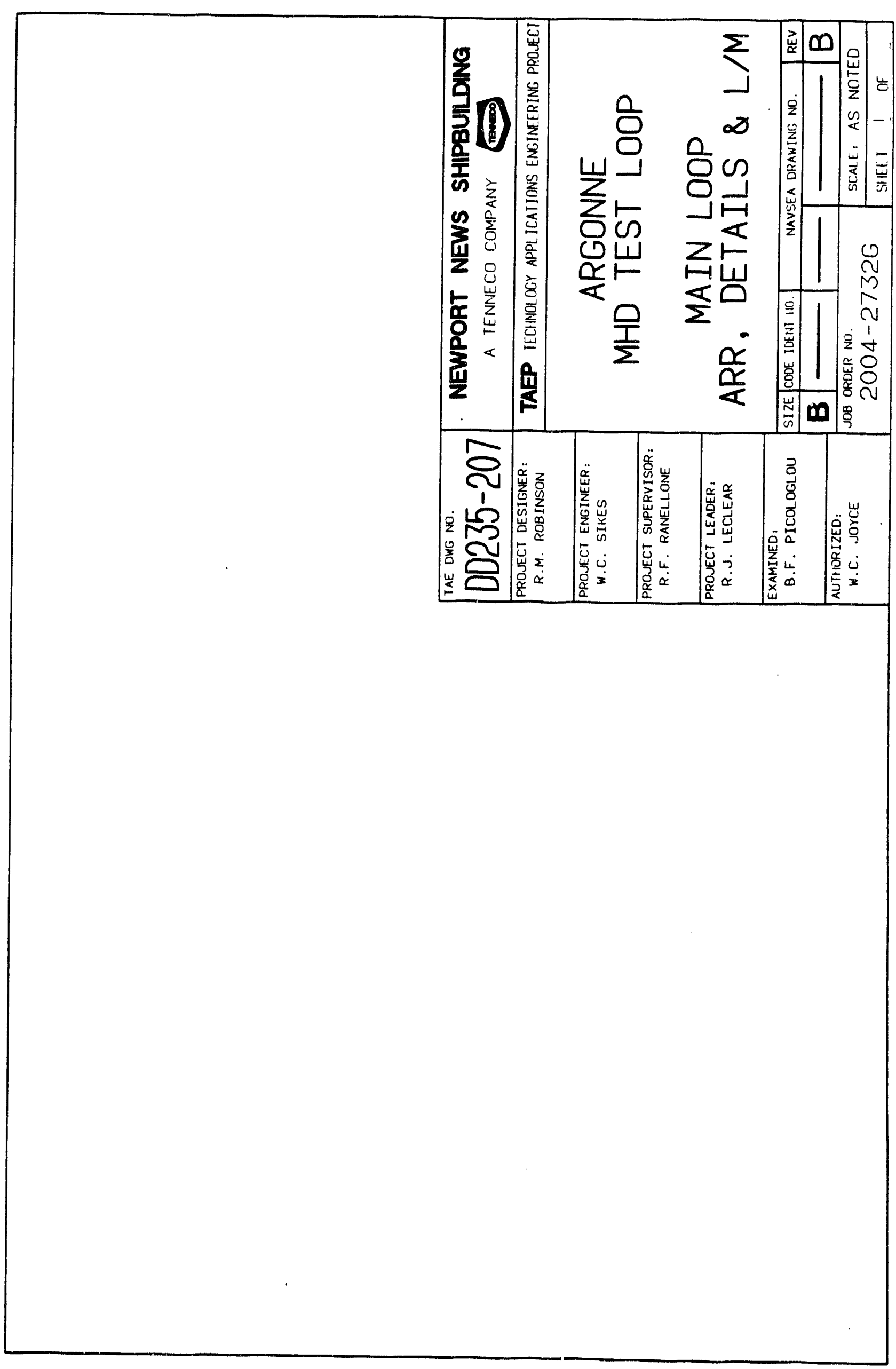




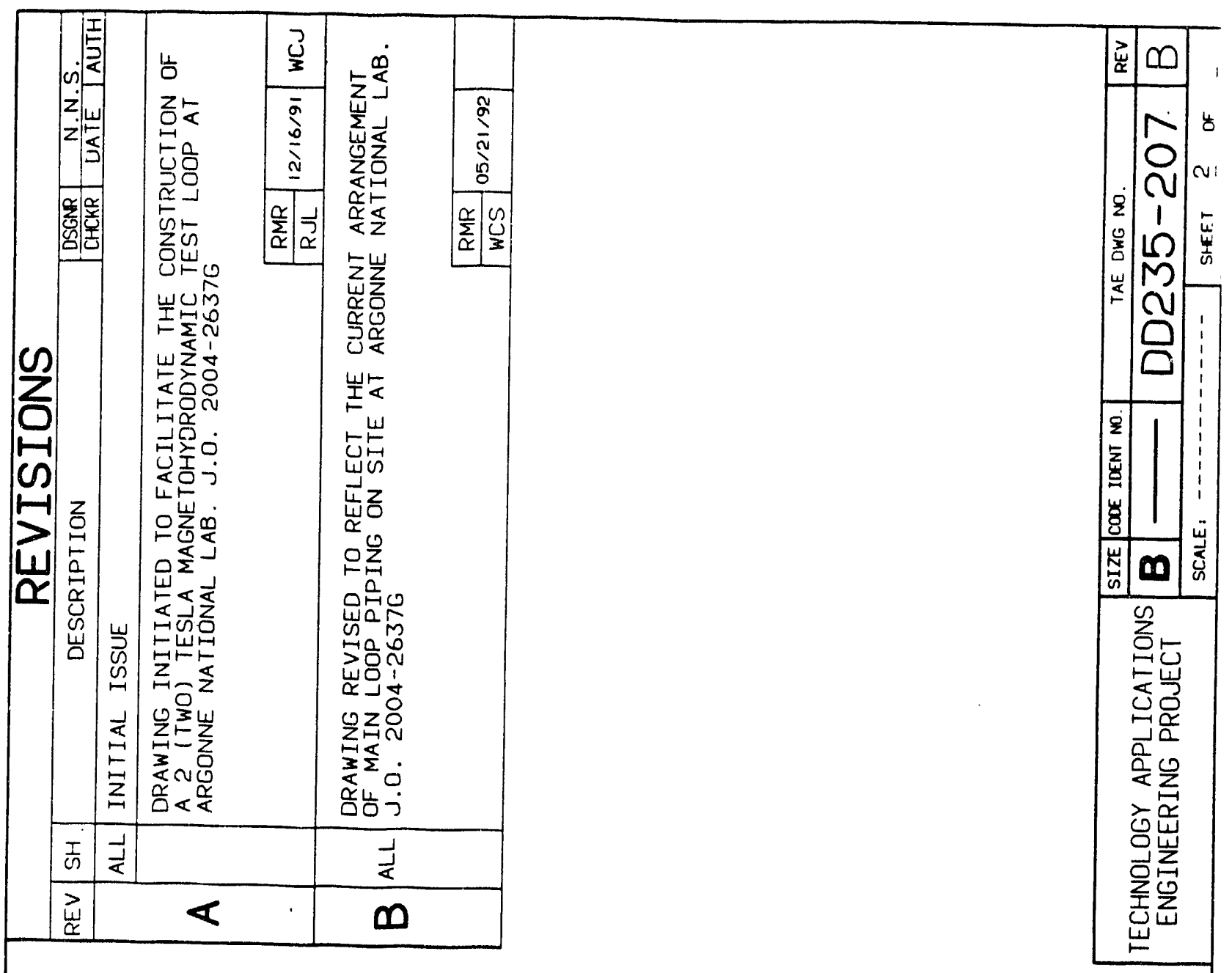




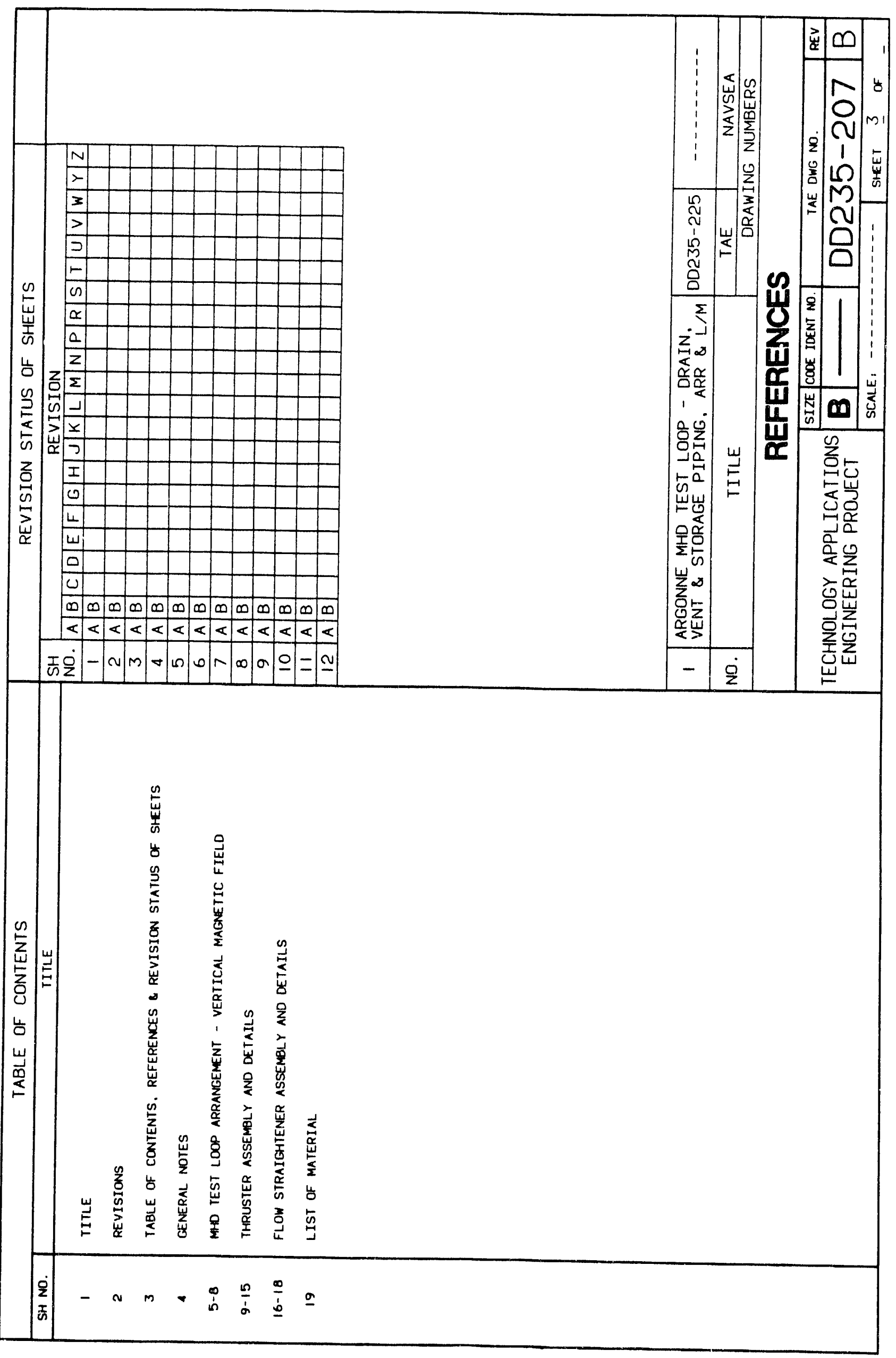




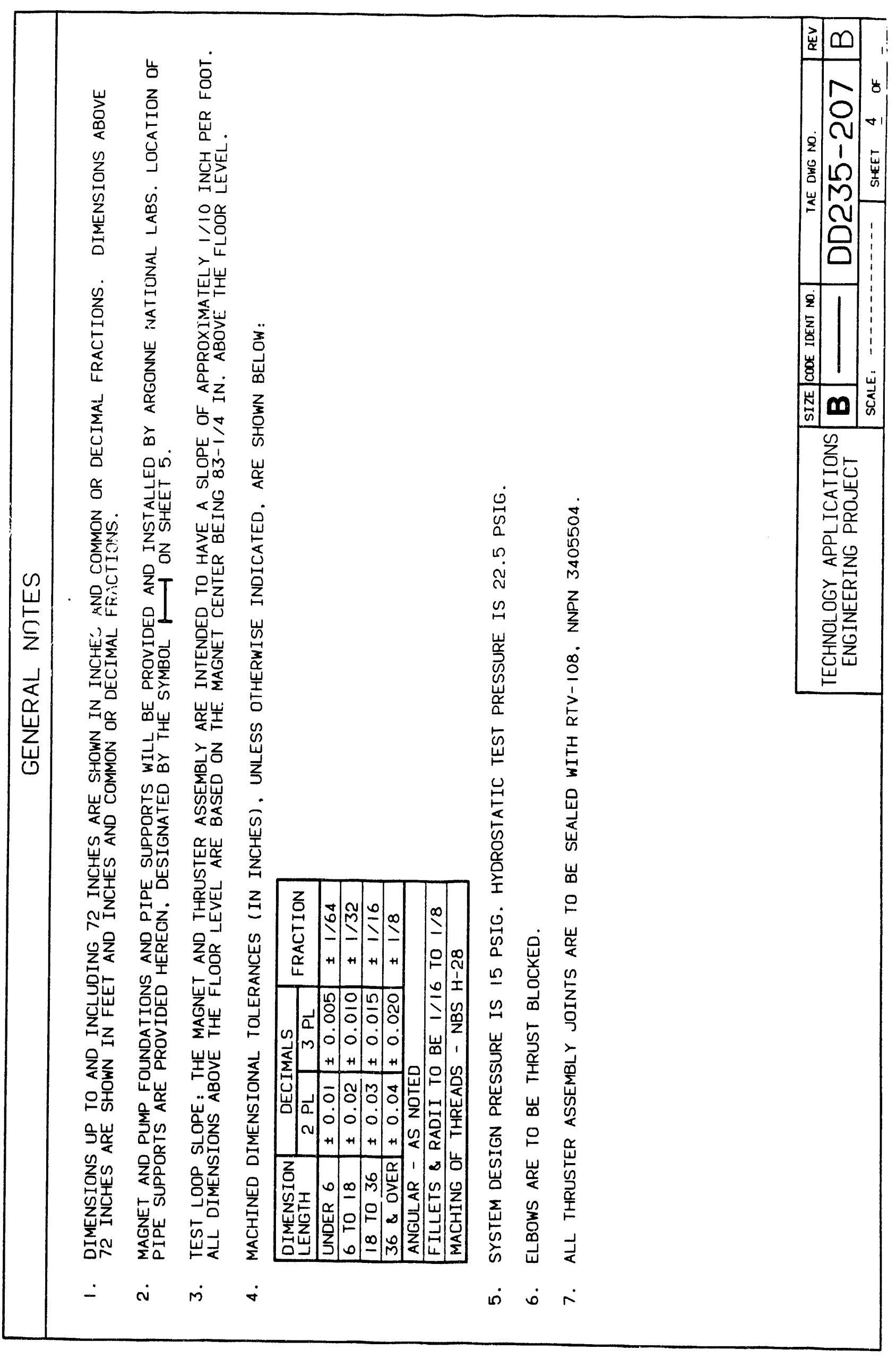




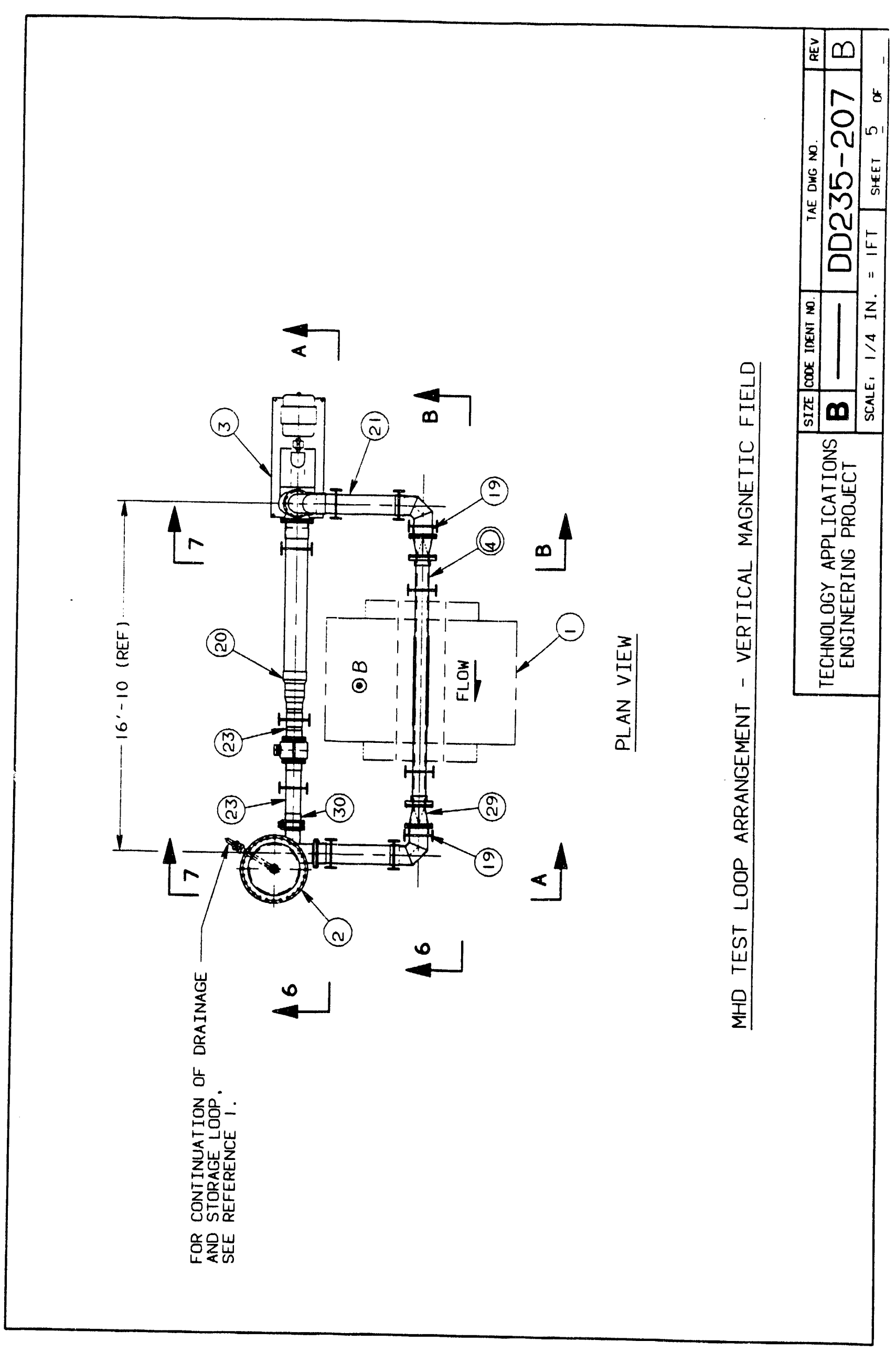




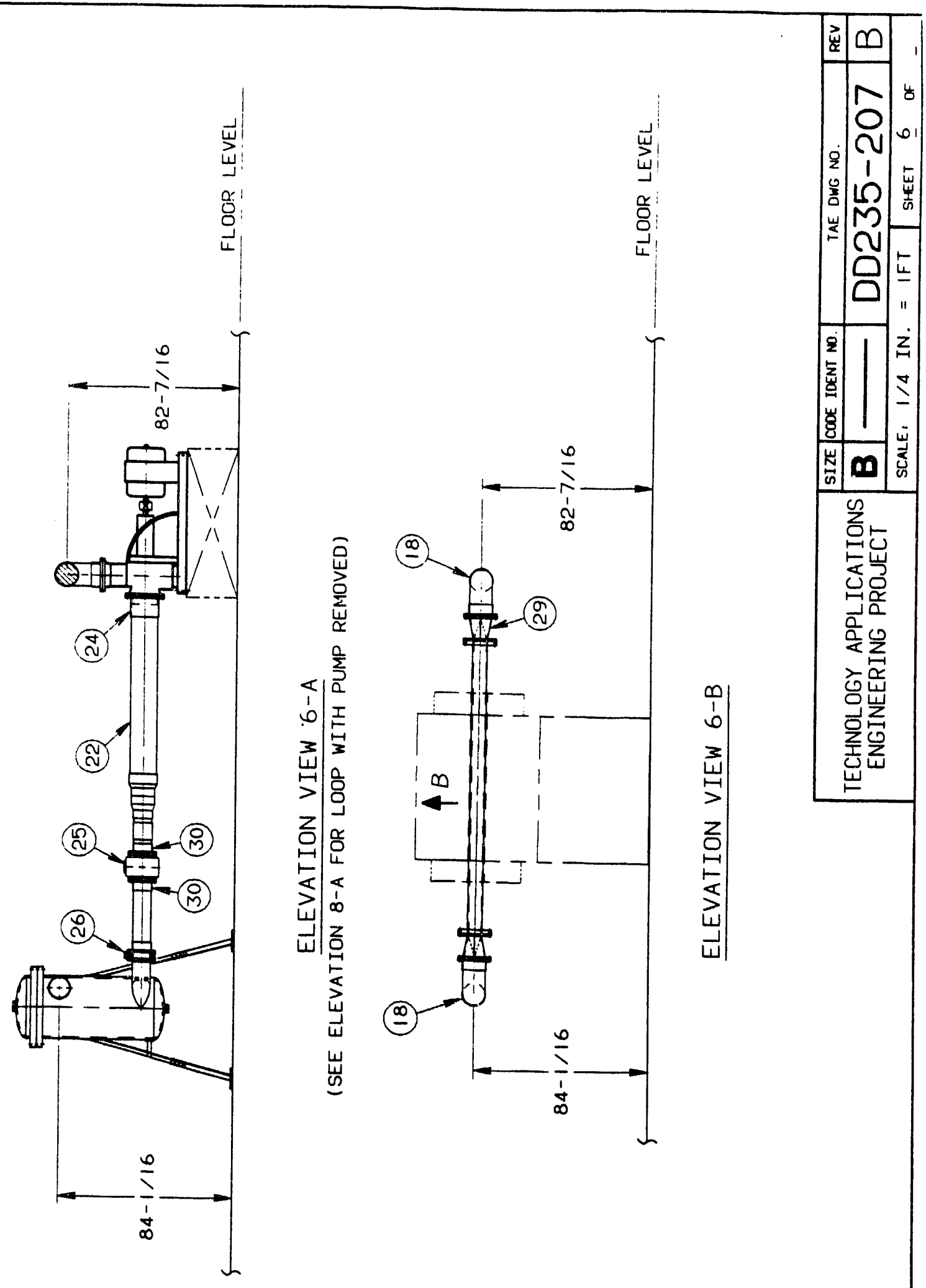




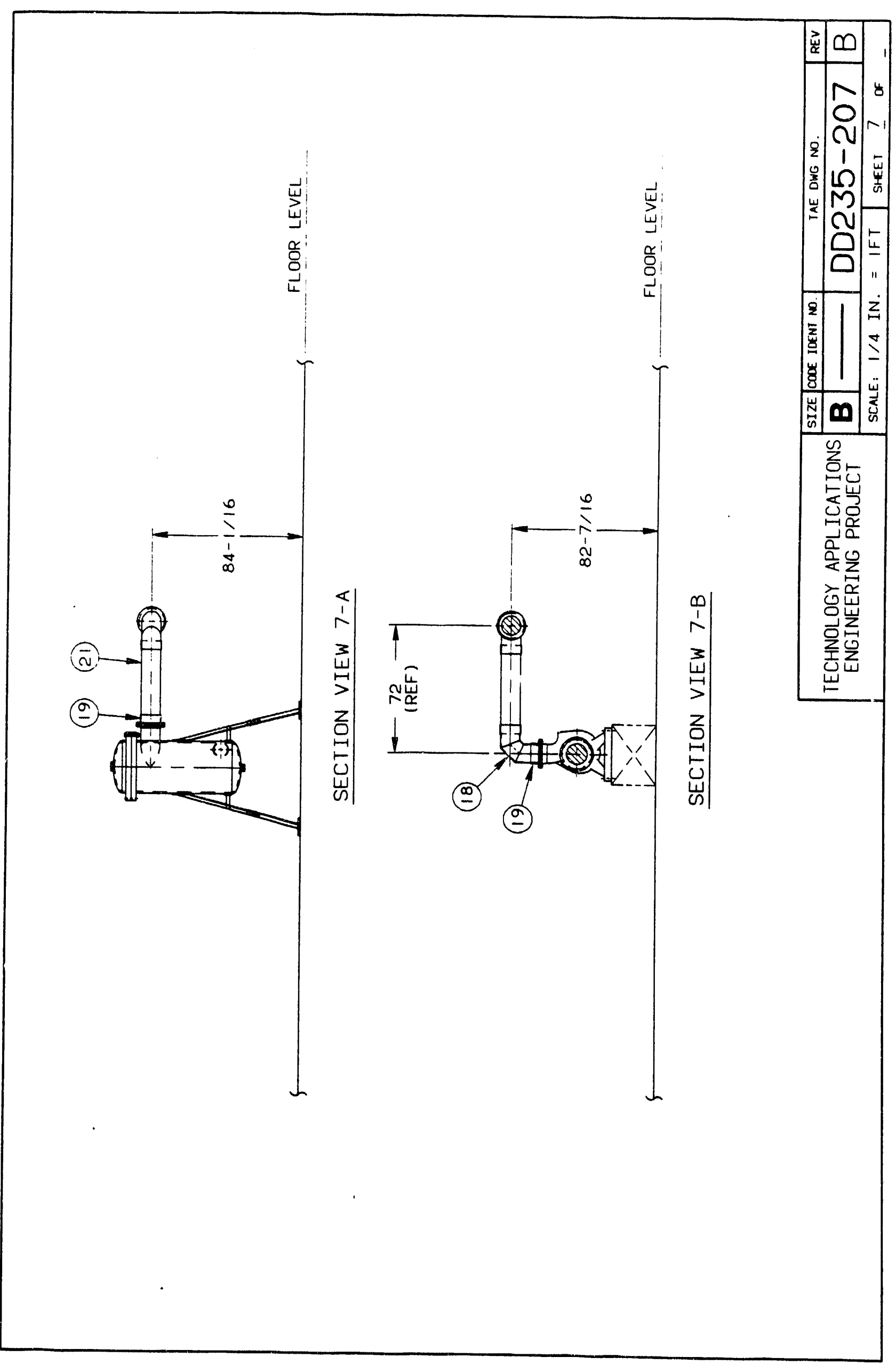




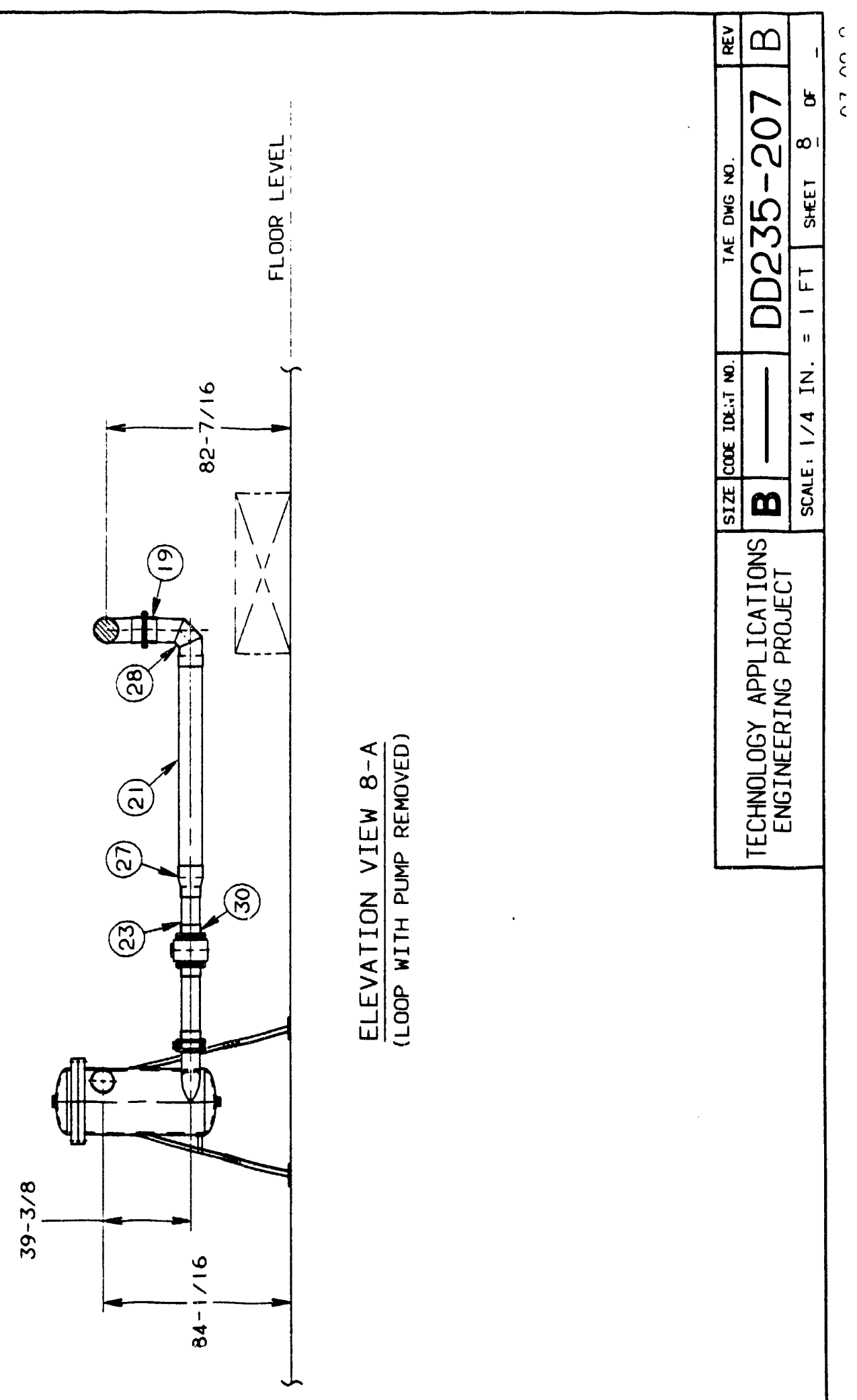




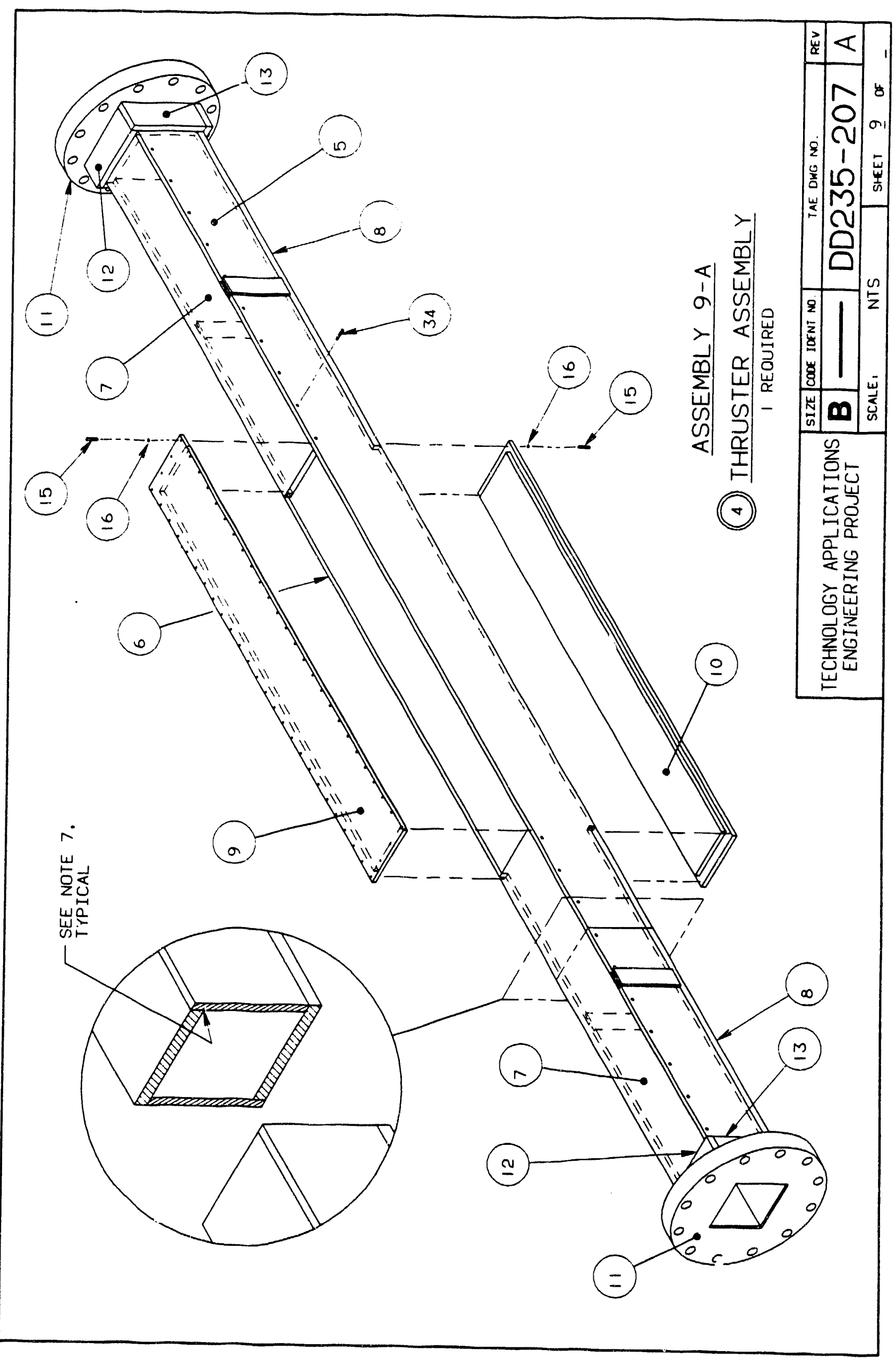




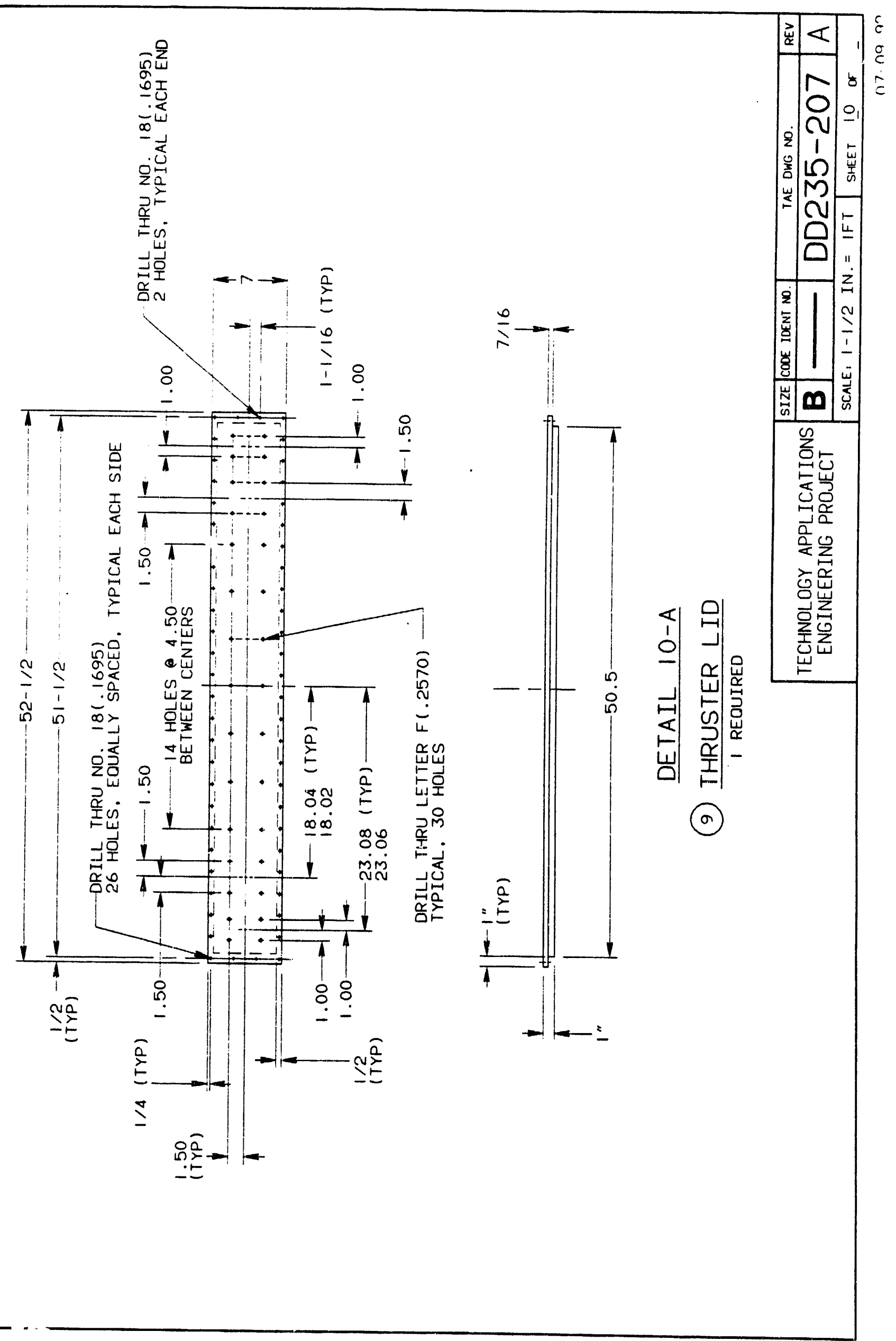




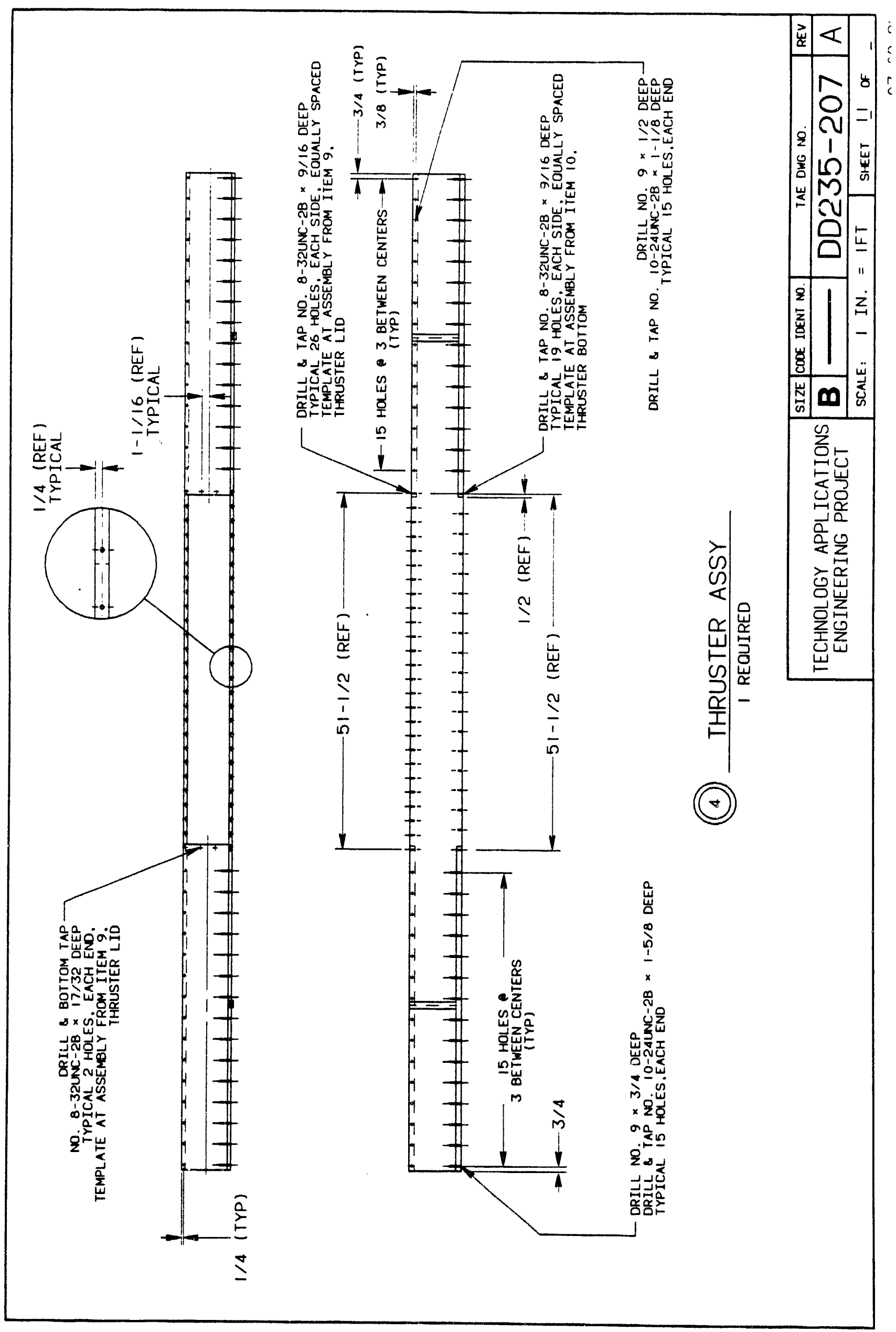




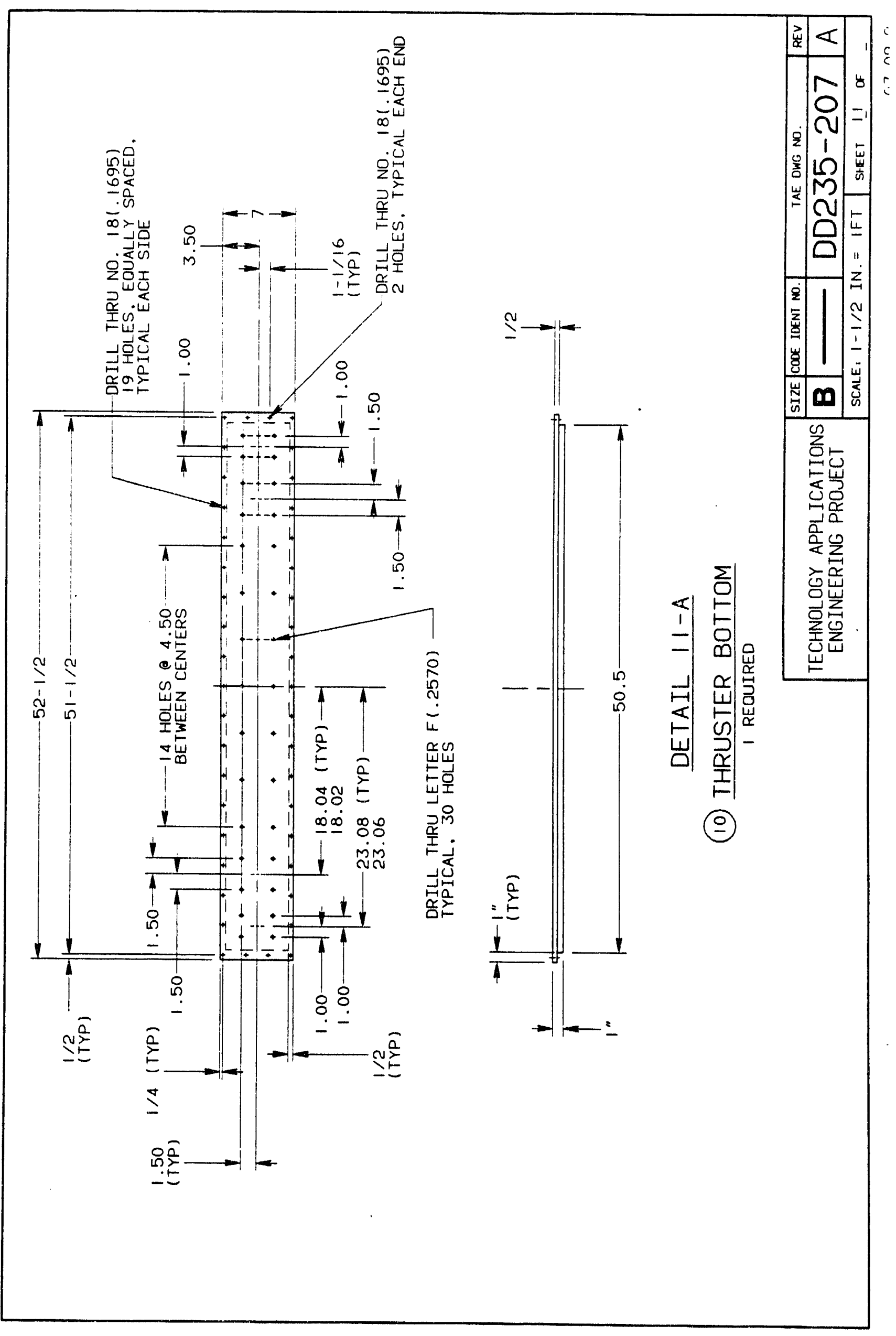




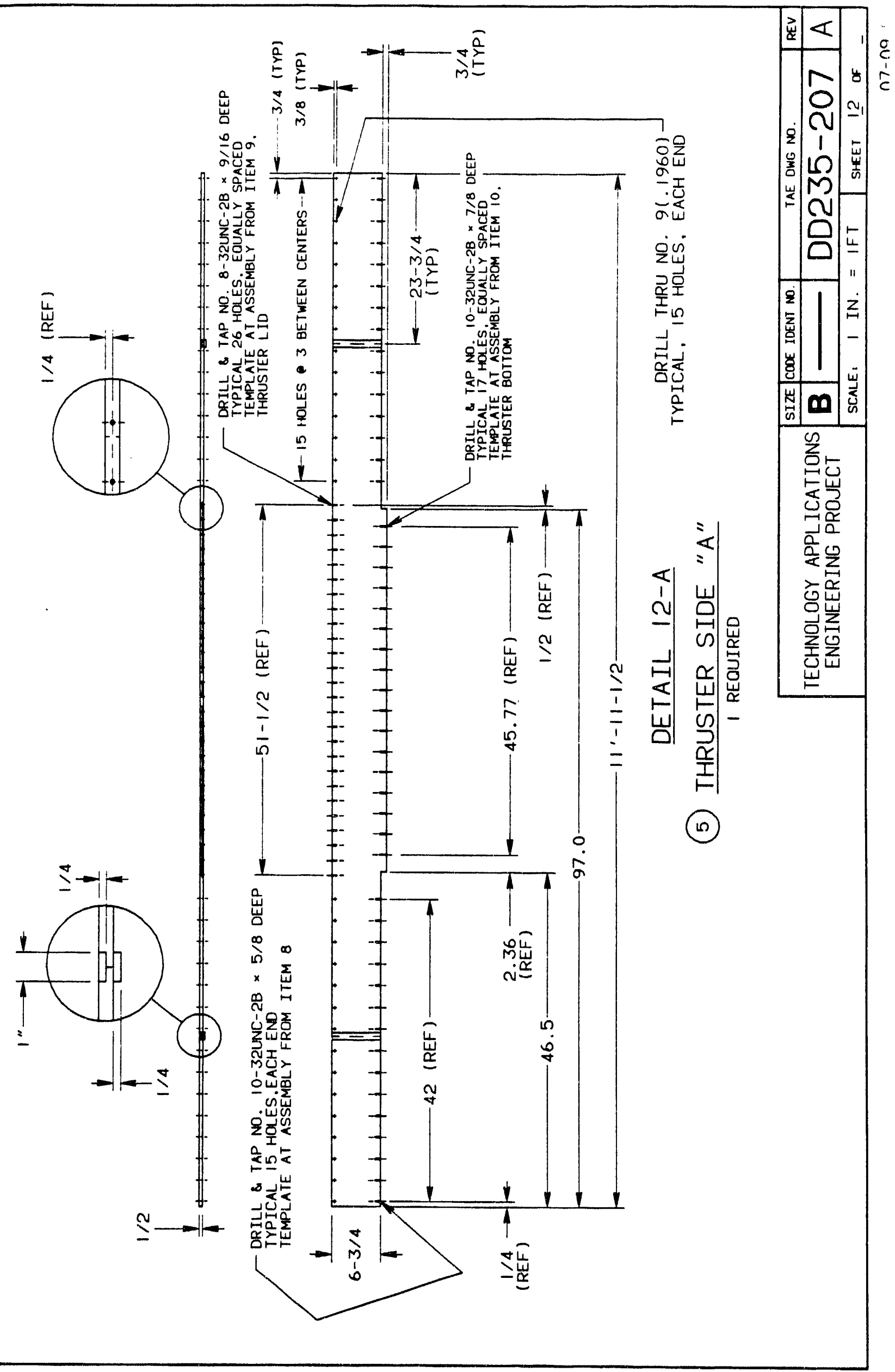




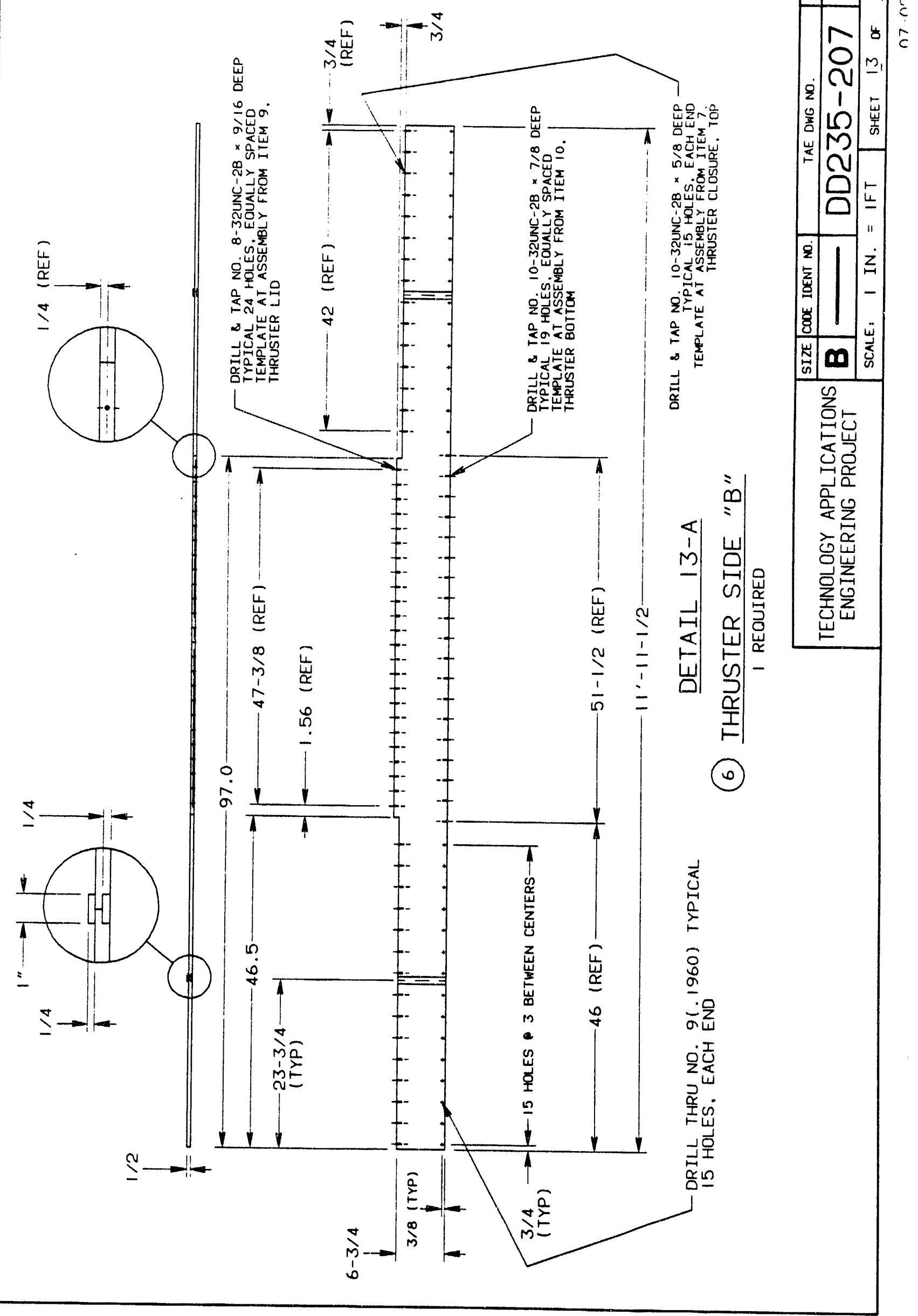



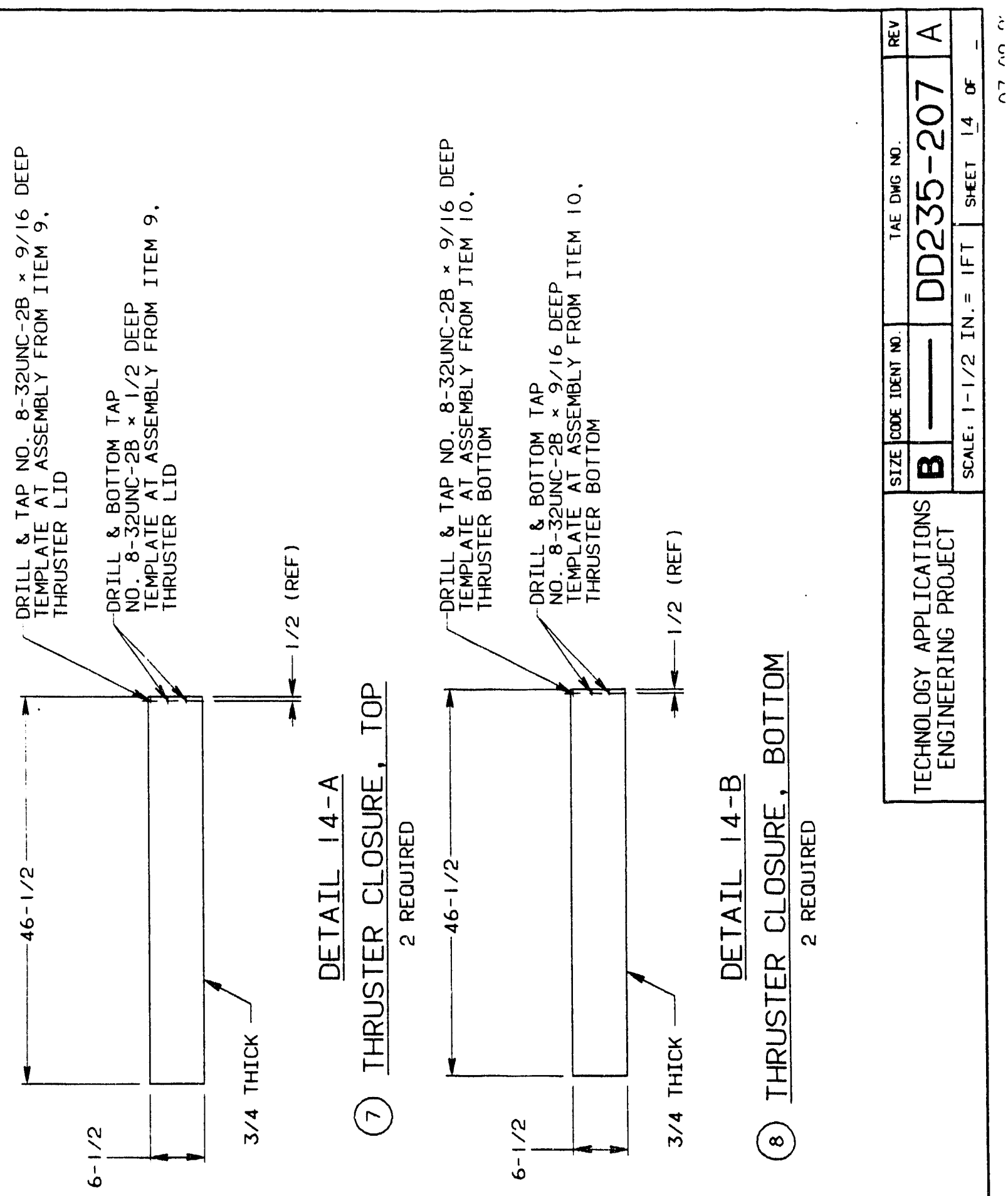

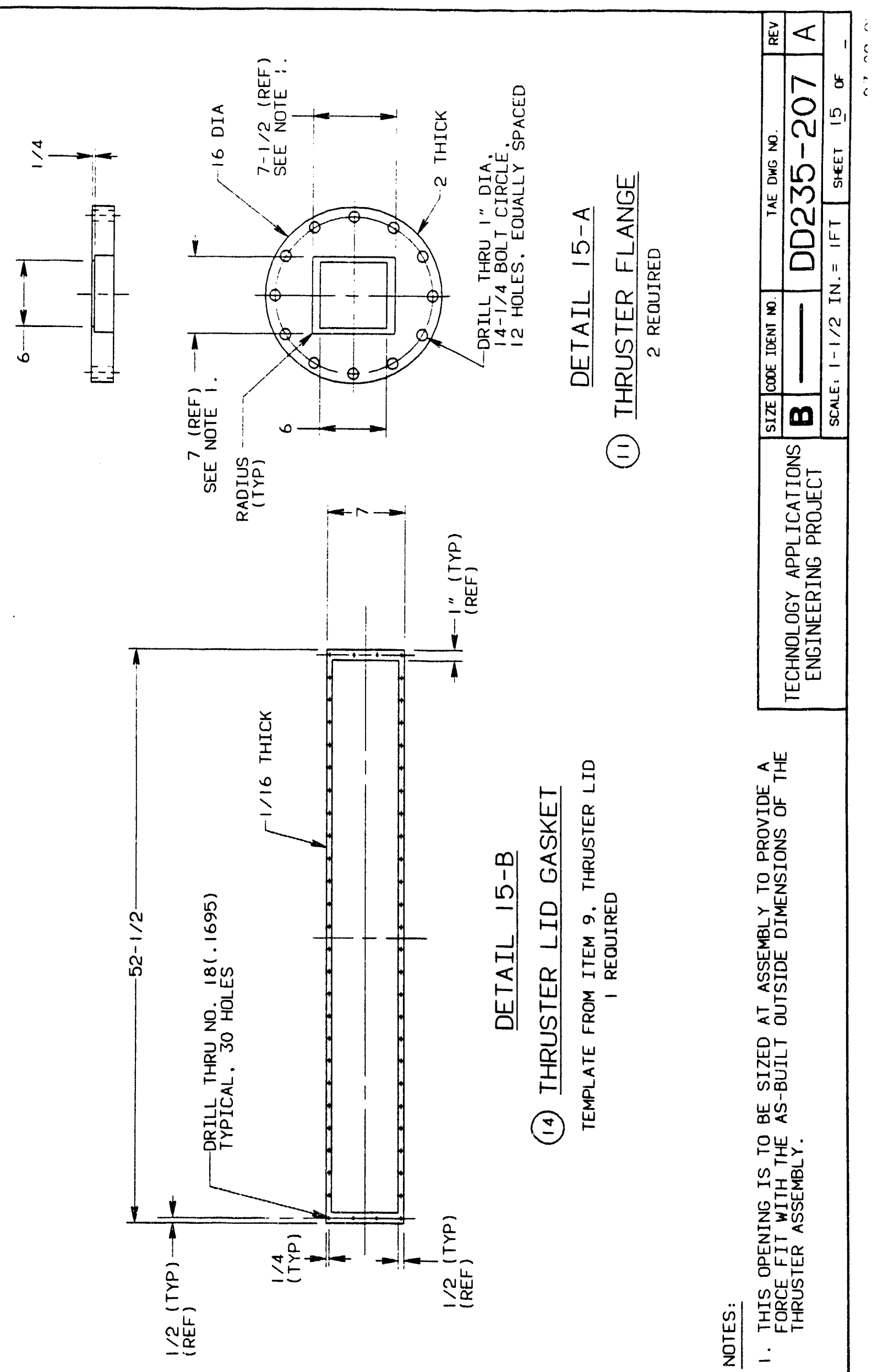


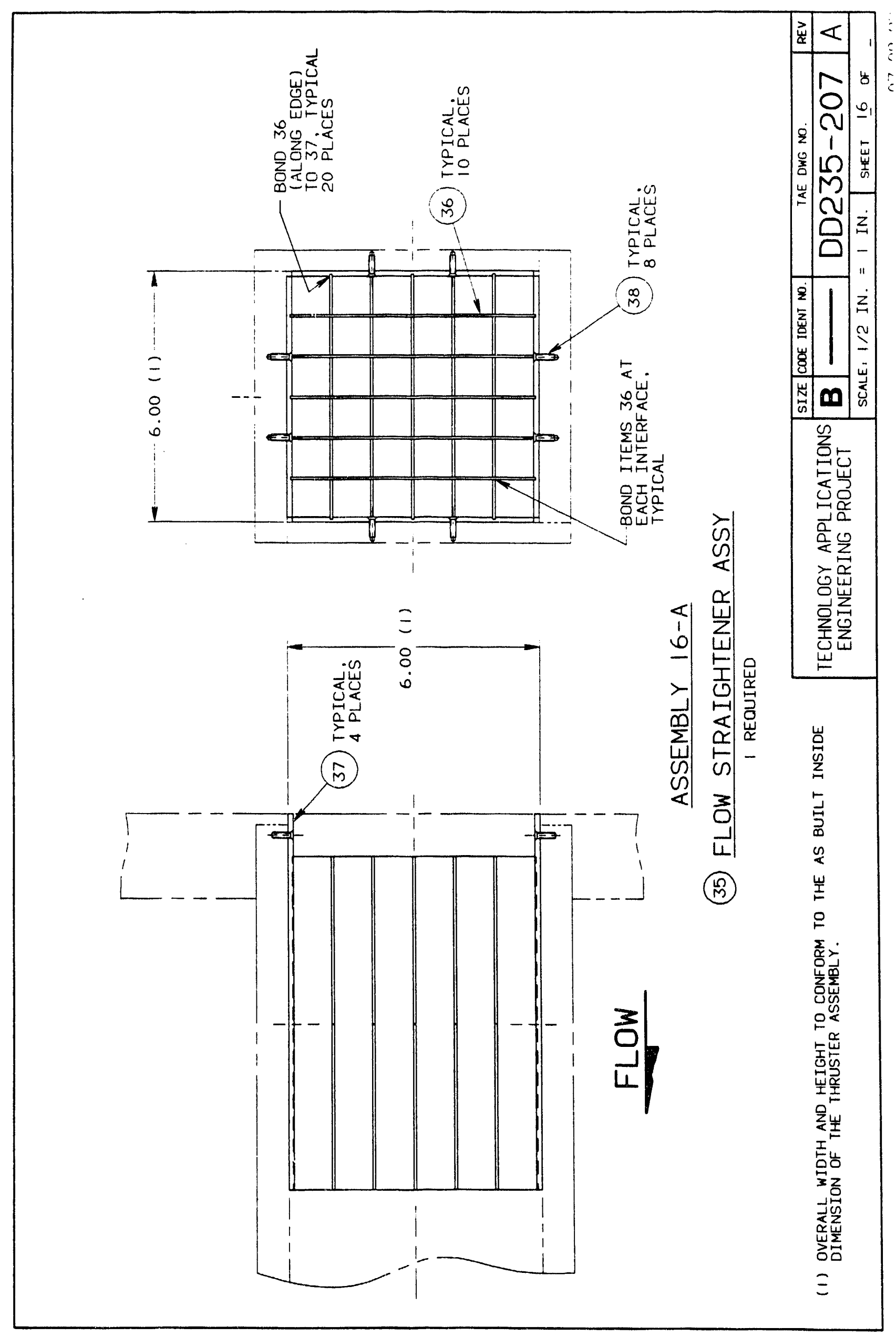




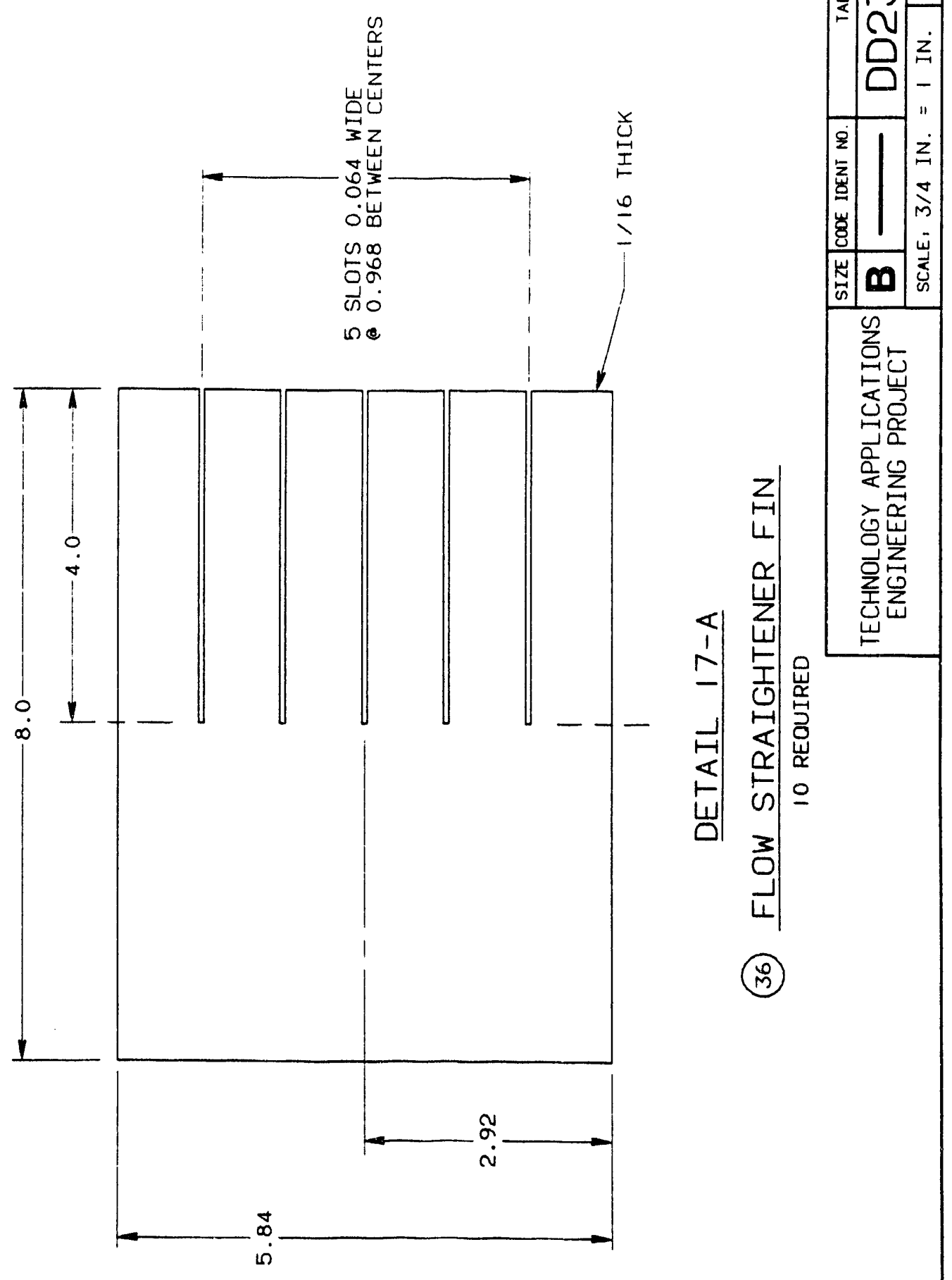




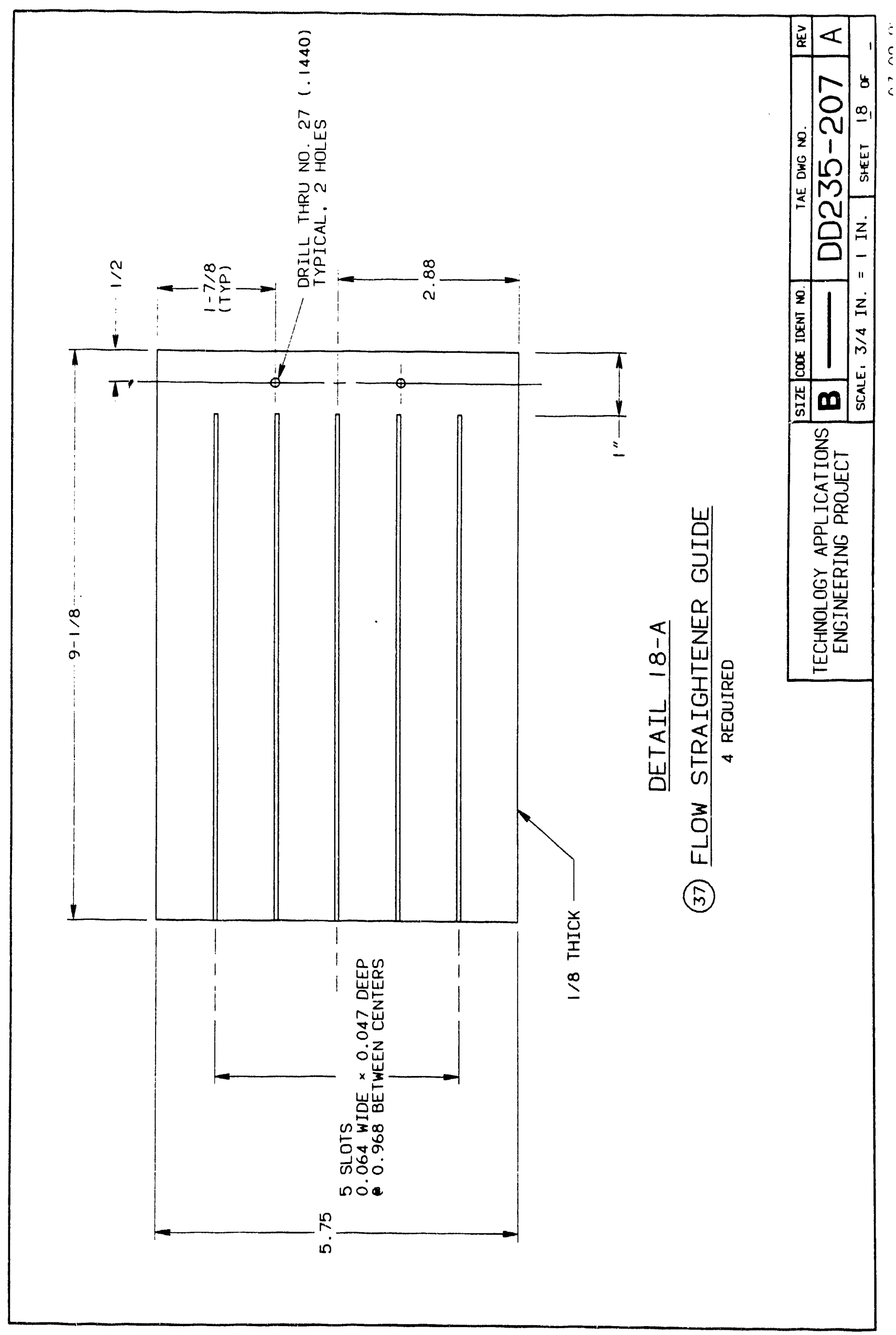




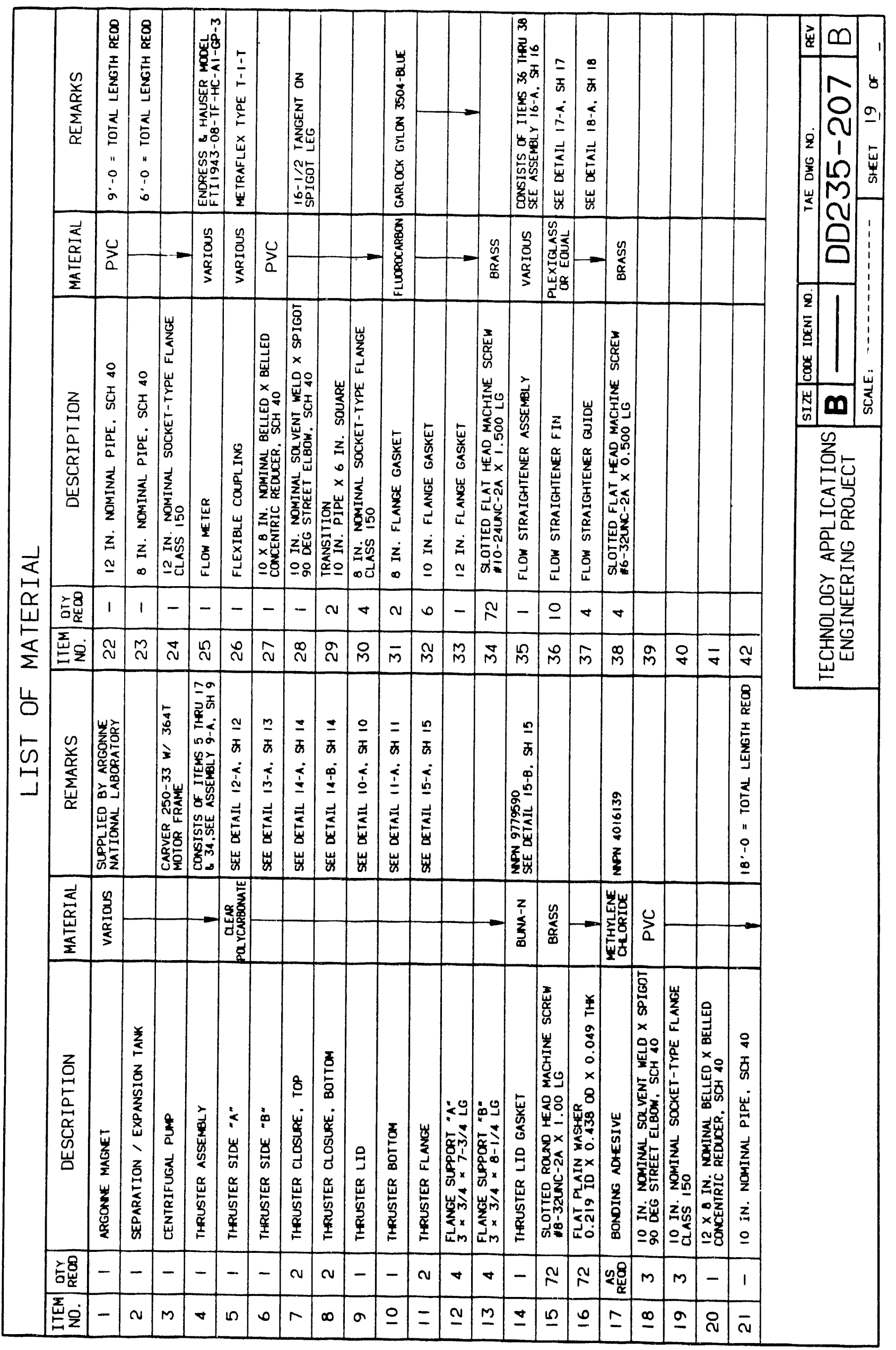


Appendix B: Angonne MHD Test Loop - Drain, Vent \& Storage Piping Arrangement

B-1 


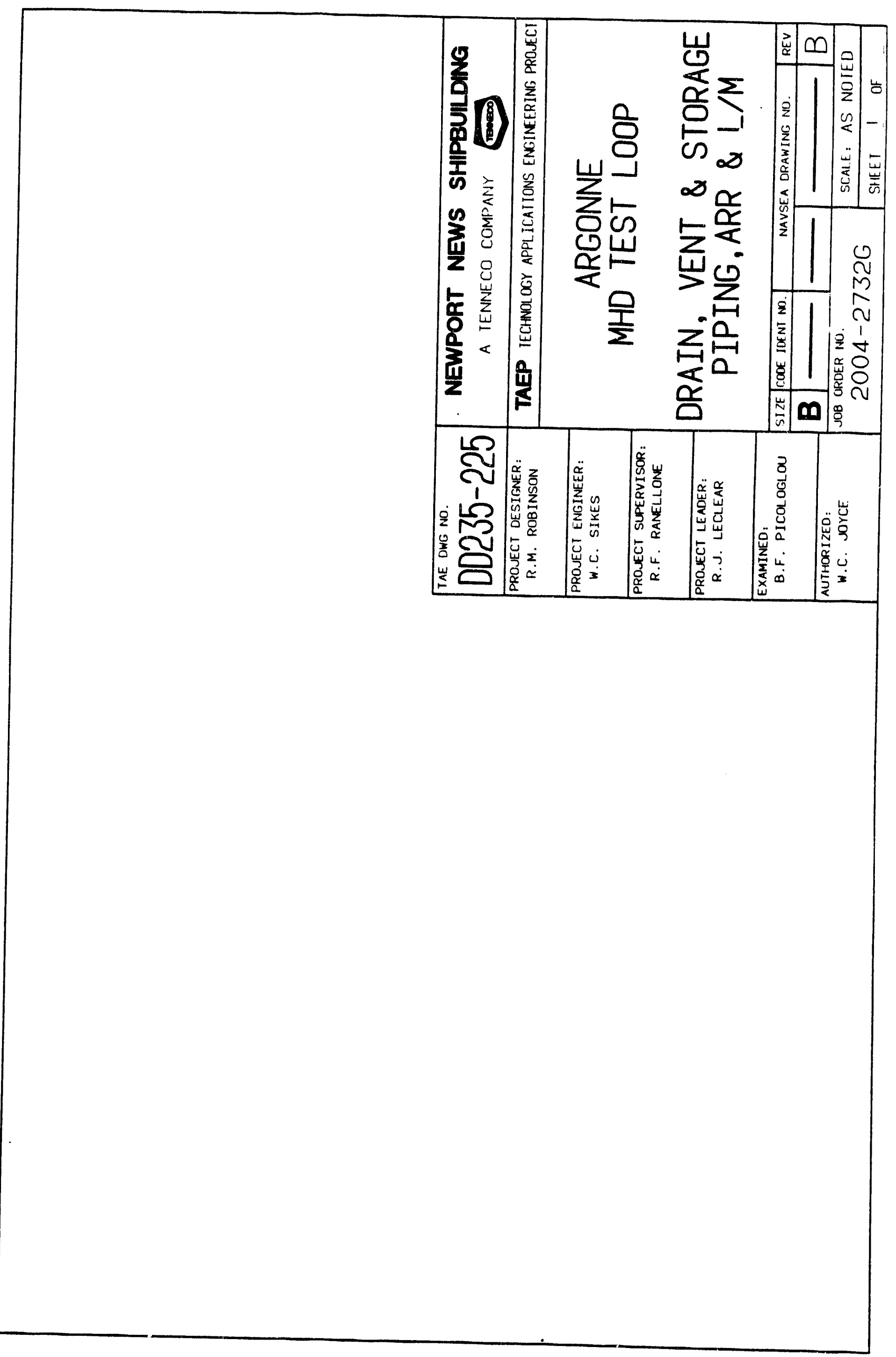




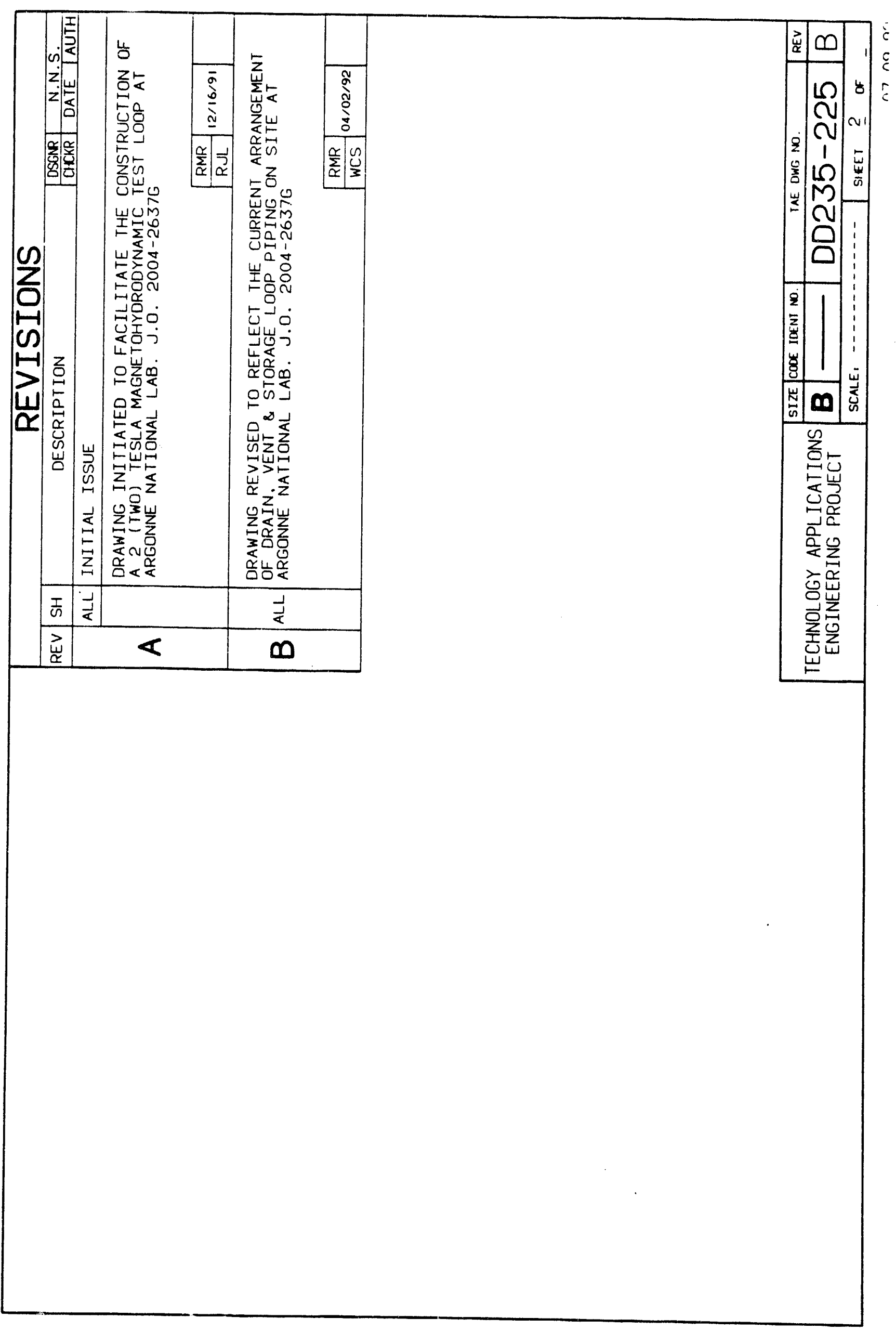




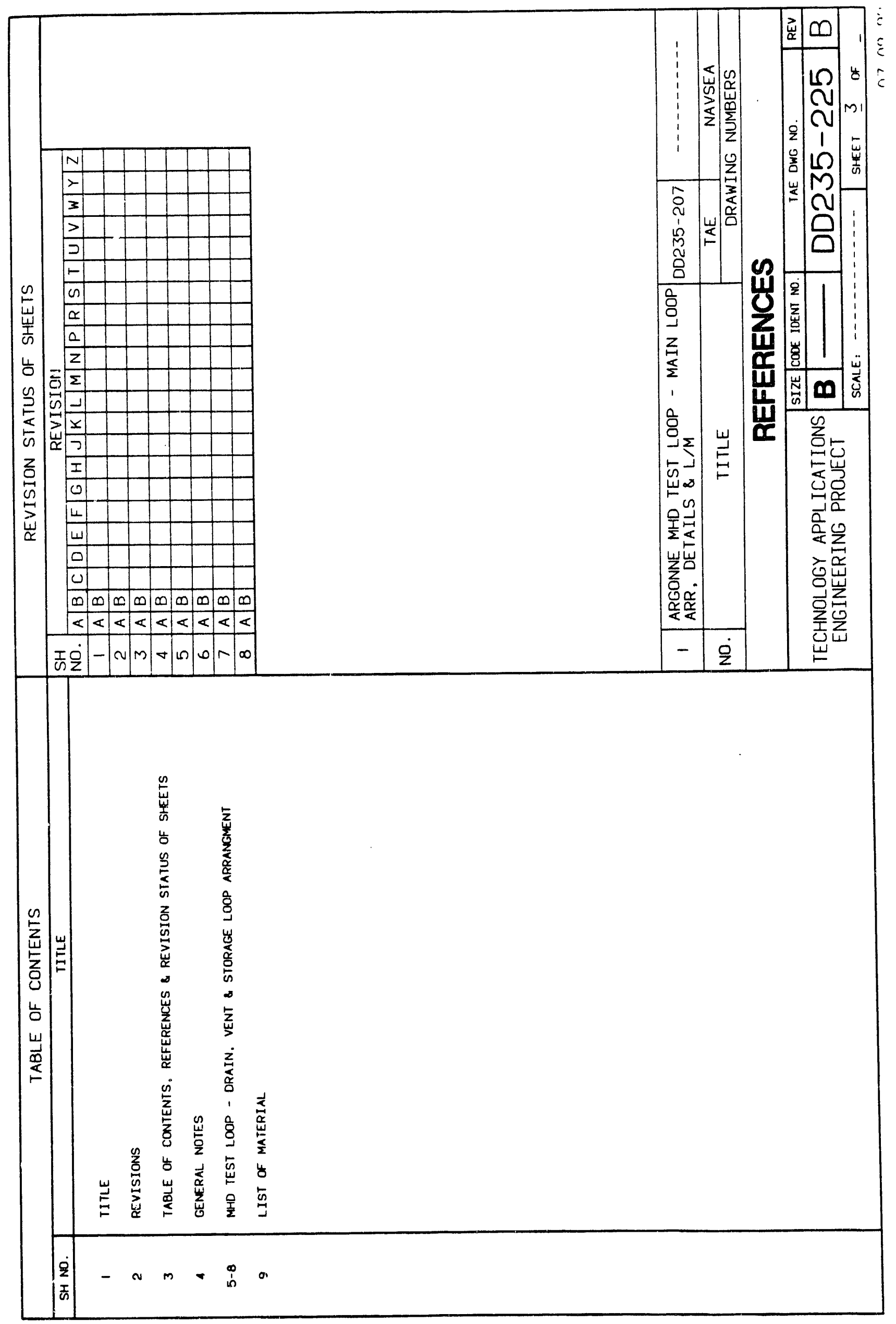




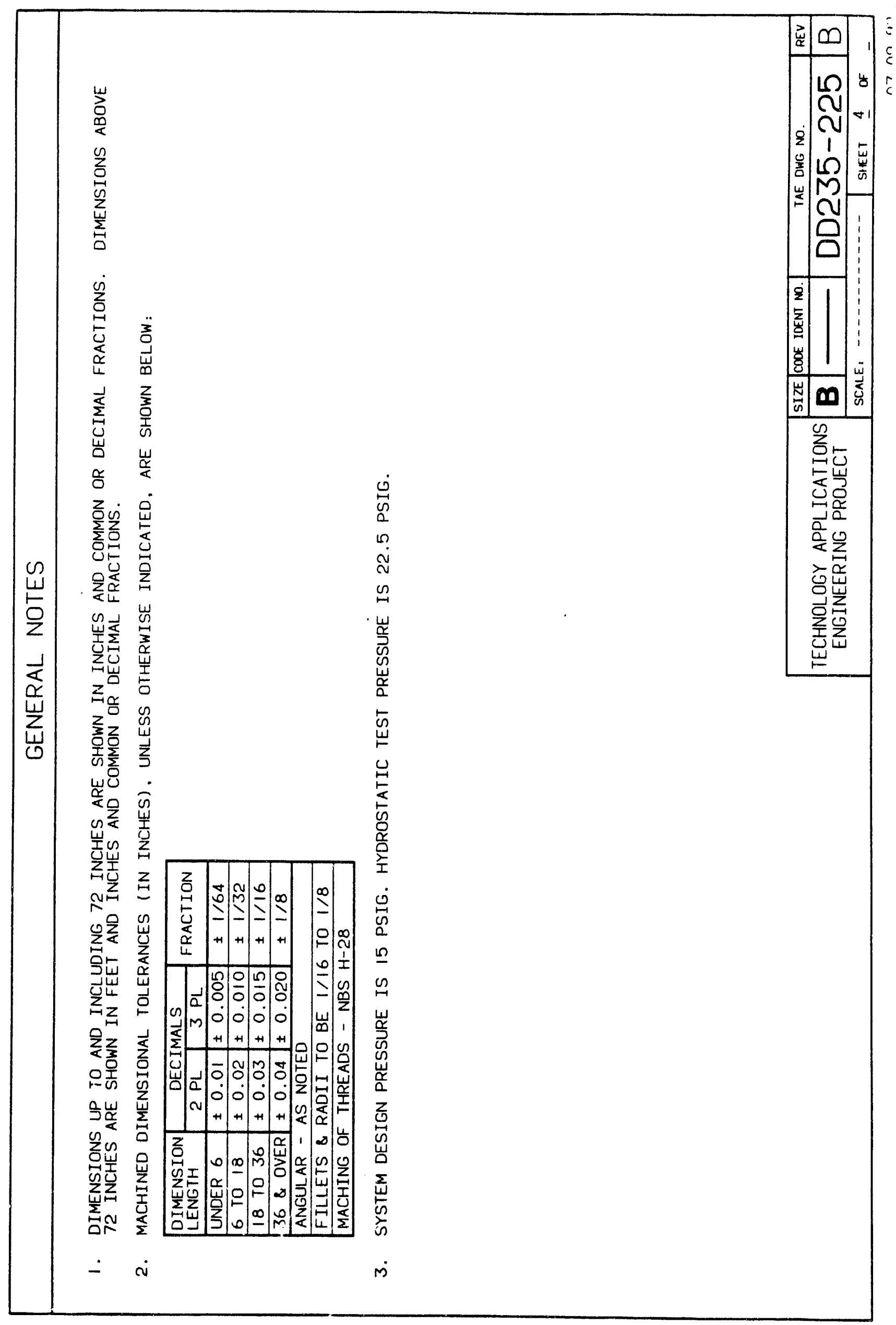




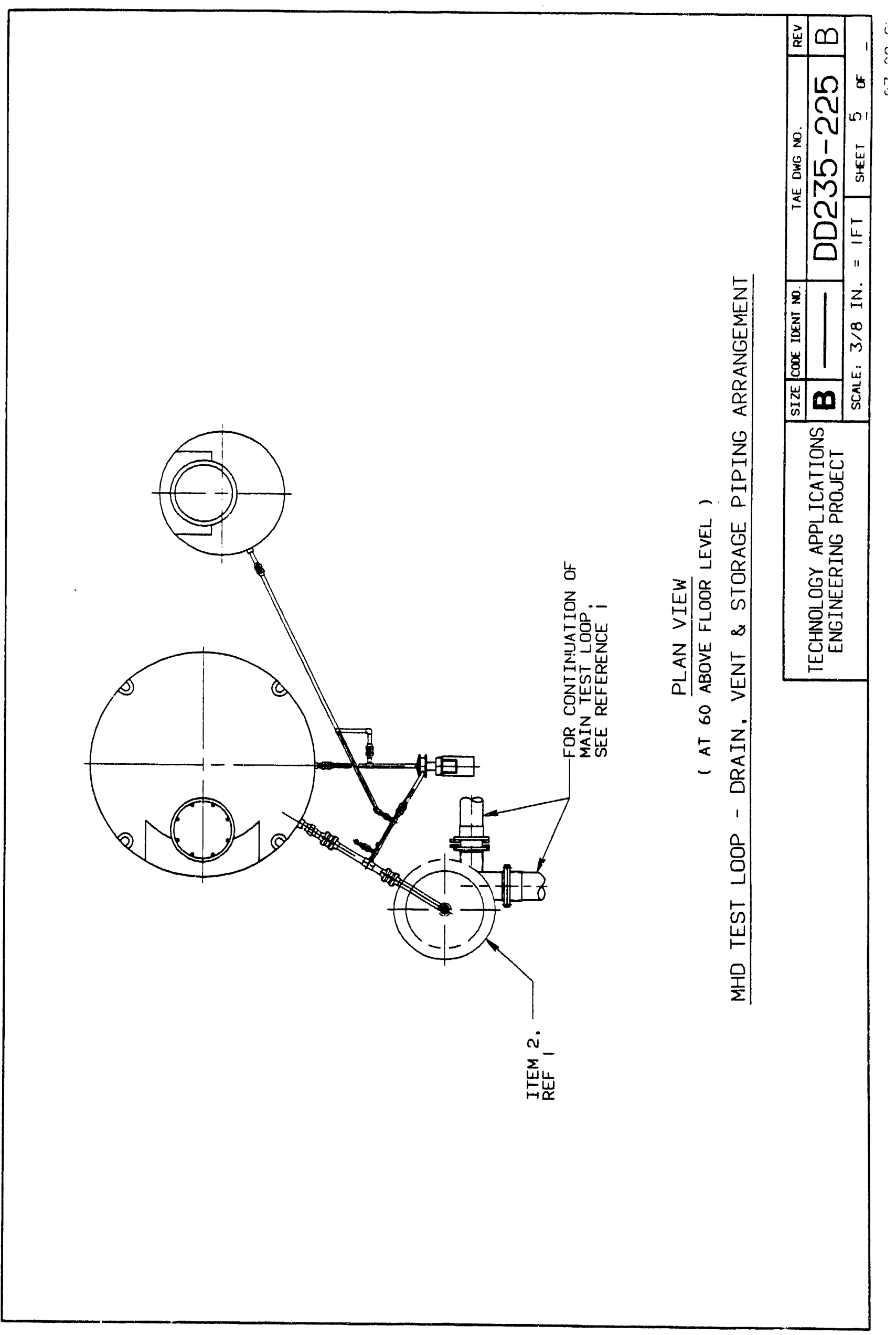



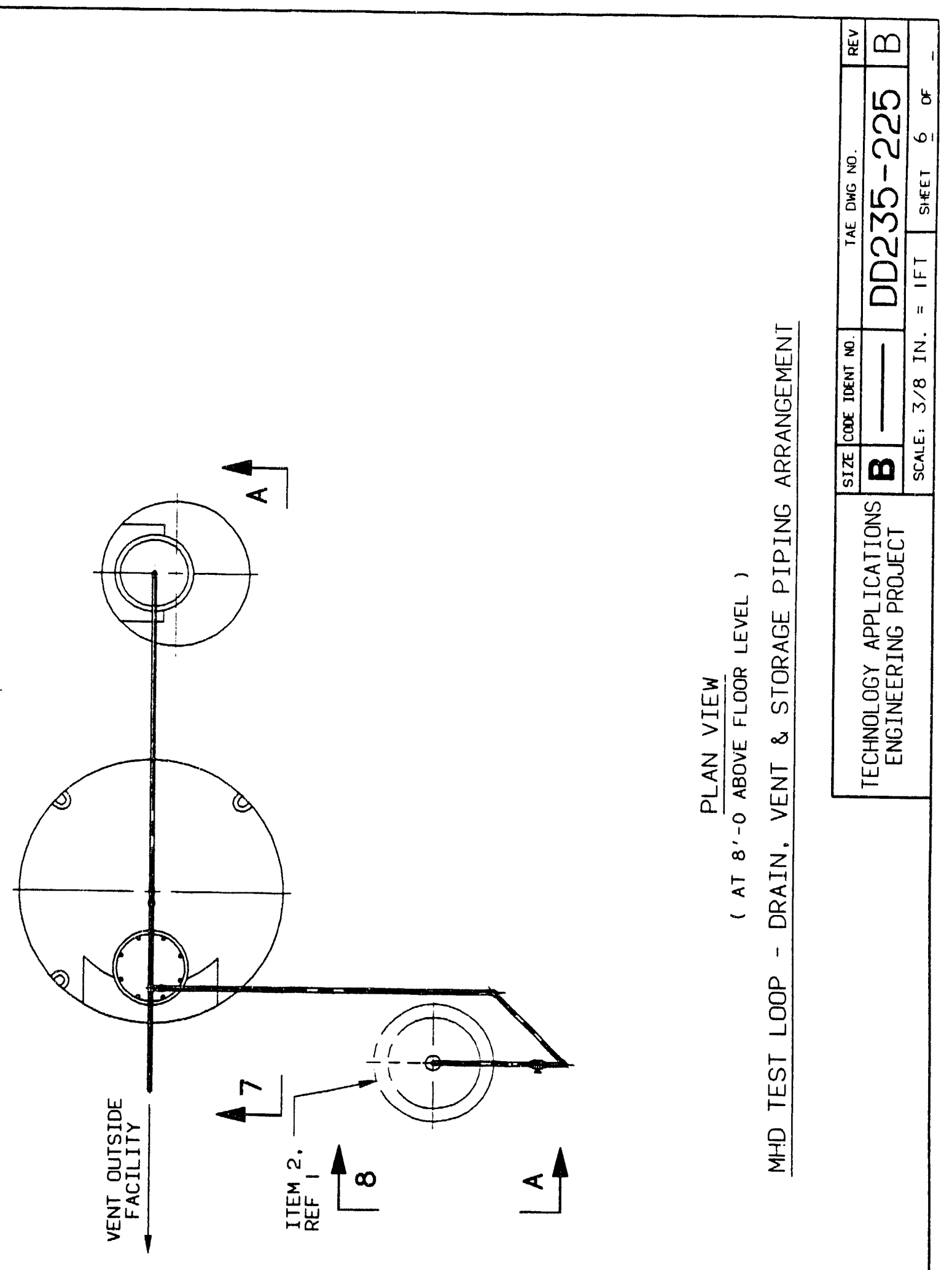


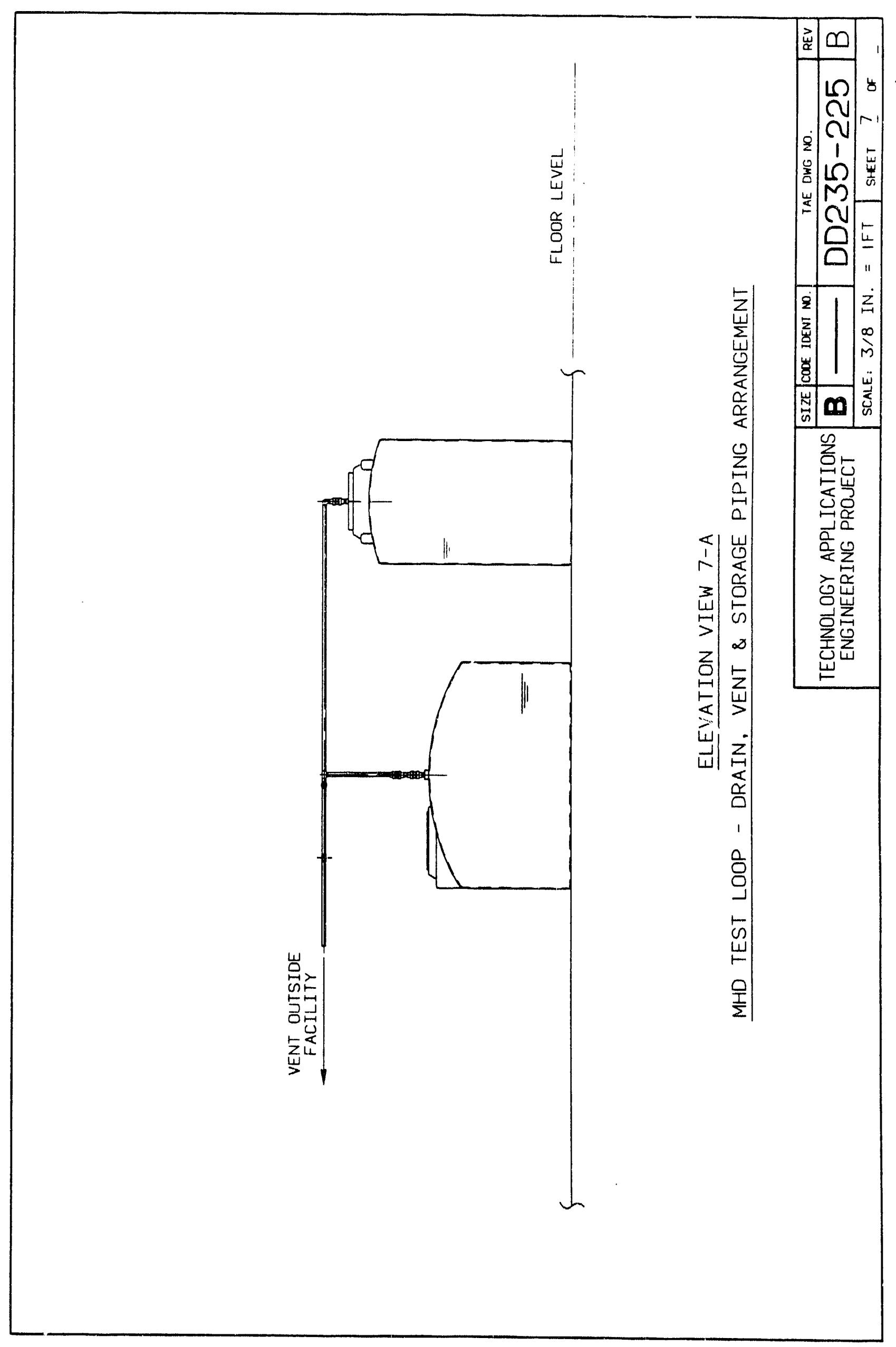




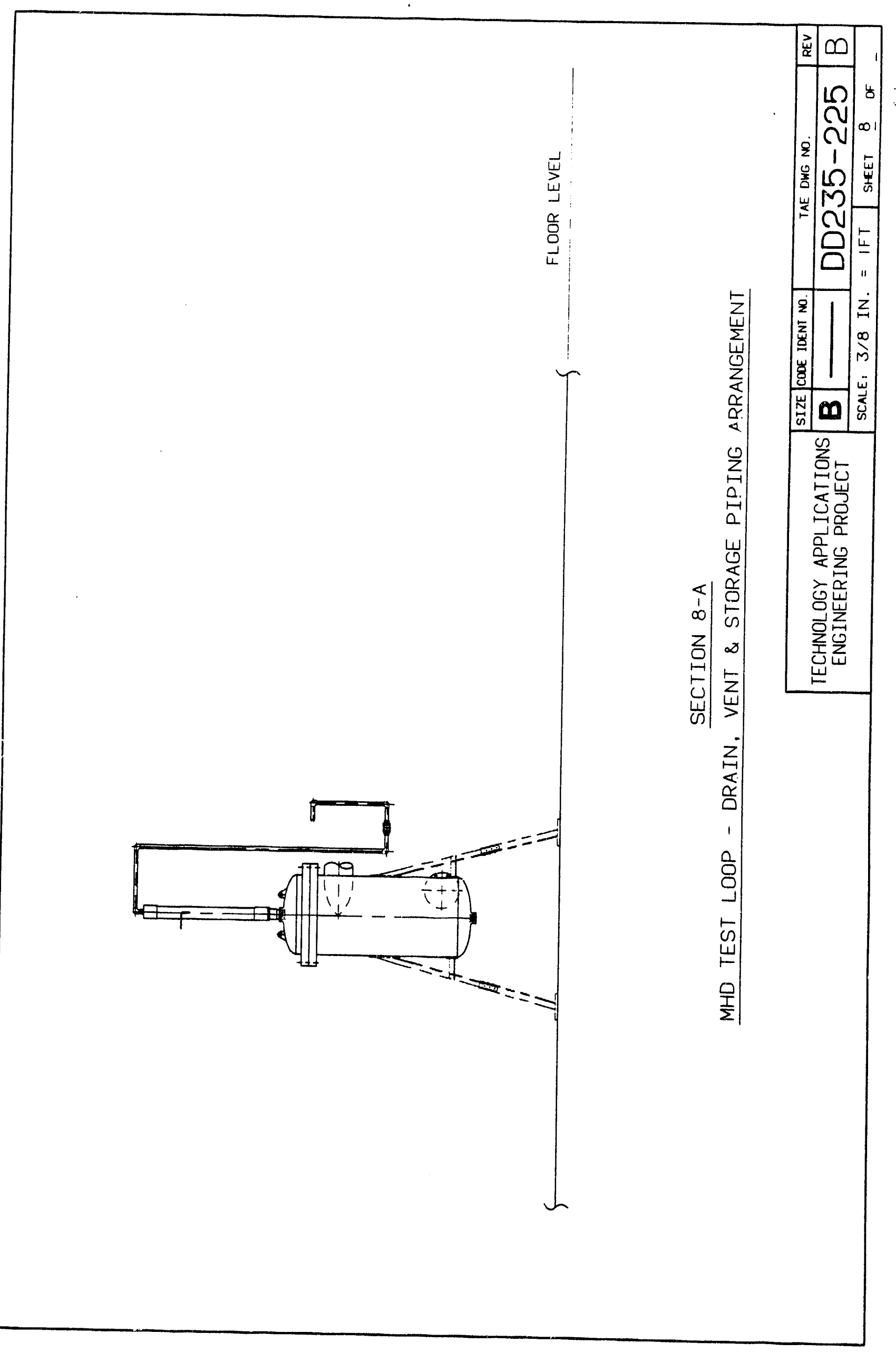




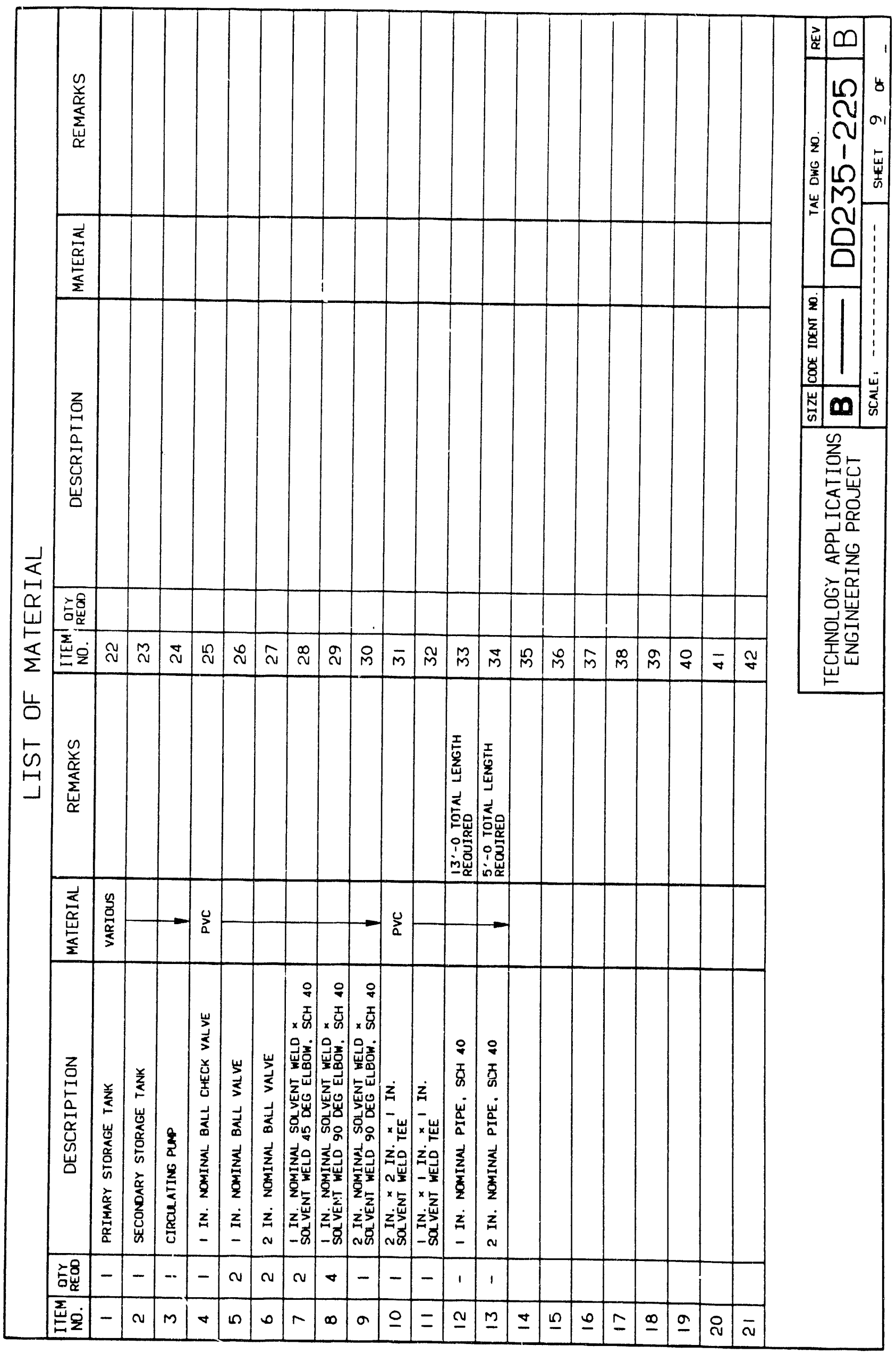


Distribution

Agonne National Laboratory

S.K. Bhattacharyya

S. Lake

D.B. Black

P.M. Dombrowski

L.G. LeSage

E.D. Doss (5)

M. Petrick

H. Drucker

B.F. Picologlou

F.Y. Fradin

R.B. Reed

B.R.T. Frost

C.E. Till

H.K. Geyer

R.W. Weeks

H. Herman

A.M. Wolsky

E.N. Kaufman

ANL Patent Office

TIS Files (2)

Newpont News Shipbuilding and Dry Dock Company

R.J. LeClear

R.F. Ranellone (10)

W.C. Sikes (10)

\section{External}

DOE-OSTI (3)

ANL Libraries

Manager, DOE-CH

S.H. Brown, Naval Surface Warfare Center

J. Daly, DOE-CH

J.K. Koester, MHD Instruments (3)

J. Meng, Naval Undersea Warfare Center

G. Roy, Office of Naval Research

G. Staats, DOE-PETC

H.O. Stevens, Naval Surface Warfare Center

K. Templemeyer, Southern Illinois University

R.L. Rosenfeld, DARPA/Undersea Warfare Office 

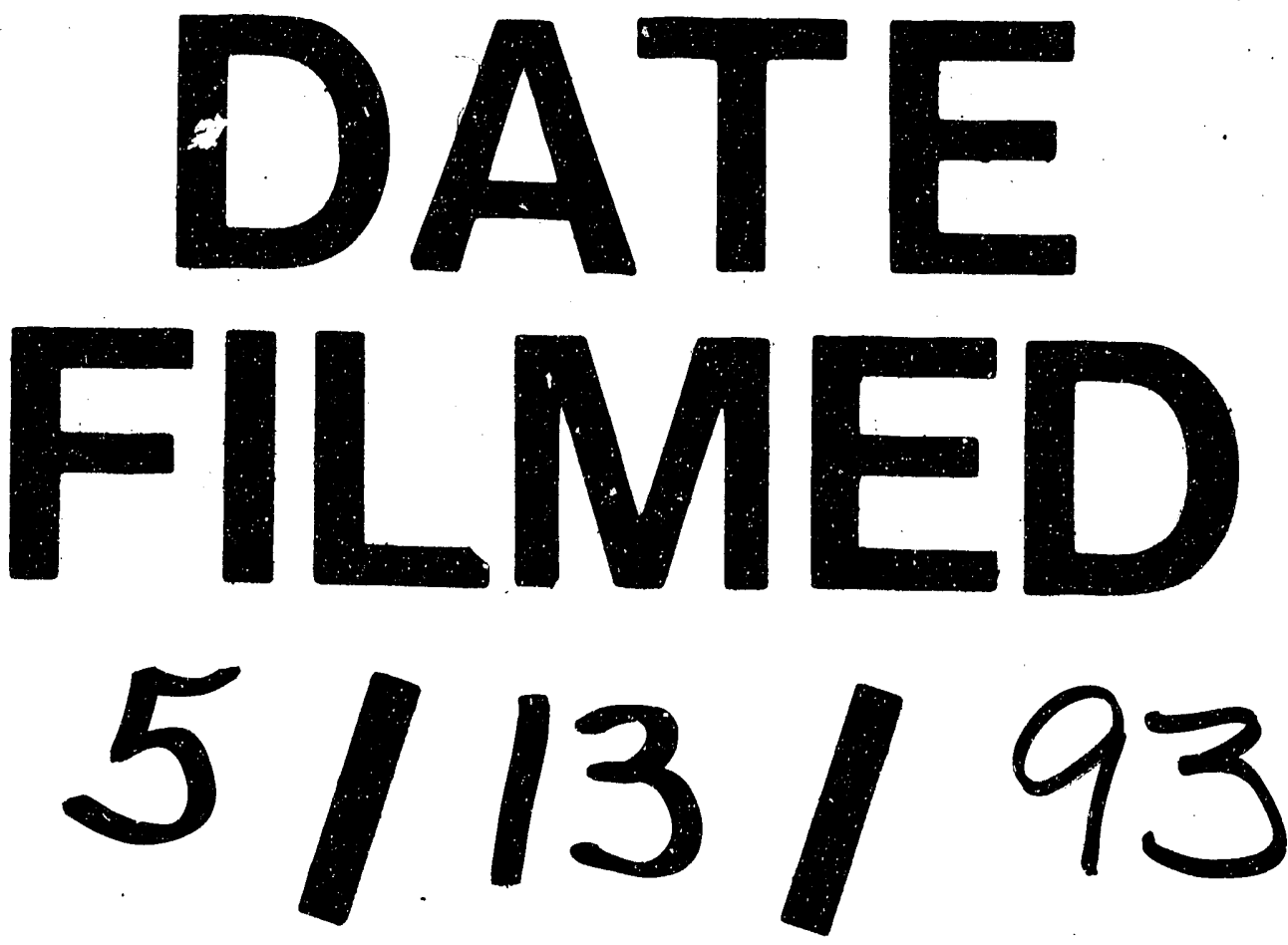
